\title{
Indications and Results of Isolated Limb Perfusion
}

Eva M. Noorda

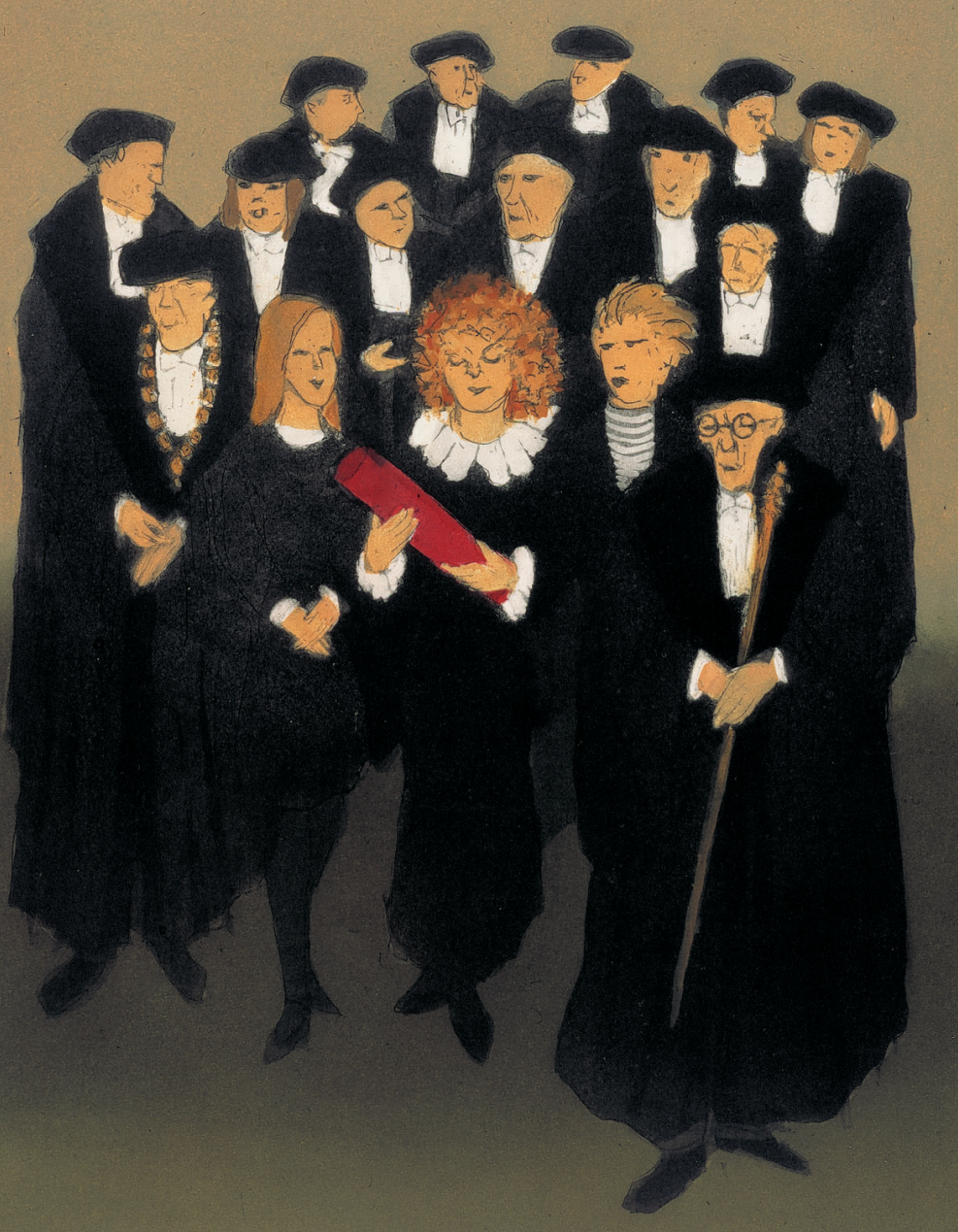

这

UNIVERSITEIT VAN AMSTERDAM 
Indications and Results of Isolated Limb Perfusion 
This study has been performed in The Netherlands Cancer Institute/Antoni van Leeuwenhoek hospital, Amsterdam and partially in the Erasmus Medical CenterDaniel den Hoed Cancer Centre, Rotterdam, the Netherlands

The publication of this thesis was made possible by financial support of The Netherlands Cancer Institute, Stichting Bevordering Kanker Onderzoek, Boehringer Ingelheim, University of Amsterdam/Academic Medical Centre and Jostra B.V.

Omslagontwerp en ontwerp binnenwerk: René Staelenberg, Amsterdam Afbeelding omslag: Willy Belinfante, Promovenda; de Bul, kleurenets, 30 x $40 \mathrm{~cm}$.

ISBN 9053566732

NUR 870

\section{(C) Amsterdam University Press, E.M. Noorda, 2004}

Alle rechten voorbehouden. Niets uit deze uitgave mag worden verveelvoudigd, opgeslagen in een geautomatiseerd gegevensbestand, of openbaar gemaakt, in enige vorm of op enige wijze, hetzij elektronisch, mechanisch, door fotokopieën, opnamen of enige andere manier, zonder voorafgaande schriftelijke toestemming van de uitgever.

Voorzover het maken van kopieën uit deze uitgave is toegestaan op grond van artikel 16B Auteurswet $1912 \mathrm{j}^{\circ}$ het Besluit van 20 juni 1974, Stb. 351, zoals gewijzigd bij het Besluit van 23 augustus 1985, Stb. 471 en artikel 17 Auteurswet 1912, dient men de daarvoor wettelijk verschuldigde vergoedingen te voldoen aan de Stichting Reprorecht (Postbus 882, 1180 AW Amstelveen). Voor het overnemen van gedeelte(n) uit deze uitgave in bloemlezingen, readers en andere compilatiewerken (artikel 16 Auteurswet 1912) dient men zich tot de uitgever te wenden. 


\title{
Indications and Results of Isolated Limb Perfusion
}

\author{
Academisch Proefschrift \\ ter verkrijging van de graad van doctor \\ aan de Universiteit van Amsterdam \\ op gezag van de Rector Magnificus \\ prof.mr P.F. van der Heijden
}

ten overstaan van een door het college voor promoties ingestelde commissie, in het openbaar te verdedigen in de Aula der Universiteit

op vrijdag 27 februari 2004, te 14:00 uur

door

\section{Eva Magdaleen Noorda}

geboren te Amsterdam 


\section{Promotiecommissie:}

Faculteit der Geneeskunde

Promotiecommissie:

Promoter:

Co-promotores:

Overige leden:
Prof. dr B.B.R. Kroon

Dr B.C. Vrouenraets

Dr O.E. Nieweg

Prof. dr J.C.J.M. de Haes

Prof. dr F.J. Lejeune

Prof. dr W.J. Mooi

Prof. dr H. Schraffordt Koops

Dr G.R. Schaap

Dr J.H.W. de Wilt 
Voor mijn ouders 



\section{Contents}

Chapter 1

Introduction and outline of the thesis

Chapter 2

Isolated limb perfusion: what is the evidence for its use? Submitted

Chapter 3

Isolated limb perfusion for unresectable melanoma of the extremities. Submitted

Chapter 4

Isolated limb perfusion prolongs the limb recurrence-free interval after several episodes of excisional surgery for locoregional recurrent melanoma. Annals of Surgical Oncology 2003, in press

Chapter 5

Safety and efficacy of isolated limb perfusion in elderly melanoma patients. Annals of Surgical Oncology 2002;9:968-74 (with editorial)

Chapter 6

Repeat isolated limb perfusion with $\mathrm{TNF} \alpha$ and melphalan for recurrent limb melanoma after failure of previous perfusion. Submitted

Chapter 7

Prognostic factors for poor survival after isolated limb perfusion: criteria for patient selection? European Journal of Surgical Oncology 2003;29: 916-21

Chapter 8

Long-term results of a double perfusion schedule using high-dose hyperthermia and melphalan sequentially in extensive melanoma of the lower limb. Melanoma Research 2003;13:395-99

Chapter 9

Quality of life in long-term survivors of isolated limb perfusion for melanoma of the limbs. Submitted

Chapter 10

Isolated limb perfusion with TNF $\alpha$ and melphalan for unresectable soft tissue sarcoma of the extremities. Cancer 2003;7:1483-90 
Chapter 11

Isolated limb perfusion with melphalan for femoral metastases of breast cancer: case report. Journal of Surgical Oncology 2002;81:209-12

Chapter 12

Summary and conclusions/Samenvatting en conclusies

Appendix

Regionale isolatie perfusie: goed toepasbaar bij de bejaarde patiënt. $\mathrm{Ne}$ derlands Tijschrift voor Geneeskunde 2003;147:529-33

Dankwoord

Curriculum Vitae 


\section{Chapter 1}

\section{Introduction and outline of the thesis}

Isolated limb perfusion (ILP) with melphalan was created by Creech et al. in 1957 at Tulane University in New Orleans and first performed in a 76-year old man with extensively recurrent melanoma of his leg. ${ }^{1}$ This patient attained a complete response and was without evidence of locoregional disease until he died at age 92 . The unique method of applying a high (cytostatic) drug dose to an isolated extremity, offered a limb sparing option for those patients with unresectable tumors on their extremities, who used to be candidates for amputation. ILP has since then been applied for various indications, with varying degrees of hyperthermia and/or sorts of drugs, aiming to improve response rates. ${ }^{2}$

The principle of ILP is that a high dose of a drug can be administered to the extremity without systemic toxicity, in order to treat extensive locoregional disease that is not amenable to excisional surgery. During ILP, the major artery and vein are clamped at the desired level, collateral vessels are ligated and a tourniquet is applied around the limb, proximal to the region of ILP. After insertion of catheters into the major vessels, the isolated limb is perfused by an extra-corporeal circulation, oxygenated and propelled by a heart-lung machine (Figure 1). A melphalan dose of $13 \mathrm{mg} / \mathrm{l}$-perfused tissue in the upper limb and $10 \mathrm{mg} / \mathrm{l}$ for the lower limb is added to the perfusate. For tumor necrosis factor $\alpha$ (TNF $\alpha)$ this is

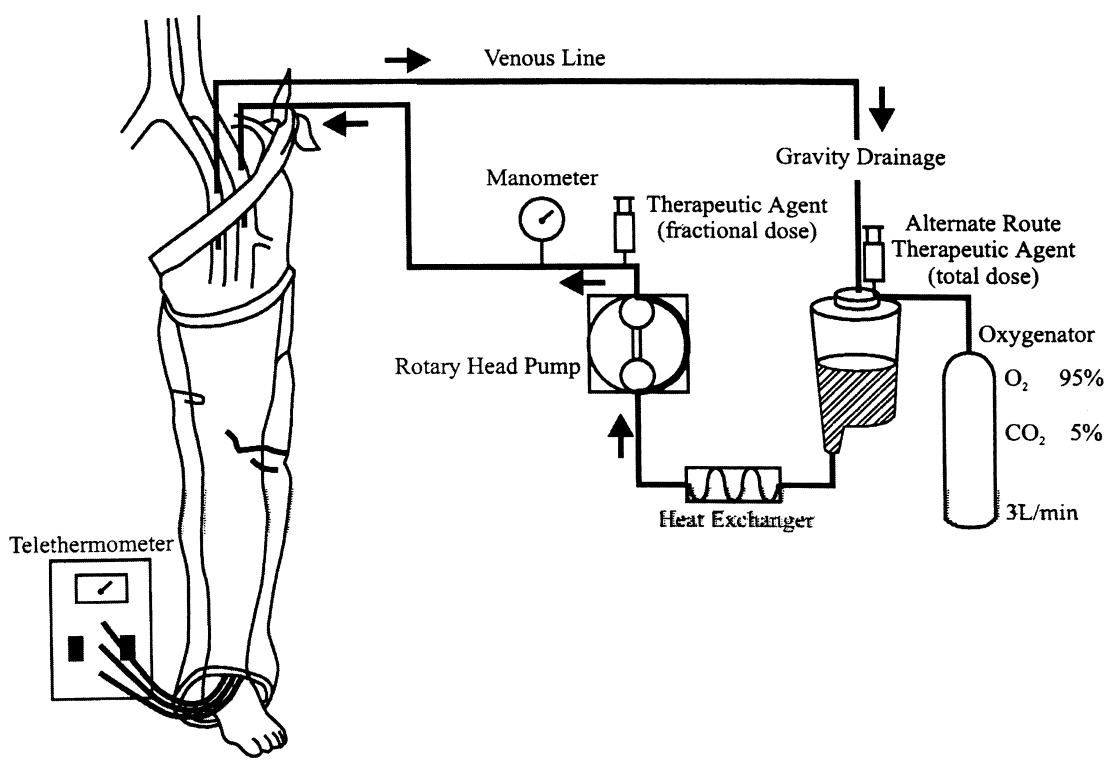

Figure 1. Schematic drawing of the isolated circuit 
$3 \mathrm{mg}$ and $4 \mathrm{mg}$ respectively, irrespective of limb volume. The concentration of melphalan is 10 to 20 times higher in this isolated circuit than what would be tolerated in systemic treatment. The systemic application of TNF $\alpha$ in these doses would be lethal. The perfusate circulates for 60 minutes if melphalan is applied and 90 minutes if TNF $\alpha$ is added. At the end of the procedure, the limb is rinsed out with an electrolyte solution and the vessels are repaired after removal of the catheters.

The indications and results of ILP have varied over the years and are now mostly limited to unresectable melanoma and soft tissue sarcoma of the extremities. This thesis aims to answer a number of questions that have arisen regarding the current applications of ILP. The aim of all chapters was to identify patients who should (or should not be) advised to undergo ILP, to determine what ILPschedule is then most effective and what results can be expected of ILP in these patients in terms of response, recurrence-free survival, overall survival and the long term impact on the patients' lives.

In chapter two, the best available evidence (preferably randomized controlled trials) supporting the current applications of ILP was assembled. A systematic analysis of evidence in the literature was performed for ILP in extremity melanoma and soft tissue sarcoma, following the principles of evidence-based medicine. ${ }^{3,4}$

While recurrent melanoma lesions on the extremity can usually be managed by local surgery, the traditional indication for ILP has been unresectable extremity melanoma. However, studies providing the results of ILP for this indication are lacking. Most series consist of patients with measurable lesions, part of which were resectable and left in situ to monitor response, some were excised and some were truly unresectable. In these heterogeneous groups of patients with measurable melanoma lesions, ILP with melphalan leads to a 54\% complete response rate. $^{2}$ Since the introduction of TNF $\alpha$ in 1992, response rates of up to $73 \%$ have been reported. ${ }^{2,5}$ The complete response rate after ILP with melphalan alone is likely to be lower than $54 \%$ in patients with truly unresectable disease, because it is known that a high tumor load (as expressed by the number of lesions, total tumor surface area and nodal status) is a negative prognostic factor for response after ILP. ${ }^{5-8}$ In chapter three, we have reported the response rates and survival after ILP with melphalan with or without TNF $\alpha$ for unresectable melanoma with special attention to prognostic factors for these outcome measures.

In some patients with in-transit metastases of extremity melanoma, locoregional recurrences develop with increasing frequency after resection of previous lesions. These in-transit metastases impose a therapeutic dilemma at each new recurrence. ${ }^{9}$ Many patients who have minimal locoregional disease can be maintained for a long time with local treatments only. There are several of such local treatment options, including excisional surgery, $\mathrm{CO}_{2}$ laser ablation and local radiotherapy, but none of these impacts the development of further limb recurrences. ${ }^{10-12}$ Prophylactic ILP however has the potential to stop or slow down the process of ongoing recurrences by eradicating micrometastases present in the limb as well as the macroscopic lesions. ${ }^{13,14}$ This has been studied in a small prospective randomized trial with 69 patients with recurrent extremity melanoma 
who were randomly treated by excision alone or excision plus ILP. This study showed an increased tumor-free survival after ILP from 10 to 17 months with a limb recurrence rate that decreased from $67 \%$ to $45 \% .{ }^{13}$ To determine whether ILP in the population of patients with resectable recurrent in-transit lesions may be indicated, the effect of ILP on further recurrences, the number of lesions per recurrence and the limb recurrence-free interval in patients with frequently recurring limb melanoma was studied and described in chapter four.

Many surgeons are reluctant to refer patients at an advanced age for ILP, whereas operative mortality from ILP is low, regional toxicity is mild and systemic leakage of the cytostatic drug(s) is negligible. ${ }^{8,15,16}$ This could be based on the fact that peri-operative mortality for major surgical procedures increases with age, ${ }^{17}$ the peri-operative complication rate is higher in patients over 70 years of age and hospital stay is generally longer. ${ }^{18-20}$ Specifically after ILP, a fear of longterm functional morbidity due to severe acute limb toxicity, ${ }^{21}$ increased systemic side-effects from melphalan ${ }^{8,16,22}$ and a severe systemic cardiovascular response to TNF $\alpha$ is expressed when elderly are concerned. ${ }^{15,22,23}$ In chapter five, we studied the safety and efficacy of ILP in melanoma patients older than 75 years of age who were treated for advanced locoregional melanoma.

Two large studies showed that in 46 to $54 \%$ of the patients with a complete response after ILP, locoregional recurrences occur. ${ }^{24,25}$ Amputation is a deterring option in such patients when these recurrences are not amenable to local surgery. Repeat ILP has been reported to result in increased acute regional toxicity compared to the first ILP and one could reason that patients who do not respond to a first ILP may have little to gain from a repeat procedure. ${ }^{26}$ Nevertheless, a complete response rate of $74 \%$ has been demonstrated after repeat ILP with melphalan in single, double, triple or sequential ILP-schedules. The latter procedure is no longer performed since the introduction of TNF $\alpha$ in ILP. ${ }^{22}$ There are a few studies on repeat ILP with TNF $\alpha$ in small series of patients with heterogeneous patient and tumor characteristics. ${ }^{27,28}$ Therefore in chapter six, we assessed the results of repeat ILP with TNF $\alpha$ in patients who relapsed or had persistent disease after previous ILP in our institutions.

After ILP for extremity melanoma a complete response is reached after a median interval of approximately seven months after ILP. ${ }^{2,5}$ The five-year survival rate with in-transit melanoma varies between $23 \%$ and $47 \%$ mainly depending on regional lymph node status..$^{29,30}$ Since ILP is an extensive procedure with possible complications and morbidity, it should be offered only to patients with a life expectancy long enough to experience its benefits. A number of prognostic factors for survival of patients who undergo ILP have been identified, but no specific attention was paid to those who die relatively shortly after ILP. ${ }^{6,31,32}$ Factors determining survival in general might differ from those that determine the risk of dying within one year from ILP. In chapter seven, these factors were identified to be able to select patients for ILP who are likely to live long enough to experience its benefits.

The degree of hyperthermia applied during ILP has been subject of discussion over the years. While single mild hyperthermic $\left(39-40^{\circ} \mathrm{C}\right)$ ILP with melphalan yields similar results as ILP under normothermic $\left(37-38^{\circ} \mathrm{C}\right)$ conditions, 33 higher temperatures have been used to improve results. True hyperthermia $\left(42-44^{\circ} \mathrm{C}\right)$ 
in combination with melphalan, however, results in severe toxic reactions with a substantial risk of amputation. ${ }^{34,35}$ ILP with melphalan using a somewhat lower temperature (borderline true hyperthermia, $41-42^{\circ} \mathrm{C}$ ) leads to a wide range of $\mathrm{CR}$ rates of $39 \%-81 \% .^{6,36-39}$ In our institution however, this was accompanied by unacceptable toxicity.40 Based on these observations, a sequential ILP schedule was developed in which both hyperthermia and melphalan could be applied at the maximum tolerable dose for each modality, aiming at a double therapeutic effect without the toxicity encountered with simultaneous application. ${ }^{41,42}$ Initial results in 10 patients were published before.$^{43}$ In chapter eight, the long-term results are presented of all 17 patients treated with a true hyperthermic ILP $\left(42-43^{\circ} \mathrm{C}\right)$ without a cytostatic drug followed by a normothermic ILP with melphalan alone.

Despite the continuing risk of loco-regional and distant metastasis, approximately $23-47 \%$ of the patients with extremity melanoma survive five-years after ILP. ${ }^{29,30}$ These long-term survivors can be subject of long-term disease- and/or ILP-related complaints, which may influence their quality of life after ILP. In long-term survivors of other forms of cancer, an increased level of fear, especially fear of recurrences, incidence of depression, disturbed sense of self and body perception has been reported. ${ }^{44-46}$ Especially fear of recurrences and the disturbed sense of self or body perception, caused by still visible (non-vital) skin lesions, edema or a difference in skin color between the perfused and healthy limb, could have an impact on long-term survivors after ILP Also, problems getting life insurance or home mortgage have been observed in long-term survivors in general. ${ }^{47,48}$ One study so far has focused specifically on quality of life of long-term survivors of melanoma and there is one study on quality of life in patients treated with ILP for melanoma. ${ }^{49}$ In this study however, short term quality of life was assessed in patients who received ILP for primary melanoma. ${ }^{50}$ Therefore, in chapter nine a study was performed to assess quality of life and possible patient-, tumor- and ILP-related factors for quality of life in long-term survivors after ILP for recurrent limb melanoma.

The application of ILP as a treatment of soft tissue sarcoma (STS) of the extremities has gained success after Liénard et al. first added TNF $\alpha$ to melphalan-ILP in $1992 .{ }^{22}$ In the first four patients with unresectable recurrent STS treated with TNF $\alpha$ and melphalan, a $100 \%$ tumor response rate was reported after ILP. $^{22}$ Before that time, no other anti-sarcoma drugs in ILP had lead to these promising response rates with acceptable toxicity.51 Later, results of TNF $\alpha$-ILP for unresectable STS of the extremities from other institutions showed overall response rates varying from 76 to $91 \% .^{52-56} \mathrm{TNF} \alpha$-ILP offers a possibility for limb-sparing surgery in responding patients, thereby aiming at a disease-free extremity with preserved function, which has shown to result in similar long-term survival as amputation of the etxremity. ${ }^{57,58}$ In chapter ten, the results of ILP in our institution for soft tissue sarcoma of the extremity are presented.

In chapter eleven, a case is described in which a patient with three large painful femoral metastases, with impending fracture, underwent ILP with melphalan as a palliative measure. 


\section{References}

1. Creech DG, Krementz ET, Ryan RF, Winblad JN. Chemotherapy of cancer: regional perfusion utilising an extracorporeal circuit. Ann Surg 1958; 148:616-32.

2. Vrouenraets BC, Nieweg OE, Kroon BBR. Thirty-five years of isolated limb perfusion for melanoma: indications and results. Br J Surg 1996; 83:1319-28.

3. Sackett DL, Straus SE, Richardson WS, Rosenberg W, Haynes RB. Evidence-based Medicine: How to Practise and Teach EBM. Edinburgh: Churchill Livingston, 2000.

4. Urschel JD, Goldsmith CH, Tandan VR, Miller JD. Users' guide to evidence-based surgery: how to use an article evaluating surgical interventions. Evidence-Based Surgery Working Group. Can J Surg 2001; 44:95-100.

5. Liénard D, Eggermont AMM, Schraffordt Koops H, Kroon B.B.R., Towse G, Hiemstra S, Schmitz P, Clarke J, Steinmann G, Rosenkaimer F, Lejeune FJ. Isolated limb perfusion with tumour necrosis factor-alpha and melphalan with or without interferongamma for the treatment of in-transit melanoma metastases: a multicentre randomized phase II study. Melanoma Res 1999; 9:491-502.

6. Di Filippo F, Calabro A, Giannarelli D, Carlini S, Cavaliere F, Moscarelli F, Cavaliere R. Prognostic variables in recurrent limb melanoma treated with hyperthermic antiblastic perfusion. Cancer 1989; 63:2551-61.

7. Fraker DL, Alexander HR, Andrich M, Rosenberg SA. Treatment of patients with melanoma of the extremity using hyperthermic isolated limb perfusion with melphalan, tumor necrosis factor, and interferon gamma: results of a tumor necrosis factor dose-escalation study. J Clin Oncol 1996; 14:479-89.

8. Vrouenraets BC, Hart GA, Eggermont AMM, Klaase JM, van Geel BN, Nieweg OE, Kroon BBR. Relation between limb toxicity and treatment outcomes after isolated limb perfusion for recurrent melanoma. J Am Coll Surg 1999; 188:522-30.

9. Lejeune FJ, Lienard D, el Douaihy M, Seyedi JV, Ewalenko P. Results of 206 isolated limb perfusions for malignant melanoma. Eur J Surg Oncol 1989; 15:510-9.

10. Hill S, Thomas JM. Use of the carbon dioxide laser to manage cutaneous metastases from malignant melanoma. Br J Surg 1996; 83:509-12.

11. Strobbe LJ, Nieweg OE, Kroon BBR. Carbon dioxide laser for cutaneous melanoma metastases: indications and limitations. Eur J Surg Oncol 1997; 23:435-8.

12. Overgaard J, Gonzalez GD, Hulshof MC, Arcangeli G, Dahl O, Mella O, Bentzen SM. Randomised trial of hyperthermia as adjuvant to radiotherapy for recurrent or metastatic malignant melanoma. European Society for Hyperthermic Oncology. Lancet 1995; 345:540-3.

13. Hafstrom L, Rudenstam CM, Blomquist E, Ingvar C, Jonsson PE, Lagerlof B, Lindholm C, Ringborg U, Westman G, Ostrup L. Regional hyperthermic perfusion with melphalan after surgery for recurrent malignant melanoma of the extremities. Swedish Melanoma Study Group. J Clin Oncol 1991; 9:2091-4.

14. Schraffordt Koops H, Vaglini M, Suciu S, Kroon BBR, Thompson JF, Gohl J, Eggermont AM, Di Filippo F, Krementz ET, Ruiter D, Lejeune FJ. Prophylactic isolated limb perfusion for localized, high-risk limb melanoma: results of a multicenter randomized phase III trial. J Clin Oncol 1998; 16:2906-12.

15. Vrouenraets BC, Eggermont AMM, Hart AAM, Klaase JM, van Geel AN, Nieweg OE, Kroon BBR. Regional toxicity after isolated limb perfusion with melphalan and 
tumour necrosis factor- alpha versus toxicity after melphalan alone. Eur J Surg Oncol $2001 ; 27: 390-5$.

16. Sonneveld EJ, Vrouenraets BC, van Geel BN, Eggermont AMM, Klaase JM, Nieweg OE, van Dongen JA, Kroon BBR. Systemic toxicity after isolated limb perfusion with melphalan for melanoma. Eur J Surg Oncol 1996; 22:521-7.

17. Thomas DR, Ritchie CS. Preoperative assessment of older adults. J Am Geriatr Soc 1995; 43:811-21.

18. Polanczyk CA, Marcantonio E, Goldman L, Rohde LE, Orav J, Mangione CM, Lee $\mathrm{TH}$. Impact of age on perioperative complications and length of stay in patients undergoing noncardiac surgery. Ann Intern Med 2001; 134:637-43.

19. Bonenkamp JJ, Songun I, Hermans J, Sasako M, Welvaart K, Plukker JT, van Elk P, Obertop H, Gouma DJ, Taat CW, . Randomised comparison of morbidity after D1 and D2 dissection for gastric cancer in 996 Dutch patients. Lancet 1995; 345:745-8.

20. Hobler KE. Colon surgery for cancer in the very elderly. Cost and 3-year survival. Ann Surg 1986; 203:129-31.

21. Vrouenraets BC, in't Veld GJ, Nieweg OE, van Slooten GW, van Dongen JA, Kroon BBR. Long-term functional morbidity after mild hyperthermic isolated limb perfusion with melphalan. Eur J Surg Oncol 1999; 25:503-8.

22. Liénard D, Ewalenko P, Delmotte JJ, Renard N, Lejeune FJ. High-dose recombinant tumor necrosis factor alpha in combination with interferon gamma and melphalan in isolation perfusion of the limbs for melanoma and sarcoma. J Clin Oncol 1992; 10:5260 .

23. Vrouenraets BC, Eggermont AMM, Klaase J, van Geel A, van Dongen JA, Kroon BBR. Long-term neuropathy after regional isolated perfusion with melphalan for melanoma of the limbs. Eur J Surg Oncol 1994; 20:681-5.

24. Thompson JF, Hunt JA, Shannon KF, Kam PC. Frequency and duration of remission after isolated limb perfusion for melanoma. Arch Surg 1997; 132:903-7.

25. Klaase JM, Kroon BBR, van Geel AN, Eggermont AMM, Franklin HR, Hart AAM. Prognos-

tic factors for tumor response and limb recurrence-free interval in patients with advanced melanoma of the limbs treated with regional isolated perfusion with melphalan. Surgery 1994; 115:39-45.

26. Klop WM, Vrouenraets BC, van Geel BN, Eggermont AMM, Klaase JM, Nieweg OE, Kroon BBR. Repeat isolated limb perfusion with melphalan for recurrent melanoma of the limbs. J Am Coll Surg 1996; 182:467-72.

27. Bartlett DL, Ma G, Alexander HR, Libutti SK, Fraker DL. Isolated limb reperfusion with tumor necrosis factor and melphalan in patients with extremity melanoma after failure of isolated limb perfusion with chemotherapeutics. Cancer 1997; 80:2084-90.

28. Feldman AL, Alexander HR, Jr., Bartlett DL, Fraker DL, Libutti SK. Management of extremity recurrences after complete responses to isolated limb perfusion in patients with melanoma. Ann Surg Oncol 1999; 6:562-7.

29. Balch CM, Buzaid AC, Soong S-J, Atkins MB, Cascinelli N, Coit DG, Fleming ID, Gershenwald JE, Houghton A, Jr., Kirkwood JM, McMasters KM, Mihm MF, Morton DL, Reintgen DS, Ross MI, Sober A, Thompson JA, Thompson JF. Final version of the American Joint Committee on Cancer staging system for cutaneous melanoma. $J$ Clin Oncol 2001; 19:3635-48.

30. Krementz ET, Sutherland CM, Muchmore JH. Isolated hyperthermia chemotherapy 
perfusion for limb melanoma. Surg Clin North Am 1996; 76:1313-30.

31. Zogakis TG, Bartlett DL, Libutti SK, Liewehr DJ, Steinberg SM, Fraker DL, Alexander HR. Factors affecting survival after complete response to isolated limb perfusion in patients with in-transit melanoma. Ann Surg Oncol 2001; 8:771-8.

32. Klaase JM, Kroon BBR, van Geel AN, van Wijk J, Franklin HR, Eggermont AMM, Hart AAM. Limb recurrence-free interval and survival in patients with recurrent melanoma of the extremities treated with normothermic isolated perfusion. $\mathrm{J} \mathrm{Am} \mathrm{Coll}$ Surg 1994; 178:564-72.

33. Klaase JM, Kroon BBR, van Geel AN, Eggermont AMM, Franklin HR, van Dongen JA. A retrospective comparative study evaluating the results of a single-perfusion versus double-perfusion schedule with melphalan in patients with recurrent melanoma of the lower limb. Cancer 1993; 71:2990-4.

34. Cavaliere R, Ciocatto EC, Giovanella BC, Heidelberger C, Johnson RO, Margottini M, Mondovi B, Moricca G, Rossi-Fanelli A. Selective heat sensitivity of cancer cells. Biochemical and clinical studies. Cancer 1967; 20:1351-81.

35. Vaglini M, Ammatuna M, Nava M, Prada A, Rovini D, Santinami M, Cascinelli N. Regional perfusion at high temperature in treatment of stage IIIA-IIIAB melanoma patients. Tumori 1983; 69:585-8.

36. Storm FK, Morton DL. Value of therapeutic hyperthermic limb perfusion in advanced recurrent melanoma of the lower extremity. Am J Surg 1985; 150:32-5.

37. Santinami M, Belli F, Cascinelli N, Rovini D, Vaglini M. Seven years experience with hyperthermic perfusions in extracorporeal circulation for melanoma of the extremities. J Surg Oncol 1989; 42:201-8.

38. Bryant PJ, Balderson GA, Mead P, Egerton WS. Hyperthermic isolated limb perfusion for malignant melanoma: response and survival. World J Surg 1995; 19:363-8.

39. Vaglini M, Andreola S, Attili A, Belli F, Marolda R, Nava M, Prada A, Santinami M, Cascinelli N. Hyperthermic antiblastic perfusion in the treatment of cancer of the extremities. Tumori 1985; 71:355-9.

40. Kroon BBR, Klaase JM, van Geel AN, Eggermont AMM. Application of hyperthermia in regional isolated perfusion for melanoma of the limbs. Regional Cancer Treatment 1992;223-6.

41. van der Zee J, Broekmeyer-Reurink MP, van den Berg AP, van Geel BN, Jansen RF, Kroon BBR, van Wijk J, Hagenbeek A. Temperature distribution and $\mathrm{pH}$ changes during hyperthermic regional isolation perfusion. Eur J Cancer Clin Oncol 1989; 25:1157-63.

42. Jansen RF, van Geel BN, van der Zee J, Hagenbeek A, Levendag PC. Intractible cutaneous non-Hodgkin's lymphoma of the lower limb. Complete remission after sequential regional isolated hyperthermic perfusion and perfusion with 1-phenylalanine-mustard (melphalan, L-Pam). Cancer 1989; 64:392-5.

43. Kroon BBR, Klaase J, van de Merwe SA, van Dongen J, van der Zee J. Results of a double perfusion schedule using high-dose hyperthermia and melphalan sequentially for recurrent melanoma of the limbs: a pilot study. Regional Cancer Treatment 1992;305-8.

44. Gotay CC, Muraoka MY. Quality of life in long-term survivors of adult-onset cancers. J Natl Cancer Inst 1998; 90:656-67.

45. Ramsey SD, Berry K, Moinpour C, Giedzinska A, Andersen MR. Quality of life in long term survivors of colorectal cancer. Am J Gastroenterol 2002; 97:1228-34. 
46. Ganz PA, Desmond KA, Leedham B, Rowland JH, Meyerowitz BE, Belin TR. Quality of life in long-term, disease-free survivors of breast cancer: a follow-up study. $J$ Natl Cancer Inst 2002; 94:39-49.

47. van Tulder MW, Aaronson NK, Bruning PF. The quality of life of long-term survivors of Hodgkin's disease. Ann Oncol 1994; 5:153-8.

48. Joly F, Heron JF, Kalusinski L, Bottet P, Brune D, Allouache N, Mace-Lesec'h J, Couette JE, Peny J, Henry-Amar M. Quality of life in long-term survivors of testicular cancer: a population-based case-control study. J Clin Oncol 2002; 20:73-80.

49. Dirksen SR. Perceived well-being in malignant melanoma survivors. Oncol Nurs Forum 1989; 16:353-8.

50. Hahn D, Meiland F, Wiarda V, Rumke Ph., van Dam F, Kroon BBR. Quality of life in early stage perfused and non-perfused melanoma patients. Unpublished,1990.

51. Klaase JM, Kroon BBR, Benckhuijsen C, van Geel AN, Albus-Lutter CE, Wieberdink $\mathrm{J}$. Results of regional isolation perfusion with cytostatics in patients with soft tissue tumors of the extremities. Cancer 1989; 64:616-21.

52. van Etten B, van Geel AN, de Wilt JH, Eggermont AMM. Fifty tumor necrosis factorbased isolated limb perfusions for limb salvage in patients older than 75 years with limb-threatening soft tissue sarcomas and other extremity tumors. Ann Surg Oncol $2003 ; 10: 32-7$.

53. Lejeune FJ, Pujol N, Liénard D, Mosimann F, Raffoul W, Genton A, Guillou L, Landry M, Chassot PG, Chiolero R, Bischof-Delaloye A, Leyvraz S, Mirimanoff RO, Bejkos D, Leyvraz PF. Limb salvage by neoadjuvant isolated perfusion with TNFalpha and melphalan for non-resectable soft tissue sarcoma of the extremities. Eur $J$ Surg Oncol 2000; 26:669-78.

54. Eggermont AMM, Schraffordt Koops H, Klausner JM, Kroon BBR, Schlag PM, Liénard D, van Geel AN, Hoekstra HJ, Meller I, Nieweg OE, Kettelhack C, Ben Ari G, Pector JC, Lejeune FJ. Isolated limb perfusion with tumor necrosis factor and melphalan for limb salvage in 186 patients with locally advanced soft tissue extremity sarcomas. The cumulative multicenter European experience. Ann Surg 1996; 224:756-64.

55. Olieman AF, Pras E, van Ginkel RJ, Molenaar WM, Schraffordt Koops H, Hoekstra HJ. Feasibility and efficacy of external beam radiotherapy after hyperthermic isolated limb perfusion with TNF-alpha and melphalan for limb-saving treatment in locally advanced extremity soft-tissue sarcoma. Int J Radiat Oncol Biol Phys 1998; 40:80714.

56. Gutman M, Inbar M, Lev-Shlush D, Abu-Abid S, Mozes M, Chaitchik S, Meller I, Klausner JM. High dose tumor necrosis factor-alpha and melphalan administered via isolated limb perfusion for advanced limb soft tissue sarcoma results in a $>90 \%$ response rate and limb preservation. Cancer 1997; 79:1129-37.

57. Rosenberg SA, Tepper J, Glatstein E, Costa J, Baker A, Brennan M, DeMoss EV, Seipp C, Sindelar WF, Sugarbaker P, Wesley R. The treatment of soft-tissue sarcomas of the extremities: prospective randomized evaluations of (1) limb-sparing surgery plus radiation therapy compared with amputation and (2) the role of adjuvant chemotherapy. Ann Surg 1982; 196:305-15.

58. Williard WC, Hajdu SI, Casper ES, Brennan MF. Comparison of amputation with limb-sparing operations for adult soft tissue sarcoma of the extremity. Ann Surg 1992; 215:269-75. 


\title{
Chapter 2
}

\section{Isolated limb perfusion: what is the evidence for its use?}

\author{
Noorda EM, Vrouenraets BC, Nieweg OE, van Coevorden F, Kroon BBR
}

Submitted

\section{Introduction}

Over time, isolated limb perfusion (ILP) has been used for various indications, with varying results. Evidence from prospective (randomized) studies, supporting the current application of ILP, is rare. To assess what evidence is available for the use of ILP, we have conducted a systematic analysis of the literature which aimed to include only the best available evidence for the various indications of ILP in extremity melanoma and soft tissue sarcoma (STS). This analysis has been performed following the principles of evidence-based medicine (www.cebm. utoronto.ca/practise/ca/). ${ }^{1,2}$ The question that we have tried to answer is "Based upon the best evidence available, what are the indications and results of ILP in patients with melanoma or sarcoma of the extremities?"

\section{Methods}

Evidence-based medicine is based upon four subsequent steps (FRAP) (www.cebm.utoronto.ca/practise/ca/): ${ }^{1}$

- Frame the clinical question

- Retrieve the evidence, through a literature search

- Appraise the evidence (critically appraised topic=CAT)

- Patient application: extrapolation of the available best-evidence to clinical practice

For the purpose of this overview these steps were followed.

First, questions regarding the various clinical applications of ILP were formulated. Clinical questions that were addressed separately were: What is the value of adjuvant ILP after excision of primary melanoma? What is the value of prophylactic ILP after excision of recurrent melanoma? What is the value of ILP in unresectable melanoma? What is the value of ILP in resectable STS of the extremity? What is the value of ILP in unresectable STS of the extremity?

Second, the best available evidence was selected, guided by the following ranking of evidence of interventional studies: ${ }^{1}$

- Level 1a. Systematic review of randomized controlled trials (RCTs) with consistent results

- Level 1b. RCT of good quality

- Level 2a. Systematic review of observational or case-control studies with consistent results

- Level 2b. RCT of less quality or observational or case-control study 
- Level 2c. Outcomes research (descriptive study)

- Level 3. Patient series, observational or case-control study of poor quality

- Level 4. The experts' opinion or generally accepted practice

Ideally, level 1 evidence was included and if that was not available, evidence from the next level etc. If no RCT was available, the largest analyses were discussed, provided that the inclusion criteria, outcome variables and statistics were reported well. Published and unpublished reports were sought through Pubmed and the Cochrane Controlled Trial Register. For melanoma, the evidence was searched using MesH terms "melanoma" and "perfusion, regional", the result of which was limited to RCTs or clinical trials. For STS, the same search was performed with "sarcoma" and the addition of radiotherapy or intra-arterial chemotherapy, if applicable. Conference reports and abstracts were retrieved from the internet, from the authors, or from participants of these conferences. The references from previous review articles were examined.

Third, for each of the aforementioned clinical questions, a CAT of the best available study was performed following the guidelines provided by the Centre for Evidence-Based Medicine in Toronto, Canada. A CAT is a judgment of the validity of the study and the size and precision of the diagnostic or therapeutic effect, wherein the following questions are answered: Are the results valid? What are the results? Are the results applicable to my patients? This is done by systematically collecting the following data from the analysis: Data regarding the design of the study, inclusion criteria, size of the study population (per group), treatment arms to which was randomized (if applicable), primary end points of the study, duration of follow-up and the results regarding the primary and other relevant endpoints. Possible endpoints were response to ILP, regional and systemic toxicity, morbidity, disease-free survival and overall survival. For randomized controlled studies, the absolute risk reduction (ARR) and number needed to treat (NNT) were given with their confidence intervals (CIs). A conclusion was drawn based upon the results and methodological validity of the study and followed by additional commentary if necessary.

\section{ILP in melanoma}

What is the value of adjuvant ILP after excision of primary melanoma lesions? In Table 1, the RCTs are described that assessed the role of adjuvant ILP with melphalan (M-ILP) in extremity melanoma. Three of these trials assessed the value of adjuvant M-ILP in primary melanoma.

The best available evidence is the report on a large, multicentre RCT from 11 centers in seven countries, which was performed between 1984 and 1994. ${ }^{3}$ This report concerns 852 patients with a so-called 'high-risk' primary melanoma (Breslow thickness $\geq 1.5 \mathrm{~mm}$ ) on the extremity who were randomized to either wide local excision (WLE) or WLE and a mild hyperthermic (38-40 $\left.{ }^{\circ} \mathrm{C}\right) \mathrm{M}-\mathrm{ILP}$. Patients were eligible if they had no locoregional or distant metastases, if tumors were located distal to the middle half of the thigh or upper arm, if they were between 15 and 75 years of age, if they had not received previous chemo- or radiotherapy and if they had no other (previous) malignancies. The European 
Table 1. Prophylactic ILP for extremity melanoma

\begin{tabular}{|c|c|c|c|c|c|c|}
\hline Study & Design & $\begin{array}{l}\text { MD Ander- } \\
\text { son stage }{ }^{*}\end{array}$ & $\begin{array}{l}\text { Treatment } \\
\text { arms }\end{array}$ & $\mathrm{N}$ & $\begin{array}{l}\text { Regional } \\
\text { LND }^{+}\end{array}$ & $\begin{array}{l}\text { Locoregional } \\
\mathrm{RR}^{\ddagger}\end{array}$ \\
\hline $\begin{array}{l}\text { Schraffordt } \\
\text { Koops } 1998^{3}\end{array}$ & $\mathrm{RCT}$ & 1 & $\begin{array}{l}\text { WLE } \\
\text { WLE + ILP }\end{array}$ & 832 & $42 \%$ & $6.6 \%$ vs. $3.3 \%$ \\
\hline Ghussen $1988^{6}$ & $\mathrm{RCT}$ & I-III & $\begin{array}{l}\text { WLE } \\
\text { WLE + ILP }\end{array}$ & 107 & All & $38 \%$ vs. $7 \%$ \\
\hline Fenn $1997^{5}$ & $\mathrm{RCT}$ & 1 & $\begin{array}{l}\text { WLE } \\
\text { WLE + ILP }\end{array}$ & 30 & None & $43 \%$ vs. $13 \%$ \\
\hline Hafstrøm $1991^{8}$ & $\mathrm{RCT}$ & $\mathrm{II} / \mathrm{III}$ & $\begin{array}{l}\text { Excision } \\
\text { Excision + ILP }\end{array}$ & 69 & All & $67 \%$ vs. $46 \%$ \\
\hline
\end{tabular}

* Stage of disease is displayed in Table 2.

$\dagger \mathrm{LND}=$ lymph node dissection

‡RR= recurrence rate, given for each treatment arm respectively

Organization for Research and Treatment of Cancer (EORTC) performed the randomization. After randomization, 20 patients (10 in each treatment arm) were not included in the analysis because they were not eligible after all $(n=15)$ or were lost to follow-up $(n=5)$. Data from 412 patients receiving WLE only and 420 WLE + ILP, served as the subject of the trial. Elective lymph node dissection (ELND) was performed according to the participating centers' protocol. A panel of pathologists reviewed all resected material and quality control of the ILP was performed at all participating centers by the surgeons who initiated the trial. The median duration of follow-up was 6.4 years. Primary end points were locoregional recurrences as the first site of recurrence and survival.

In-transit metastases occurred in a significantly smaller number of patients in the group with ILP than those with WLE alone $(3.3 \%, 95 \%$ CI $2.8 \%-3.8 \%$ vs. $6.6 \%, 95 \%$ CI $6.1 \%-7.1 \%, \mathrm{P}=0.05)$, although the ARR of $3.3 \%$ (95\% CI $0.3 \%$ $6.0 \%$ ) was small with a high NNT of 33 (95\% CI 16-333). The incidence of regional node metastases in all patients, regardless of whether they underwent ELND or not, was not significantly decreased from $16.7 \%$ (95\% CI $13.1 \%$ $20.3 \%$ ) in those who underwent only WLE to $12.6 \%$ (95\% CI $9.4 \%-15.7 \%$ $\mathrm{P}=0.11)$ in the ILP group, with an ARR of $4.1 \%$ (95\% CI $-0.6 \%-9 \%)$ and a NNT of 24 (95\% CI 11-167). The differences in nodal recurrence rate were also not significant in the subgroups who had undergone ELND and those who had not. The disease-free survival was significantly increased in the ILP group $(\mathrm{P}=0.02)$ in the first two to three years following primary treatment, but no long-term effect was observed. There was no impact on overall survival.

In conclusion, the limited regional benefit and absence of an increase in overall survival by M-ILP does not outweigh its costs and morbidity, and M-ILP can therefore not be recommended as an adjunct to WLE in this group of patients with primary melanoma. 
Commentary 1. It is remarkable that a single chemotherapeutic treatment session significantly affects micrometastatic disease, resulting in a relative risk reduction (RRR) of in-transit metastases of 50\% (95\% CI 4.4\%-72.9\%) and a RRR of lymph node metastases of $25 \%$ (95\% CI 4.7\%-84.4\%). This reduction in risk of locoregional recurrences was particularly evident in the patients with tumor thickness between 1.5 and $3 \mathrm{~mm}$. Thicker melanoma lesions were more likely to have their first recurrences at distant sites. This difference in pattern of dissemination in melanoma lesions thicker and thinner than $4 \mathrm{~mm}$ has been reported before. $^{4}$

Commentary 2. Two other RCTs have been performed comparing WLE or WLE and M-ILP for primary high-risk melanoma. ${ }^{5,6}$ Ghussen et al randomized 107 patients with stage I-III melanoma (Table 2), only 37 of whom with primary melanoma, and followed them for at least four years. ${ }^{5}$ The applicability of their results to clinical practice is strongly doubted because of the extremely high locoregional recurrence rate of $39 \%$ in the control group (compared to $8 \%$ in the ILP-group (ARR 31\%, 95\% CI 9\%-58\%)). In general, recurrence rates are about $2-3 \%$ after adequately resected primary melanoma. ${ }^{7}$ Secondly, survival in this series is exceptionally high considering the fact that $65 \%$ of the patients had locoregionally recurrent disease, with a 3-year disease-free survival of approximately $94 \%$ in the ILP group and $73 \%$ for the controls $(\mathrm{P}=0.02)$. A small and prematurely closed RCT by Fenn et al. included only 30 patients with a mean duration of follow-up of 72 months (range 16-113 months). ${ }^{5}$ The locoregional recurrence rates of $13 \%$ and $43 \%$, in favor of the ILP-group, were high $(\mathrm{P}=0.14$, ARR $30 \%, 95 \%$ CI $-2 \%-61 \%$ ). This trial suggested a survival advantage for patients after ILP, with 5-year survival rates of $88 \%$ versus $60 \%$, respectively $(\mathrm{P}<0.03)$. However, because of its small size, the value of these findings is limited.

What is the value of prophylactic M-ILP after excision of recurrent melanoma lesions?

The best available evidence comes from a single centre, randomized trial, performed by the Swedish Melanoma Study Group between 1981 and 1989 (Table 1). ${ }^{8}$

Sixty-nine patients with locoregionally recurrent melanoma were randomized to WLE alone (36 patients) or WLE with borderline hyperthermic $\left(41-42^{\circ} \mathrm{C}\right) \mathrm{M}$ -

\section{Table 2. MD Anderson classification for melanoma}

\begin{tabular}{ll}
\hline Stage I & Primary melanoma \\
Stage IIA* & Local recurrence \\
Stage IIB & Satellite $\leq 3 \mathrm{~cm}$ from primary/scar/skin graft \\
Stage IIIA & Satellite/ln-transit metastasis $>3 \mathrm{~cm}$ from primary/scar/skin graft \\
Stage IIIB & Regional lymph node metastases \\
Stage IIIAB & Satellite/in-transit metastasis with regional lymph node metastases \\
Stage IV & Distant metastases
\end{tabular}

* Stage II was divided in stage IIA and stage IIB, according to Klaase et al. ${ }^{37}$ 
ILP (33 patients). Patients were not eligible if they had distant metastases. Both treatment arms were well balanced for sex, age, tumor thickness and tumor site on the upper or lower extremity. All patients were subjected to a regional lymph node dissection and had a mean follow-up of 39 months. Follow-up was performed at the patients' local hospital. The primary endpoints were further locoregional recurrences and survival.

A lower locoregional recurrence rate was seen in the ILP-group: 45\% (95\% CI 28-62\%) of these patients experienced recurrence compared to 67\% (95\% CI 52$82 \%)$ in the group with excision only $(\mathrm{P}=0.13)$. The ARR was $22 \%(95 \% \mathrm{CI}-2 \%$ to $44 \%)$ with a NNT of 5 (95\% CI 2-59). The median disease-free interval was prolonged to 17 months after ILP compared to 10 months after WLE alone $(\mathrm{P}=0.04)$. No difference in overall survival was observed, with approximate 5year survival rates of $39 \%$ and $44 \%$ respectively, in favor of the ILP group $(\mathrm{P}=0.28)$.

In conclusion, a significant increase in tumor-free survival was observed after ILP with a trend for a lower locoregional recurrence rate. However, since no overall survival benefits were observed, prophylactic M-ILP with all its costs and associated morbidity cannot be recommended in recurrent melanoma as adjunct to simple excision of these lesions.

Commentary. This study confirms that ILP influences micrometastatic disease, with a RRR in further locoregional metastases of 32\% (95\% CI -5.8\%-58.0\%) and a prolonged disease-free interval in patients at high risk of micrometastatic extremity metastases at the time of treatment. This study did not specify whether the patients had early stage recurrent disease (i.e. a first single recurrence) or later stage (multiple second or further recurrences) as the indication for their ILP. However, this RCT also shows the remarkable effect of a single application of regional chemotherapy on micrometastatic disease, with a reduction in further locoregional metastases.

To establish the role of ILP as an adjuvant treatment for resectable recurrences of melanoma, larger randomized studies are needed. Because these trials suggest that adjuvant M-ILP has a significant effect on micrometastatic disease, ILP may provide valuable locoregional disease control in selected patients groups (for example those with frequently recurring and multiple lesions) compared to WLE only. For future studies, it might be necessary to select specific patient groups, for example with a third or more recurrence, because these patients have proved their tendency for repeat recurrences. ${ }^{9}$

\section{What is the value of therapeutic ILP for unresectable extremity melanoma?}

An overview of the results of ILP in patients with measurable recurrent melanoma lesions is given in Table 3 . There have been no RCTs studying ILP versus other treatments for patients with measurable disease. Although the generally accepted indication for M-ILP is unresectable limb melanoma, there are also no RCTs comparing ILP with other possible treatment options (e.g. radiotherapy, chemotherapy etc.) for this indication. Since most results on tumor response after ILP are from series in which the lesions were deliberately left in situ to monitor the ILP-effect, it is difficult to assess the results of ILP for truly unresectable extremity melanoma. ${ }^{10}$ 
Table 3. Therapeutic ILP for melanoma

\begin{tabular}{|c|c|c|c|c|c|c|}
\hline Study & Design & $\begin{array}{l}\text { MD Anderson } \\
\text { stage* }\end{array}$ & $\begin{array}{l}\text { Treat- } \\
\text { ment }\end{array}$ & $\mathrm{N}$ & End points & $\mathrm{CR}$ \\
\hline Fraker $2002^{11}$ & $\mathrm{RCT}$ & $\begin{array}{l}\text { In-transit melano- } \\
\text { ma, } \geq 2 \text { lesions }\end{array}$ & $\begin{array}{l}\text { TIM-ILP } \\
\text { M-ILP }\end{array}$ & 103 & $\begin{array}{l}\text { Response } \\
\text { Recurrences } \\
\text { Disease-free } \\
\text { survival }\end{array}$ & $72 \%$ vs $58 \%$ \\
\hline Liénard $1999^{13}$ & $\mathrm{RCT}$ & $\begin{array}{l}\text { Measurable } \\
\text { stage II/III }\end{array}$ & $\begin{array}{l}\text { TM-ILP } \\
\text { TIM-ILP } \\
\text { M-ILP }\end{array}$ & 69 & $\begin{array}{l}\text { Response } \\
\text { Recurrences } \\
\text { Disease-free } \\
\text { survival }\end{array}$ & $\begin{array}{l}69 \% \text { vs } 78 \% \\
\text { vs } 52 \%\end{array}$ \\
\hline $\begin{array}{l}\text { Vrouenraets } \\
1996^{10 \dagger}\end{array}$ & Review & $\begin{array}{l}\text { Measurable } \\
\text { stage II/III }\end{array}$ & M-ILP & 21 & $\begin{array}{l}\text { CR } \\
\text { Recurrences }\end{array}$ & $54 \%$ \\
\hline
\end{tabular}

$\mathrm{CR}=$ complete response

* Stage of disease is displayed in Table 2

$\dagger$ A review of retrospective series with at least 10 patients

The best available evidence comes from a subgroup analysis of a multicentre phase III trial carried out in five US centers. ${ }^{11}$ In a preliminary report, 103 patients were included with two or more recurrent melanoma lesions on the extremity. These patients were randomized to mild hyperthermic M-ILP ( $\mathrm{n}=51)$ or ILP with melphalan, tumor necrosis factor alpha (TNF $\alpha)$ and interferon-gamma (IFN $\alpha$, TIM-ILP) $(\mathrm{n}=52)$.

In the subgroup of patients with a high tumor load (i.e. more than 10 lesions or lesions larger than $5 \mathrm{~cm}$ ), a $19 \%$ CR rate after M-ILP was attained versus $58 \%$ when TNF $\alpha$ and melphalan were used.

In conclusion, this study suggests that high tumor load extremity melanoma lesions are best treated with TIM-ILP, compared to the (remarkably) low CR rate after M-ILP.

Commentary 1. The traditional indication for ILP, namely unresectable limb melanoma, is based on level 3 or 4 evidence. The largest retrospective study that analyzed results of ILP in patients with unresectable melanoma lesions was performed by Kapteijn et al. ${ }^{12}$ Forty-nine patients were treated with various ILP schedules varying from single normothermic to double normothermic and single hyperthermic to a sequential schedule in which high-dose hyperthermia and melphalan were separately and sequentially applied. Criteria for unresectability of melanoma lesions were not given. In $28(57 \%)$ of the patients a CR was attained. Except for the single normothermic ILPs, these results are based upon ILP-types that are no longer performed. Therefore, new studies with M-ILP and T(I)M-ILP seem warranted, preferentially RCTs comparing ILP with extensive locoregional treatment, such as $\mathrm{CO}_{2}$ laser ablation or excisions.

Commentary 2. These results are preliminary and it is unknown on how many patients with a high tumor load they are based. However, the results after M-ILP 
and TIM-ILP for high tumor burden disease are disappointing compared to the results of both ILP-types for measurable lesions, as reported in a retrospective comparative study by Liénard et al., with a 73\% CR rate after T(I)M-ILP compared to $52 \%$ after M-ILP. ${ }^{13}$ In addition, a large meta-analysis of retrospective series showed that M-ILP resulted in a CR rate of $54 \% .^{10}$

Commentary 3. Results obtained with multiple surgical excisions or $\mathrm{CO}_{2}$ laser ablation are generally satisfactory if recurring lesions are not too extensive and superficially localized. ${ }^{14,15}$ Therefore, there is no evidence for the use of ILP in extensive but still resectable lesions. In pursuit of locoregional control with limb salvage for patients with lesions that cannot be managed with excisional surgery, other local treatment options seem subject to limitations. For example, $\mathrm{CO}_{2}$ laser ablation can only be applied to lesions smaller than $2 \mathrm{~cm}$ in the cutis or superficial subcutis. ${ }^{14,15}$ Radiotherapy \pm hyperthermia can result in a $35-62 \%$ CR rate, depending on the application of hyperthermia, but has the best effect in tumors smaller than $4 \mathrm{~cm}$ with the disadvantage that it cannot be applied to large areas with multiple lesions. ${ }^{16}$ Other intralesional applications of drugs or cytokines result in reasonable response rates up to $50 \%$ but mostly for only a short duration. ${ }^{17,18}$ The local application of dinitrochlorobenzen combined with systemic dacarbazine has resulted in a maximum of $25 \% \mathrm{CR} .{ }^{19}$

Commentary 4. The definition of unresectability is subjective to individual judgment and often not clearly defined. Fraker et al. have proposed a division based on high and low tumor load in which high tumor load is defined by more than 10 (small) lesions or lesions larger than $5 \mathrm{~cm} \cdot{ }^{20}$ Rossi et al defined a high tumor load as lesions larger than $3 \mathrm{~cm}$ or more than 15 in number. ${ }^{21}$

\section{ILP in soft tissue sarcoma}

The local treatment of advanced STS of the extremity requires a multimodality approach to obtain maximum local tumor control with preservation of limb function. Advanced STS of the extremities was conventionally treated with amputation of the extremity, until 1982 when Rosenberg et al. published the results of a $\mathrm{RCT}$, in which patients were randomized to either amputation of the limb or limb sparing surgery (excision and radiation therapy), which showed no significant difference in overall survival between the treatment arms. ${ }^{22}$ This was a landmark in the treatment of STS of the extremity, and a tendency for limb sparing treatment modalities then developed. The best available evidence was searched for the effectiveness of ILP and other locoregional, limb sparing treatment modalities for patients with extremity STS. No RCTs or other studies were found that provide information on the value of ILP in resectable STS. The value of ILP in unresectable STS will therefore only be discussed, as well as three other possible neoadjuvant treatment modalities in these patients, namely radiotherapy, intraarterial chemotherapy and systemic chemotherapy. The best available evidence was selected and appraised in the same way as for melanoma.

What is the value of ILP for patients with unresectable STS of the extremity? There was no RCT or other comparative study available comparing ILP with other treatment options (i.e. neoadjuvant or amputation) for locally unresectable 
Table 4. TNF $\alpha$-ILP in patients with unresectable extremity soft tissue sarcoma

\begin{tabular}{llrllll}
\hline Study & $\begin{array}{l}\text { Nr. of } \\
\text { centers }\end{array}$ & N & $\begin{array}{l}\text { Treat- } \\
\text { ment }\end{array}$ & Final RR & CR rate & LSR \\
& Multi & 186 & T(I)M & $82 \%$ & $29 \%$ & $82 \%$ \\
Eggermont $1996^{23}$ & Single & 31 & TM & $92 \%$ & $37 \%$ & $85 \%$ \\
Gutman $1997^{28}$ & Single & 34 & TIM & $94 \%$ & $35 \%$ & $85 \%$ \\
Olieman $1998^{25}$ & Single & 22 & T(I)M & $82 \%$ & $18 \%$ & $86 \%$ \\
Lejeune $2000^{27}$ & Single & 30 & T(I)M & $77 \%$ & $40 \%$ & $76 \%$ \\
Van Etten $2003^{26}$ & Single & 49 & T(I)M & $63 \%$ & $8 \%$ & $57 \%$ \\
Noorda $2003^{38}$ & & & & & & \\
\hline
\end{tabular}

$\mathrm{RR}=$ response rate, $\mathrm{CR}=$ complete response, $\mathrm{LSR}=\mathrm{Limb}$ salvage rate

STS. Therefore, only (retrospective) case series can be discussed (Table 4.).

The best available evidence, i.e. largest series on ILP for unresectable STS of the extremities, is a retrospective, multicentre study by eight European centers that provides data from 186 patients treated according to the same protocol with melphalan and TNF $\alpha$ (TM-ILP) in $1995 .^{23}$ The patients were selected on the basis of unresectable STS of the limb based upon the following criteria of unresectability: multifocality, fixation to vital structures (nerve/vessels/bone), recurrence in a previously irradiated area, location in or near a joint, large size which would necessitate an extent of resection that would severely compromise limb function or a combination of these factors. They underwent a mild hyperthermic $\left(38-40^{\circ} \mathrm{C}\right) \mathrm{TM}-\mathrm{ILP}$, and in 55 patients IFN $\alpha$ was added (TIM-ILP). If sufficient response allowed resection, the tumor remnant was subsequently removed. Median follow-up was 22 months (range 6-58 months). The major endpoints were tumor response, divided in clinical, histologic and final response, and limb salvage rate.

Clinically, tumor response was complete in 33 patients (18\%), partial in 106 $(57 \%)$, no change was observed in $42(22 \%)$ and progression occurred in five patients $(3 \%)$. In $126(68 \%)$ patients, the tumor remnant could be resected after ILP. Sixty patients did not undergo post-ILP resection due to excessive number of tumors, systemic metastases or refusal to be amputated. The final response was based upon a combined judgment of clinical response and pathological review of the resection specimen (if available) and was complete in 54 patients (29\%), partial in $99(53 \%)$, no change was observed in $29(16 \%)$ and progressive in four patients $(2 \%)$. The limb of 34 patients had to be amputated during the course of follow-up, seven of whom had initially been rendered tumor-free by ILP \pm resection. The limb salvage rate was $82 \%$.

In conclusion, limb salvage could be obtained in the majority of patients who would otherwise have undergone amputation.

Commentary 1 . The actual limb salvage rate is $64 \%$, since only $64 \%$ attained local tumor control with preservation of the limb (function).

Commentary 2. Other reports on the use of T(I)M-ILP for this indication are also displayed in Table 4. In 1992, TNF $\alpha$ was first used in ILP with a 100\% response 
rate in the first four patients with unresectable recurrent STS treated with TNF $\alpha$ in combination with melphalan. ${ }^{24}$ Later, results of T(I)M-ILP for unresectable STS of the extremities from different institutions showed overall response rates varying from 77 to $94 \% .^{23,25-28}$ Various other drugs have been tried in ILP prior to $\mathrm{TNF} \alpha$ in these patients. An overview of all series containing more than 15 patients and reporting response and limb salvage rates, is given in Table 5.

Commentary 3. There are no RCTs or prospective studies on preoperative radiotherapy in unresectable STS of the extremity. The largest retrospective series is from the Massachusetts General Hospital Cancer Center (Table 6) ${ }^{29}$ A total of 220 patients had unresectable STS (70 on the extremity) that were rendered resectable by preoperative radiotherapy. No criteria are provided on which unresectability was based. The minimum follow-up was five years. No information is given on the completeness of tumor response after radiotherapy. Ten percent of the patients who had undergone local resection had a local recurrence. No limb salvage rate is mentioned. This was a biased series because only patients with resectable tumors after neoadjuvant radiotherapy were selected and thus no limb salvage rate, a measure for the effectiveness of preoperative radiotherapy, was provided.

Another study, by Tanabe et al. from the MD Anderson Cancer Center, on preoperative radiotherapy for patients with resectable extremity sarcomas does provide information about response after preoperative radiotherapy (Table 6).$^{30} \mathrm{~A}$ group of 95 patients, treated with preoperative radiotherapy and subsequent resection was retrospectively studied after a median follow-up of 66 months (range 16-236 months). In 54\% of them the tumor was smaller than $8 \mathrm{~cm}$. A $46 \%$ overall tumor response to radiotherapy was seen at histology. After resection of

Table 5. ILP with various drugs for unresectable extremity soft tissue sarcoma

\begin{tabular}{|c|c|c|c|c|c|c|}
\hline Study & $\begin{array}{l}\text { Design/patients } \\
\text { selection }\end{array}$ & $\mathrm{N}$ & Treatment & $\begin{array}{l}\text { Final } \\
\text { RR }\end{array}$ & $\begin{array}{l}\mathrm{CR} \\
\text { rate }\end{array}$ & LSR \\
\hline Krementz $1977^{39}$ & Retrospective & 56 & $\begin{array}{l}\text { Melphalan } \pm \text { nitro- } \\
\text { gen mustard } \\
\pm \text { actinomycine D }\end{array}$ & $32 \%$ & $7 \%$ & $N / R$ \\
\hline Lehti $1986^{40}$ & Retrospective & 50 & $\begin{array}{l}\text { Melphalan and } \\
\text { actinomycine D }\end{array}$ & $N / R$ & $\mathrm{~N} / \mathrm{R}$ & $74 \%$ \\
\hline Klaase $1989^{41}$ & Retrospective & 17 & $\begin{array}{l}\text { Doxorubicine } \\
\text { and/or melphalan }\end{array}$ & $24 \%$ & 24 & $81 \%$ \\
\hline Di Fillipo $1990^{42}$ & Retrospective & 47 & $\begin{array}{l}\text { Melphalan and } \\
\text { actinomycine D }\end{array}$ & $57 \%$ & $\mathrm{~N} / \mathrm{R}$ & $57 \%$ \\
\hline $\begin{array}{l}\text { Stephens Moseley } \\
1992^{43}\end{array}$ & Prospective & 20 & Cisplatin & $20 \%$ & $5 \%$ & $100 \%$ \\
\hline Rossi $1996^{44}$ & Prospective & 47 & Doxorubicine & $96 \%$ & 0 & $96 \%$ \\
\hline
\end{tabular}

Studies with more than 15 patients with response and/or limb salvage rates were included. $\mathrm{RR}=$ Response rate, $\mathrm{CR}=$ Complete response, $\mathrm{LSR}=$ Limb salvage rate, $\mathrm{N} / \mathrm{R}=$ not reported 
the tumor, recurrences were observed in $14(15 \%)$ of the patients. Seven of these patients had to undergo amputation, resulting in a limb salvage rate of $92 \%$.

O'Sullivan et al. have recently published the results of a preliminary closed RCT comparing pre- and postoperative radiotherapy in resectable extremity STS. The main outcome measure of this trial was the wound complication rate. Unfortunately, it did not provide information on the tumor response rate after preoperative radiotherapy. ${ }^{31}$

Commentary 4. The largest prospective series on the application of neo-adjuvant intra-arterial chemotherapy was published by Eilber et al., who combined this treatment modality with radiotherapy in high-risk (intermediate or high grade) extremity STS, with undefined resectability. In the first 107 patients, doxorubicin was delivered intra-arterially during three days followed by 10 fractions of $35 \mathrm{~Gy}$ of irradiation (Table 6). ${ }^{32}$ This resulted in a $98 \%$ limb salvage rate and a $3 \%$ local recurrence rate after a median follow-up of 8 years. However, a high local toxicity and complication rate of $43 \%$, with pathological fractures in a third of them, was encountered. This led them to reduce the radiation dose with $50 \%$. The next 137 patients were treated with the same intra-arterial scheme but with five fractions of $17.5 \mathrm{~Gy} .33 \mathrm{~A}$ limb salvage rate of $97 \%$ was attained, but with a $12 \%$ local recurrence rate after a median follow-up of 48 months. Compared to the first scheme a lower complication rate of $26 \%$ occurred, however at the cost of a higher local recurrence rate. ${ }^{33}$ Subsequent studies showed local recurrence rates varying from 3 to $29 \%$, limb salvage rates of $80-98 \%$ and varying complication rates of 3 to $26 \%$ (Table 6 ). ${ }^{34-36}$

Concluding, from the aforementioned reports it is clear that the application of

Table 6. Preoperative radiotherapy and intraarterial chemotherapy for soft tissue sarcoma of the extremities

\begin{tabular}{|c|c|c|c|c|c|c|}
\hline Study & $\begin{array}{l}\text { Design/patient } \\
\text { selection }\end{array}$ & $\mathrm{N}$ & $\begin{array}{l}\text { Rad.dose } \\
\text { (Gy) }\end{array}$ & $\begin{array}{l}\text { Local } \\
\text { resection }(\mathrm{n})\end{array}$ & $\begin{array}{l}\text { Local } \\
\text { RR }\end{array}$ & LSR \\
\hline Suit $1988^{29}$ & $\begin{array}{l}\text { Retrospective } \\
\text { Unresectable }\end{array}$ & 70 & $50-56$ & 64 & $10 \%$ & $91 \%$ \\
\hline Tanabe $1994^{30}$ & $\begin{array}{l}\text { Retrospective } \\
\text { Resectable }\end{array}$ & 95 & 50 & All & $15 \%$ & $92 \%$ \\
\hline Eilber $1985^{32}$ & $\begin{array}{l}\text { Prospective } \\
\text { High-risk }\end{array}$ & 107 & 35 & All & $3 \%$ & $98 \%$ \\
\hline Huth $1988^{33}$ & $\begin{array}{l}\text { Prospective } \\
\text { High-risk }\end{array}$ & 137 & 17 & All & $12 \%$ & $97 \%$ \\
\hline Azzarelli $1992^{36}$ & $\begin{array}{l}\text { Retrospective } \\
\text { (un)resectable }\end{array}$ & 78 & No & 62 & $29 \%$ & $80 \%$ \\
\hline Levine $1993^{34}$ & $\begin{array}{l}\text { Retrospective } \\
\text { Unresectable }\end{array}$ & 55 & 25 & 47 & $15 \%$ & $87 \%$ \\
\hline Temple $1997^{35}$ & $\begin{array}{l}\text { Prospective } \\
\text { High-risk }^{42}\end{array}$ & 30 & 40 & $3 \%$ & $98 \%$ & \\
\hline
\end{tabular}

$R R=$ recurrence rate,$L S R=$ Limb salvage rate 
all neoadjuvant treatment modalities is limited by the complications and toxicity they entail. Considering the effectiveness of ILP and the reported complication rates, ILP seems the best option. However, to be conclusive, RCTs are warranted comparing preoperative radiotherapy or intraarterial chemotherapy with ILP in patients with unresectable extremity STS.

\section{Summary}

Due to the limited regional benefit and absence of an increase in overall survival, M-ILP cannot be recommended as an adjunct to WLE in patients with primary melanoma (level $1 \mathrm{~b}$ evidence). Prophylactic M-ILP next to the excision of recurrent melanoma has not resulted in a benefit in recurrence rate or survival (level $2 b$ evidence). It is remarkable that ILP has a definite effect on micrometastatic disease in both situations, illustrated by a reduction in risk of further locoregional recurrences of $33 \%$ to $50 \%$. Therapeutic ILP seems indicated in unresectable melanoma (level 3-4 evidence), although RCTs comparing ILP with other treatment options are lacking. In unresectable STS of the extremities, limb salvage can be obtained in 57-86\% of patients with neoadjuvant T(I)M-ILP (level 3 evidence). However, there are no comparative studies with other neoadjuvant treatment options (or major amputation) for unresectable STS of the extremity. Further RCTs should establish its role in these patients.

\section{References}

1. Sackett DL, Straus SE, Richardson WS, Rosenberg W, Haynes RB. Evidence-based Medicine: How to Practise and Teach EBM. Edinburgh: Churchill Livingston, 2000.

2. Urschel JD, Goldsmith CH, Tandan VR, Miller JD. Users' guide to evidence-based surgery: how to use an article evaluating surgical interventions. Can J Surg 2001; 44:95-100.

3. Schraffordt Koops H, Vaglini M, Suciu S, Kroon BBR, Thompson JF, Gohl J, Eggermont AM, Di Filippo F, Krementz ET, Ruiter D, Lejeune FJ. Prophylactic isolated limb perfusion for localized, high-risk limb melanoma: results of a multicenter randomized phase III trial. J Clin Oncol 1998; 16:2906-12.

4. Balch CM, Soong SJ, Murad TM, Ingalls AL, Maddox WA. A multifactorial analysis of melanoma. II. Prognostic factors in patients with stage I (localized) melanoma. Surgery 1979; 86:343-51.

5. Fenn NJ, Horgan K, Johnson RC, Hughes LE, Mansel RE. A randomized controlled trial of prophylactic isolated cytotoxic perfusion for poor-prognosis primary melanoma of the lower limb. Eur J Surg Oncol 1997; 23:6-9.

6. Ghussen F, Nagel K, Groth W, Muller JM, Stutzer H. A prospective randomized study of regional extremity perfusion in patients with malignant melanoma. Ann Surg 1984; 200:764-8.

7. Kroon BBR, Nieweg OE. Management of malignant melanoma. Ann Chir Gynaecol 2000; 89:242-50.

8. Hafstrom L, Rudenstam CM, Blomquist E, Ingvar C, Jonsson PE, Lagerlof B, Lindholm C, Ringborg U, Westman G, Ostrup L. Regional hyperthermic perfusion with 
melphalan after surgery for recurrent malignant melanoma of the extremities. Swedish Melanoma Study Group. J Clin Oncol 1991; 9:2091-4.

9. Takkenberg RB, Noorda EM, Vrouenraets BC, Nieweg OE, van Geel AN, Eggermont AMM, Hart AAM, Kroon BBR. Does isolated limb perfusion prolong the limb recurrence-free interval after several episodes of excisional surgery for limb recurrences of melanoma? Ann Surg Oncol 2003; 10:S18.

10. Vrouenraets BC, Nieweg OE, Kroon BBR. Thirty-five years of isolated limb perfusion for melanoma: indications and results. Br J Surg 1996; 83:1319-28.

11. Fraker D, Alexander H, Ross M, Bartlett D, Tyler D, Libutti LS, Boddie A, Briele H, Karakousis G. A phase III trial of isolated limb perfusion for extremity melanoma comparing melphalan alone versus melphalan plus tumor necrosis factor (TNF) plus interferon gamma. Ann Surg Oncol 2002;S8.

12. Kapteijn BA, Klaase JM, van Geel AN, Eggermont AMM, Kroon BBR. Results of regional isolated perfusion for locally inoperable melanoma of the limbs. Melanoma Res 1994; 4:135-8.

13. Liénard D, Eggermont AMM, Schraffordt Koops H, Kroon B.B.R., Towse G, Hiemstra S, Schmitz P, Clarke J, Steinmann G, Rosenkaimer F, Lejeune FJ. Isolated limb perfusion with tumour necrosis factor-alpha and melphalan with or without interferongamma for the treatment of in-transit melanoma metastases: a multicentre randomized phase II study. Melanoma Res 1999; 9:491-502.

14. Hill S, Thomas JM. Use of the carbon dioxide laser to manage cutaneous metastases from malignant melanoma. Br J Surg 1996; 83:509-12.

15. Strobbe LJ, Nieweg OE, Kroon BBR. Carbon dioxide laser for cutaneous melanoma metastases: indications and limitations. Eur J Surg Oncol 1997; 23:435-8.

16. Overgaard J, Gonzalez GD, Hulshof MC, Arcangeli G, Dahl O, Mella O, Bentzen SM. Randomised trial of hyperthermia as adjuvant to radiotherapy for recurrent or metastatic malignant melanoma. European Society for Hyperthermic Oncology. Lancet 1995; 345:540-3.

17. Storm FK, Sparks FC, Morton DL. Treatment for melanoma of the lower extremity with intralesional injection of bacille Calmette Guerin and hyperthermic perfusion. Surg Gynecol Obstet 1979; 149:17-21.

18. von Wussow P, Block B, Hartmann F, Deicher H. Intralesional interferon-alpha therapy in advanced malignant melanoma. Cancer 1988; 61:1071-4.

19. Strobbe LJ, Hart AA, Rumke P, Israels SP, Nieweg OE, Kroon BB. Topical dinitrochlorobenzene combined with systemic dacarbazine in the treatment of recurrent melanoma. Melanoma Res 1997; 7:507-12.

20. Fraker DL, Alexander HR, Andrich M, Rosenberg SA. Treatment of patients with melanoma of the extremity using hyperthermic isolated limb perfusion with melphalan, tumor necrosis factor, and interferon gamma: results of a tumor necrosis factor dose-escalation study. J Clin Oncol 1996; 14:479-89.

21. Rossi CR, Foletto M, Pilati P, Mocellin S, Lise M. Isolated limb perfusion in locally advanced cutaneous melanoma. Semin Oncol 2002; 29:400-9.

22. Rosenberg SA, Tepper J, Glatstein E, Costa J, Baker A, Brennan M, DeMoss EV, Seipp C, Sindelar WF, Sugarbaker P, Wesley R. The treatment of soft-tissue sarcomas of the extremities: prospective randomized evaluations of (1) limb-sparing surgery plus radiation therapy compared with amputation and (2) the role of adjuvant chemotherapy. Ann Surg 1982; 196:305-15. 
23. Eggermont AMM, Schraffordt Koops H, Klausner JM, Kroon BBR, Schlag PM, Liénard D, van Geel AN, Hoekstra HJ, Meller I, Nieweg OE, Kettelhack C, Ben Ari G, Pector JC, Lejeune FJ. Isolated limb perfusion with tumor necrosis factor and melphalan for limb salvage in 186 patients with locally advanced soft tissue extremity sarcomas. The cumulative multicenter European experience. Ann Surg 1996; 224:756-64.

24. Liénard D, Ewalenko P, Delmotte JJ, Renard N, Lejeune FJ. High-dose recombinant tumor necrosis factor alpha in combination with interferon gamma and melphalan in isolation perfusion of the limbs for melanoma and sarcoma. J Clin Oncol 1992; 10:5260.

25. Olieman AF, Pras E, van Ginkel RJ, Molenaar WM, Schraffordt Koops H, Hoekstra HJ. Feasibility and efficacy of external beam radiotherapy after hyperthermic isolated limb perfusion with TNF-alpha and melphalan for limb-saving treatment in locally advanced extremity soft-tissue sarcoma. Int J Radiat Oncol Biol Phys 1998; 40:80714.

26. van Etten B, van Geel AN, de Wilt JH, Eggermont AMM. Fifty tumor necrosis factorbased isolated limb perfusions for limb salvage in patients older than 75 years with limb-threatening soft tissue sarcomas and other extremity tumors. Ann Surg Oncol 2003; 10:32-7.

27. Lejeune FJ, Pujol N, Liénard D, Mosimann F, Raffoul W, Genton A, Guillou L, Landry M, Chassot PG, Chiolero R, Bischof-Delaloye A, Leyvraz S, Mirimanoff RO, Bejkos D, Leyvraz PF. Limb salvage by neoadjuvant isolated perfusion with TNFalpha and melphalan for non-resectable soft tissue sarcoma of the extremities. Eur $J$ Surg Oncol 2000; 26:669-78.

28. Gutman M, Inbar M, Lev-Shlush D, Abu-Abid S, Mozes M, Chaitchik S, Meller I, Klausner JM. High dose tumor necrosis factor-alpha and melphalan administered via isolated limb perfusion for advanced limb soft tissue sarcoma results in a $>90 \%$ response rate and limb preservation. Cancer 1997; 79:1129-37.

29. Suit HD, Mankin HJ, Wood WC, Gebhardt MC, Harmon DC, Rosenberg A, Tepper JE, Rosenthal D. Treatment of the patient with stage M0 soft tissue sarcoma. J Clin Oncol 1988; 6:854-62.

30. Tanabe KK, Pollock RE, Ellis LM, Murphy A, Sherman N, Romsdahl MM. Influence of surgical margins on outcome in patients with preoperatively irradiated extremity soft tissue sarcomas. Cancer 1994; 73:1652-9.

31. O'Sullivan B, Davis AM, Turcotte R, Bell R, Catton C, Chabot P, Wunder J, Kandel R, Goddard K, Sadura A, Pater J, Zee B. Preoperative versus postoperative radiotherapy in soft-tissue sarcoma of the limbs: a randomised trial. Lancet 2002; 359:2235-41.

32. Eilber FR, Guiliano AE, Huth J, Mirra J, Morton DL. High-grade soft-tissue sarcomas of the extremity: UCLA experience with limb salvage. Prog Clin Biol Res 1985; 201:59-74.:59-74.

33. Huth JF, Eilber FR. Patterns of metastatic spread following resection of extremity softtissue sarcomas and strategies for treatment. Semin Surg Oncol 1988; 4:20-6.

34. Levine EA, Trippon M, Das Gupta TK. Preoperative multimodality treatment for soft tissue sarcomas. Cancer 1993; 71:3685-9.

35. Temple WJ, Temple CL, Arthur K, Schachar NS, Paterson AH, Crabtree TS. Prospective cohort study of neoadjuvant treatment in conservative surgery of soft tissue sarcomas. Ann Surg Oncol 1997; 4:586-90.

36. Azzarelli A, Quagliuolo V, Fissi S, Casali P, Garbuglia A, Bignami P, Santoro A, 
Andreola S, Gennari L. Intra-arterial induction chemotherapy for soft tissue sarcomas. Ann Oncol 1992; 3 Suppl 2:S67-S70.

37. Klaase JM, Kroon BBR, van Geel AN, van Wijk J, Franklin HR, Eggermont AMM, Hart AAM. Limb recurrence-free interval and survival in patients with recurrent melanoma of the extremities treated with normothermic isolated perfusion. $J$ Am Coll Surg 1994; 178:564-72.

38. Noorda EM, Vrouenraets BC, Nieweg OE, van Coevorden F, van Slooten GW, Kroon B.B.R. Isolated IImb perfusion with TNF-alpha and melphalan for unresectable soft tissue sarcoma of the extremities. Cancer 2003; In press.

39. Krementz ET, Carter RD, Sutherland CM, Hutton I. Chemotherapy of sarcomas of the limbs by regional perfusion. Ann Surg 1977; 185:555-64.

40. Lehti PM, Moseley HS, Janoff K, Stevens K, Fletcher WS. Improved survival for soft tissue sarcoma of the extremities by regional hyperthermic perfusion, local excision and radiation therapy. Surg Gynecol Obstet 1986; 162:149-52.

41. Klaase JM, Kroon BBR, Benckhuijsen C, van Geel AN, Albus-Lutter CE, Wieberdink J. Results of regional isolation perfusion with cytostatics in patients with soft tissue tumors of the extremities. Cancer 1989; 64:616-21.

42. Di Filippo F, Carlini S, Cavaliere F, Giannarelli D, Cavallero L, Moscarelli F, Aloe L, Cavaliere R. The role of hyperthermic perfusion in the treatment of tumors of the extremities. Adv Exp Med Biol 1990; 267:223-34.:223-34.

43. Moseley HS. An evaluation of two methods of limb salvage in extremity soft-tissue sarcomas. Arch Surg 1992; 127:1169-73.

44. Rossi CR, Foletto M, Alessio S, Menin N, D’Amore E, Rigon A, Lise M. Limb-sparing treatment for soft tissue sarcomas: influence of prognostic factors. J Surg Oncol 1996; 63:3-8. 


\title{
Chapter 3
}

\section{Isolated limb perfusion for unresectable melanoma of the extremities}

\author{
Noorda EM, Vrouenraets BC, Nieweg OE, van Geel $A N^{*}$, \\ Eggermont AMM*, Kroon BBR \\ Department of Surgery, The Netherlands Cancer Institute / Antoni van Leeuwenhoek hospital, \\ Amsterdam, the Netherlands * Department of Surgery, Erasmus Medical Center-Daniel den Hoed \\ Cancer Center, Rotterdam, the Netherlands
}

Submitted

\section{Introduction}

Recurrent melanoma lesions on the extremity can usually be managed by local surgery. Large numbers of small cutaneous or superficial subcutaneous lesions can effectively be treated with $\mathrm{CO}_{2}$ laser ablation. ${ }^{1,2}$ If the number, size or location of the lesions prohibits these simple treatments, ILP with high-dose chemotherapy is indicated. The more since other treatments, such as radiotherapy and systemic chemo- and/or immunotherapy have only limited effectiveness. . $^{3-}$ ${ }^{5}$ Amputation is an unattractive option for patients who are believed to have a poor prognosis.

In patients with measurable melanoma lesions, melphalan-ILP leads to a $54 \%$ complete response rate. ${ }^{6}$ Since the introduction of tumor necrosis factor-alpha (TNF $\alpha$ ) in 1992, response rates of up to $73 \%$ have been reported. ${ }^{7,8}$ The complete response rate after ILP with melphalan alone is likely to be lower than $54 \%$ in patients with truly unresectable disease, because it is known that a high tumor load (as expressed by the number of lesions, total tumor surface area and nodal status) is a negative prognostic factor for response after ILP. ${ }^{9-11}$ Since the results are unknown for this selected group of patients with truly unresectable melanoma lesions, we have analyzed the response rates and survival after ILP with melphalan with or without TNF $\alpha$ with special attention to prognostic factors for these outcome measures.

\section{Patients and methods}

From 1978 to 2001, 130 therapeutic ILPs were performed in our institutions in 108 patients with unresectable melanoma lesions. There were 24 men $(22 \%)$ and 84 women (78\%) with a mean age of 67 years (range 34-90 years). Eight of these patients $(7 \%)$ underwent two ILPs and seven patients $(6 \%)$ were perfused three times because of recurrent lesions. Forty ILPs were performed with melphalan (M-ILP) and in 90 ILPs TNF $\alpha$ was added (TM-ILP), combined with IFN $\alpha$ in eleven cases. The average number of lesions was nineteen (range 1- >100 
Table 1. Population characteristics: MD Anderson stage of disease (adapted for stage II) ${ }^{25}$

No. of patients

\begin{tabular}{llcc}
\hline Stage I & Primary melanoma & 1 & $(1 \%)$ \\
Stage II a & Local recurrence & 4 & $(3 \%)$ \\
Stage II b & Satellites & 5 & $(4 \%)$ \\
Stage III a & In transit metastases & 50 & $(38 \%)$ \\
Stage III b & Regional node metastases & $2 *$ & $(2 \%)$ \\
Stage III ab & In transit - and regional lymph node metastases & 59 & $(45 \%)$ \\
Stage IV & Distant metastases & 9 & $(7 \%)$ \\
\hline
\end{tabular}

* One patient with a local recurrence $(5 \times 5 \mathrm{~cm})$ located on the foot sole and regional lymph node metastases. The other patient had a large primary melanoma $(9 \times 9 \mathrm{~cm})$ on the lower limb and regional lymph node metastases.

lesions) with a median size of $3 \mathrm{~cm}$ (interquartile range 1-5 cm). Fifty-eight ILPs were performed for lesions located on the lower leg, 35 ILPs for lesions distributed over the whole lower extremity, 20 for lesions on the thigh and knee, 15 patients for lesions on the foot (extending up to the knee in six) and two patients for lesions on the arm. A hundred and five ILPs (81\%) were performed for more than ten lesions or lesions $\geq 5 \mathrm{~cm}$, which are the criteria for high tumor load according to Fraker et al. ${ }^{9}$ Ten ILPs were performed for lesions which were considered unresectable because of their localization: on the foot $(\mathrm{n}=3)$, near a joint $(n=2)$ and multiple lesions, but less than ten, spread out over a large area $(n=5)$. Fifteen ILPs were performed for relatively large lesions which were between 3 and $5 \mathrm{~cm}$ in size, one of the two criteria for high tumor load according to Rossi et al. ${ }^{8}$ None of the patients were considered suitable candidates for laser ablation according to the criteria of Hill et al. (cutaneous or superficial subcutaneous metastases smaller than $2 \mathrm{~cm}$ in diameter). ${ }^{1}$ The MD Anderson stage of disease at the time of ILP is displayed in Table 1.

Our ILP technique has been described previously in detail..$^{12}$ During ILP, the major artery and vein are clamped at the desired level, collateral vessels are ligated and a tourniquet is applied around the limb, proximal to the region of ILP. After insertion of the catheters, the isolated limb is perfused by an extracorporeal circulation, oxygenated and propelled by a heart-lung machine. A melphalan dose of $13 \mathrm{mg} / \mathrm{l}$-perfused tissue for the upper limb and $10 \mathrm{mg} / \mathrm{l}$ for the lower limb is added to the perfusate. For TNF $\alpha$ this is $3 \mathrm{mg}$ and $4 \mathrm{mg}$ respectively, irrespective of limb volume. In 11 patients with TM-ILP, $0.2 \mathrm{mg}$ IFN $\alpha$ was additionally applied and injected subcutaneously for two days before surgery. The same dose was given intraoperatively and injected in the perfusate. During ILP, adequate tissue temperatures are achieved and maintained by heating the heparinized perfusate and application of a warm water blanket around the limb. Limb temperatures are kept between 37 and $38^{\circ} \mathrm{C}$ (normothermia) or 38 and $40^{\circ} \mathrm{C}$ (mild hyperthermia) in case of ILP with TNFa. ILP with melphalan lasts 
one hour and when TNF $\alpha$ is used 90 minutes. At termination of the ILP, the perfusate is drained out and the limb is rinsed with an electrolyte solution. The tourniquet is then released and catheters are removed. In 71 patients (55\%) an inguinal lymph node dissection had already been done before ILP or was performed at ILP.

Regional toxicity after ILP was graded according to Wieberdink et al. ${ }^{13}$ Tumor response was measured by WHO criteria. ${ }^{14}$ Postoperatively, patients stay in bed with the leg elevated until acute toxic limb reactions subside. Patients were gradually mobilized with the help of a physiotherapist and discharged when fully ambulant. Long-term morbidity was routinely scored by identifying the following signs/symptoms: edema, venous thrombosis, arterial thrombosis, nerve injury, muscle atrophy/fibrosis, recurrent erysipelas and subjective complaints of pain and malfunction of the perfused limb. All were scored until two years after ILP and morbidity was considered irreversible if symptoms were persistent longer than two years after ILP. The median duration of follow-up was 21 months, ranging from two days to 17 years (interquartile range 9-40 months).

Statistical analysis was performed with Student's t-test when comparing groups with a normal distribution or with the $\mathrm{X}^{2}$ test when proportions were concerned. Non-parametrical tests, mostly the Mann-Whitney test, were used if the distribution of data was not normal. For limb recurrence-free survival, a Kaplan Meier analysis was performed and a log-rank test for comparison of differences between independent groups. A p-value of $\leq 0.05$ was regarded significant.

\section{Results}

\section{Tumor response}

Tumor response after ILP is displayed in Table 2. A complete response (CR) was attained after 72 of all 130 ILPs (55\%) at a median of two months after the procedure. A CR had a median duration of ten months (interquartile range 5-25 months). A partial response (PR) $(22 \%, 95 \%$ CI 15-30\%) was obtained after 28 ILPs and six of these patients were rendered locoregionally disease-free after additional resection of the lesions. Thirty-six of the patients with a CR $(50 \%$, 95\% CI 39-63\%) had a recurrence at a median of six months after ILP (interquartile range 3-13 months). The median duration of follow-up in those without recurrence was 21 months (interquartile range 6-50 months). Median limb recurrence-free survival (LRFS) was 18 months. The CR rate was $45 \%$ after M-ILP and $59 \%$ after TM-ILP $(\mathrm{P}=0.14)$. The median time to $\mathrm{CR}$ was significantly different between M-ILP and TM-ILP with three and two months respectively $(\mathrm{P}=0.01)$. The recurrence rate after M-ILP was $56 \%$, which was not significantly higher than the $48 \%$ after TM-ILP $(\mathrm{P}=0.59)$. The LRFS attained after M-ILP of 30 months proved not to be significantly longer than the 16 months after TM-ILP $(\mathrm{P}=0.68)$. LRFS after $\mathrm{CR}$ is displayed in Figure 1.

In patients with a high tumor load according to the Fraker criteria $(n=105)$, ILP resulted in a CR in 54 cases $(52 \%, 95 \%$ CI 42-61\%) that was attained after a median of two months (interquartile range 1-4 months). The CR rate after M-ILP was $41 \%$ (95\% CI 24-59\%) and not significantly lower than the 58\% (95\% CI 45$68 \%)$ attained after TM-ILP $(\mathrm{P}=0.11)$. The time to $\mathrm{CR}$ was significantly shorter 


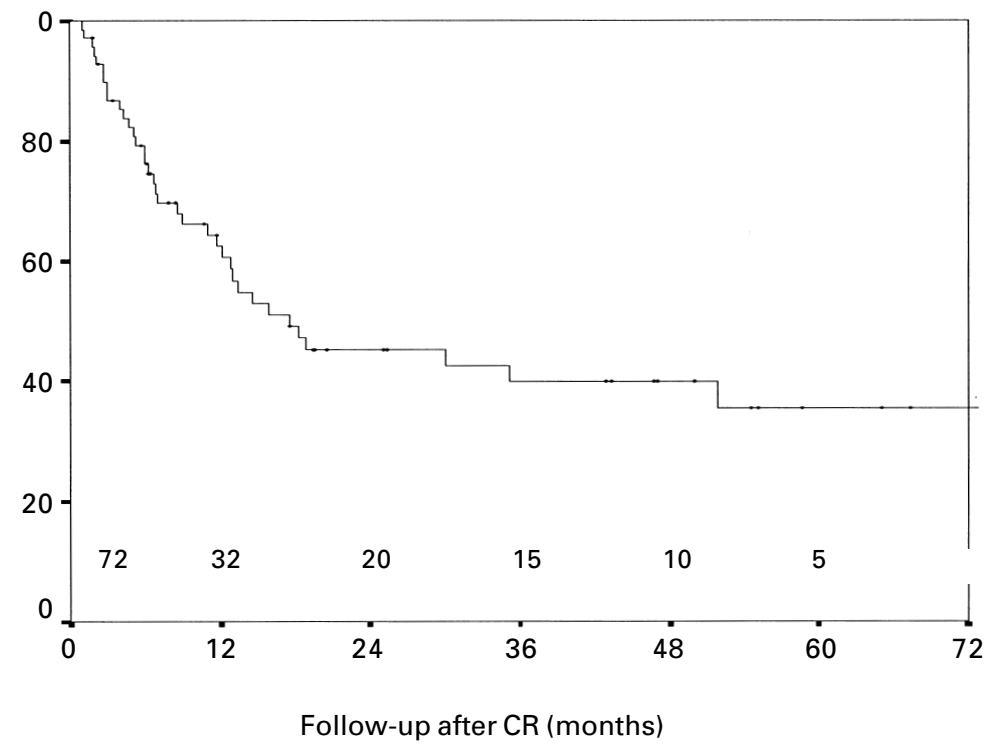

Numbers of patients at risk are provided at each point in time

after TM-ILP compared to M-ILP with two (interquartile range 1-4 months) and three months (interquartile range 2-7 months) respectively $(\mathrm{P}=0.03)$. Median LRFS after M-ILP was 30 months (95\% CI 3-58 months) which was not significantly different from the 16 months $(95 \% \mathrm{CI} \infty)$ after TM-ILP $(\mathrm{P}=0.64)$.

A significant better effect of TM-ILP on bulky lesions as opposed to multiple small lesions could not be demonstrated. The CR rate after TM-ILP or M-ILP in those with a few lesions that were larger than $5 \mathrm{~cm}(\mathrm{n}=18)$ was $50 \%$ in both groups. In those patients with more than 15 lesions that were smaller than $5 \mathrm{~cm}$ $(\mathrm{n}=65)$, the CR rate was 59\% (95\% CI 44-73\%) after TM-ILP compared to MILP with $37 \%$ (95\% CI 13-61\%, P=0.11).

\section{Prognostic factors for CR and limb recurrence-free survival}

Regression analysis for predictors of CR and limb recurrence-free survival were performed in which the following parameters were tested: sex, Breslow thickness and ulceration of the primary tumor, number of previous episodes of excisional surgery on same limb, site of indicator lesions (arm/thigh/lower leg), tumor load (high or low according to Fraker's criteria), ${ }^{9}$ MD Anderson stage of disease and ILP-type (M-ILP versus TM-ILP). From a multivariable logistic regression analysis the absence of lymph node metastases (stage IIIA disease) appeared to be the single significant independent prognostic factor for $\mathrm{CR}$, with an odds ratio of 3.5 (95\% CI 1.34-9.43, $\mathrm{P}=0.01)$. In a Cox-regression analysis, MD Anderson stage IIIA disease proved also to be the strongest predictive factor for limb-recurrence free survival with an odds ratio of 0.3 (95\% CI $0.12-0.83, \mathrm{P}=0.02)$. 


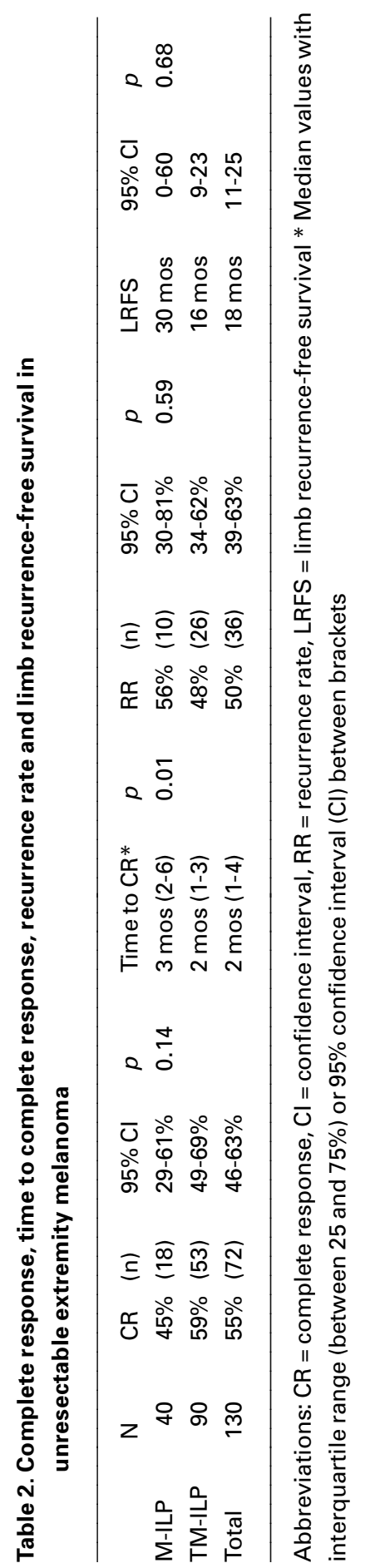


Management of recurrences and persisting lesions after ILP

Data on follow-up after ILP are displayed in Table 3 in which the treatment of limb recurrences and persistent lesions is specified. In four patients the limb was amputated during further follow-up: After a CR, one patient had a persistent wound infection with extensive, infected necrotic soft tissues and three months after ILP exarticulation at the hip joint was inevitable. Another patient underwent an above knee amputation because of intractable recurrences 18 months after CR. In two other patients who had persistent lesions after ILP, an amputation of the lower leg was performed three months after ILP and an above knee amputation 14 months later. The last patient was initially treated with radiation therapy for these lesions but developed infected radiation-induced necrosis. After a median follow-up of 21 months, the total limb salvage rate for all 108 patients was $96 \%$.

\section{Metastases and survival}

In Table 4, the development of regional node and distant metastases in relation to response after ILP is displayed. Distant metastases developed $72 \%$ of the patients who relapsed locoregionally after a CR which was significantly ore than the $47 \%$ in those without relapse after CR. Median survival was not significantly different between these groups.

Overall 5-year survival of all patients was $29 \%$ (95\% CI 20-38\%). Median survival was 25 months. In a Cox regression analysis the following variables for survival were tested for their independent prognostic value: sex, age, MD Anderson stage of disease, Breslow thickness of the primary, ulceration of the primary,

Table 3. Treatment of limb relapse or persistent lesions after ILP

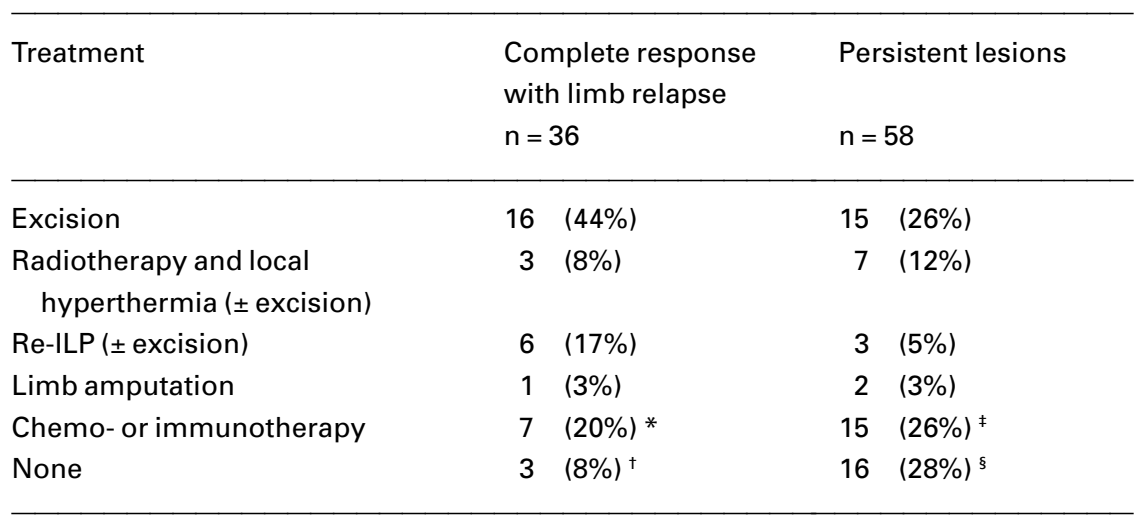

* Three of these patients also underwent excision of lesions, one radiation therapy with local hyperthermia and one a repeat-ILP.

$\dagger$ No additional therapy because of progressive distant metastases.

₹ Three patients also underwent local excision of lesions, two radiation therapy with local hyperthermia.

$\S$ Fourteen patients underwent no additional therapy because of progressive distant metastases, one patient had complications after ILP with subsequent death and another died of myocardial infarction two days after ILP. 
Table 4. Regional lymph node involvement, distant metastases and survival related to response after ILP

\begin{tabular}{|c|c|c|c|c|c|c|}
\hline & $\begin{array}{l}\text { Regional lymph } \\
\text { node metastases } \\
(95 \% \mathrm{Cl})\end{array}$ & $p^{*}$ & $\begin{array}{l}\text { Distant } \\
\text { metastases } \\
(95 \% \mathrm{Cl})\end{array}$ & $p^{*}$ & $\begin{array}{l}\text { Median } \\
\text { survival } \\
(95 \% \mathrm{Cl})\end{array}$ & $p^{*}$ \\
\hline $\begin{array}{l}\text { CR w/o } \\
\text { relapse }\end{array}$ & $3(9 \%, 0-22 \%)$ & 0.26 & $17(47 \%, 30-64 \%)$ & $<0.05$ & $52 \operatorname{mos}(24-81)$ & 0.57 \\
\hline $\begin{array}{l}\text { CR with } \\
\text { relapse }\end{array}$ & 7 (19\%, 6-33\%) & & $26(72 \%, 57-88 \%)$ & & $43 \operatorname{mos}(39-47)$ & \\
\hline No CR & $15(26 \%, 15-40 \%)$ & 0.18 & $34(59 \%, 50-76 \%)$ & 0.31 & $15 \operatorname{mos}(11-19)$ & $<0.001$ \\
\hline Total & $25(19 \%, 13-28 \%)$ & & 77 (59\%, 52-69\%) & & $25 \operatorname{mos}(19-31)$ & $<0.001$ \\
\hline
\end{tabular}

* first p-value is for the difference between $\mathrm{CR}$ w/o relapse and with relapse; the second $p$-value is for the difference between $C R$ with relapse and no $C R$.

smaller or larger tumor size than $3 \mathrm{~cm}$, high or low tumor load (according to Fraker), ILP-type and response (CR or no CR) to ILP. A stepwise backward analysis, identified CR and small tumor size than $3 \mathrm{~cm}$ as independent prognostic factors for a better survival with odds ratios of 0.3 (95\% CI $0.18-0.55$, $\mathrm{P}<0.001)$ and $2.0(95 \% \mathrm{CI} 1.16-3.53, \mathrm{P}=0.013)$, respectively. In Figure 2, sur-

Figure 2. Overall survival related to response after ILP

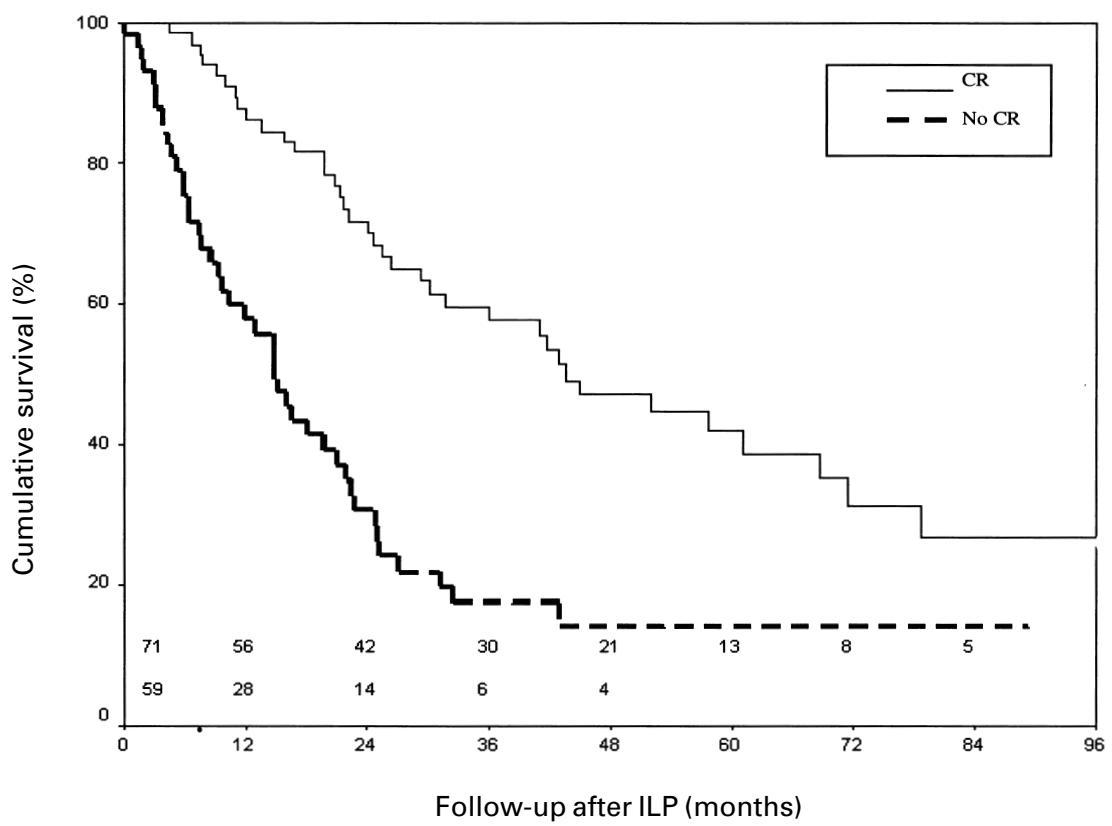

Numbers of patients at risk are provided at each point in time for both groups 
vival curves are displayed separately for those who attained a CR on ILP compared to those without CR. Survival was significantly different between these groups with a median survival of 44 months (95\% CI 30-57 months) and 15 months (95\% CI 11-19 months) respectively ( $\mathrm{P}<0.001)$. The median survival of 43 months was also significantly longer in those who relapsed after CR compared to 15 months in those without $\mathrm{CR}(\mathrm{P}<0.001)$.

\section{Toxicity and morbidity}

Acute regional toxicity consisted of a mild grade I/II reaction (slight erythema and/or edema) after 97 ILPs (75\%). Thirty ILPs (23\%) were followed by a moderately severe grade III tissue reaction with blistering. Three patients $(2 \%)$ had a grade IV toxicity reaction with reversible nerve dysfunction in two patients. There was no significant systemic toxicity. Long-term morbidity was limited: One year after ILP, seven patients $(9 \%)$ had edema of the perfused extremity and at two years only two patients (4\%) had edema. Objective atrophy or fibrosis of the musculature was seen in five patients $(6 \%)$ at one year and in one patient $(2 \%)$ two years after ILP. Two patients (3\%) had irreversible nerve dysfunction at one year after ILP. Subjective complaints of limited function of the perfused limb were reported in four patients $(5 \%)$ after one year and in three patients $(6 \%)$ two years after ILP.

\section{Discussion}

Locally unresectable extremity melanoma is a major therapeutic problem since few treatment options remain and the prognosis is unclear and probably limited. Radiation therapy with or without hyperthermia results in an overall response rate of $80 \%$ with the best response in tumors smaller than $4 \mathrm{~cm}$. The disadvantages are that it cannot be applied to large areas of disease and has no effect on micrometastatic disease in the rest of the extremity. ${ }^{3}$

Traditionally, ILP has been considered the treatment of choice for patients with truly unresectable melanoma lesions limited to the extremity. However, results of ILP in the particular patient group with truly unresectable lesions are lacking with most series presenting data on mixed groups of patients with varying numbers of tumor nodules. The definition of unresectability of melanoma lesions is not generally agreed upon and seems to be subjected to the personal assessment of the treating surgeon. In the present series, most of the lesions $(81 \%)$ were judged to be unresectable on the basis of Fraker's criteria for a high tumor burden. ${ }^{9}$ In a few patients ( $10 \%$ of this series), lesions were unresectable based upon other criteria such as localization, lesions with unclear margins and/or an inflammatory component, widely spread lesions, not permitting multiple excisions at one time. In the latter case, $\mathrm{CO}_{2}$ laser ablation was not optional since lesions were localized in the deep subcutis. Rossi et al. judged patients with more than 15 lesions or nodules larger than $3 \mathrm{~cm}$ as high tumor burden disease, comprising $82 \%$ of our study group. ${ }^{8}$ In the present series patients with a high tumor load according to the Fraker criteria had similar response and recurrence rates compared to the overall study population.

Overall, $55 \%$ of our patients attained a CR after ILP, with 36 patients (28\%) 
being cured locoregionally by a single ILP for the rest of the follow-up period of 21 months. The $45 \% \mathrm{CR}$ rate after M-ILP in our patients with unresectable melanoma is somewhat lower than the approximate mean 54\% CR rate after MILP seen in patients with lesions varying in resectability. ${ }^{15}$ This can be explained by the difference in tumor load since it has been shown that tumor load, in terms of the number of lesions, total tumor surface area and nodal status, is an important prognostic factor for tumor response after ILP. ${ }^{10,11,16}$ Our CR rate of $45 \%$ after M-ILP is however remarkably higher than the 19\% CR rate after M-ILP as reported by Fraker et al. in a same subgroup of patients with a high tumor burden. $^{7}$ The reason for this difference is unknown, with our $59 \%$ CR rate after TMILP of being similar to the $58 \%$ CR rate after TM-ILP in the Fraker trial. CR rates after TM-ILP in populations with varying disease burden varied from 64 to $90 \%,,^{7,9,17-21}$ probably due to a generally lower tumor load in these studies.

In the present analysis, the difference in complete response rates after M-ILP (45\%) compared with TM-ILP (59\%) was not statistically significant, although a tendency for a higher response rate in unresectable lesions after TM-ILP was apparent. This tendency was also shown in the multicenter European phase II trial that randomized patients with measurable disease to ILP with TM-ILP with IFN $\alpha$ (TIM-ILP) or without IFN $\alpha$ (TM-ILP) and compared them to a historical control group treated with M-ILP, where a $52 \% \mathrm{CR}$ rate after M-ILP and a $73 \% \mathrm{CR}$ rate after T(I)M-ILP were observed. ${ }^{19}$ The time to CR in the present series was significantly shorter after TM-ILP compared to M-ILP. Although this was only a onemonth difference, it confirms what has been observed in the mentioned European trial where this difference was 61 versus 225 days. In that study the LRFS for those with CR was 15 months after T(I)M-ILP compared to 19 months after M-ILP, which in the present series was 16 and 30 months respectively. These results suggest that TM-ILP leads to a faster achievement of CR than M-ILP, but that TM-ILP has no additional positive impact on long-term locoregional control in those who attain CR. This was also the case in the Fraker trial, in which this benefit of TMILP was especially observed in those with a high tumor load. ${ }^{7}$ Lejeune suggested that large and well-vascularized tumors are particularly sensitive to TNF $\alpha$ because it acts on their newly formed vessels. ${ }^{22}$ However, the CR rates in both large and small lesions were similar after M-ILP and TM-ILP.

The single prognostic factor for attaining a CR was stage IIIA disease. The fact that the chance of a CR is higher in the absence of nodal involvement confirms what has been found in previous studies..$^{10,11,16}$ Also, subsequent LRFS was significantly influenced by the presence of nodal metastases. In our high tumor burden group, the number of lesions did not have prognostic value for attaining a $\mathrm{CR},{ }^{10,11,16}$ in contrast to other reports with more mixed stages of disease.

Approximately half of the patients with a CR recurred in the perfused limb after a median interval of only six months after ILP. These recurrences could be managed with simple local treatment modalities in $70 \%$ of the patients. Unfortunately two patients needed an amputation of the limb. More than half of the patients without $\mathrm{CR}(\mathrm{n}=33)$ could not be managed by local limb-sparing treatments only and in two patients amputation was inevitable. Considering that all patients had truly unresectable tumors from the start, the limb salvage rate of $96 \%$ is impressive. 
Overall five-year survival in this series was $29 \%$, which is in the lower range of the $26-46 \%$, typical for patients with in-transit metastases with or without lymph node involvement. ${ }^{23}$ This is assumed to be due to selection of melanoma patients with more extensive disease in the present series. CR, with or without relapse, and relatively small tumors were positive prognostic factors for survival. Tumor size proved to be of independent prognostic value in other studies as well, with larger tumors having a worse prognosis. ${ }^{24,25}$ The significant difference in the occurrence of distant metastatic disease between those with CR who did not relapse locoregionally and who relapsed is probably a reflection of the more aggressive nature of the disease in the latter group. However, this did not lead to a significant difference in median survival between these groups.

Concluding, after a single ILP for locoregionally unresectable melanoma 55\% of the patients attain a CR. This group has a median limb recurrence-free survival of 18 months with approximately $50 \%$ of them rendered disease-free for a long time. These patients have a three to four fold increase in overall survival as compared to those with no CR. The response to ILP is probably partly dictated by the nature of the disease in the individual patient, but may be influenced by the drugs and schedule used in ILP. Due to ILP, amputation can be avoided in $96 \%$ of the patients with high tumor burden disease. Since survival is so much better after a CR, maximum efforts should be made to obtain this. In this and other studies, a tendency for better tumor response after TM-ILP in patients with a high-tumor burden has been found which has to be proved by ongoing randomized studies. Application of lower doses of $\mathrm{TNF} \alpha$ in these patients will be interesting, to reduce the costs with comparable anti-tumor effects. ${ }^{17}$

\section{References}

1. Hill S, Thomas JM. Use of the carbon dioxide laser to manage cutaneous metastases from malignant melanoma. Br J Surg 1996; 83:509-512.

2. Strobbe LJ, Nieweg OE, Kroon BBR. Carbon dioxide laser for cutaneous melanoma metastases: indications and limitations. Eur J Surg Oncol 1997; 23:435-438.

3. Overgaard J, Gonzalez GD, Hulshof MC, Arcangeli G, Dahl O, Mella O, Bentzen SM. Randomised trial of hyperthermia as adjuvant to radiotherapy for recurrent or metastatic malignant melanoma. European Society for Hyperthermic Oncology. Lancet 1995; 345:540-543.

4. Eton O, Legha SS, Bedikian AY, Lee JJ, Buzaid AC, Hodges C, Ring SE, Papadopoulos NE, Plager C, East MJ, Zhan F, Benjamin RS. Sequential biochemotherapy versus chemotherapy for metas-tatic melanoma: results from a phase III randomized trial. J Clin Oncol 2002; 20:2045-2052.

5. Keilholz U, Conradt C, Legha SS, Khayat D, Scheibenbogen C, Thatcher N, Goey SH, Gore M, Dorval T, Hancock B, Punt CJ, Dummer R, Avril MF, Brocker EB, Benhammouda A, Eggermont AM, Pritsch M. Results of interleukin-2-based treatment in advanced melanoma: a case record-based analysis of 631 patients. J Clin Oncol 1998; 16:2921-2929.

6. Creech DG, Krementz ET, Ryan RF, Winblad JN. Chemotherapy of cancer: regional perfusion utilising an extracorporeal circuit. Ann Surg 1958; 148:616-632. 
7. Fraker D, Alexander H, Ross M, Bartlett D, Tyler D, Libutti LS, Boddie A, Briele H, Karakousis G. A phase III trial of isolated limb perfusion for extremity melanoma comparing melphalan alone versus melphalan plus tumor necrosis factor (TNF) plus interferon gamma. Ann Surg Oncol 2002;S8.

8. Rossi CR, Foletto M, Pilati P, Mocellin S, Lise M. Isolated limb perfusion in locally advanced cutaneous melanoma. Semin Oncol 2002; 29:400-409.

9. Fraker DL, Alexander HR, Andrich M, Rosenberg SA. Treatment of patients with melanoma of the extremity using hyperthermic isolated limb perfusion with melphalan, tumor necrosis factor, and interferon gamma: results of a tumor necrosis factor dose-escalation study. J Clin Oncol 1996; 14:479-489.

10. Di Filippo F, Calabro A, Giannarelli D, Carlini S, Cavaliere F, Moscarelli F, Cavaliere R. Prognostic variables in recurrent limb melanoma treated with hyperthermic antiblastic perfusion. Cancer 1989; 63:2551-2561.

11. Vrouenraets BC, Hart GA, Eggermont AMM, Klaase JM, van Geel BN, Nieweg OE, Kroon BBR. Relation between limb toxicity and treatment outcomes after isolated limb perfusion for recurrent melanoma. J Am Coll Surg 1999; 188:522-530.

12. Kroon BBR. Regional isolation perfusion in melanoma of the limbs; accomplishments, unsolved problems, future. Eur J Surg Oncol 1988; 14:101-110.

13. Wieberdink J, Benckhuijsen C, Braat RP, van Slooten EA, Olthuis GA. Dosimetry in isolation perfusion of the limbs by assessment of perfused tissue volume and grading of toxic tissue reactions. Eur J Cancer Clin Oncol 1982; 18:905-910.

14. WHO handbook for reporting results of cancer treatment. Geneva: WHO; 1979.

15. Vrouenraets BC, Nieweg OE, Kroon BBR. Thirty-five years of isolated limb perfusion for melanoma: indications and results. Br J Surg 1996; 83:1319-1328.

16. Klaase JM, Kroon BBR, van Geel AN, Eggermont AMM, Franklin HR, Hart AAM. Prognostic factors for tumor response and limb recurrence-free interval in patients with advanced melanoma of the limbs treated with regional isolated perfusion with melphalan. Surgery 1994; 115:39-45.

17. Vaglini M, Santinami M, Manzi R, Inglese MG, Santoro N, Persiani L, Belli F. Treatment of in-transit metastases from cutaneous melanoma by isolation perfusion with tumour necrosis factor-alpha (TNF-alpha), melphalan and interferon-gamma (IFNgamma). Dose-finding experience at the National Cancer Institute of Milan. Melanoma Res 1994; 4 Suppl 1:35-38.

18. Liénard D, Eggermont AMM, Schraffordt Koops H, Kroon BBR, Rosenkaimer F, Autier P, Lejeune FJ. Isolated perfusion of the limb with high-dose tumour necrosis factor-alpha (TNF-alpha), interferon-gamma (IFN-gamma) and melphalan for melanoma stage III. Results of a multi-centre pilot study. Melanoma Res 1994; 4 Suppl 1:21-26.

19. Liénard D, Eggermont AMM, Schraffordt Koops H, Kroon B.B.R., Towse G, Hiemstra S, Schmitz P, Clarke J, Steinmann G, Rosenkaimer F, Lejeune FJ. Isolated limb perfusion with tumour necrosis factor-alpha and melphalan with or without interferongamma for the treatment of in-transit melanoma metastases: a multicentre randomized phase II study. Melanoma Res 1999; 9:491-502.

20. Eggermont AMM. Treatment of melanoma in-transit metastases confined to the limb. Cancer Surv 1996; 26:335-349.

21. Liénard D, Ewalenko P, Delmotte JJ, Renard N, Lejeune FJ. High-dose recombinant tumor necrosis factor alpha in combination with interferon gamma and melphalan in 
isolation perfusion of the limbs for melanoma and sarcoma. J Clin Oncol 1992; 10:5260.

22. Lejeune FJ. High dose recombinant tumour necrosis factor (rTNF alpha) administered by isolation perfusion for advanced tumours of the limbs: a model for biochemotherapy of cancer. Eur J Cancer 1995; 31A:1009-1016.

23. Balch CM, Buzaid AC, Soong S-J, Atkins MB, Cascinelli N, Coit DG, Fleming ID, Gershenwald JE, Houghton A, Jr., Kirkwood JM, McMasters KM, Mihm MF, Morton DL, Reintgen DS, Ross MI, Sober A, Thompson JA, Thompson JF. Final version of the American Joint Committee on Cancer staging system for cutaneous melanoma. $J$ Clin Oncol 2001; 19:3635-3648.

24. Zogakis TG, Bartlett DL, Libutti SK, Liewehr DJ, Steinberg SM, Fraker DL, Alexander HR. Factors affecting survival after complete response to isolated limb perfusion in patients with in-transit melanoma. Ann Surg Oncol 2001; 8:771-778.

25. Klaase JM, Kroon BBR, van Geel AN, van Wijk J, Franklin HR, Eggermont AMM, Hart AAM. Limb recurrence-free interval and survival in patients with recurrent melanoma of the extremities treated with normothermic isolated perfusion. $\mathrm{J} \mathrm{Am} \mathrm{Coll}$ Surg 1994; 178:564-572. 


\title{
Chapter 4
}

\section{Isolated limb perfusion prolongs the limb recurrence-free interval after several episodes of excisional surgery for locoregional recurrent melanoma}

\author{
Noorda EM, Vrouenraets BC, Nieweg OE, van Geel $A N^{*}$, \\ Eggermont AMM*, Hart AAM, Kroon BBR \\ Department of Surgery, The Netherlands Cancer Institute / Antoni van Leeuwenhoek hospital, \\ Amsterdam, the Netherlands * Department of Surgery, Erasmus Medical Center-Daniel den Hoed \\ Cancer Center, Rotterdam, the Netherlands
}

Annals of Surgical Oncology 2003 in press

\section{Introduction}

In some patients with in-transit metastases of extremity melanoma, locoregional recurrences seem to develop with increasing frequency after resection of previous lesions. Distant metastases, however, are often not (yet) present and these intransit metastases can impose a major therapeutic dilemma at each new recurrence. ${ }^{1}$ Many patients who have minimal locoregional disease can be maintained for a long time with local treatments only. ${ }^{2}$ There are several of such local treatment options, including excisional surgery, $\mathrm{CO}_{2}$ laser ablation if lesions are numerous and superficially located and local radiotherapy if these two simple treatments fail, but none of these impacts the development of further limb recurrences..$^{3-5}$ Isolated limb perfusion (ILP) however can treat both macroscopic lesions as well as microscopic disease by delivering a high dose of therapeutic agent(s) to the whole limb. ${ }^{6}$ Therefore, prophylactic ILP has the potential to stop or slow down the process of ongoing recurrences by eradicating micrometastases present in the limb. ILP provides a complete response in 54\% of the patients with a probably lower complete response rate in those with unresectable compared to resectable lesions. ${ }^{5}$ In a small prospective randomized trial conducted by the Swedish Melanoma Study Group, 69 patients with recurrent extremity melanoma were randomly treated by excision alone or excision plus ILP. Tumor-free survival was increased after ILP from ten to seventeen months with a limb recurrence rate that decreased from $67 \%$ to $45 \% .^{7}$ To determine whether ILP in the population of patients with resectable recurrent in-transit lesions may be indicated, the effect of ILP on further recurrences, the number of lesions per recurrence and the limb recurrence-free interval in patients with frequently recurring limb melanoma was studied. 


\section{Patients and methods}

Between 1978 and 2001, 451 patients underwent 505 therapeutic ILPs for locoregional recurrent and/or unresectable melanoma of the limbs in our institutions. A computer-assisted database containing all patient, tumor, ILP and follow-up data, allowed the selection of 43 patients in whom ILP was performed for a third or later limb recurrence. There were 40 women and three men with a mean age of 62 years (range 35-83 years). The patients were divided into two groups with unresectable and resectable lesions for the purpose of analysis. Unresectable lesions can be categorized as either due to a high tumor load or due to localization or diffuse spread over a large area. A high tumor load is either defined according to Fraker et al. (ten lesions or more or lesions larger than $5 \mathrm{~cm})^{8}$ or according to Rossi et al. (more than fifteen lesions or lesions larger than $3 \mathrm{~cm}$ ). ${ }^{9}$ According to either of these criteria, eighteen patients had resectable and 25 patients had unresectable melanoma lesions. The lesions forming the indication for ILP were located on the upper arm in three patients, on the thigh in two, on the lower leg in 27 , on the foot in three, on the foot extending up to the lower leg in five and three patients had lesions widely spread over the lower limb. The stage of disease was classified according to the MD Anderson melanoma staging system adapted for stage II. ${ }^{10}$ The median number of previous recurrences was two (range 2-10) and the median number of lesions forming the indication for ILP was four (range 2-8). Details about number and size of the lesions and stage of disease are shown in Table 1. Twenty-five patients underwent ILP for their third recurrence, nine for their fourth, one for his fifth, four for their sixth, two for their seventh and one for his eighth and one for his eleventh recurrence. The indication for ILP was based on unresectability or resectable disease that was felt to impose future problems in locoregional disease control.

Table 1. Patient and tumor characteristics of patients with resectable or unresectable lesions

\begin{tabular}{|c|c|c|c|}
\hline & $\begin{array}{l}\text { Resectable } \\
(n=18)\end{array}$ & $\begin{array}{l}\text { Unresectable } \\
(\mathrm{n}=25)\end{array}$ & $\begin{array}{l}\text { Total } \\
(n=43)\end{array}$ \\
\hline Median nr. of lesions * & $2.0(1.0-4.0)$ & $5.5(2.0-10)^{\dagger}$ & $3.5(1.0-7.25)$ \\
\hline Median size $\left(\mathrm{cm}^{2}\right)^{*}$ & $0.82(0.09-1.5)$ & $0.63(0.23-6.0)^{\ddagger}$ & $1.0(0.25-4.0)$ \\
\hline \multicolumn{4}{|l|}{ MD Anderson classification } \\
\hline IIA (local recurrence) & 0 & $1(4 \%)$ & $1(2 \%)$ \\
\hline IIB (satellite) & $2(11 \%)$ & $3(12 \%)$ & $5 \quad(12 \%)$ \\
\hline IIIA (in-transit) & $13(72 \%)$ & $12(48 \%)$ & $25(58 \%)$ \\
\hline $\begin{array}{l}\text { IIIAB (satellite/intransit + } \\
\text { regional node metastases) }\end{array}$ & $3(17 \%)$ & $9(36 \%)$ & $12(28 \%)$ \\
\hline
\end{tabular}

\footnotetext{
* Interquartile range is given in parentheses

$\dagger \mathrm{P}=0.05$

‡ $\mathrm{P}=0.641$
} 
Our technique of ILP has been described in detail elsewhere. ${ }^{11}$ In short, isolation of the blood circuit of a limb is achieved by clamping the major artery and vein, by ligating collateral vessels and by applying a tourniquet around the base of the limb. After cannulation of the vessels, the isolated limb is provided with an artificial circulation by means of an extracorporeal circuit, into which the drugs are administered.

ILP with melphalan is usually carried out with normothermia $\left(37-38^{\circ} \mathrm{C}\right)$; ILP with tumor necrosis factor-a (TNF $\alpha)$ and melphalan is performed under mild hyperthermia $\left(38-40^{\circ} \mathrm{C}\right)$. The circulating time of melphalan is 60 minutes. Nineteen patients were treated with melphalan alone, nineteen with melphalan and TNF $\alpha$ and five with melphalan, TNF $\alpha$ and interferon- $\alpha$ (IFN $\alpha$ ). In these latter patients $0.2 \mathrm{mg}$ IFN $\alpha$ was injected subcutaneously for two days before surgery. The same dose was given intraoperatively into the isolated circuit. One patient was treated with a sequential ILP type, in which ILP with hyperthermia (42-43 ${ }^{\circ} \mathrm{C}$ ) without drugs was followed by ILP with melphalan one week later under normothermic conditions. ${ }^{12}$

Regional toxicity after ILP was graded according to Wieberdink ${ }^{13}$ and tumor response was defined according to the standard WHO criteria. ${ }^{14}$ The median follow up after ILP was 35 months (interquartile range 14-64 months).

Limb recurrence-free intervals (LRFIs) were computed from the time of complete remission (CR) after ILP to the next recurrence or the end of follow up. If a partial remission (PR), no change (NC) or progressive disease was present after ILP, the subsequent interval was scored as zero months.

Statistical analysis for the LRFI was performed with an accelerated failure time analysis with a frailty per patient. ${ }^{15,16}$ A Weibull survival distribution for the within patient interval lenghts (untransformed) was used in conjunction with a gamma distribution for the frailties. To check the sensitivity of the results a second analysis was performed based on a proportional hazard analysis of the interval-length data. Correlation between intervals within the same patients was accounted for using the method of Wei, Lin and Weissfield. ${ }^{17}$ For the analysis of the number of lesions per interval, the method of General Estimating Equations $(\mathrm{GEE})^{18}$ based on an overdispersed Poisson distribution was used, because of the obvious non-normality of the number of lesions and the possibility that the number of lesions in different intervals for the same patients are correlated. The number of lesions was the dependent variable, the recurrence number and the status of the interval with respect to perfusion (before or after) were used as independent variables. Several models were used: an arbitrary or a linear relation between ln (number of lesions) and recurrence number and including or excluding interaction between recurrence number and interval status.

\section{Results}

\section{Tumor response}

Results regarding tumor response after ILP are shown in Table 2. Twenty-seven patients had a CR $(63 \%, 95 \mathrm{CI} 48-78 \%)$ with a median duration of 12 months (interquartile range 5-46 months). Thirteen of them (48\%) experienced a recurrence in the perfused area after a median time of six months (interquartile range 
Table 2. Response after ILP in resectable and unresectable lesions

\begin{tabular}{lcccc}
\hline Response & $\begin{array}{l}\text { Resectable } \\
(\mathrm{n}=18)\end{array}$ & $\begin{array}{l}\text { Unresectable } \\
(\mathrm{n}=25)\end{array}$ & $\begin{array}{l}\text { Total } \\
(\mathrm{n}=43)\end{array}$ \\
\hline $\mathrm{CR}$ & $11(61 \%)$ & $16(64 \%)$ & $27(63 \%)$ \\
$\mathrm{PR}$ & $1^{*}(6 \%)$ & $5(24 \%)$ & $5(12 \%)$ \\
$\mathrm{NC}$ & 0 & 1 & $(4 \%)$ & $2(5 \%)$ \\
$\mathrm{PD}$ & $2(12 \%)$ & $2(8 \%)$ & $3(7 \%)$ \\
$\mathrm{N} / \mathrm{E}$ & $4^{\dagger}(22 \%)$ & $1^{\ddagger}(4 \%)$ & $6(14 \%)$ \\
\hline
\end{tabular}

$\mathrm{CR}=$ complete response, $\mathrm{PR}=$ partial response, $\mathrm{NC}=$ no change, $\mathrm{PD}=$ progressive disease, $\mathrm{N} / \mathrm{E}=$ not evaluable

* Lesions were resected at maximal response

$\dagger$ Excision at ILP

₹ Lesions were not evaluated due to postoperative complications

5-13 months) after ILP. Fourteen patients of the total study group (33\%) had a persistent CR till the end of follow-up, which had a median duration of 37 months (9.5-62 months). Ten of these patients were still alive without evidence of locoregional disease at the time of analysis.

\section{Limb recurrence-free interval}

The median LRFI before and after ILP decreases significantly over time $(\mathrm{P}<0.0001)$. Figure 1 shows the estimated median LRFIs after CR with their $95 \%$ confidence intervals. The LRFI after ILP is longer than the LRFI before ILP at the same recurrence number. The latter is also shown in figure 2, which gives the ratio (after versus before) of the median LRFIs. The horizontal line is at a ratio of one, i.e. equal medians. Above this line the median LRFI is higher for patients after ILP. Although figures 1 and 2 may create the impression that the relative differences between the "after" and "before" intervals decrease over time, this is not supported statistically $(\mathrm{P}=0.27)$. Assuming a constant ratio, the median LRFI for patients after ILP is estimated to be $4.7(95 \% \mathrm{CI}: 2.8-7.9, \mathrm{P}<0.0001)$ times longer than for patients at the same recurrence number treated with excision alone before ILP. For example, if the ILP is performed at the third recurrence, the subsequent median LRFI is 23 months (95\% CI 12-43 months) compared to the LRFI of three months (95\% CI 2-6 months) in those who have not undergone ILP at the same recurrence number (Figure 1). The last median LRFI before ILP is 2 months (interquartile range 1-4 months) and the first LRFI after ILP is 7 months (interquartile range 2-26 months, $\mathrm{P}=0.005$ ).

\section{Number of lesions}

The median number of lesions forming the indication for ILP was four (interquartile range 2-8) and significantly larger than the number of lesions at the first recurrence after ILP which was one (interquartile range 1-3, P=0.006). Overall, at the same recurrence number, patients before ILP have a 2.6 fold $(95 \% \mathrm{CI}$ 
Figure 1. Effect of ILP on limb recurrence-free interval: median interval lengths with $95 \% \mathrm{Cl}$ per recurrence number in the whole study population $(n=43)$

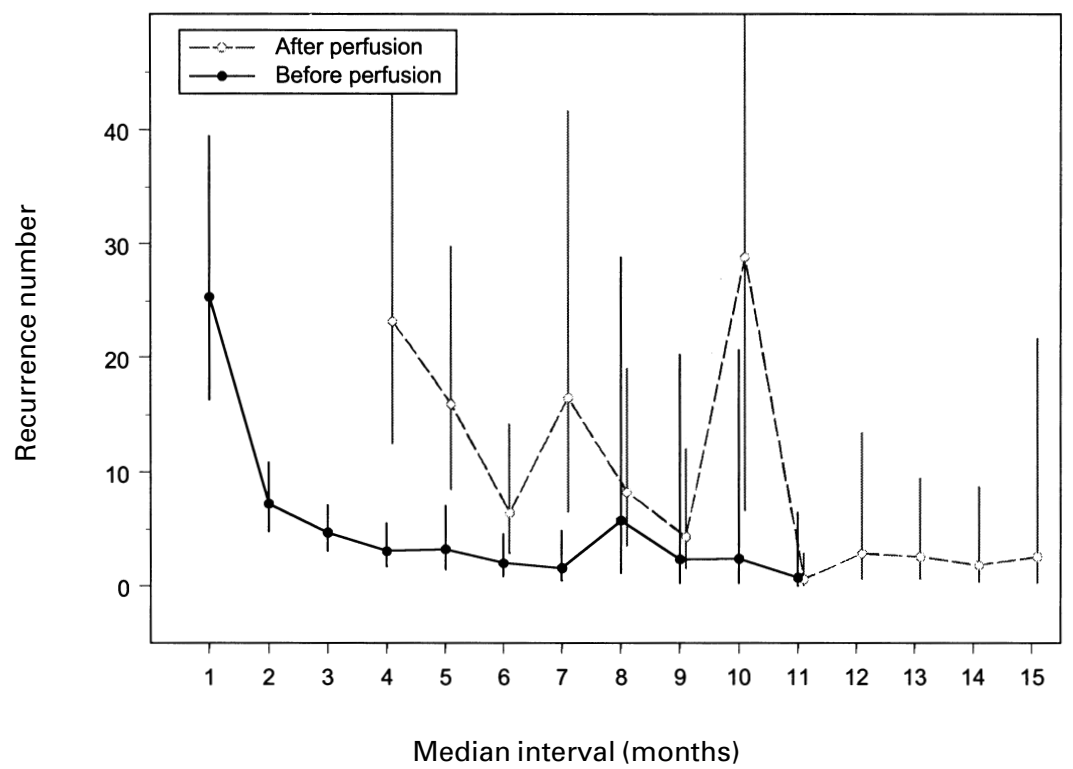

Figure 2. Effect of ILP on limb recurrence-free interval: ratios of median interval lengths with $95 \% \mathrm{Cl}$ in whole study population $(n=43)$

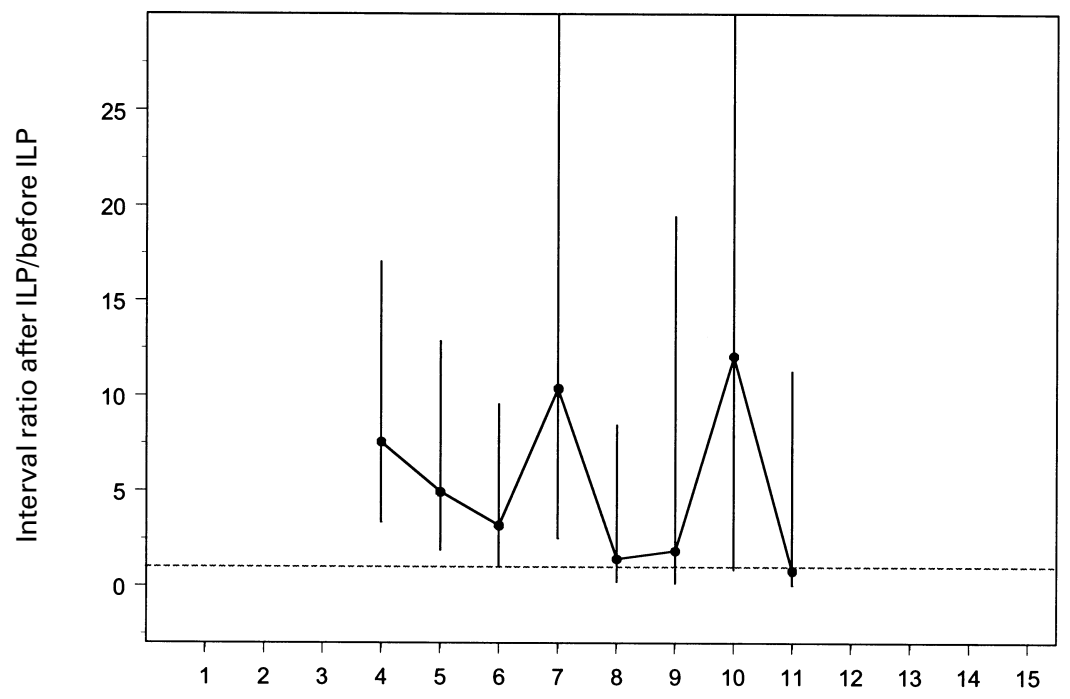

Recurrence number 
Figure 3. Effect of ILP on number of lesions: number of lesions with $68 \% \mathrm{Cl}$ per recurrence in the whole study population $(n=43)$

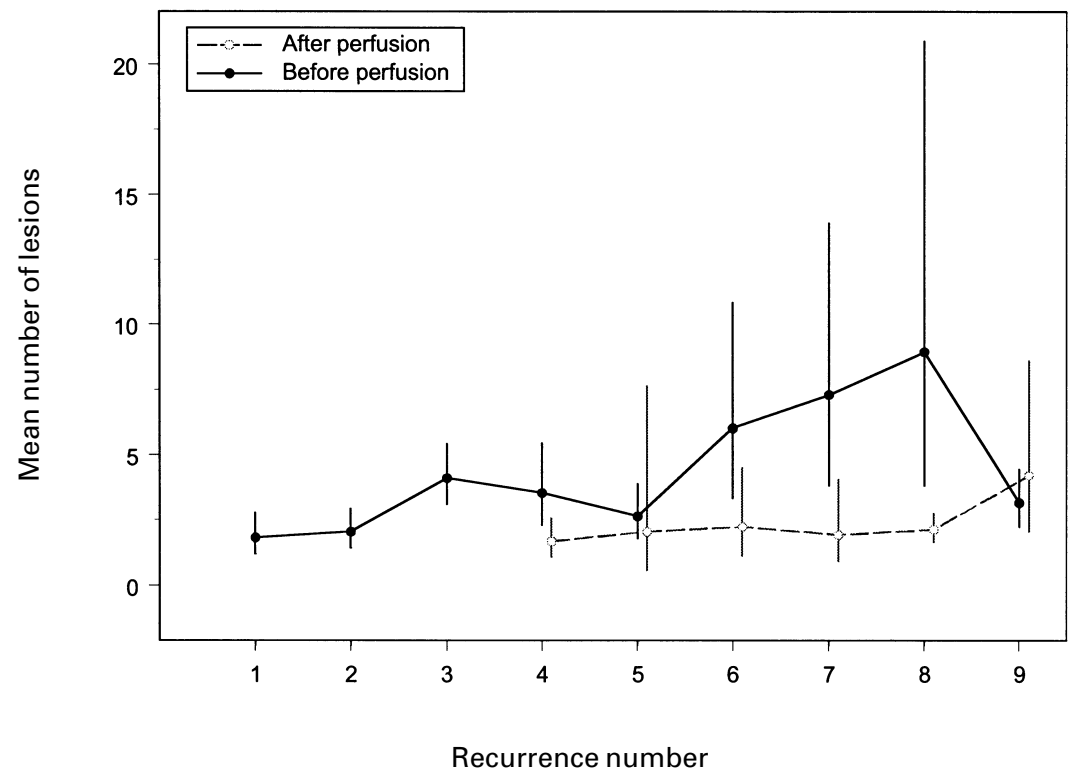

1.6-4.5) higher mean number of lesions compared to patients after ILP $(\mathrm{P}<0.001)$. The number of lesions increases with the recurrence number and this increase is estimated to be $22 \%$ per recurrence (95\% CI $10-35 \%, \mathrm{P}=0.02)$. This is similar before and after ILP with a $23 \%$ increase in number of lesions per recurrence number before and $16 \%$ increase after ILP $(\mathrm{P}=0.55)$. In Figure 3, the relation between the mean number of lesions and recurrence number is shown before and after ILP. It shows that the mean number of lesions increases with the recurrences number before as well as after ILP and that the number of lesions for patients after ILP is lower than for patients before ILP. For example at the fourth recurrence, the mean number of lesions after ILP is 0.6 (68\% CI 0.3-2) compared to a mean number of $4(68 \%$ CI 3.5-4.6) if lesions had only been excised at the third recurrence.

\section{Toxicity and complications}

Acute regional toxicity consisted of a grade I or II reaction with mild erythema and/or edema in 30 patients (69\%). Twelve patients (28\%) had a more severe acute toxicity reaction with blistering and in one patient an amputation was necessary nine days after ILP due to extensive tissue necrosis.

\section{Management of further recurrences}

In two patients a transfemoral amputation of the lower limb was done for intractable recurrences and failure of local radiotherapy with hyperthermia at one year and two years after ILP respectively. The limb salvage rate was 93\%. The management of recurrences and persisting disease after ILP is displayed in Table 3. 
Table 3. Treatment of limb relapse or persistent lesions after ILP

\begin{tabular}{|c|c|c|}
\hline Treatment limb recurrence & $\begin{array}{l}\text { Limb relapse } \\
\text { after } C R(n=16) *\end{array}$ & $\begin{array}{l}\text { Persistent lesions } \\
(\mathrm{n}=12)\end{array}$ \\
\hline Excision & $6(37.5 \%)$ & $4(33 \%)$ \\
\hline $\begin{array}{l}\text { Radiotherapy and local } \\
\text { hyperthermia ( } \pm \text { excision) }\end{array}$ & $2(12.5 \%)$ & $1(8 \%)$ \\
\hline Re-ILP ( \pm excision) & $3(19 \%)^{\dagger}$ & $0(0 \%)$ \\
\hline Limb amputation & $0(0 \%)$ & $3(25 \%)$ \\
\hline Chemo- or immunotherapy & $4(25 \%)^{\ddagger}$ & $2(17 \%)$ \\
\hline None & $1(6 \%)$ & $2(17 \%)^{\S}$ \\
\hline \multicolumn{3}{|c|}{$\mathrm{CR}=$ complete response, $\mathrm{PR}=$ partial response, $\mathrm{NC}=$ no change,} \\
\hline \multicolumn{3}{|c|}{$\mathrm{PD}=$ progressive disease } \\
\hline \multicolumn{3}{|c|}{$\begin{array}{l}\text { * Including the patients with concomitant excision of lesions at ILP, who relapsed in } \\
\text { the perfused area }(n=3)\end{array}$} \\
\hline \multicolumn{3}{|c|}{$\begin{array}{l}\text { One patient underwent multiple laser ablations and excisions before repeat-ILP and } \\
\text { additional systemic chemotherapy }\end{array}$} \\
\hline \multicolumn{3}{|c|}{ ‡ One patient underwent local radiotherapy and excision } \\
\hline \multicolumn{3}{|c|}{$\begin{array}{l}\text { § One patient underwent no additional treatment because of distant metastases } \\
\text { leading to her death within two months after ILP. In another patient lesions were not } \\
\text { evaluated due to postoperative complications. }\end{array}$} \\
\hline
\end{tabular}

\section{Survival}

Overall five-year survival after ILP was $46 \%$ (95\% CI 28-64\%), with a median of 56 months (95\% CI 35-78 months). There was no significant difference in survival between those with unresectable and resectable lesions with five-year survival rates of $41 \%(95 \%$ CI $16-66 \%)$ and $54 \%$ (95\% CI 31-78\%), respectively $(\mathrm{P}=0.38)$.

\section{Patients with resectable lesions at the time of ILP}

\section{Tumor response}

One patient had more than nine LRFIs. As this caused estimation problems, we analyzed only the first nine intervals. Eleven of the 18 patients with resectable lesions developed a CR (61\%: CI 36\%-86\%) after ILP. Four patients had no evaluable tumor response because the lesions were excised at ILP. One other patient had a PR and underwent excision of lesions at the time of maximal response. Two patients had lesions that progressed rapidly after ILP and were treated with local radiotherapy combined with hyperthermia. Five of the eleven patients with CR had a recurrence $(46 \%, 95 \%$ CI $10-81 \%)$ after a median of five months (interquartile range 4-15 months). The mean duration of $\mathrm{CR}$ was 25 months (95\% CI; 4-81 months). 
Figure 4. Effect of ILP on limb recurrence-free interval: median interval lengths with $95 \% \mathrm{Cl}$ per recurrence interval number in the patients with resectable lesions $(n=18)$

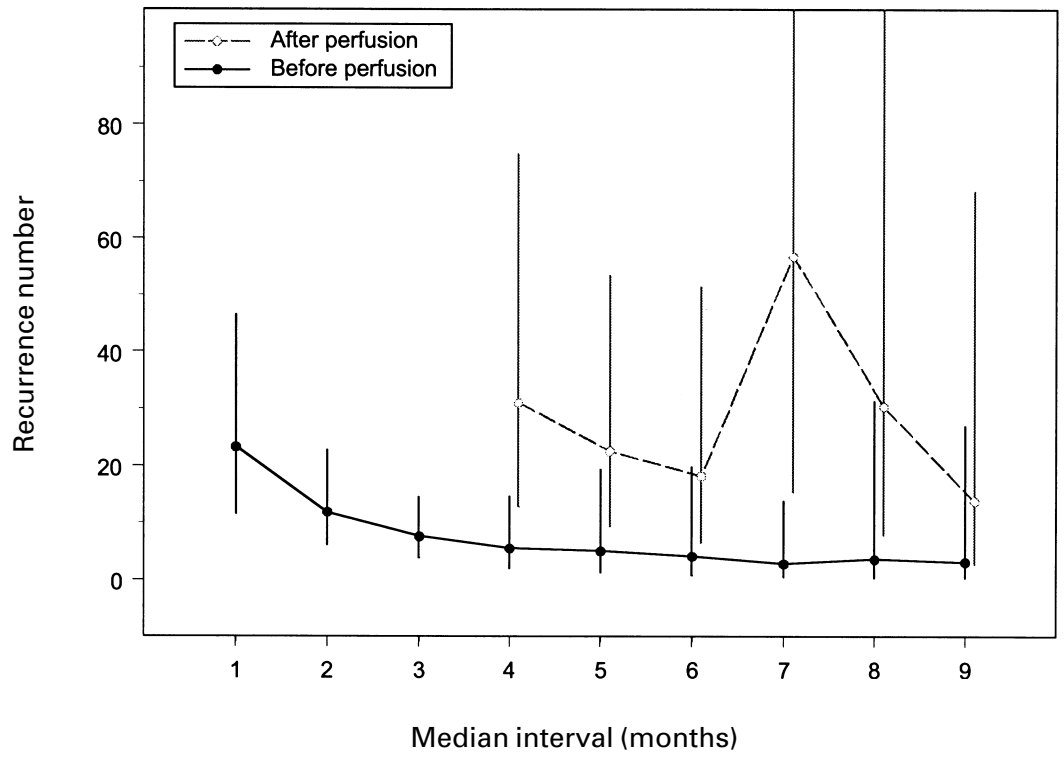

Figure 5. Effect of ILP on limb recurrence-free interval: ratios of median interval lengths with $95 \% \mathrm{Cl}$ in the patients with resectable lesions ( $n=18$ )

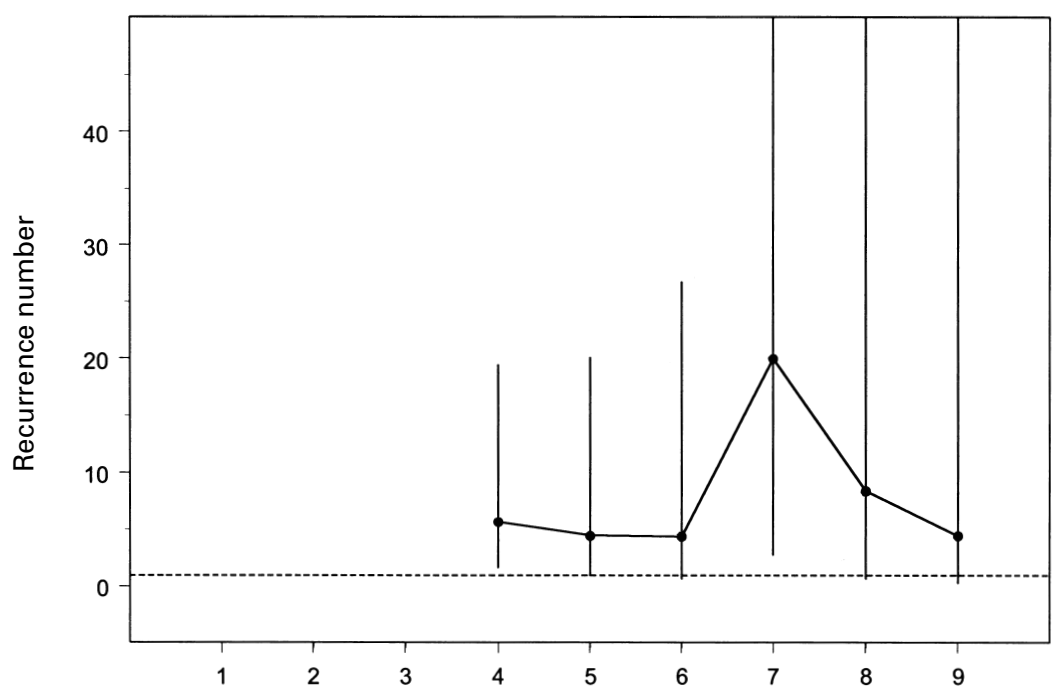

Interval ratio after ILP/before ILP 


\section{Limb recurrence-free interval}

Figure 4 shows the estimated median LRFIs with their $95 \%$ confidence intervals. The median LRFI decreases when the number of times of recurrence increases $(\mathrm{P}=0.05)$. Also, the intervals for patients after ILP in this subgroup are longer than for patients before ILP at the same recurrence number. If for instance ILP is performed at the third recurrence, the subsequent median LRFI is 30 months (95\% CI 12-75 months) compared to five months (95\% CI 2-15 months) in those who have not undergone ILP at the same recurrence number (Figure 4). In figure 5 the ratios of median intervals after versus before ILP are given. Assuming a constant ratio, the median LRFI for patients with resectable lesions after ILP is 5.9 (95\% CI: $2.7-13, \mathrm{P}<0.0001)$ times longer than for patients at the same recurrence number before ILP.

\section{Discussion}

The recurrent nature of melanoma in-transit metastases after adequate resection imposes a therapeutic dilemma. If these lesions are amenable to local treatments, excision or $\mathrm{CO}_{2}$ laser ablation are simple and effective treatment methods which have little impact on the patient's life., ${ }^{3,4}$ Systemic treatments such as biochemotherapy, high-dose interleukin-2, dacarbazine or temozolomide-containing regimens are optional if there are (skin) metastases beyond the extremity. ${ }^{19-22}$ The main indication for ILP has traditionally been in-transit metastases confined to the limb that cannot be removed by local surgery. We speculated whether there might be an indication for ILP in patients with resectable lesions who have a high tendency for locoregional recurrences without evidence of haematological spread. A theoretical advantage of ILP over other local treatment options could be the elimination of any microscopic disease already present in the limb with consequently a lengthening of the limb recurrence-free interval and reduction of the number of recurrent lesions.

This study showed a significant increase in LRFI after ILP compared to excision only. For the entire population, the LRFI was five times longer and for the patients with resectable lesions this was even six times longer at a given recurrence number. For all patients, at the third recurrence, ILP led to a median LRFI of 23 months compared to three months for patients who underwent excision only at that time. This LRFI is longer than the 9-19 months that is known from other reports after ILP with melphalan with or without TNF $\alpha .^{7,9,23-26}$ A single ILP stopped the process of recurring disease in a third of our patients who were rendered locoregionally tumor-free until the end of follow-up, at a median of three years after ILP. These results seem considerably better than results of excision alone for in-transit melanoma in which 15 to $17 \%$ of the patients become longterm free of disease. ${ }^{7,24}$ Apart from the time between recurrences, the number of lesions per recurrence was also shown to decrease after ILP. These findings strongly suggest that ILP influences the outgrowth of micrometastases in the affected limb. This is supported by the results of a small prospective randomized trial conducted by the Swedish Melanoma Study Group in which 69 patients with recurrent extremity melanoma were randomly treated by excision or excision plus ILP. The tumor-free survival was increased after ILP from ten to seventeen 
months and the limb recurrence rate was decreased from $67 \%$ to $45 \%$ after a median follow-up of five years. ${ }^{7}$ In a large international randomized trial comparing adjuvant ILP to the excision of primary extremity melanoma with excision alone, a trend for a longer disease-free interval was also seen. Both a reduction of the incidence of in-transit metastases (3\% vs. $7 \%$ ) and regional lymph node metastases $(13 \%$ vs. $17 \%)$ in the patients that underwent ILP was observed. ${ }^{6}$ Another study on the management of extremity recurrences after CR to ILP in 28 patients demonstrated an increased median duration of $\mathrm{CR}$ of fifteen months after repeat ILP compared to six months after excision alone. ${ }^{24}$

Single ILP with melphalan results in a CR in approximately $54 \%$ of the patients..$^{5}$ Our CR rate of $63 \%$ compares favorable to this figure with a similar rate of recurrence in about half of these patients. Waiting for a third or further recurrence does not seem to diminish the chance of a CR after ILP. This is in contrast to previous studies in which the tumor load on the extremity, which increases over time in these patients, was the strongest negative prognostic factor for tumor response. ${ }^{26-28}$ We could however confirm the other finding of these studies that a high tumor load is a negative predictor of recurrence-free survival, with a larger gain in limb recurrence-free interval after ILP performed at the third recurrence than at a later stage. A higher complete response rate of $72 \%$ and $73 \%$ has been reported after ILP with TNF $\alpha$ and melphalan, compared to 58\% and 52\% after ILP with melphalan alone in these studies. ${ }^{9,23}$ In the present study, results of these two regimens were not analyzed separately because of the small size of the groups and the fact that the effect on micrometastases is mainly due to the melphalan as expressed by a similar limb disease free survival after both regimens.

The main disadvantages of ILP lie in the involved costs, risk of acute regional toxicity and long-term morbidity. After single ILP with melphalan, regional toxicity is mild in $85 \%$ of the patients with slight edema and erythema, resolving completely within two weeks. ${ }^{29}$ More severe acute skin and soft-tissue reactions with blistering occur in approximately $15 \%$ of the patients, but a compartmental syndrome necessitating fasciotomy or amputation occurs in a maximum of $5 \%$ of the patients. Clinically observed long-term morbidity after iliac ILP with melphalan consists mostly of restricted function of the ankle and edema. Significant edema is reported in $28 \%$ of the patients ${ }^{28}$ and although an objective restricted function of the ankle has been found in 25 to $40 \%$ of the patients, ${ }^{30,31}$ only $8 \%$ of these patients complained of ankle stiffness. ${ }^{30}$ In elderly patients, the same efficacy, toxicity and morbidity have been observed after ILP. ${ }^{22}$ The risk of the aforementioned downsides of ILP should be weighed against multiple surgical excisions or sessions of $\mathrm{CO}_{2}$ laser ablation which are likely to be necessary with increasing frequency for a growing number of lesions.

Some argue that systemic treatment would benefit these patients with localized metastatic disease since they are at high risk of distant metastatic disease. ${ }^{2}$ However, only small groups of patients with systemic treatment for localized inoperable disease have been reported. In a phase II randomized trial, biochemotherapy (consisting of chemotherapy combined with IFNa and IL-2) resulted in a $60 \%$ response rate and chemotherapy in a $45 \%$ response rate in the small proportion of patients with AJCC stage III (in-transit or lymph node metastases) localized metastatic disease. ${ }^{19}$ This was achieved at the cost of systemic toxicity, such as 
fatigue, anorexia, altered sensorium and hypotension, in a considerable number of patients, mostly in the combined treatment group. In a non-randomized analysis of 631 patients, high-dose IL-2, with the addition of chemotherapy or, IFN $\alpha$ or both, resulted in a $43 \%$ overall response rate in patients with cutaneous metastases without lymph node involvement with a five-year survival rate of $27 \% .^{20}$ Dacarbazine as a single agent results in a mere $10-20 \%$ overall response rate and also has no proved benefit in terms of survival. ${ }^{21}$ The value of systemic treatment in localized metastatic melanoma is unclear and local treatment options should be applied until distant metastases appear.

In conclusion, controlling the locoregional disease process in patients with frequently recurring limb melanoma is of great importance since the prognosis for these patients is reasonable. ILP slows down and sometimes stops this process with a markedly increased LRFI compared to excision alone and diminished tumor load at the next recurrence. Although a randomized trial would be warranted to provide definitive recommendations, ILP should be considered in patients with a third episode of limb melanoma recurrences.

\section{References}

1. Lejeune FJ, Lienard D, el Douaihy M, Seyedi JV, Ewalenko P. Results of 206 isolated limb perfusions for malignant melanoma. Eur J Surg Oncol 1989; 15:510-519.

2. McMasters KM. Isolated limb perfusion in elderly melanoma patients. Ann Surg Oncol 2002; 9:939-940.

3. Hill S, Thomas JM. Use of the carbon dioxide laser to manage cutaneous metastases from malignant melanoma. Br J Surg 1996; 83:509-512.

4. Strobbe LJ, Nieweg OE, Kroon BBR. Carbon dioxide laser for cutaneous melanoma metastases: indications and limitations. Eur J Surg Oncol 1997; 23:435-438.

5. Vrouenraets BC, Nieweg OE, Kroon BBR. Thirty-five years of isolated limb perfusion for melanoma: indications and results. Br J Surg 1996; 83:1319-1328.

6. Schraffordt Koops H, Vaglini M, Suciu S, Kroon BB, Thompson JF, Gohl J, Eggermont AM, Di Filippo F, Krementz ET, Ruiter D, Lejeune FJ. Prophylactic isolated limb perfusion for localized, high-risk limb melanoma: results of a multicenter randomized phase III trial. J Clin Oncol 1998; 16:2906-2912.

7. Hafstrom L, Rudenstam CM, Blomquist E, Ingvar C, Jonsson PE, Lagerlof B, Lindholm C, Ringborg U, Westman G, Ostrup L. Regional hyperthermic perfusion with melphalan after surgery for recurrent malignant melanoma of the extremities. Swedish Melanoma Study Group. J Clin Oncol 1991; 9:2091-2094.

8. Fraker DL, Alexander HR, Andrich M, Rosenberg SA. Treatment of patients with melanoma of the extremity using hyperthermic isolated limb perfusion with melphalan, tumor necrosis factor, and interferon gamma: results of a tumor necrosis factor dose-escalation study. J Clin Oncol 1996; 14:479-489.

9. Rossi CR, Foletto M, Pilati P, Mocellin S, Lise M. Isolated limb perfusion in locally advanced cutaneous melanoma. Semin Oncol 2002; 29:400-409.

10. Klaase JM, Kroon BBR, van Geel AN, van Wijk J, Franklin HR, Eggermont AMM, Hart AAM. Limb recurrence-free interval and survival in patients with recurrent melanoma of the extremities treated with normothermic isolated perfusion. $\mathrm{J} \mathrm{Am} \mathrm{Coll}$ 
Surg 1994; 178:564-572.

11. Kroon BBR. Regional isolation perfusion in melanoma of the limbs; accomplishments, unsolved problems, future. Eur J Surg Oncol 1988; 14:101-110.

12. Kroon BBR, Klaase J, van de Merwe SA, van Dongen J, van der Zee J. Results of a double perfusion schedule using high-dose hyperthermia and melphalan sequentially for recurrent melanoma of the limbs: a pilot study. Regional Cancer Treatment 1992;305-308.

13. Wieberdink J, Benckhuijsen C, Braat RP, van Slooten EA, Olthuis GA. Dosimetry in isolation perfusion of the limbs by assessment of perfused tissue volume and grading of toxic tissue reactions. Eur J Cancer Clin Oncol 1982; 18:905-910.

14. WHO handbook for reporting results of cancer treatment. Geneva: WHO; 1979.

15. Kalbfleisch JD, Prentice RL. The statistical analysis of failure time data. New York: Wiley; 1980.

16. Lee EW, Wei LJ, Amato D. Cox-type regression analysis for large number of small groups of correlated failure timeobservations. In J.P Klein, P.K.Goel (eds). Survival Analysis, State of the Art. Netherlands: Kluwer Academic Publishers; 1992:237-247.

17. Wei LJ, Lin DY, Weissfeld L. Regression analysis of multivariate incomplete failure time data by modeling marginal distributions. Journal of the American Statistical Association 1989; 84:1065-1073.

18. Liang KY, Zeger SL. Longitudinal Data Analysis using Generalized Linear Models. Biometrika 1986; 73:13-22.

19. Eton O, Legha SS, Bedikian AY, Lee JJ, Buzaid AC, Hodges C, Ring SE, Papadopoulos NE, Plager C, East MJ, Zhan F, Benjamin RS. Sequential biochemotherapy versus chemotherapy for metastatic melanoma: results from a phase III randomized trial. $J$ Clin Oncol 2002; 20:2045-2052.

20. Keilholz U, Conradt C, Legha SS, Khayat D, Scheibenbogen C, Thatcher N, Goey SH, Gore M, Dorval T, Hancock B, Punt CJ, Dummer R, Avril MF, Brocker EB, Benhammouda A, Eggermont AM, Pritsch M. Results of interleukin-2-based treatment in advanced melanoma: a case record-based analysis of 631 patients. J Clin Oncol 1998; 16:2921-2929.

21. Hwu WJ. New approaches in the treatment of metastatic melanoma: thalidomide and temozolomide. Oncology (Huntingt) 2000; 14:25-28.

22. Noorda EM, Vrouenraets BC, Nieweg OE, van Geel AN, Eggermont AMM, Kroon BBR. Safety and efficacy of isolated limb perfusion in elderly melanoma patients. Ann Surg Oncol 2002; 9:968-974.

23. Fraker D, Alexander H, Ross M, Bartlett D, Tyler D, Libutti LS, Boddie A, Briele H, Karakousis G. A phase III trial of isolated limb perfusion for extremity melanoma comparing melphalan alone versus melphalan plus tumor necrosis factor (TNF) plus interferon gamma. Ann Surg Oncol 2002;S8.

24. Feldman AL, Alexander HR, Jr., Bartlett DL, Fraker DL, Libutti SK. Management of extremity recurrences after complete responses to isolated limb perfusion in patients with melanoma. Ann Surg Oncol 1999; 6:562-567.

25. Lejeune FJ, Deloof T, Ewalenko P, Fruhling J, Jabri M, Mathieu M, Nogaret JM, Verhest A. Objective regression of unexcised melanoma in-transit metastases after hyperthermic isolation perfusion of the limbs with melphalan. Recent Results Cancer Res 1983; 86:268-76.:268-276.

26. Klaase JM, Kroon BBR, van Geel AN, Eggermont AMM, Franklin HR, Hart AAM. 
Prognostic factors for tumor response and limb recurrence-free interval in patients with advanced melanoma of the limbs treated with regional isolated perfusion with melphalan. Surgery 1994; 115:39-45.

27. Di Filippo F, Calabro A, Giannarelli D, Carlini S, Cavaliere F, Moscarelli F, Cavaliere R. Prognostic variables in recurrent limb melanoma treated with hyperthermic antiblastic perfusion. Cancer 1989; 63:2551-2561.

28. Vrouenraets BC, Hart GA, Eggermont AMM, Klaase JM, van Geel BN, Nieweg OE, Kroon BBR. Relation between limb toxicity and treatment outcomes after isolated limb perfusion for recurrent melanoma. J Am Coll Surg 1999; 188:522-530.

29. Vrouenraets BC, Eggermont AMM, Klaase J, van Geel A, van Dongen JA, Kroon BBR. Long-term neuropathy after regional isolated perfusion with melphalan for melanoma of the limbs. Eur J Surg Oncol 1994; 20:681-685.

30. Vrouenraets BC, in't Veld GJ, Nieweg OE, van Slooten GW, van Dongen JA, Kroon BBR. Long-term functional morbidity after mild hyperthermic isolated limb perfusion with melphalan. Eur J Surg Oncol 1999; 25:503-508.

31. van Geel AN, van Wijk J, Wieberdink J. Functional morbidity after regional isolated perfusion of the limb for melanoma. Cancer 1989; 63:1092-1096. 



\title{
Chapter 5
}

\section{Safety and efficacy of isolated limb perfusion in elderly melanoma patients}

\author{
Noorda EM, Vrouenraets BC, Nieweg OE, van Geel $A N^{*}$, \\ Eggermont AMM*, Kroon BBR \\ Department of Surgery, The Netherlands Cancer Institute / Antoni van Leeuwenhoek hospital, \\ Amsterdam, the Netherlands * Department of Surgery, Erasmus Medical Center-Daniel den Hoed \\ Cancer Center, Rotterdam, the Netherlands
}

Annals of Surgical Oncology 2002; 9:968-74

\section{Introduction}

Isolated limb perfusion (ILP) with melphalan is an accepted treatment modality to achieve locoregional control in advanced melanoma of extremities. ${ }^{1}$ The principle of ILP is that a high dose of chemotherapy can be administered to a melanoma-bearing limb without systemic side-effects. Since the introduction of recombinant tumor necrosis factor-alpha (TNF $\alpha)$ in ILP, this procedure is also applied successfully to irresectable limb sarcoma and bulky or melphalan resistant melanoma. ${ }^{2-5}$

Nowadays, operative mortality from ILP is low, regional toxicity is mild and systemic leakage of the cytostatic drug(s) is negligible. ${ }^{6-8}$ Still, many surgeons are reluctant to refer patients at an advanced age for ILP because the peri-operative mortality for major surgical procedures increases with age, ${ }^{9}$ the peri-operative complication rate is higher in patients over 70 years of age and hospital stay is generally longer. ${ }^{10-12} \mathrm{~A}$ fear for long-term functional morbidity due to severe acute limb toxicity, ${ }^{13}$ increased systemic side-effects from melphalan ${ }^{6}$ and a severe systemic cardiovascular response to TNF $\alpha$ is felt when elderly are concerned. ${ }^{14}$

To assess whether these assumptions are true, we studied the safety and efficacy of ILP in melanoma patients older than 75 years of age who were treated for advanced locoregional melanoma.

\section{Patients and methods}

From 1978 to 2001, 218 single therapeutic ILPs were performed with either melphalan $(n=84)$ or the combination of TNF $\alpha$ and melphalan $(n=134)$ under normothermic $\left(37-38^{\circ} \mathrm{C}\right)$ or mild hyperthermic $\left(38-40^{\circ} \mathrm{C}\right)$ conditions for advanced unexcised melanoma of a limb. Patients were included if they had measurable disease at the time of ILP. These procedures were carried out in a total of 202 patients. A group of 53 patients (27.6\%) was 75 years of age or older, (mean 
79, range 75-90 years) at the time of ILP and they underwent 58 ILPs. Results from this older age group were compared with those from patients younger than 75 years of age. Patient characteristics of both age groups are summarized in Table 1. Stage of disease was classified according to the MD Anderson classification system Table 2 . A few patients with stage IV disease $(n=8)$, were treated with palliative intent only, because of distressing symptoms of bulky, irresectable

Table 1. Patient characteristics in the two age groups

\begin{tabular}{|c|c|c|c|}
\hline & $<75 \mathrm{yr}$ & $\geq 75 \mathrm{yr}$ & P-value ${ }^{\dagger}$ \\
\hline No. of ILPs & 160 & 58 & \\
\hline No. of patients & 149 & 53 & \\
\hline Gender $\sigma^{r}: ?$ & $35: 114(77 \%)$ & $8: 45(85 \%)$ & 0.20 \\
\hline Mean age (range) & $60(29-74)$ & $79 \quad(75-90)$ & \\
\hline MD Anderson & & & 0.77 \\
\hline Stage I * & $2(1.2 \%)$ & $1 \quad(1.7 \%)$ & \\
\hline Stage II & 17 (10.7\%) & $6(10.3 \%)$ & \\
\hline Stage III & 133 (83.2\%) & $50 \quad(86.2 \%)$ & \\
\hline Stage IV & $8 \quad(5.0 \%)$ & $1(1.7 \%)$ & \\
\hline \multicolumn{4}{|l|}{ Level of ILP } \\
\hline Axillary & $17 \quad(10.7 \%)$ & $1 \quad(1.7 \%)$ & 0.024 \\
\hline Iliac & $97 \quad(60.6 \%)$ & $24 \quad(41.4 \%)$ & 0.012 \\
\hline Femoral & $46 \quad(28,7 \%)$ & $33 \quad(56.9 \%)$ & 0.000 \\
\hline $\mathrm{M}: \mathrm{T} \& \mathrm{M}^{\ddagger}$ & $60: 100(62.5 \%)$ & $24: 34(58.6 \%)$ & 0.60 \\
\hline
\end{tabular}

* locally irresectablemelanoma

$\dagger \chi^{2}$ test, significant if $\mathrm{P}<0.05$

$\ddagger \mathrm{M}=\mathrm{ILP}$ with melphalan only, T\&M=ILP with TNF $\alpha$ and melphalan

Table 2. MD Anderson classification (adapted for stage II) ${ }^{30}$

MD Anderson stage

$\begin{array}{ll}\text { IA } & \text { Intact primary } \\ \text { IB } & \text { Excised primary } \\ \text { IC } & \text { Multiple primaries } \\ \text { IIA } & \text { Local recurrence } \\ \text { IIB } & \text { Satellite } \leq 3 \mathrm{~cm} \text { from primary/skin graft } \\ \text { IIIA } & \text { Satellite/in-transit }>3 \mathrm{~cm} \text { from primary/skin graft } \\ \text { IIIB } & \text { Regional node metastasis } \\ \text { IIIAB } & \text { Satellite/in-transit with regional node metastasis } \\ \text { IV } & \text { Distant metastasis }\end{array}$


locoregional metastases. Patients were all considered fit for operation by a regular preoperative screening procedure including ECG, chest X-ray, lung function tests, standard hematological and chemical lab and screening for distant metastatic disease.

During ILP, the major artery and vein are clamped at the desired level, collateral vessels are ligated and a tourniquet is applied around the limb, proximal to the region of ILP. After insertion of the catheters, the isolated limb is perfused by an extracorporeal circulation, oxygenated and propelled by a heart-lung machine. A melphalan dose of $13 \mathrm{mg} / \mathrm{l}$-perfused tissue in the upper limb and $10 \mathrm{mg} / \mathrm{l}$ for the lower limb is added to the perfusate. For TNF $\alpha$ this is $3 \mathrm{mg}$ and $4 \mathrm{mg}$ respectively, irrespective of limb volume. Adequate tissue temperatures are achieved and maintained by heating the heparinized perfusate and application of a warm blanket around the limb. Limb temperatures are kept between 37 and $38^{\circ} \mathrm{C}$ (normothermia) or 38 and $40^{\circ} \mathrm{C}$ (mild hyperthermia) in case of ILP with TNF $\alpha$. ILP with melphalan lasts one hour and when TNF $\alpha$ is used 90 minutes. At termination of the ILP, the perfusate is drained out and the limb is rinsed with an electrolyte solution. The tourniquet is then released and catheters are removed.

In our routine, to limit the surgical dissection and total melphalan dose, lower limb ILP in older patients is usually performed at the femoral level instead of the iliac level, unless the disease extends up to the femoral region. This is reflected in our data showing significantly less iliac and more femoral ILPs being performed in patients over age 75 than in younger patients (Table $1, \mathrm{P}=0.002$ ). There was no difference in the use of TNF $\alpha$ between older and younger patients. Regional toxicity after ILP was graded according to Wieberdink et al. (Table 3). ${ }^{15}$ Postoperatively, patients stay in bed with the leg elevated until acute toxic limb reactions subside. Systemic toxicity and tumor response were measured by WHO criteria. ${ }^{16}$ Patients were gradually mobilized with the help of a physiotherapist and discharged when fully mobile. Long-term morbidity was routinely scored by identifying the following signs/symptoms: edema, venous thrombosis, arterial thrombosis, nerve injury, muscle atrophy/fibrosis, recurrent erysipelas and subjective complaints of pain and malfunction the perfused limb. All were scored at one month, three months, one year and two years after ILP and morbidity was considered irreversible if complaints were persistent longer than 2 years after ILP. Median follow-up was six years (25-75\% interval 3-10 years). Some patients had an amputation of the limb despite the effort for limb sparing surgery. This

\section{Table 3. Classification of acute regional toxicity reactions following ILP ${ }^{15}$}

$\begin{array}{ll}\text { Grade I } & \begin{array}{l}\text { No evidence of reaction } \\ \text { Grade II }\end{array} \\ \text { Slight erythema or edema } \\ \text { Grade III } & \begin{array}{l}\text { Considerable erythema and/or edema with some blistering; slightly } \\ \text { disturbed motility permissible }\end{array} \\ \text { Grade IV } & \begin{array}{l}\text { Extensive epidermiolysis and/or obvious damage to the deep tissues, } \\ \text { causing definite functional disturbances;threatening or manifest } \\ \text { compartmental syndrome }\end{array} \\ \text { Grade V } & \text { Reaction which may necessitate amputation }\end{array}$


was only done in the case of locally irresectable progressive recurrences that could not be excised without severely compromising limb function or be ablated by $\mathrm{CO}_{2}$ laser and had previously shown no or little response to ILP, so that repeat ILP was not an option.

The following tests were used for statistical analysis: proportions were compared using the $\mathrm{X}^{2}$ test. Survival and limb recurrence-free interval were analyzed using Kaplan-Meier analyses with the logrank test assessing equality of distributions. Multivariate linear regression analysis was performed to determine the most important factors leading to increased hospital stay. A P-value of less than 0.05 was considered significant. The following independent variables were tested in this analysis: age, sex, level of ILP, time period in which the ILP was performed, the administered drug, limb toxicity (grade III/IV versus grade I/II), complications such as wound infection and seroma needing drainage. The level of ILP was tested because of the more extensive procedure of ILP at the iliac level compared to the femoral level and the usually higher melphalan peak concentration that is obtained in ILP at the iliac level. To study an effect of increasing experience gained with ILP, the time period in which the ILP was performed was evaluated by defining four time periods: 1978-1984, 1985-1990, 1991-1995 and 1996-2001.

\section{Results}

\section{Tumor response and limb recurrence}

Tumor response was not evaluated in one patient in the group of 75 years of age or older due to severe postoperative complications. She had an incarcerated hernia of small bowel in the iliac fossa with severe bleeding from a lacerated artery. After ileocecal resection and multiple transfusions, an enterocutaneous fistula developed. Subsequently, she developed an acute respiratory distress syndrome and hepatic failure and died six months after ILP. Therefore, objective responses of 57 ILPs in 52 older patients could be analyzed. In the younger age group, the tumor response was not evaluated in two patients. One patient without a history of cardiovascular disease suddenly died with ventricular fibrillation two days after an uncomplicated ILP procedure with melphalan alone. In another patient, local tumor response was not recorded due to progressive metastases at other sites leading to her death three months after ILP. Objective tumor response after 158 procedures in 147 younger patients could be analyzed.

Patients 75 years of age or older had a complete response rate of $56.1 \%(n=32$, $95 \%$ confidence interval (CI) $43 \%-69 \%$ ) compared to $58.2 \%$ in the younger group $(\mathrm{n}=92,95 \% \mathrm{CI} 48 \%-64 \%, \mathrm{P}=0.79)$. Eighteen of the older patients relapsed in the perfused area $(56.3 \%, 95 \%$ CI $39 \%-73 \%)$ after a median period of nine months (25-75\% interval 5-18 months). This was not statistically different from the younger group with a $51.1 \%$ relapse rate $(n=47,95 \%$ CI $41 \%-61 \%)$ after a median period of six months (25-75\% interval 4-14 months, $\mathrm{P}=0.61)$. Five-year limb recurrence-free survival was $53.4 \%$ for patients 75 years of age or older who attained a CR on the ILP and did not differ from that in the younger patients (48.9\%, $\mathrm{P}=0.36$ ) (Figure 1). Five-year disease-specific survival in the elderly compared to those younger than 75 years of age was also similar (40.6\% versus $37.0 \%, \mathrm{P}=0.49$ ) (Figure 2). 
Figure 1. Relapse-free survival for those with CR after ILP

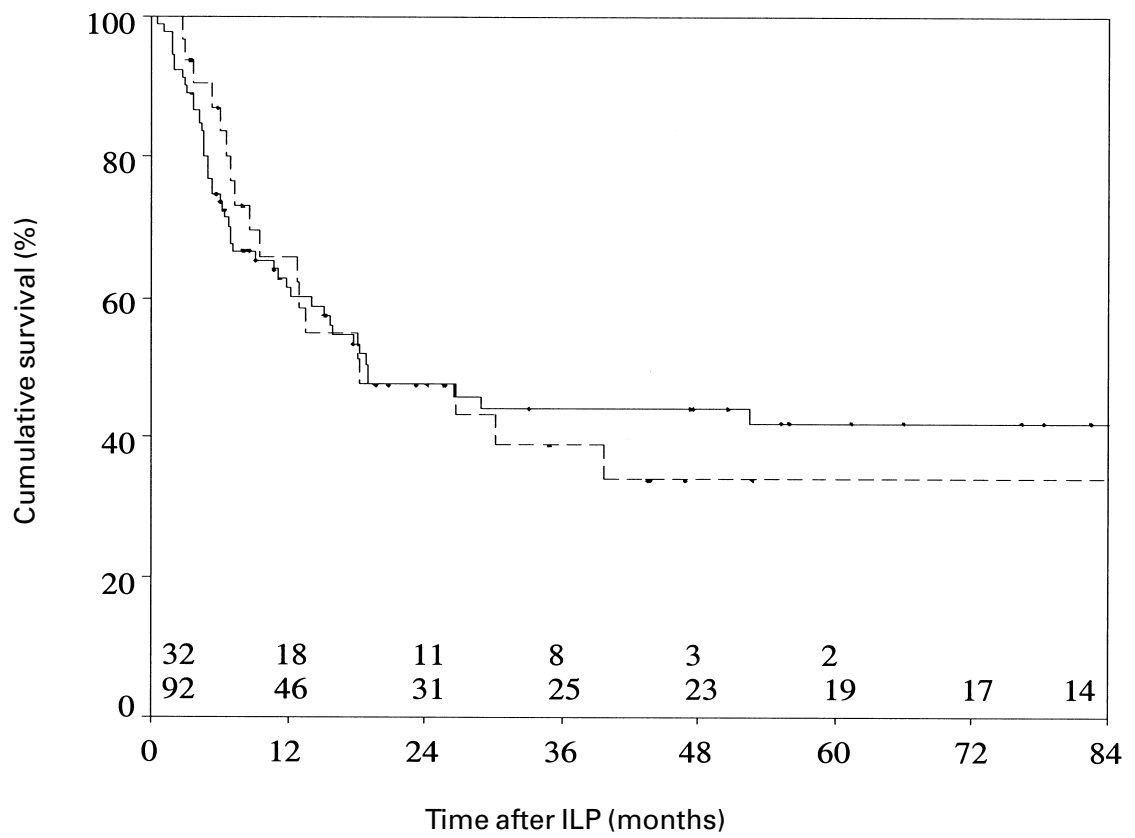

Numbers of patients at risk are provided at each point in time for both groups

Figure 2. Disease specific survival

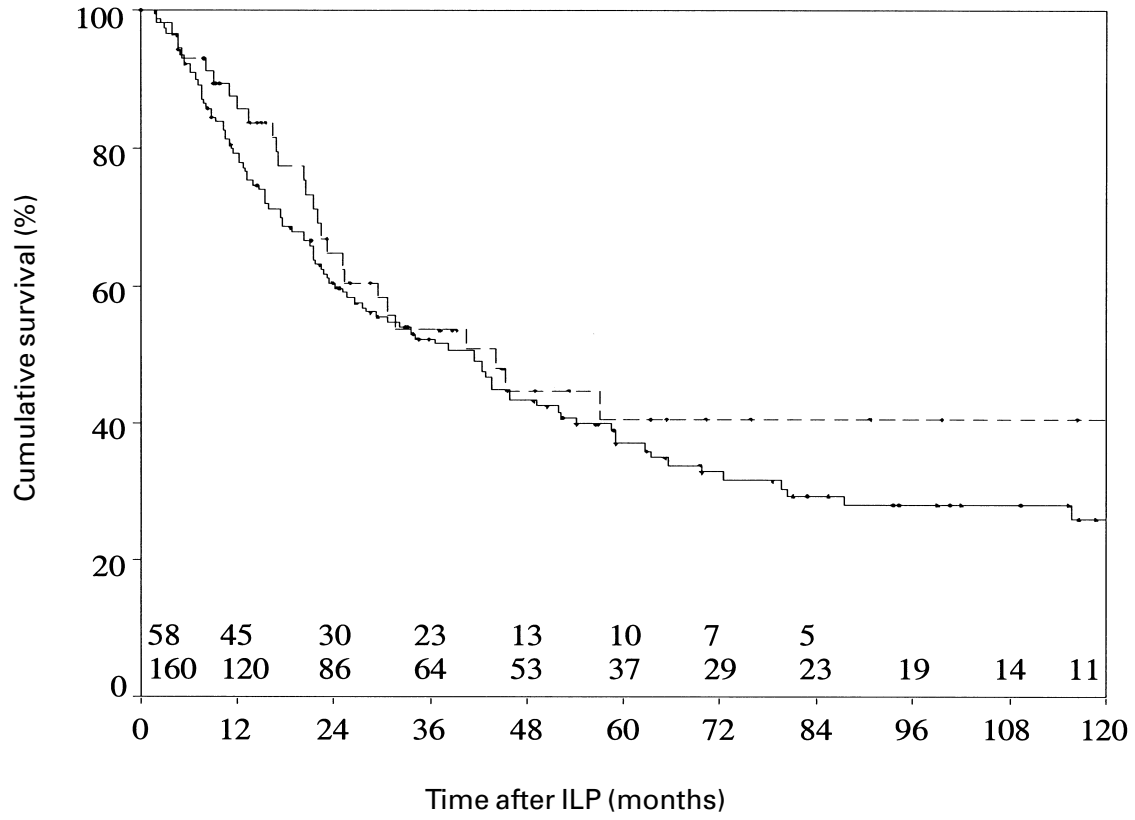

Numbers of patients at risk are provided at each point in time for both groups 
Table 4. Toxicity, complications and hospital stay after ILP in patients in the two age groups

\begin{tabular}{|c|c|c|c|c|}
\hline & & $<75$ yr. $(n, \%)$ & $\geq 75$ yr. $(n, \%)$ & P-value ${ }^{\ddagger}$ \\
\hline \multirow[t]{2}{*}{ Limb toxicity } & Grade I/II & $14 / 97(72.1 \%)$ & $5 / 42(81.0 \%)$ & 0.20 \\
\hline & Grade III/IV & $40 / 3(27.9 \%)$ & $10 / 1(19.0 \%)$ & 0.18 \\
\hline \multirow[t]{5}{*}{ Other complications } & Seroma & $10(6.3 \%)$ & $4(6.9 \%)$ & 0.86 \\
\hline & Wound infection & $22(13.8 \%)$ & $10(17.2 \%)$ & 0.52 \\
\hline & Arterial thrombosis & $1(0.6 \%)$ & 0 & \\
\hline & $D V T^{+}$ & $3(1.9 \%)$ & 0 & \\
\hline & Bleeding at art. site ${ }^{+}$ & $1(0.6 \%)$ & $1(1.9 \%)$ & \\
\hline \multirow[t]{3}{*}{ Systemic toxicity } & Nausea & $33(20.8 \%)$ & $14(20.7 \%)$ & 0.99 \\
\hline & $\operatorname{Low} W B C^{+}$ & $10(6.3 \%)$ & $6(10.3 \%)$ & 0.31 \\
\hline & Fever & $12(12.0 \%)$ & $7(20.5 \%)$ & 0.25 \\
\hline Median hospital stay* & & $17(12-24)$ & $21(15.5-28)$ & $0.002^{\S}$ \\
\hline Peri-operative mortality & & $1(0.6 \%)$ & $1(1.9 \%)$ & 0.46 \\
\hline \multirow[t]{3}{*}{ Long-term morbidity } & Edema $3 \mathrm{~ms}$ & $11(7.4 \%)$ & $6(10.9 \%)$ & 0.42 \\
\hline & $12 \mathrm{~ms}$ & $4(3.6 \%)$ & $3(7.5 \%)$ & 0.28 \\
\hline & Limb malfunction $2 y r$ & $9(5.7 \%)$ & $4(6.9 \%)$ & 0.37 \\
\hline
\end{tabular}

\footnotetext{
* between parentheses: $25 \%-75 \%$ range in days

† DVT $=$ deep venous thrombosis, art. site $=$ arteriotomy site, low $\mathrm{WBC}=$ white blood cell count lower than $3.0 \times 109 /$ liter

$\ddagger \mathrm{X}^{2}$ test

$\S$ Mann-Whitney test for non-parametric distributions
}

\section{Limb toxicity and locoregional complications}

Toxicity and complications are listed in Table 4 . The encountered limb toxicity in the elderly was comparable to toxicity in the younger patients, with only a not significantly larger proportion grade I/ II and less grade III/IV reactions in the older patients. No grade $\mathrm{V}$ reactions of tissue necrosis necessitating amputation were seen. In a univariate analysis, limb toxic reactions after femoral ILP were not significantly different in both age groups, with $18.5 \%$ grade III/IV reactions among the elderly compared with $28.6 \%$ in the younger $(\mathrm{P}=0.27)$. After iliac ILPs, regional toxicity was comparable for both age groups (20.8\% versus $23.7 \%$ grade III/IV reactions respectively, $\mathrm{P}=0.51$ ). When regional toxicity after ILP was univariately tested irrespective of patient age, the occurrence of more severe toxicity appeared not different after ILP at the iliac or femoral level (20.8\% versus $18.5 \%, \mathrm{P}=0.84)$.

The incidence of wound infections and seroma was similar in both groups. A 37-year old man developed arterial thrombosis, which could be treated conservatively. Postoperative bleeding at the arteriotomy site occurred in two patients, one in each age group, requiring reoperation in the older patient. 


\section{Systemic toxicity}

In both age groups, an equal percentage of patients $(20,7 \%$ in the elderly and $20.8 \%$ in the younger group respectively) experienced some degree of nausea. Similar minor systemic toxicity was encountered in both age groups regarding white blood cell count and TNF $\alpha$ induced postoperative fever. No other signs of $\mathrm{TNF} \alpha$ toxicity were encountered in both age groups.

\section{Peri-operative mortality}

Peri-operative mortality, usually defined as 30-day mortality, was low. No patient in the older age group died within 30 days from ILP, whereas in the younger group one earlier described patient died after two days due to myocardial infarction $(0.6 \%)$. However, the one older patient mentioned earlier who died of complications of the procedure was regarded a peri-operative death, since it was clearly procedure related. Among the older patients, the 90 -day mortality rate was $1.7 \%$, i.e. one patient died after two months due to systemic metastases of melanoma. Four additional patients $(2.5 \%)$ in the younger age group died within 90 days postoperatively due to metastatic melanoma.

\section{Hospital stay}

Hospital stay was normally distributed when one outlier was left out from the analysis. This was the patient who was described earlier with a complicated hospital stay of 120 days. Patients over 75 years of age stayed significantly longer in the hospital than younger patients with a mean stay of 23.0 days (range 7-65 days, SD 10.6) and 18.8 days (2-69 days, SD 9.5) respectively ( $\mathrm{P}=0.007)$. Results of a multivariable linear regression analysis, performed to determine prognostic factors for length of hospital stay, are shown in Table 5. Age older than 75 years remained an independent risk factor for a significantly longer hospital stay. Also female sex, wound infection, more severe limb toxicity (grade III/IV) and ILP performed between 1978 and 1984, were risk factors for a longer hospital stay.

Long-term morbidity

No significant differences in long-term morbidity were found between the age

Table 5. Factors associated with difference in hospital stay after ILP: Results from a multivariable linear regression analysis

\begin{tabular}{llll}
\hline & \multicolumn{2}{l}{ Hospital stay (days) * } & p-value \\
\hline Female sex & 20.6 & $(17.2)$ & 0.018 \\
Age $\geq 75$ yr. & 23.0 & $(18.8)$ & 0.000 \\
Wound infection & 27.0 & $(18.9)$ & 0.000 \\
Limb toxicity & $26.0(18.3)$ & 0.000 \\
1978-1984 & $25.3(18.8)$ & 0.000 \\
\hline
\end{tabular}

\footnotetext{
* Numbers indicated are the length of hospital stay if the tested characteristic is present and between parentheses if characteristic is absent.
} 
groups. Limb malfunction at two years after ILP in the younger age groups consisted of ankylosis, fibrosis and/or muscle atrophy in nine patients $(6 \%)$. One of these patients also had recurrent ulcers, another had peroneal nerve dysfunction and one patient suffered from all three long-term side-effects. Three patients in the older group suffered from ankylosis, fibrosis and/or muscle atrophy (6\%). None of the older patients had clinically significant edema two years after ILP.

During follow-up, limb amputations were performed after ILP in three patients younger than age $75(2 \%)$ and four older patients $(7.6 \%, \mathrm{P}=0.29)$. In four patients this was because of progressive lesions and in three because of extensive relapse after an initial complete response. In none of the patients the indication for amputation was due to toxicity and/or morbidity caused by the ILP.

\section{Discussion}

The mean life expectancy at age 75 is 8.5 years for males and 11 years for females. ${ }^{17}$ Maintaining or improving the quality of life in this age group is desirable. Therefore, effective palliative measures like ILP are important also in this phase of life.

Melanoma of the limb locally recurs mostly in the form of in-transit metastases (in 5-8\% of melanoma patients) in the extremity and can present an appalling problem to the patient. Various locoregional treatment options exist, but effective management of regionally recurrent melanoma remains a challenge. The choice depends primarily on the number and size of the lesions and on the general condition of the patient. Treatments vary form (multiple) excision(s), laser-evaporation, intralesional injection of interferons and regional chemotherapy i.e. isolated limb infusion or perfusion. ${ }^{18}$ Over the years, we have become more and more conservative in our approach to the application of ILP. The indication of its use has been debated and the opinions varied from ILP being the first choice of treatment for all patients with in-transit metastases to for only those with truly irresectable, often bulky, disease..$^{19}$ The utility of ILP with melphalan has now been limited to the locoregional multiple metastatic and advanced metastastic cases. TNF-based ILP is only applied in the case of two indications, i.e. in bulky metastatic disease and on the occasion of recurrent disease after previous ILP with melphalan alone. ${ }^{4,5}$

Recurrent melanoma can be a substantial problem in elderly patients. The current study was performed to see whether ILP, when indicated, is sufficiently effective and feasible in these patients. Sofar, only one report focusing on the application of ILP in patients older than 70 years of age has been published. No conclusions could be drawn from that study because of the small number of patients who underwent therapeutic ILP and the use of various unconventional drugs. ${ }^{20}$ Our study shows that complete response rate and limb recurrence-free interval after ILP for advanced locoregional melanoma among patients older and younger than age 75 are similar. The complete response rate of $56 \%$ in older patients with advanced melanoma is comparable to data in the literature where a mean complete remission rate of about $54 \%$ is reported, regardless of age. ${ }^{1}$ After a long median follow-up of six years, our locoregional relapse rate in patients older than age 75 is higher than reported in the literature (56.3\% versus $24-54 \%)$, 
but not significantly different from the younger age group. ${ }^{1}$ Still, a third of the older patients are rendered locoregionally tumor-free for at least five years. Thus, ILP in older patients appears to be as effective as in younger patients.

We found no increase in mortality among the older patients with one procedure related death of ILP, in spite of the general finding that mortality increases with age after any surgical procedure. ${ }^{9}$ Peri-operative mortality rates after ILP with melphalan generally range from $0-9 \%$, with nowadays the majority being between $0-1 \%{ }^{6}$ Functional status, comorbidity and emergency situations are the risk factors that account for peri-operative mortality and complications rather than chronological age itself., ${ }^{21,22}$ So, careful assessment of patient's specific comorbidities is more important than age in determining the preoperative risk..$^{23}$ In recent studies from the Dutch ILP centers, it has been clear that no appreciable systemic toxicity occurs with TNF-based ILPs in patients without leakage, while patients with high leakage $(>15 \%)$ were reported to have toxicity that can be easily managed. ${ }^{24}$ Apart from fever in the immediate postoperative phase, we did not see any increase in systemic toxicity after TNFo-ILP in either age group.

In the present study, limb toxicity was similar in older patients compared to younger patients. The proportion of patients with a more severe toxicity reaction, i.e. grade III-IV according to the Wieberdink criteria, was even lower (although not statistically significant) in the older patients $19 \%$ versus $27.9 \%$ ) and comparable to data in the literature $(15 \%) .{ }^{25}$ Since the major predictor of long-term morbidity and functional impairment is acute limb toxicity ${ }^{13}$, we also found little long-term morbidity in patients older than 75 years of age. We generally choose to perform ILP at the femoral level in the elderly unless the disease extends beyond this level, because of the smaller dissection and the potentially increased limb toxicity due to a higher melphalan peak concentration at the iliac level. ${ }^{27}$ However, there was no difference in toxicity between both age groups at neither the femoral nor the iliac level. In this study, we could not demonstrate an increase in toxicity at the iliac compared with the femoral isolation level.

It has been suggested that older patients are prone to the systemic side-effects of the chemotherapy used in ILP, ${ }^{6}$ but this was not the case in this series. Melphalan leakage at our institutions is negligible ${ }^{7}$ which is reflected by our low incidence of any degree of bone marrow depression (7.3\%) compared to the literature (up to 59\%) and with no significant difference between older and younger patients. ${ }^{6}$ Systemic toxicity with nausea and vomiting occurred in one-fifth of the patients, equally divided between the two age groups. This is probably a sideeffect of regional tissue damage by the ILP but also an adverse effect of anesthesia for it is known that $10-50 \%$ of patients experience nausea following surgery under general anaesthesia. ${ }^{28}$

Other postoperative complications, such as wound infections and seroma, were evenly distributed among both age groups or, like deep venous or arterial thrombosis, did not occur in patients older than 75 years of age.

Not unexpectedly, patients over 75 had a significantly longer length of hospital stay than younger patients. Hospital stay is known to be mostly determined by either medical causes such as complications or severity of disease, or by social factors such as waiting for a nursing home..$^{29}$ In our hospital the main limiting factor for discharge is mobilization, apart from complications such as wound infec- 
tions or more severe regional toxicity. Patients should be able to pursue daily activities in a reasonable way when discharged, with the aid of physiotherapy. Older patients tend to recover more slowly and need more time to be fully mobile after ILP in comparison with younger patients. Also, time was needed to arrange sufficient support during the first weeks at home since most older patients in our study population were still living independently. In our study female sex, wound infections and grade III/IV limb toxicity were independent determining factors for a longer hospital stay. Hospital stay was also significantly longer from 1978 to 1984 , reflecting the relative inexperience with the procedure and the generally accepted longer hospital stay in those years.

In conclusion, patients older than 75 years of age with advanced melanoma of a limb benefit as much from ILP as younger patients, without a higher risk of mortality and morbidity.

\section{References}

1. Vrouenraets BC, Nieweg OE, Kroon BBR. Thirty-five years of isolated limb perfusion for melanoma: indications and results. Br J Surg 1996; 83:1319-28.

2 Eggermont AMM, Schraffordt Koops H, Kroon BBR, et al: Isolated limb perfusion with high-dose tumor necrosis factor-alpha in combination with interferon-gamma and melphalan for nonresectable extremity soft tissue sarcomas: a multicenter trial. J Clin Oncol 1996; 14:2653-65.

3 Fraker DL, Alexander HR, Andrich M, Rosenberg SA. Treatment of patients with melanoma of the extremity using hyperthermic isolated limb perfusion with melphalan, tumor necrosis factor, and interferon gamma: results of a tumor necrosis factor dose-escalation study. J Clin Oncol 1996;14: 479-89.

4 Fraker DL, Alexander HR, Andrich M, et al: Palliation of regional symptoms of advanced extremity melanoma by isolated limb perfusion with melphalan and highdose tumor necrosis factor. Cancer J Sci Am 1995;1:122.

5 Bartlett DL, Grace M, Alexander HR, Libutti SK, Fraker DL. Isolated limb perfusion with tumor necrosis factor and melphalan in patients with extremity melanoma after failure of isolated limb perfusion with chemotherapeutics. Cancer 1997;80:2084-90.

6. Sonneveld EJ, Vrouenraets BC, van Geel BN, et al. Systemic toxicity after isolated limb perfusion with melphalan for melanoma. Eur J Surg Oncol 1996; 22:521-7.

7. Vrouenraets BC, Kroon BBR, Ogilvie AC, Van Geel AN, Nieweg OE, Swaak AJ, Eggermont AMM. Absence of severe systemic toxicity after leakage-controlled isolated limb perfusion with tumor necrosis factor-alpha and melphalan. Ann Surg Oncol 1999; 6:405-12.

8. Vrouenraets BC, Eggermont AMM, Hart AA, Klaase JM, van Geel AN, Nieweg OE, Kroon BBR. Regional toxicity after isolated limb perfusion with melphalan and tumor necrosis factor-alpha versus toxicity after melphalan alone. Eur J Surg Oncol 2001; 27:390-5.

9. Thomas DR, Ritchie CS. Preoperative assessment of older adults. J Am Geriatr Soc 1995; 43:811-21.

10. Polanczyk CA, Marcantonio E, Goldman L, Rohde LE, Orav J, Mangione CM, Lee 
TH. Impact of age on peri-operative complications and length of stay in patients undergoing noncardiac surgery. Ann Intern Med 2001; 134:637-43.

11. Bonenkamp JJ, Songun I, Hermans J, et al. Randomised comparison of morbidity after D1 and D2 dissection for gastric cancer in 996 Dutch patients. Lancet 1995; 345:745-8.

12. Hobler KE. Colon surgery for cancer in the very elderly. Cost and 3-year survival. Ann Surg 1986; 203:129-31.

13. Vrouenraets BC, Klaase JM, Kroon BBR, Van Geel BN, Eggermont AMM, Franklin HR. Long-term morbidity after regional isolated perfusion with melphalan for melanoma of the limbs. The influence of acute regional toxic reactions. Arch Surg 1995; 130:43-7.

14. Liénard D, Ewalenko P, Delmotte JJ, Renard N, Lejeune FJ. High-dose recombinant tumor necrosis factor alpha in combination with interferon gamma and melphalan in isolation perfusion of the limbs for melanoma and sarcoma. J Clin Oncol 1992; 10:5260.

15. Wieberdink J, Benckhuijsen C, Braat RP, van Slooten EA, Olthuis GA. Dosimetry in isolation perfusion of the limbs by assessment of perfused tissue volume and grading of toxic tissue reactions. Eur J Cancer Clin Oncol 1982; 18:905-10.

16. WHO handbook for reporting results of cancer treatment. Geneva: WHO, 1979.

17. Zenilman ME. Surgery in the elderly. Curr Probl Surg 1998;35:99-179.

18. Eggermont AMM. Treatment of melanoma intransit metastases confined to the limb. Cancer Surveys 1996; 26:335-49.

19. Schraffordt Koops H, Garbe C, Hohenberger P. Is isolated limb perfusion of metastatic malignant melanoma of the extremity worthwhile? Eur J Cancer 1996;32A:163340.

20. Ariyan S, Poo WJ. Safety and efficacy of isolated perfusion of extremities for recurrent tumor in elderly patients. Surgery 1998; 123:335-43.

21. Leung JM, Dzankic S. Relative importance of preoperative health status versus intraoperative factors in predicting postoperative adverse outcomes in geriatric surgical patients. J Am Geriatr Soc 2001; 49:1080-5.

22. Daley J, Khuri SF, Henderson W, et al. Risk adjustment of the postoperative morbidity rate for the comparative assessment of the quality of surgical care: results of the National Veterans Affairs Surgical Risk Study. J Am Coll Surg 1997; 185:328-40.

23. Schwarz RE, Karpeh MS, Brennan MF. Factors predicting hospitalization after operative treatment for gastric carcinoma in patients older than 70 years. $J$ Am Coll Surg 1997; 184:9-15.

24. Stam TC, Swaak AJ, de Vries MR, ten Hagen TL, Eggermont AM. Systemic toxicity and cytokine/acute phase protein levels in patients after isolated limb perfusion with tumor necrosis factor-alpha complicated by high leakage. Ann Surg Oncol 2000;7: 268-75.

25. Klaase JM, Kroon BBR, Van Geel BN, Eggermont AMM, Franklin HR, Hart GA. Patient- and treatment-related factors associated with acute regional toxicity after isolated perfusion for melanoma of the extremities. Am J Surg 1994; 167:618-20.

26. van Geel AN, van Wijk J, Wieberdink J. Functional morbidity after regional isolated perfusion of the limb for melanoma. Cancer 1989; 63:1092-6.

27. Klaase JM, Kroon BBR, van Slooten GW, Benckhuijsen C. Relation between calculated melphalan peak concentrations and toxicity in regional isolated perfusion for melanoma. Regional Cancer Treatment 1992; 4:309-12. 
28. Sear JW, Rosewarme F. Anaesthesia for surgeons. In: Morris PJ, Malt RA, eds. Oxford textbook of surgery. New York: Oxford University Press, 1994: 53-82.

29. McAleese P, Odling-Smee W. The effect of complications on length of stay. Ann Surg 1994; 220:740-4.

30. Klaase JM, Kroon BBR, van Geel AN et al. Limb recurrence-free interval and survival in patients with recurrent melanoma of the extremities treated with normothermic isolated perfusion. J.Am.Coll.Surg. 1994 ;178:564-72. 


\title{
Editorial
}

\section{Isolated Limb Perfusion in Elderly Melanoma Patients}

\author{
Kelly M. McMasters, MD, PhD
}

In-transit melanoma of the extremity can pose a terrible local disease control problem. Isolated limb perfusion (ILP), originally developed by Creech et al. ${ }^{1}$ in the 1950 s, is capable of inducing a complete response in a substantial fraction of patients. Often this complete response is durable, perhaps even curative. Although enthusiasm for ILP has waxed and waned over the ensuing decades, and adjuvant ILP for primary melanomas has fallen out of favor, ${ }^{2}$ there can be no question that ILP plays an important role in local disease control of patients with extremity in-transit disease.

In this issue, Noorda et al. ${ }^{3}$ report their retrospective experience with 218 therapeutic ILP procedures in 202 patients. Fifty-three of these patients were 75 years of age or older. Response rates, toxicity, complications, and long-term morbidity were similar comparing patients $<75$ years of age with those over 75 . Hospital stay was somewhat longer in older patients as would be expected. Interestingly, $56 \%$ of the older patients and $58 \%$ of the younger patients achieved complete response to ILP, and of those who achieved complete response, roughly half achieved durable long-term locoregional disease control. If one considers long-term limb-specific disease-free survival as the measure of success for this procedure, approximately one quarter of the patients had unequivocal benefit from the operation.

The article by Noorda et al. ${ }^{3}$ clearly demonstrates that older patients can undergo ILP safely and can enjoy the same degree of benefit as younger patients. This is encouraging, especially when we are faced with very difficult decisions about aggressive operation for advanced locoregional disease in melanoma patients who are el-

Received October 15, 2002; accepted October 16, 2002.

From the Division of Surgical Oncology, University of Louisville, James Graham Brown Cancer Center, Louisville, Kentucky.

Address correspondence to: Kelly M. McMasters, MD, PhD, Division of Surgical Oncology, University of Louisville, James Graham Brown Cancer Center, 315 East Broadway, Room 308, Louisville, KY 40202 Fax: 502-629-3393; E-mail: kelly.mcmasters@nortonhealthcare.org.

Published by Lippincott Williams \& Wilkins (C) 2002 The Society of Surgical Oncology, Inc. derly with other medical problems. The clear message is that for patients who need ILP, age should not be a contraindication.

However, the bigger question arises: who really needs ILP? Although the patients in the study by Noorda et al. ${ }^{3}$ were reported to have significant locoregional disease, the extent of the disease is rather poorly defined except for the M. D. Anderson staging classification, which gives us little real insight into the nature of the in-transit disease. For example, a patient with a single satellite lesion or local recurrence, which might be easily treated with simple surgical excision, could be included. Although ILP may be beneficial for patients who present with minimal in-transit metastasis or local recurrence, the population of patients who have significant risk to warrant this procedure remains poorly defined. The fact that $19 \%$ and $28 \%$ of the older and younger age groups, respectively, experienced significant grade III/IV limb toxicity underscores the fact that ILP remains a major operation with a risk of major complications, including limb loss in rare instances.

It has certainly been our experience that many patients who have minimal disease can forego ILP in favor of local excision, intralesional therapy with interferon or Calmette-Guérin Bacille or other local therapies. Many patients can be maintained for a long time with local treatment only. Furthermore, because patients with intransit disease are at high risk for systemic metastasis, they may benefit from systemic treatment with biochemotherapy, high-dose interleukin-2, temozolomide-containing regimens, or other agents. It is clear that skin and subcutaneous metastases respond much better to systemic therapy than visceral metastases. Patients with a complete response, or a good partial response to systemic treatment, combined with surgical resection, may never need ILP for local disease control. We have been impressed with the fact that, at least at our center, uncontrolled in-transit disease requiring ILP is relatively uncommon. One could certainly argue that ILP as primary therapy for in-transit disease may have advantages over 
these other types of therapy. However, whether ILP is used as front-line therapy or as backup therapy, given the fact that the majority of patients with in-transit disease will suffer locoregional recurrence, it is useful to have additional modalities at our disposal.

Further study is certainly necessary to define the population of patients in which ILP is best indicated. Because many patients can be managed with less invasive procedures, ILP can be reserved truly for local disease control in the extremity when other measures fail. For patients who present with more advanced regional disease, ILP plays an important role, with a long-standing track record for local disease control. The important experience from Noorda et al. ${ }^{3}$ indicates that, when ILP is necessary, age should not be a concern in deciding whether or not to perform the procedure. Whether or not tumor necrosis factor should be included in melphalan- based ILP remains a subject of some controversy and is undergoing further study at the present time in the American College of Surgeons Oncology Group trial Z0020.

\section{REFERENCES}

1. Creech O Jr, Krementz ET, Ryan RF, et al. Chemotherapy of cancer: regional perfusion utilizing an extracorporeal circuit. Ann Surg 1958;148:616.

2. Koops HS, Vaglini M, Suciu S, et al. Prophylactic isolated limb perfusion for localized, high-risk limb melanoma: results of a multicenter randomized phase III trial. European Organization for multicenter randomized phase III trial. European Organization for
Research and Treatment of Cancer Malignant Melanoma Cooperative Group Protocol 18832, the World Health Organization Melanoma Program Trial 15, and the North American Perfusion Group Southwest Oncology Group-8593. J Clin Oncol 1998;16:2906-12.

3. Noorda EM, Vrouenraets BC, Nieweg OE, van Geel AN, Eggermont AMM, Kroon BBR. Safety and efficacy of isolated limb perfusion in elderly melanoma patients. Ann Surg Oncol 2002;9: 968-974 


\title{
Repeat isolated limb perfusion with $\mathrm{TNF} \alpha$ and melphalan for recurrent limb melanoma after failure of previous perfusion
}

\author{
Noorda EM, Vrouenraets BC, Nieweg OE, van Geel $A N^{*}$, \\ Eggermont $A M M^{*}$, Kroon BBR \\ Department of Surgery, The Netherlands Cancer Institute / Antoni van Leeuwenhoek hospital, \\ Amsterdam, the Netherlands * Department of Surgery, Erasmus Medical Center-Daniel den Hoed \\ Cancer Center, Rotterdam, the Netherlands
}

Submitted

\section{Introduction}

Isolated limb perfusion (ILP) with melphalan for locoregionally recurrent limb melanoma generally results in an $80 \%$ tumour response rate with $54 \%$ complete responses. ${ }^{1}$ Two large studies showed 46 to $54 \%$ recurrence after a complete response with ILP have been reported. ${ }^{2,3}$ Amputation is a deterring option in such patients when recurrences are not amenable to local surgery. There is reluctance to perform a repeat ILP since acute regional toxicity has been reported to be more severe and it could be assumed that patients not responding to a first ILP may have little to gain from a repeat procedure. ${ }^{4}$ Nevertheless, a complete response rate of $74 \%$ has been demonstrated after repeat ILP with melphalan applied in single, double, triple or sequential ILP-schedules, has been demonstrated. ${ }^{5}$ The latter elaborate procedures are no longer performed since the introduction of tumour necrosis factor-alpha $(\mathrm{TNF} \alpha)$ in the isolated circuit with good results. However, studies about TNF $\alpha$ in repeat ILP procedures are scarce with a few small patient series with heterogeneous patient and tumour characteristics. ${ }^{6,7}$ Therefore, we assessed the results of repeat ILP with TNF $\alpha$ in patients who relapsed or had persistent disease after previous ILP in our institutions.

\section{Patients and methods}

From 1978 to 2001, 505 ILPs were performed in 451 patients with recurrent and/or locally advanced extremity melanoma in our institutions. All patient, tumour, treatment and follow-up data were maintained in a computer database. In this database, 21 patients were identified who underwent 29 repeat ILPs between 1991 and 1999, using TNF $\alpha$ and melphalan for persisting or recurrent melanoma lesions after a previous ILP. Six of these patients underwent three ILPs and one four. There were three male patients (15\%) and the mean age was 65 years (range 29-83 years). Recurrent melanoma lesions were located on the lower limb in 19 
and on the upper limb in two patients. Stage of disease was classified according to the MD Anderson staging system adapted for stage II (Table 1). ${ }^{8}$

Our ILP technique has been described in detail elsewhere. ${ }^{9}$ During ILP, the major artery and vein are clamped at the desired level, collateral vessels are ligated and a tourniquet is applied around the limb, proximal to the region of ILP. After insertion of the catheters, the isolated limb is perfused by an extra-corporeal circulation, oxygenated and propelled by a heart-lung machine. A melphalan dose of $13 \mathrm{mg} / \mathrm{l}$-perfused tissue in the upper limb and $10 \mathrm{mg} / \mathrm{l}$ for the lower limb is added to the perfusate. For TNF $\alpha$ this is $3 \mathrm{mg}$ and $4 \mathrm{mg}$ respectively, irrespective of limb volume. In seven patients, $0.2 \mathrm{mg}$ interferon-gamma (IFN $\alpha$ ) was additionally injected subcutaneously for two days before repeat ILP. The same dose was given intraoperatively in the isolated circuit. Adequate tissue temperatures are achieved and maintained by heating the heparinised perfusate and application of a warm water blanket around the limb. Limb temperatures are kept between 37 and $38^{\circ} \mathrm{C}$ (normothermia) in ILP with melphalan alone or 38 and $40^{\circ} \mathrm{C}$ (mild hyperthermia) in case of ILP with TNFo. ILP with melphalan lasts one hour, when TNF $\alpha$ is used 90 minutes. At termination of the ILP, the perfusate is drained out and the limb is rinsed with an electrolyte solution. The tourniquet is then released and catheters are removed. In one patient, the first ILP consisted of a sequential ILP scheme, in which ILP with hyperthermia $\left(42-43^{\circ} \mathrm{C}\right)$ was followed one week later by ILP with melphalan alone under normothermic conditions. ${ }^{10}$

Acute regional tissue toxicity after ILP was graded according to Wieberdink et al. ${ }^{11}$ Tumour response was measured by WHO criteria. ${ }^{12}$ Postoperatively, patients stayed in bed with the leg elevated until acute toxic limb reactions subsided. They were gradually mobilised with the help of a physiotherapist and discharged when fully ambulant.

In Table 1 characteristics and results of the first ILP are shown. In four patients tumour response of the first ILP was not evaluable because the procedure was performed as adjuvant to the excision of a primary tumour $(n=2)$ as part of a randomised trial, ${ }^{13}$ or prophylactically after the excision of in-transit metastases $(n=2)$. Twelve patients $(71 \%)$ with in-transit metastases or a local recurrence had a high tumour load according to the combined criteria of Fraker and Rossi, i.e. more than ten lesions and/or lesions larger than $3 \mathrm{~cm} \cdot{ }^{14,15}$ After the first ILP, 11 of 17 patients $(65 \%, 95 \%$ CI $39-90 \%)$ with measurable disease attained a complete response (CR). Median duration of that CR was seven months (IQ range 5-25 months). All acute regional toxicity reactions were between grades I and III, with three $(14.5 \%)$ grade I, $15(71 \%)$ grade II and three $(14.5 \%)$ grade III reactions. Two patients had neuropathy still present at the time of the repeat ILP. One of the two had undergone the sequential schedule with peroneal nerve dysfunction following the first hyperthermic ILP. The other patient had sensory nerve disturbances of the lower leg. Before or at the time of the first ILP, 15 patients had undergone lymph node clearance with two axillary dissections, one inguinal dissection, ten combined inguinal/iliac/obturator dissections and two dissections at the iliac/obturator level. The median time between first and repeat ILP was 17 months (IQ range 10-30 months). Within this interval, 16 patients had several recurrences, which were all managed by excision. 


$\begin{array}{lc}\text { MD Anderson stage of disease } & \\ \text { Stage I primary melanoma } & 2(9 \%) \\ \text { Stage IIB satellitosis } & 6(29 \%) \\ \text { Stage IIIA in-transit sin lymph node metastases } & 9(43 \%) \\ \text { Stage IIIAB in-transit with lymph node metastases } & 4(19 \%) \\ \text { Number of lesions (median, IO range) } & 9(2-23) \\ \text { ILP-type } & \\ \text { Melphalan } & 12 \\ \text { TNF } \alpha+\text { melphalan } & 8(3 \text { with IFN } \gamma) \\ \text { HT and melphalan sequentially } & 1 \\ \text { Level of ILP } & \\ \text { Axillary/iliac/femoral } & 2 / 10 / 9 \\ \text { Tumour response ( } \mathrm{n}=17 \text { ) } & \\ \text { Complete response } & 11(65 \%) \\ \text { Partial response } & 2(12 \%) \\ \text { No change } & 3(17 \%) \\ \text { Progression } & 1(6 \%) \\ \text { Acute regional toxicity } & \\ \text { Grade I (no reaction) } & 3(14.5 \%) \\ \text { Grade II (mild erythema/edema) } & 15(71 \%) \\ \text { Grade III (mild erythema, edema and blistering) } & 3(14.5 \%) \\ \text { Mean (range) hospital stay (days) } & 19.5(6-39)\end{array}$

$\mathrm{HT}=$ true hyperthermia $\left(42-43^{\circ} \mathrm{C}\right)$

* Four patients had no evaluable lesions since ILP was adjuvant to excision of the primary tumour $(n=2)$ or in-transit metastases $(n=2)$.

Characteristics of repeat ILP are displayed in Table 2. The stage of disease was different from that at first ILP, with significantly more regional lymph nodal involvement (stage IIIAB disease) in 11 out of 21 patients $(52 \%, \mathrm{P}<0.05)$. The median number of lesions was nine (IQ range 5-25). Fifteen patients (71\%) had a high tumour load according to the combined Fraker and Rossi criteria. Of the other six patients, one had lesions on the sole of the foot that were considered locally unresectable due to their localisation and five patients had multiple but less than ten small lesions spread over a large area of the extremity. Repeat-ILP was indicated in these patients, because either new lesions were developing more frequently and progressively, and/or lesions were considered unresectable. All repeat ILPs were performed with TNF $\alpha$ and melphalan, with the addition of IFN $\alpha$ in seven cases. At the time of the repeat procedure, five patients underwent an iliac/obturator lymph node dissection. Only one patient did not undergo any lymph node dissection at all during the course of his disease. Mean follow-up after the repeat ILP was 48 months, ranging from 2 to 115 months.

Statistical analysis was performed with Student's t-test when comparing groups with a normal distribution or $\mathrm{X}^{2}$ test when proportions were concerned. 
Table 2. Characteristics and results of repeat ILP

\begin{tabular}{|c|c|c|}
\hline MD Anderson stage of disease & & P-value* \\
\hline Stage IIIA in-transit sin lymph node metastases & $10(48 \%)$ & 0.76 \\
\hline Stage IIIAB in-transit with lymph node metastases & $11(52 \%)$ & $<0.05$ \\
\hline Number of lesions (median, IQ range) & $9(5-25)$ & \\
\hline \multicolumn{3}{|l|}{ ILP-type } \\
\hline TNF $\alpha+$ Melphalan & $21(7+\operatorname{IFN} \gamma)$ & \\
\hline \multicolumn{3}{|l|}{ Level of ILP } \\
\hline Axillary/iliac/femoral & $2 / 5 / 14$ & 0.61 \\
\hline Tumour response $(n=21) *$ & & 0.41 \\
\hline Complete response & $13(62 \%)$ & 0.53 \\
\hline Partial response & $2(9 \%)$ & \\
\hline No change & $1(5 \%)$ & \\
\hline Progression & $5(24 \%)$ & \\
\hline Acute regional toxicity & & 0.28 \\
\hline Grade I (no reaction) & $3(14 \%)$ & \\
\hline Grade II (mild erythema/oedema) & $11(52 \%)$ & \\
\hline Grade III (mild erythema, oedema and blistering) & $6(29 \%)$ & \\
\hline \multicolumn{3}{|l|}{$\begin{array}{l}\text { Grade IV (extensive epidermiolysis, obvious damage } \\
\text { to the deep tissues; threatening compartment }\end{array}$} \\
\hline syndrome) & $1(5 \%)$ & \\
\hline Mean (range) hospital stay (days) & $23(9-65)$ & 0.26 \\
\hline
\end{tabular}

* compared with characteristics at first ILP (see Table1)

Non-parametrical tests, mostly the Mann-Whitney test, were used if the distribution of data was not normal. For limb recurrence-free survival, a Kaplan-Meier analysis was performed and a log-rank test for comparison of differences between independent groups. A P-value of $\leq 0.05$ was regarded as significant.

\section{Results}

\section{Tumour response}

In Table 2, results of repeat ILP with TNF $\alpha$ and melphalan are shown and compared to those after the first ILP. Repeat ILP resulted in a CR in 13 patients (62\%, 95\% CI 39-85\%), which was comparable to the $65 \%$ CR rate after the first procedure $(95 \%$ CI $39-90 \%, \mathrm{P}=0.9)$. Two patients $(9 \%)$ attained a partial response, one patient $(5 \%)$ had no change of disease and five $(24 \%)$ had progressive disease despite repeat ILP. Locoregional recurrences occurred in nine complete responders $(69 \%, 95 \%$ CI $40-98 \%)$ after a median period of nine months (IQ range 7-14 months) after repeat ILP. The limb recurrence-free survival for those with a CR was $31 \%(95 \%$ CI 6\%-56\%) with a median limb recurrence-free interval of 13 months (95\% CI 5-22 months, Figure 1).

Seven $(64 \%)$ of the complete responders to the first ILP $(n=11)$ attained a com- 
Figure 1. Limb recurrence-free survival for those with CR after repeat ILP

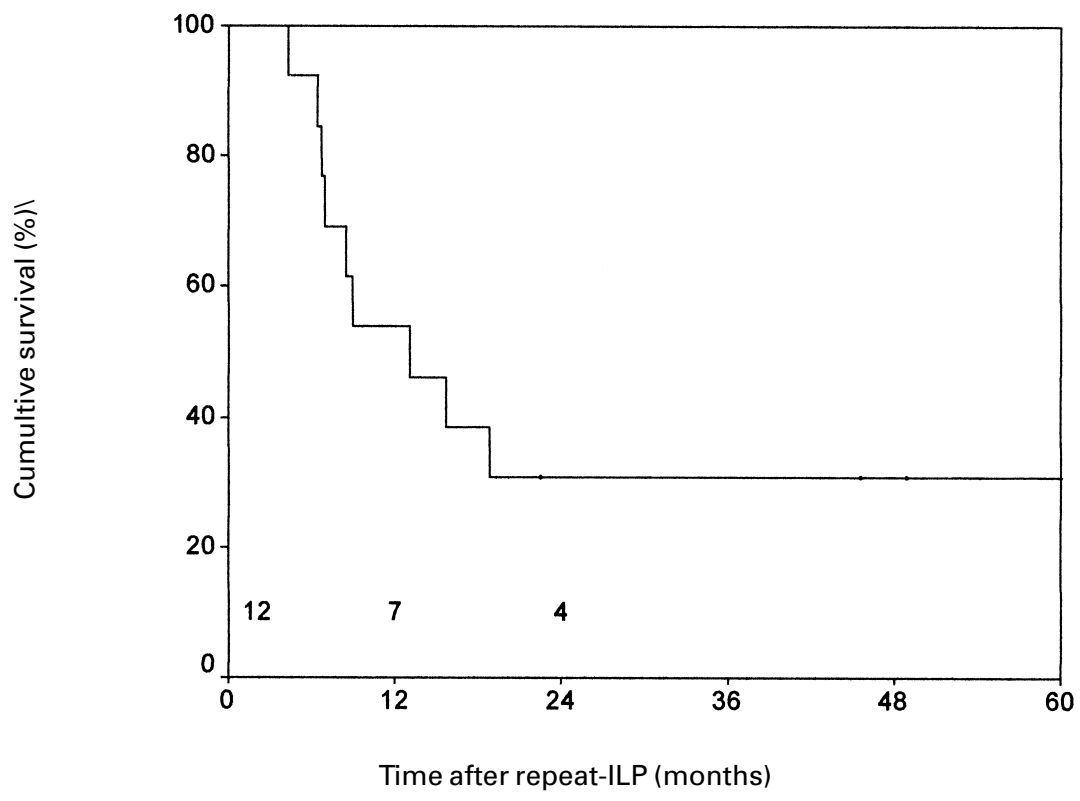

plete response after the repeat ILP as well, whereas two (33\%) of the six without $\mathrm{CR}$ to the first ILP attained a CR after repeat ILP $(\mathrm{P}=0.49)$.

\section{Toxicity and long-term morbidity}

Acute regional toxicity after the repeat ILP was not significantly different from the first ILP, when mild grade I/II reactions were compared (85\% and $67 \%$, respectively) with severe grade III-IV reactions (15\% and $33 \%$, respectively, $\mathrm{P}=0.28)$. No grade $\mathrm{V}$ reaction occurred. The patient with a grade IV reaction after repeat ILP, had an impending compartment syndrome following ILP that resolved without sequelae. One patient with a grade II toxicity reaction and a CR, had severe atherosclerotic disease of the perfused extremity with wound healing problems that necessitated amputation of the limb 10 months after the repeat ILP. There was no neuropathy due to repeat ILP. One patient developed limb malfunction with muscle atrophy and fibrosis after radiation therapy for further limb recurrences. The mean hospital stay was 23 days (range 9-65 days), which was not significantly longer than after the first procedure (20 days, $\mathrm{P}=0.26$ ).

\section{Management of recurrences or persistent disease after repeat ILP}

Management after repeat ILP and (locoregional) disease status at the end of follow-up is shown in Table 3 . The 17 patients with locoregionally recurrent or persistent disease after repeat ILP were treated with excision(s) $(n=10)$, radiation therapy $(n=3)$, repeat ILP $(n=7)$, systemic chemotherapy and/or immunotherapy $(n=5)$ and in one patient no treatment was instituted due to progressive distant metastasic disease. 
Table 3. Response and management of persistent disease and recurrences after repeat ILP

\begin{tabular}{|c|c|c|c|c|c|c|}
\hline $\mathrm{Nr}$ & $\begin{array}{l}\text { Respons } \\
\text { first ILP }\end{array}$ & $\begin{array}{l}\text { Response } \\
\text { repeat } \\
\text { ILP }\end{array}$ & $\begin{array}{l}\text { Limb } \\
\text { recurrence } \\
\text { after } \\
\text { CR (mos) }\end{array}$ & $\begin{array}{l}\text { Treatment limb } \\
\text { recurrence/ } \\
\text { persistent dis. }\end{array}$ & $\begin{array}{l}\text { Survival } \\
\text { (fup, mos) }\end{array}$ & $\begin{array}{l}\text { Loco- } \\
\text { regional } \\
\text { disease } \\
\text { status }\end{array}$ \\
\hline 1 & NE & $\mathrm{CR}$ & Yes (13) & Excision & Dead (62) & ED \\
\hline 2 & CR & CR & No (49) & & Alive (50) & NED \\
\hline 3 & CR & $\mathrm{CR}$ & Yes (9) & Excision, ILP & Alive (115) & NED \\
\hline 4 & $\mathrm{CR}$ & PD & & $\begin{array}{l}\text { Excision, } \\
\mathrm{CO}_{2} \text { laser, ILP }\end{array}$ & Dead (64) & ED \\
\hline 5 & NE & $\mathrm{CR}$ & Yes (4) & Excision, ILP & Dead (16) & NED \\
\hline 6 & NE & $\mathrm{CR}$ & No (99) & & Alive (103) & NED \\
\hline 7 & PR & $\mathrm{CR}$ & Yes (7) & Excision & Alive (108) & NED \\
\hline 8 & CR & $\mathrm{CR}$ & Yes (6) & Excision, ILP & Dead (47) & ED \\
\hline 9 & $\mathrm{CR}$ & PR & Excision, ILP & Dead (39) & ED & \\
\hline 10 & NE & $\mathrm{NC}$ & RT, systemic & Dead (65) & ED & \\
\hline 11 & $\mathrm{CR}$ & $\mathrm{CR}$ & Yes (9) & Systemic, ILP & Dead (69) & ED \\
\hline 12 & $\mathrm{CR}$ & $\mathrm{CR}$ & Yes (16) & Excision, ILP & Alive (115) & ED \\
\hline 13 & $\mathrm{CR}$ & $\mathrm{CR}$ & Yes (19) & Excision & Alive (23) & NED \\
\hline 14 & $\mathrm{CR}$ & $\mathrm{CR}$ & No (23) & Amputation & Dead (23) & NED \\
\hline 15 & PR & PR & RT, systemic & Dead (15) & ED & \\
\hline 16 & $\mathrm{CR}$ & PD & None* & Dead (13) & ED & \\
\hline 17 & $\mathrm{CR}$ & $\mathrm{CR}$ & No (46) & & Dead (51) & NED \\
\hline 18 & NC & PD & Systemic & Dead (6) & ED & \\
\hline 19 & $\mathrm{NC}$ & $\mathrm{CR}$ & Yes (7) & Excision & Dead (15) & ED \\
\hline 20 & NC & PD & RT & Dead (2) & ED & \\
\hline 21 & PD & PD & Systemic & Dead (6) & ED & \\
\hline
\end{tabular}

Persistent dis. $=$ persistent disease, $\mathrm{NE}=$ not evaluable, $\mathrm{CR}=$ complete remission, $\mathrm{PR}=$ partial remission, $\mathrm{NC}=$ no change, $\mathrm{PD}=$ progressive disease, mos $=$ months, $\mathrm{RT}=$ radiotherapy, $\mathrm{ED}=$ evidence of disease, $\mathrm{NED}=$ no evidence of disease, fup $=$ follow-up.

* Due to progressive distant metastases

Seven patients underwent a third ILP at a median of 19 months after the second ILP-procedure (IQ range 8-55 months). Tumour response after the third ILP was complete in four patients $(57 \%)$, partial in one $(9 \%)$ and two patients $(14 \%)$ had progressive disease despite the third ILP. Three patients with CR recurred in the perfused area after five, 13 and 19 months of the third ILP. Acute regional toxicity was mild with a grade II reaction in five patients and a grade III reaction in two patients. One patient had wound healing problems after additional radiotherapy and excisions of progressive lesions after ILP and general muscle atrophy and fibrosis of the treated extremity. Another patient underwent a fourth ILP for 
recurrent disease, 42 months after the third ILP, which again resulted in a CR with a duration of three months.

The limb salvage rate for all 21 patients was $95 \%$. Seven patients $(33 \%)$ were rendered locoregionally disease-free until the end of their follow-up with a median duration of 51 months (IQ range 23-103 months). Five of these patients were disease-free after the repeat ILP and two patients after a third procedure, with additional excisions in four patients.

\section{Survival}

Overall five-year survival after repeat ILP was 46\% (95\% CI 24-68\%) with a median survival of 51 months (95\% CI 19-83 months). Median overall survival for patients with CR was 62 months (95\% CI 36-89 months). All patients who had persistent disease after the repeat ILP died after a median of 13 months (95\% CI 0.4-26 months, $\mathrm{P}=0.006$ ). Survival curves are provided in Figure 2.

\section{Discussion}

After successful treatment of locoregionally recurrent limb melanoma with ILP using melphalan, further recurrences develop in $46-54 \%$ of the patients. ${ }^{2,3}$ Persistent disease after unsuccessful ILP with melphalan is present in approximately $46 \%$ of the perfused patients. ${ }^{1}$ Treatment options for recurring or persistent disease after ILP vary depending on the extent of the disease. Further local excisions

Figure 2. Overall survival after repeat ILP for all patients, and separately for those with CR and no CR by repeat ILP

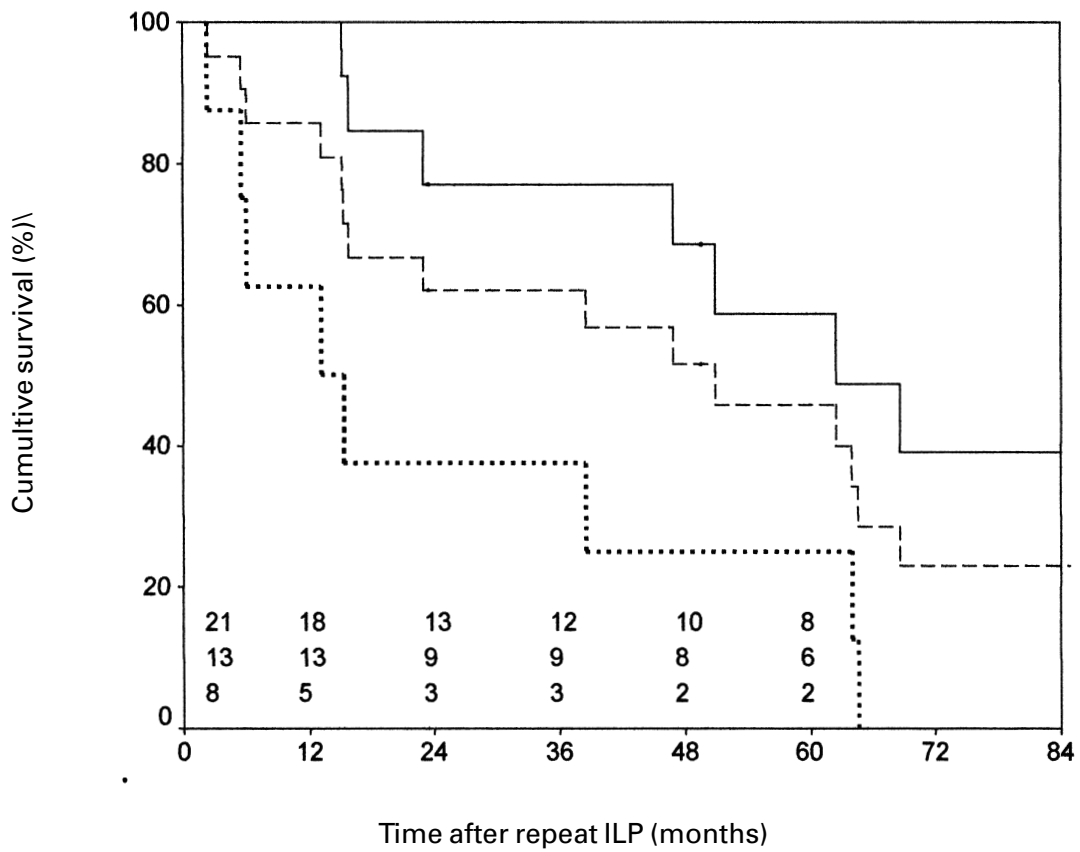


of recurring lesions, when not too extensive, can provide local control in a substantial number of patients. If cutaneous or superficial subcutaneous lesions are smaller than $2 \mathrm{~cm}, \mathrm{CO}_{2}$ laser ablation is also a valuable treatment option. ${ }^{16,17}$ Radiotherapy with or without hyperthermia is an option if the number of lesions is less than seven and they are smaller than $4 \mathrm{~cm}$ but difficult to resect, ${ }^{18} \mathrm{Howev-}$ er, if large or numerous (sub)cutaneous lesions are involved, ILP seems the only alternative to avoid amputation. In the present series, repeat ILP was performed in $71 \%$ of the cases for high tumour load lesions, according to recently defined criteria, ${ }^{15,19}$ and one patient had unresectable lesions because of their location on the sole of the foot. Although most of the patients in this study had deep subcutaneous in-transit metastases, $\mathrm{CO}_{2}$ laser ablation could have been possible in a few patients, while radiation therapy could have been given in some others. However, the advantage of ILP compared to these local treatments is that the whole area at risk of recurrence is treated, with the possibility of eradicating microscopic disease that may be present in the affected limb. The longer disease-free interval after ILP compared to excision alone for locoregionally recurrent melanoma, as observed in several studies, ${ }^{7,20,21}$ seems to be the result of this additional locoregional tumour-cell-killing effect.

In the present study, the CR rate of repeat ILP with TNF $\alpha$ was $62 \%$ which seems comparable to the $74 \% \mathrm{CR}$ rate reported from our previous repeat ILP series and in the lower range of the $58-90 \%$ CR rate that has generally been reported after TNF $\alpha$-ILP. ${ }^{4,14,22-25}$ Compared to melphalan alone ILP, with its 54\% CR rate, our $62 \%$ is good in view of the extent of the disease in the present series, which is probably the result of the addition TNF $\alpha$. Our limb recurrence rate after $\mathrm{CR}$ of $69 \%$ is high compared to the limb recurrence rate of $38-58 \%$ after TNF $\alpha$ ILP in other series. ${ }^{14,22-24}$ This is probably due to the longer duration of follow-up of the present series and reflects the strong tendency for the disease to recur in our specific group of patients. In a retrospective analysis performed by Feldman et al., ${ }^{7}$ the management of limb recurrences after ILP was described in 28 patients. Repeat ILP was performed in six patients, resulting in five CRs with recurrences occurring in three of them. Bartlett et al. showed a $50 \% \mathrm{CR}$ rate after repeat TNF $\alpha$-ILP in a series of ten patients with persistent disease after the initial ILP with melphalan alone. ${ }^{6}$

The median duration of CR of 13 months in the present study is comparable to the 12-17 months reported after initial ILP with TNF $\alpha .^{7,14,15,20}$ In our patient population with a high tendency for locoregionally recurrent melanoma and failure after earlier ILP, a third of the patients were rendered locoregionally diseasefree by repeat ILP(s), with or without additional excisional surgery, for a median period of more than four years. All patients who were locoregionally disease-free at the end of follow-up, had attained a complete response on the repeat ILP, a result that is generally not attained with excision alone in these patients groups. In 14 patients, Feldman et al found only two patients who remained locoregionally disease-free until the end of follow-up with excisional surgery alone. ${ }^{7}$ Hill et al. described that local control could be obtained in $56 \%$ of 32 patients with extensive in-transit metastases after multiple sessions of $\mathrm{CO}_{2}$ laser ablation within a period of up to two and a half years.

Repeat ILP can be effective despite a failure of a previous ILP, because it may 
Table 5. Factors that are significantly related to the mental or physical component score (multivariable logistic regression analysis)

\begin{tabular}{|c|c|c|c|c|c|}
\hline \multicolumn{3}{|l|}{ Physical ( $\left.R^{2}=38 \%\right)$} & \multicolumn{3}{|l|}{ Mental $\left(R^{2}=24 \%\right)$} \\
\hline Factor & B & P-value & Factor & B & P-value \\
\hline $\begin{array}{l}\text { Stiffness of the } \\
\text { perfused extremity }\end{array}$ & -6.4 & 0.000 & $\begin{array}{l}\text { Stiffness of the } \\
\text { perfused extremity }\end{array}$ & -5.8 & 0.000 \\
\hline \multirow[t]{3}{*}{ Lesions on lower leg } & 5.8 & 0.02 & $\begin{array}{l}\text { Necessity for } \\
\text { supportive stockings }\end{array}$ & -0.007 & 0.004 \\
\hline & & & $\begin{array}{l}\text { Age at the time } \\
\text { of analysis }\end{array}$ & -2.9 & 0.007 \\
\hline & & & Fear of recurrences & -2.1 & 0.045 \\
\hline
\end{tabular}

be that recurrent disease after ILP consists of grown lesions that were not yet vascularised at the time of the first procedure, which have to become sensitive to therapeutic agents at the time of the repeat procedure. ${ }^{2,6}$ It remains unclear whether TNF $\alpha$ needs to be added to melphalan in the repeat setting. No results are available on response after single repeat ILP with melphalan alone, under normothermic conditions. In our previous report on repeat ILP, merely double, triple and hyperthermic ILP-schedules were applied, which have been abandoned after the introduction of TNF $\alpha$ in ILP. ${ }^{4}$ A better response of high tumour burden disease on ILP with TNF $\alpha$ compared to ILP with melphalan alone has been suggested in several reports. ${ }^{14,15}$ Bulky, well vascularised lesions have been suggested to be particularly susceptible to TNF $\alpha .{ }^{26}$ Since it is likely that recurring or persistent lesions after previous ILP are more extensive, TNF $\alpha$ could be especially useful in these repeat procedures.

Acute regional toxicity after repeat ILP was not higher than after the first ILP. This is a confirmation of what others have found, ${ }^{7}$ although more severe toxicity has been encountered in our previous report on repeat ILPs with melphalan using various schedules. Probably these schedules are responsible for the increased toxicity.

Our $46 \%$ five-year survival rate is considerable, however it should be interpreted cautiously because of the relatively small group of patients. Generally, five-year survival for patients with in-transit metastases with or without regional lymph node metastases ranges between 27 and $46 \% .{ }^{27}$ In a large series of patients who underwent a first ILP for these stages of disease, Krementz et al. reported five-year survival rates of 23 to $36 \%$, depending on the presence of lymph node metastases. ${ }^{28}$ Lejeune et al. presented the interesting finding that among 206 patients treated with ILP for locoregionally recurring melanoma, distant metastases occurred in only $24 \%$ of them as the first site of recurrence..$^{29}$ This confirms our impression that there is probably a subgroup of patients with a rather good prognosis, whose recurrences remain limited to the locoregional area and do not spread to distant sites for a long period of time. Nevertheless, all our patients with residual disease after ILP died and the favourable prognosis applies only to patients who attain a CR to ILP, which has also been found by others. ${ }^{30}$ 
Concluding, repeat ILP with TNF $\alpha$ is feasible in patients with recurrent disease after previous ILP. It seems indicated for patients not suitable for other, less invasive, treatment options due to the extent of the disease after failure of a previous ILP. In these patients, a relatively high complete response rate can be attained that is comparable to that of the first procedure. The high recurrence rate is probably a reflection of the nature of the disease in these patients. The limb recurrence-free interval seems longer than what is generally observed by other local treatment modalities, an important benefit since some of these patients have a rather good prognosis in terms of survival. A third of these patients are without locoregional evidence of disease after long-term follow-up.

\section{References}

1. Creech DG, Krementz ET, Ryan RF, Winblad JN. Chemotherapy of cancer: regional perfusion utilising an extracorporeal circuit. Ann Surg 1958; 148:616-632.

2. Thompson JF, Hunt JA, Shannon KF, Kam PC. Frequency and duration of remission after isolated limb perfusion for melanoma. Arch Surg 1997; 132:903-907.

3. Klaase JM, Kroon BBR, van Geel AN, Eggermont AMM, Franklin HR, Hart AAM. Prognostic factors for tumor response and limb recurrence-free interval in patients with advanced melanoma of the limbs treated with regional isolated perfusion with melphalan. Surgery 1994; 115:39-45.

4. Klop WM, Vrouenraets BC, van Geel BN, Eggermont AMM, Klaase JM, Nieweg OE, Kroon BBR. Repeat isolated limb perfusion with melphalan for recurrent melanoma of the limbs. J Am Coll Surg 1996; 182:467-472.

5. Liénard D, Ewalenko P, Delmotte JJ, Renard N, Lejeune FJ. High-dose recombinant tumor necrosis factor alpha in combination with interferon gamma and melphalan in isolation perfusion of the limbs for melanoma and sarcoma. J Clin Oncol 1992; 10:5260 .

6. Bartlett DL, Ma G, Alexander HR, Libutti SK, Fraker DL. Isolated limb reperfusion with tumor necrosis factor and melphalan in patients with extremity melanoma after failure of isolated limb perfusion with chemotherapeutics. Cancer 1997; 80:20842090.

7. Feldman AL, Alexander HR, Jr., Bartlett DL, Fraker DL, Libutti SK. Management of extremity recurrences after complete responses to isolated limb perfusion in patients with melanoma. Ann Surg Oncol 1999; 6:562-567.

8. Klaase JM, Kroon BBR, van Geel AN, van Wijk J, Franklin HR, Eggermont AMM, Hart AAM. Limb recurrence-free interval and survival in patients with recurrent melanoma of the extremities treated with normothermic isolated perfusion. $\mathrm{J} \mathrm{Am} \mathrm{Coll}$ Surg 1994; 178:564-572.

9. Kroon BBR. Regional isolation perfusion in melanoma of the limbs; accomplishments, unsolved problems, future. Eur J Surg Oncol 1988; 14:101-110.

10. Kroon BBR, Klaase J, van de Merwe SA, van Dongen J, van der Zee J. Results of a double perfusion schedule using high-dose hyperthermia and melphalan sequentially for recurrent melanoma of the limbs: a pilot study. Regional Cancer Treatment 1992;305-308. 
11. Wieberdink J, Benckhuijsen C, Braat RP, van Slooten EA, Olthuis GA. Dosimetry in isolation perfusion of the limbs by assessment of perfused tissue volume and grading of toxic tissue reactions. Eur J Cancer Clin Oncol 1982; 18:905-910.

12. WHO handbook for reporting results of cancer treatment. Geneva: WHO; 1979.

13. Schraffordt Koops H, Vaglini M, Suciu S, Kroon BB, Thompson JF, Gohl J, Eggermont AM, Di Filippo F, Krementz ET, Ruiter D, Lejeune FJ. Prophylactic isolated limb perfusion for localized, high-risk limb melanoma: results of a multicenter randomized phase III trial. J Clin Oncol 1998; 16:2906-2912.

14. Fraker D, Alexander H, Ross M, Bartlett D, Tyler D, Libutti LS, Boddie A, Briele H, Karakousis G. A phase III trial of isolated limb perfusion for extremity melanoma comparing melphalan alone versus melphalan plus tumor necrosis factor (TNF) plus interferon gamma. Ann Surg Oncol 2002;S8.

15. Rossi CR, Foletto M, Pilati P, Mocellin S, Lise M. Isolated limb perfusion in locally advanced cutaneous melanoma. Semin Oncol 2002; 29:400-409.

16. Hill S, Thomas JM. Use of the carbon dioxide laser to manage cutaneous metastases from malignant melanoma. Br J Surg 1996; 83:509-512.

17. Strobbe LJ, Nieweg OE, Kroon BBR. Carbon dioxide laser for cutaneous melanoma metastases: indications and limitations. Eur J Surg Oncol 1997; 23:435-438.

18. Overgaard J, Gonzalez GD, Hulshof MC, Arcangeli G, Dahl O, Mella O, Bentzen SM. Randomised trial of hyperthermia as adjuvant to radiotherapy for recurrent or metastatic malignant melanoma. European Society for Hyperthermic Oncology. Lancet 1995; 345:540-543.

19. Fraker DL, Alexander HR, Andrich M, Rosenberg SA. Treatment of patients with melanoma of the extremity using hyperthermic isolated limb perfusion with melphalan, tumor necrosis factor, and interferon gamma: results of a tumor necrosis factor dose-escalation study. J Clin Oncol 1996; 14:479-489.

20. Hafstrom L, Rudenstam CM, Blomquist E, Ingvar C, Jonsson PE, Lagerlof B, Lindholm C, Ringborg U, Westman G, Ostrup L. Regional hyperthermic perfusion with melphalan after surgery for recurrent malignant melanoma of the extremities. Swedish Melanoma Study Group. J Clin Oncol 1991; 9:2091-2094.

21. Takkenberg RB, Noorda EM, Vrouenraets BC, Nieweg OE, van Geel AN, Eggermont AMM, Hart AAM, Kroon BBR. Does isolated limb perfusion prolong the limb recurrence-free interval after several episodes of excisional surgery for limb recurrences of melanoma? Ann Surg Oncol 2003; 10:S18.

22. Eggermont AMM. Treatment of melanoma in-transit metastases confined to the limb. Cancer Surv 1996; 26:335-349.

23. Liénard D, Eggermont AMM, Schraffordt Koops H, Kroon BBR, Rosenkaimer F, Autier P, Lejeune FJ. Isolated perfusion of the limb with high-dose tumour necrosis factor-alpha (TNF-alpha), interferon-gamma (IFN-gamma) and melphalan for melanoma stage III. Results of a multi-centre pilot study. Melanoma Res 1994; 4 Suppl 1:21-26.

24. Vaglini M, Santinami M, Manzi R, Inglese MG, Santoro N, Persiani L, Belli F. Treatment of in-transit metastases from cutaneous melanoma by isolation perfusion with tumour necrosis factor-alpha (TNF-alpha), melphalan and interferon-gamma (IFNgamma). Dose-finding experience at the National Cancer Institute of Milan. Melanoma Res 1994; 4 Suppl 1:35-38.

25. Liénard D, Eggermont AMM, Schraffordt Koops H, Kroon B.B.R., Towse G, Hiem- 
stra S, Schmitz P, Clarke J, Steinmann G, Rosenkaimer F, Lejeune FJ. Isolated limb perfusion with tumour necrosis factor-alpha and melphalan with or without interferongamma for the treatment of in-transit melanoma metastases: a multicentre randomized phase II study. Melanoma Res 1999; 9:491-502.

26. Lejeune FJ. High dose recombinant tumour necrosis factor (rTNF alpha) administered by isolation perfusion for advanced tumours of the limbs: a model for biochemotherapy of cancer. Eur J Cancer 1995; 31A:1009-1016.

27. Balch CM, Buzaid AC, Soong S-J, Atkins MB, Cascinelli N, Coit DG, Fleming ID, Gershenwald JE, Houghton A, Jr., Kirkwood JM, McMasters KM, Mihm MF, Morton DL, Reintgen DS, Ross MI, Sober A, Thompson JA, Thompson JF. Final version of the American Joint Committee on Cancer staging system for cutaneous melanoma. $J$ Clin Oncol 2001; 19:3635-3648.

28. Krementz ET, Muchmore JH, Carter RD, Sutherland CM. Multiple perfusions for melanoma. Melanoma Res 1994; 4 Suppl 1:39-44.

29. Lejeune FJ, Lienard D, el Douaihy M, Seyedi JV, Ewalenko P. Results of 206 isolated limb perfusions for malignant melanoma. Eur J Surg Oncol 1989; 15:510-519.

30. Zogakis TG, Bartlett DL, Libutti SK, Liewehr DJ, Steinberg SM, Fraker DL, Alexander HR. Factors affecting survival after complete response to isolated limb perfusion in patients with in-transit melanoma. Ann Surg Oncol 2001; 8:771-778.

31. Vaglini M, Ammatuna M, Belli F, Mascheroni L, Perego G, Santinami M, Santoro N. Evaluation of a second isolated perfusion for melanoma of the limbs. Melanoma Res. 3, 100. 1993.

32. Noorda EM, Vrouenraets BC, Nieweg OE, van Coevorden F, van Slooten GW, Kroon B.B.R. Isolated limb perfusion with TNF-alpha and melphalan for unresectable soft tissue sarcoma of the extremities. Cancer 2003;in press. 


\title{
Chapter 7
}

\section{Prognostic factors for poor survival after isolated limb perfusion: criteria for patient selection?}

\author{
Noorda EM, Vrouenraets BC, Nieweg OE, van Geel $A N^{*}$, \\ Eggermont AMM*, Kroon BBR \\ Department of Surgery, The Netherlands Cancer Institute / Antoni van Leeuwenhoek hospital, \\ Amsterdam, the Netherlands * Department of Surgery, Erasmus Medical Center-Daniel den Hoed \\ Cancer Center, Groene Hilledijk 301, 3075 EA Rotterdam, the Netherlands
}

Revised version in European Journal of Surgical Oncology 2003, in press

\section{Introduction}

Isolated limb perfusion (ILP) is generally applied for locally unresectable in-transit melanoma or soft tissue sarcoma of the extremities. ${ }^{1,2}$ In melanoma, ILP with melphalan results in a complete response in 54\% of patients that is reached after a median interval of approximately seven months after ILP., ${ }^{1,3}$ The five-year survival rate with in-transit melanoma varies between $23 \%$ and $47 \%$ mainly depending on regional lymph node status. ${ }^{4,5}$ Since ILP is an extensive procedure with possible severe complications and morbidity, it should be offered only to patients with a life expectancy long enough to experience its benefits.

Previous studies have focused on prognostic factors for survival after ILP for loco-regional metastatic melanoma. Gender, the number of previous relapses, the number of lesions forming the indication for ILP, the size of the indicator lesions and prior systemic therapy were found to be of prognostic value for survival. ${ }^{6,7}$ In an earlier study, we also found age, Breslow thickness and Clark level of invasion of the primary to be prognostic. ${ }^{8}$ In these studies a survival analysis was performed, but no specific attention was paid to those who die relatively shortly after ILP. Factors determining survival in general might differ from those that determine the risk of dying within one year from ILP. This analysis aims to identify a group of patients that is at risk of death within one year after ILP in order to recommend ILP only to patients who are expected to live long enough to experience its benefits.

\section{Patients and methods}

From 1978 to 2001, 505 ILPs were performed for mostly recurrent melanoma of the extremities in a total of 447 patients in our two institutions. A computer database containing all patient, tumour and treatment data allowed the selection of 443 patients in whom analysis took place at least one year after ILP. Four of these patients had been lost to follow-up after return to their home countries, leaving 
Table 1. MD Anderson classification (adapted for stage II) ${ }^{8}$

MD Anderson stage of disease

\begin{tabular}{ll}
\hline I & Primary melanoma \\
IIA* & Local recurrence \\
IIB & Satellite $\leq 3 \mathrm{~cm}$ from primary, scar or skin graft \\
IIIA & Satellite/in-transit $>3 \mathrm{~cm}$ from primary, scar or skin graft \\
IIIB & Regional node metastasis \\
IIIAB & Satellite/in-transit with regional node metastasis \\
IV & Distant metastasis \\
\hline
\end{tabular}

* Stage II was divided in stage IIA (local recurrence) and stage IIB (satellitosis within $3 \mathrm{~cm}$ of primary, scar or skin graft).

439 patients who underwent 492 ILPs for analysis. For patients with multiple ILPs, the data concerning the first ILP were included.

Stage of disease was classified according to the MD Anderson classification, adapted for stage II according to Klaase et al. in which stage II was divided in IIA (local recurrence) and IIB (satellites within $3 \mathrm{~cm}$ from the primary tumor/skin graft) (Table 1). ${ }^{8}$ Four patients had locally unresectable stage I disease (1\%), 34 stage IIA (8\%), 63 stage IIB (14\%), 176 stage IIIA (40\%), 44 stage IIIB (10\%), 111 patients stage IIIAB $(25 \%)$ and seven patients $(2 \%)$ had stage IV disease with (a combination of) pulmonary $(n=4)$, brain $(n=4)$ or extensive distant cutaneous metastases $(n=1)$. The indication for ILP in those patients with stage IIIB disease was an unresectable primary $(n=3)$, a local recurrence $(n=24)$ or adjuvant to the excision of primary melanoma lesions, which had been mostly performed in the framework of an ongoing trial between 1984 and $1994(n=17)$. Although in the latter patients, initially no clinical suspicion of lymph node metastases was present, regional metastases were found in the routine lymph node dissection specimen at iliac ILP. In these patients an additional inguinal lymph node dissection was performed at six weeks after the ILP. Lymph node metastases were classified as regional if located in the inguinal/iliac region for lower extremity disease or in the axilla for melanoma of the upper extremity. Patients with stage IV disease were treated with palliative intent for extensive symptomatic loco-regional disease. Depending on the treatment period and extent of loco-regional disease, patients underwent different ILP schedules: in 246 patients (56\%) ILP was performed with melphalan alone under normothermic $\left(37-38^{\circ} \mathrm{C}\right)$ conditions (1978$2001)$, in 58 patients (18\%) triple or double normothermic ILP schedules with melphalan alone (1985-1990) were applied, in eight patients (2\%) ILP took place with melphalan under borderline hyperthermic $\left(40-41^{\circ} \mathrm{C}\right)$ conditions (1988$1990)$ and in five patients $(1 \%)$ hyperthermia $\left(40-41^{\circ} \mathrm{C}\right)$ was added during the last 30 minutes of drug circulation (1988-1990). Another seventeen patients (4\%) underwent an ILP with only high-dose hyperthermia $\left(42-43^{\circ} \mathrm{C}\right)$ followed one week later by a procedure with melphalan under normothermia (1989-1994) and finally in 105 patients (24\%) ILP was performed with TNFo and melphalan 
under mild hyperthermic $\left(38-40^{\circ} \mathrm{C}\right)$ conditions $(1992-2001)$. The number of lesions forming the indication for ILP ranged from one to over 100 lesions, with a median number of two (25-75\% range 1-6). The size of the largest lesions varied from $0.01 \mathrm{~cm}^{2}$ to $150 \mathrm{~cm}^{2}$ with a median size of $1.0 \mathrm{~cm}^{2}(25-75 \%$ range $0.25-$ $\left.4.6 \mathrm{~cm}^{2}\right)$. In 174 cases $(39 \%)$ the lesions were completely excised before or at ILP. The lesions were unresectable in 139 cases (32\%) and in 126 cases (29\%) they were resectable but not (completely) removed to monitor the ILP effect.

During ILP, the major artery and vein are clamped at the desired level, collateral vessels are ligated and a tourniquet is applied around the extremity, proximal to the region of ILP. After insertion of the catheters, the isolated extremity is perfused by an extra-corporeal circulation, oxygenated and propelled by a heart-lung machine. In single ILPs, a melphalan dose of $13 \mathrm{mg} / \mathrm{l}$-perfused tissue in the upper extremity and $10 \mathrm{mg} / \mathrm{l}$ for the lower extremity is added to the perfusate. For $\mathrm{TNF} \alpha$ this is $3 \mathrm{mg}$ and $4 \mathrm{mg}$ respectively, unrespective of extremity volume. In the double or triple ILP schedules a reduced melphalan dosage was used. ${ }^{9}$ ILP with melphalan lasts one hour and when TNFo is used 90 minutes. In the sequential schedule, a two-hour ILP with high-dose hyperthermia only was performed. One week later the normothermic, one-hour ILP with melfalan took place. ${ }^{10} \mathrm{Gen}$ erally, the intended tissue temperatures are achieved and maintained by heating the heparinised perfusate and application of a warm blanket around the extremity. At termination of the ILP, the perfusate is drained out and the extremity is rinsed with an electrolyte solution. The tourniquet is then released and catheters are removed.

Depending on the site of loco-regional disease, ILP is performed at the brachial, axillary, femoral or iliac level. Acute regional toxicity after ILP is graded according to Wieberdink et al. ${ }^{11}$ Postoperatively, patients stay in bed with the leg elevated until acute toxic extremity reactions subside. Systemic toxicity and tumour response are measured by WHO criteria. ${ }^{12}$ Median follow-up was 3.2 years after ILP (25-75\% interval 1.4-7.9 years). Analysis took place at a mean of 10.3 years after ILP (range 1-23.6 years).

A multivariable logistic regression analysis was performed to identify prognostic variables quantifying the risk of death within one year after ILP. It might have been more interesting to assess these factors for mortality within six months of ILP, but this group of patients was too small $(n=25)$. That is why we chose to determine factors for death within one year. No patients were lost to follow-up within one year. The following independent variables were tested: gender, age, Breslow thickness of primary, ulceration at histology of primary, interval between primary tumour and ILP, number of previous recurrences, number of lesions forming the indication for ILP, size of the largest indicator lesion, stage of disease and type of ILP. The number of missing data was reduced as much as possible, but the retrospective nature of this study left some information inevitably missing. Breslow thickness was recorded in 354 cases $(81 \%)$, ulceration in $326(74 \%)$, size of the largest indicator lesion in $339(77 \%)$ and the number of indicator lesions was recorded in 427 cases (97\%). Primary tumour characteristics such as Breslow thickness and ulceration were not further retrievable due to either unknown primary lesions, inadequately excised primaries that allowed no accurate assessment of Breslow thickness and/or ulceration and tissue samples from patients in the 
early phase of this series that were no longer available for revision. For all other variables, data were complete. To include all cases at every step of the regression analysis, missing values were corrected by including an indicator variable and a variable in which missing values where replaced by the median of the available values. A P-value $<0.05$ was considered significant.

\section{Results}

\section{Overall survival}

In Figure 1, overall survival of the study population per stage of disease is displayed. Median overall survival was 46 months (95\% confidence interval (CI) 38-54 months). Overall five-year survival was $42 \%$ (95\% CI 37-46\%). Within the first twelve months following ILP, 69 patients (16\%) died, 25 (36\%) of them within six months. Sixty-four patients died of distant metastatic melanoma. There was one procedure-related death which concerned a woman who died six months after ILP from septic complications of a concurrent incarcerated hernia of the ileocoecal junction in the iliac fossa with severe bleeding from a lacerated artery. After bowel resection and multiple transfusions, an enterocutaneous fistula developed. Subsequently, she went through acute respiratory distress syndrome and hepatic failure and died six months after ILP. One other patient suddenly died two days after ILP from acute myocardial infarction, with no previous cardiovascular history. Three patients died due to intracranial haemorrhage without evidence of melanoma.

\section{Figure 1. Overall survival for patients in each stage of disease}

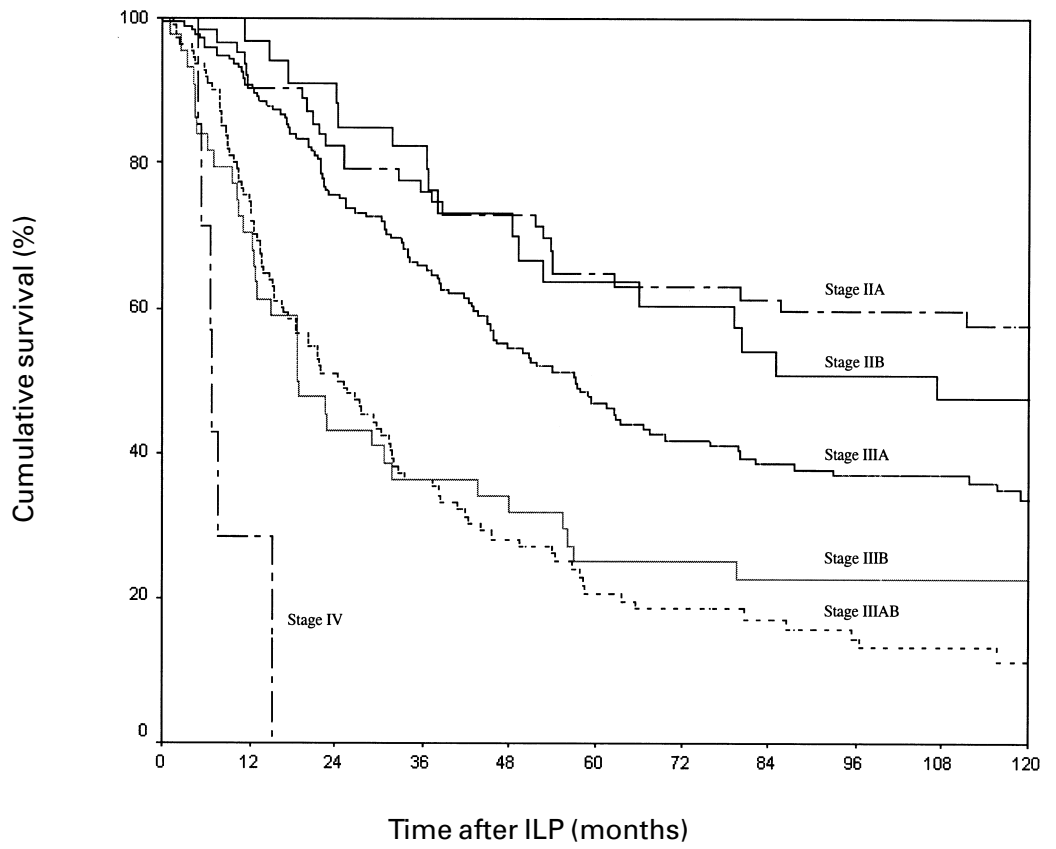


Table 2. Univariate analysis of prognostic factors for poor survival after ILP

\begin{tabular}{|c|c|c|c|}
\hline & Dead < one year & Alive $>$ one year & P-value \\
\hline Gender M/F & $18(26 \%) / 51(74 \%)$ & $77(21 \%) / 293(79 \%)$ & 0.21 \\
\hline Age (years) & 61 (range 19-83) & 59 (range 17-90) & 0.35 \\
\hline Breslow thickness (mm) & $3.5(\mathrm{IQ}$ range * $2.0-4.3)$ & 2.7 (IO range $1.7-4.1)$ & 0.16 \\
\hline Ulceration present & $25(49 \%)$ & $117(43 \%)$ & 0.42 \\
\hline Nr. of previous recurrences & 0.7 (range $0-10$ ) & 0.7 (range $0-10$ ) & 0.88 \\
\hline Interval primary-ILP (mos.) & 19 (IO range $5-50)$ & 22 (IQ range 7-54) & 0.57 \\
\hline Nr. lesions & 3 (IQ range $1-14)$ & 2 (IO range $1-6)$ & 0.02 \\
\hline Size largest lesion & $4.0(\mathrm{IQ}$ range $0.7-10.1)$ & 1.0 (IQ range $0.25-4.0)$ & 0.000 \\
\hline Stage of disease & & & 0.000 \\
\hline 1 & 0 & $4(1.1 \%)$ & \\
\hline II A & $1(1.4 \%)$ & $33(8.9 \%)$ & \\
\hline II B & $6(8.7 \%)$ & $57(15.4 \%)$ & \\
\hline III A & $16(23.2 \%)$ & $160(43.2 \%)$ & \\
\hline $\mathrm{III} \mathrm{B}^{\dagger}$ & $13(18.8 \%)$ & $31(8.4 \%)$ & \\
\hline III $A B$ & $28(40.6 \%)$ & $83(22.4 \%)$ & \\
\hline IV & $5(7.2 \%)$ & $2(0.5 \%)$ & \\
\hline Type of ILP & & & 0.46 \\
\hline Melphalan & $33(47.8 \%)$ & $213(57.6 \%)$ & \\
\hline Double/triple & $8(11.6 \%)$ & $50(13.5 \%)$ & \\
\hline TNF $\alpha /$ melphalan & $22(31.9 \%)$ & $83(22.4 \%)$ & \\
\hline Hyperthermia/melphalan & $2(2.9 \%)$ & $11(3 \%)$ & \\
\hline Sequential & $4(5.8 \%)$ & $13(3.5 \%)$ & \\
\hline
\end{tabular}

* IQ range $=$ interquartile range i.e. between $25 \%$ and $75 \%$ of values

† The indication for ILP was an unresecTableprimary lesion in three patients, a local recurrence in 24 patients and adjuvant to local excision of primary melanoma lesions in 17 patients.

The overall complete response rate was 61\% (95\% CI 55-66\%) for patients with unexcised lesions. Complete response rates were significantly different for those who died within one year, with a complete response rate of $47 \%$ (95\% CI $33-61 \%)$ compared to $64 \%(95 \%$ CI $57-70 \%)$ in the surviving group $(\mathrm{p}=0.03)$.

\section{Prognostic factors}

In Table 2, a univariate analysis of prognostic factors for death within one year after ILP is shown. The number of lesions and the size of the largest lesion forming the indication for ILP were significantly greater in the group that survived less than one year after ILP. There was also a significantly different distribution of stage of disease between the two groups, with more patients with stage I to IIIA disease who were still alive one year after ILP and more stage IIIB, stage IIIAB and stage IV disease in the group with poor survival. Lymph node status still had a significant influence on survival in patients who attained a complete response after ILP with a one-year survival rate of $90 \%$ in these patients without 
Figure 2. Overall survival for patients with and without lymph node involvement

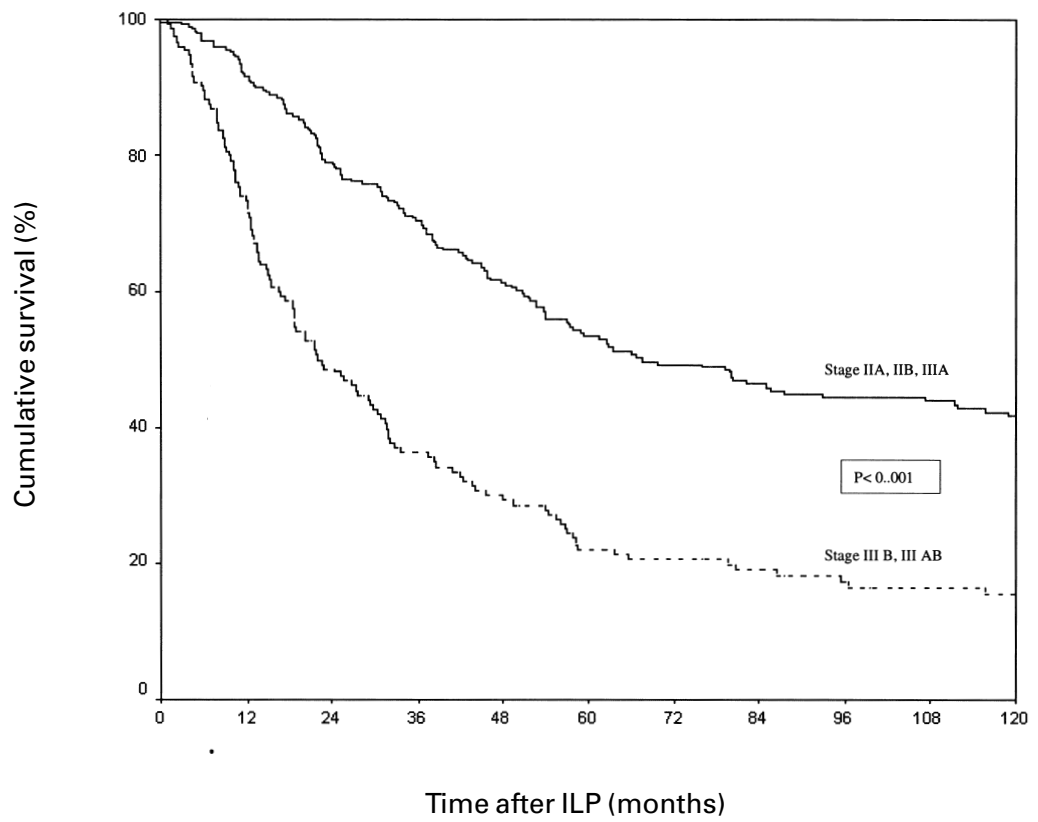

lymph node metastases $(\mathrm{n}=113)$ and $75 \%$ for patients with lymph node metastases $(n=48, p<0.001)$. The difference in survival for patients with and without lymph node involvement is displayed in Figure 2.

Results of the multivariable logistic regression analysis are presented in Table 3. It appeared that MD Anderson stage IIIAB, stage IIIB or stage IV were remaining independent risk factors for death within one year from ILP. The calculated odds ratio (OR) indicates the increase in risk of dying within one year after ILP if one of these factors is present compared to if the factor is absent.

\section{Toxicity and morbidity}

More severe acute regional toxicity with blistering occurred in 76 patients (17\%), four of whom had persistent nerve injury up until three months after ILP. Seven patients $(2 \%)$ had a compartmental compression syndrome following ILP, with persistent nerve injury in four patients up until three months after ILP. At three

Table 3. Results from a multivariable logistic regression analysis of risk factors for death within one year

\begin{tabular}{llll}
\hline Risk factor & OR & $\mathrm{Cl}(\%)$ & P-value \\
\hline Stage of disease IIIAB & 3.6 & $2.1-10$ & $<0.001$ \\
Stage of disease IIIB & 4.6 & $2.0-6.6$ & $<0.001$ \\
Stage of disease IV & 22 & $3.8-127$ & 0.001 \\
\hline
\end{tabular}


months after ILP, a total of eighteen patients had symptomatic nerve injury (4\%), which decreased to eleven patients $(3 \%)$ at one year after ILP. At that time, 45 patients $(10 \%)$ had complaints of fibrosis and/or ankylosis, mostly of the ankle.

\section{Discussion}

ILP is a sophisticated procedure which can offer local control in advanced melanoma of the extremities in a considerable number of patients. However, most patients with loco-regional metastases of melanoma eventually die of distant disease. Overall five-year survival for non-perfused patients with in-transit metastases confined to an extremity varies between 23 to $47 \%$, depending on the presence of regional lymph node metastases. ${ }^{5}$ In a recent study of perfused patients with regional metastatic disease a $43 \%$ five-year survival rate has been reported. ${ }^{7}$ Overall five-year survival in our study population, consisting mostly of patients with satellites, in-transit metastases with or without lymph node metastases is $42 \%$ and thus comparable to data from the literature.

Generally, patients with recurrent extremity melanoma have several treatment options, depending on tumour load. First, local surgical excision(s) of recurring lesions, when not too extensive, can provide local control in a substantial number of patients. If cutaneous or superficial subcutaneous lesions are smaller than $2 \mathrm{~cm}, \mathrm{CO}_{2}$ laser ablation is also a valuable treatment option. ${ }^{13,14}$ If lesions are fewer than seven and smaller than $4 \mathrm{~cm}$, but difficult to resect, radiation therapy with or without hyperthermia could be used..$^{15}$ However, if large or numerous (sub)cutaneous lesions are involved, ILP seems the only alternative to avoid amputation and obtain local disease control. Furthermore, an advantage of ILP over the other local treatment modalities is that possible microscopic metastatic disease present in affected extremity, may also be eradicated.

In our series, sixty-nine patients $(16 \%)$ died within one year after ILP. Presence of regional lymph node metastases and/or distant metastases at the time of ILP were identified as significant prognostic factors for this early death. Those with distant metastases at presentation are likely to have a poor survival, since these patients are reported to have an overall one-year survival rate of 41-59\%.4 Patients with nodal metastases, however, have a one-year survival rate ranging between 71-96\% depending on nodal tumour load and the presence of ulceration of the primary tumour. ${ }^{4}$ In this series also $74 \%$ of the patients with nodal metastases survived over one year after ILP. However, these patients appeared to have a higher risk of poor survival compared to those with in-transit metastases or satellites without lymph node involvement. Interestingly this observed difference in survival confirms the adjustment that the AJCC has made in the staging system of cutaneous malignant melanoma wherein patients with in-transit metastases without involvement of regional lymph nodes are separately staged from patients with in-transit metastases and lymph node metastases. ${ }^{4}$ In another recent study, consisting of patients who attained a complete response after ILP, regional node status, however, had no additional prognostic value. ${ }^{7}$ These contrasting results may be due to patient selection, because only patients with a complete response after ILP were enrolled in the latter study.

Approximately half of our patients with measurable disease who died within 
the year following ILP had not attained a complete response, but had the described risk of morbidity: a more severe toxicity reaction of the extremity occurred in 19\% of them and some degree of functional impairment at one year after ILP in $10 \%$. We are therefore of the opinion that ILP in these patients with poor prognosis should only be applied if lesions are truly unresectable with no other local treatment options. Since it has been shown that increased tumour burden is a negative prognostic factor for response after ILP, ${ }^{1,16}$ it can be expected that complete response rates in this patient group are lower than the average of $54 \%$ that can be obtained by ILP with melphalan. In this respect it is interesting that in a multicentre European study an increased complete response rate $(73 \%)$ as well as a reduction in median duration to complete response from 225 to 61 days was shown when TNF $\alpha$ was added to melphalan. ${ }^{3}$ Also, Fraker et al. comparing melphalan-ILP with the combination of melphalan and TNF $\alpha$ in a prospective randomised trial, found improved complete response rates from 58\% to $72 \%$ if TNF $\alpha$ was added. ${ }^{17}$ The complete response rate in patients with high tumour burden was increased from $19 \%$ to $58 \%$ by applying TNF $\alpha$. Therefore, when there is an indication for ILP in high tumour burden patients whose survival is expected to be short the addition of TNF $\alpha$ to melphalan should be considered.

Concluding, no patients could be identified whom ILP should be withheld due to an unacceptably high risk of poor survival. However, in patients with stage IV disease ILP should only be performed when strictly necessary for palliative reasons. In patients with regional lymph node involvement the procedure should be limited to those with truly unresectabele lesions, because of the approximately $25 \%$ one-year mortality rate. In the case of either regional lymph node involvement or distant metastases it might be more effective to apply TNF $\alpha$-ILP, since higher complete response rates and shorter times to complete response have been reported.

\section{References}

1. Vrouenraets BC, Nieweg OE, Kroon BBR. Thirty-five years of isolated limb perfusion for melanoma: indications and results. Br J Surg 1996; 83:1319-1328.

2. Eggermont AMM, Schraffordt Koops H, Liénard D, Kroon BBR, van Geel AN, Hoekstra HJ, Lejeune FJ. Isolated limb perfusion with high-dose tumor necrosis factoralpha in combination with interferon-gamma and melphalan for nonresectable extremity soft tissue sarcomas: a multicenter trial. J Clin Oncol 1996; 14:2653-2665.

3. Liénard D, Eggermont AMM, Schraffordt Koops H, Kroon B.B.R., Towse G, Hiemstra S, Schmitz P, Clarke J, Steinmann G, Rosenkaimer F, Lejeune FJ. Isolated limb perfusion with tumour necrosis factor-alpha and melphalan with or without interferongamma for the treatment of in-transit melanoma metastases: a multicentre randomized phase II study. Melanoma Res 1999; 9:491-502.

4. Balch CM, Buzaid AC, Soong S-J, Atkins MB, Cascinelli N, Coit DG, Fleming ID, Gershenwald JE, Houghton A, Jr., Kirkwood JM, McMasters KM, Mihm MF, Morton DL, Reintgen DS, Ross MI, Sober A, Thompson JA, Thompson JF. Final version of the American Joint Committee on Cancer staging system for cutaneous melanoma. $J$ Clin Oncol 2001; 19:3635-3648. 
5. Krementz ET, Sutherland CM, Muchmore JH. Isolated hyperthermia chemotherapy perfusion for limb melanoma. Surg Clin North Am 1996; 76:1313-1330.

6. Di Filippo F, Calabro A, Giannarelli D, Carlini S, Cavaliere F, Moscarelli F, Cavaliere R. Prognostic variables in recurrent limb melanoma treated with hyperthermic antiblastic perfusion. Cancer 1989; 63:2551-2561.

7. Zogakis TG, Bartlett DL, Libutti SK, Liewehr DJ, Steinberg SM, Fraker DL, Alexander HR. Factors affecting survival after complete response to isolated limb perfusion in patients with in-transit melanoma. Ann Surg Oncol 2001; 8:771-778.

8. Klaase JM, Kroon BBR, van Geel AN, van Wijk J, Franklin HR, Eggermont AMM, Hart AAM. Limb recurrence-free interval and survival in patients with recurrent melanoma of the extremities treated with normothermic isolated perfusion. $\mathrm{J} \mathrm{Am} \mathrm{Coll}$ Surg 1994; 178:564-572.

9. Kroon BBR, Klaase J, van Geel A, Eggermont AMM, Franklin H, van Dongen J. Results of a double perfusion schedule with melphalan in patients with melanoma of the lower limb. Eur J Cancer 1993; 29A:325-328.

10. Kroon BBR, Klaase J, van de Merwe SA, van Dongen J, van der Zee J. Results of a double perfusion schedule using high-dose hyperthermia and melphalan sequentially for recurrent melanoma of the limbs: a pilot study. Regional Cancer Treatment 1992;305-308.

11. Wieberdink J, Benckhuijsen C, Braat RP, van Slooten EA, Olthuis GA. Dosimetry in isolation perfusion of the limbs by assessment of perfused tissue volume and grading of toxic tissue reactions. Eur J Cancer Clin Oncol 1982; 18:905-910.

12. WHO handbook for reporting results of cancer treatment. Geneva: WHO; 1979.

13. Hill S, Thomas JM. Use of the carbon dioxide laser to manage cutaneous metastases from malignant melanoma. Br J Surg 1996; 83:509-512.

14. Strobbe LJ, Nieweg OE, Kroon BBR. Carbon dioxide laser for cutaneous melanoma metastases: indications and limitations. Eur J Surg Oncol 1997; 23:435-438.

15. Overgaard J, Gonzalez GD, Hulshof MC, Arcangeli G, Dahl O, Mella O, Bentzen SM. Randomised trial of hyperthermia as adjuvant to radiotherapy for recurrent or metastatic malignant melanoma. European Society for Hyperthermic Oncology. Lancet 1995; 345:540-543.

16. Klaase JM, Kroon BBR, van Geel AN, Eggermont AMM, Franklin HR, Hart AAM. Prognostic factors for tumor response and limb recurrence-free interval in patients with advanced melanoma of the limbs treated with regional isolated perfusion with melphalan. Surgery 1994; 115:39-45.

17. Fraker D, Alexander H, Ross M, Bartlett D, Tyler D, Libutti LS, Boddie A, Briele H, Karakousis G. A phase III trial of isolated limb perfusion for extremity melanoma comparing melphalan alone versus melphalan plus tumor necrosis factor (TNF) plus interferon gamma. Ann Surg Oncol 2002;S8. 



\title{
Chapter 8
}

\section{Long-term results of a double perfusion schedule using high-dose hyperthermia and melphalan sequentially in extensive melanoma of the lower limb}

\author{
Noorda EM, Vrouenraets BC, Nieweg OE, Klaase JM*, \\ van der Zee J†, Kroon BBR \\ Department of Surgery, The Netherlands Cancer Institute/Antoni van Leeuwenhoek hospital, \\ Amsterdam, the Netherlands \\ * Department of Surgery, Medisch Spectrum Twente, Enschede, the Netherlands \\ $\dagger$ Department of Radiation Oncology, unit Hyperthermia, \\ University Hospital Rotterdam-Daniel den Hoed Cancer Centre, Rotterdam, the Netherlands
}

Melanoma Research 2003;13:395-399

\section{Introduction}

Isolated limb perfusion (ILP) with melphalan has a well-established role in the treatment of recurrent melanoma of the limbs. Single normothermic $\left(37-38^{\circ} \mathrm{C}\right)$ or mild hyperthermic $\left(39-40^{\circ} \mathrm{C}\right)$ ILP with melphalan produces complete response (CR) rates of $54 \%$ with a mean limb recurrence rate of $44 \%$ after CR. ${ }^{1}$ Different ILP schedules have been used in order to improve response rates and duration of response. Double normothermic ILP schedules with melphalan increase CR rates to $76 \%$, although the limb recurrence-free interval does not improve., ${ }^{2,3}$ While single mild hyperthermic ILP with melphalan yields similar results as ILP under normothermic conditions,${ }^{4}$ higher temperatures have been used to improve results. True hyperthermia $\left(42-44^{\circ} \mathrm{C}\right)$ in combination with melphalan, however, results in severe toxic reactions with a substantial risk of amputation. ${ }^{5,6}$ ILP with melphalan using a somewhat lower temperature (borderline true hyperthermia, $41-42^{\circ} \mathrm{C}$ ) leads to a wide range of CR rates of $39 \%-81 \% .^{7-11}$ In our institution however, this was accompanied by unacceptable toxicity. ${ }^{12}$ In all these studies using hyperthermia, the higher toxicity is caused by the potentiating effect of hyperthermia on melphalan leading to enhanced drug uptake in both tumour and normal cells..$^{13,14}$ Interestingly, hyperthermia $\left(42-45^{\circ} \mathrm{C}\right)$ on itself has a selective cell killing effect on tumour cells, while sparing normal cells because it is especially toxic to cells in insufficiently perfused hypoxic and acidotic areas of tumour tissue. ${ }^{15-17}$

Based on these observations, we developed a sequential ILP schedule in which both hyperthermia and melphalan would be applied at the maximum tolerable dose for each modality, aiming at a double therapeutic effect without the toxicity encountered with simultaneous application. ${ }^{18,19}$ Initial results in ten patients 
were published before..$^{20}$ Here we present the long-term results of all patients treated with a true hyperthermic ILP $\left(42-43^{\circ} \mathrm{C}\right)$ without a cytostatic drug followed by a normothermic ILP with melphalan alone.

\section{Patients and methods}

From 1989 to 1994, seventeen consecutive patients with grossly recurrent melanoma were selected for this study. There were sixteen women and one man with a mean age of 65 years (range 48-78 years). Patient and tumour characteristics are listed in Table 1. Fifteen patients had disease confined to the lower leg and/or foot, one had a large local recurrence in the popliteal fossa and one patient had multiple lesions on the entire lower limb. All patients had extensive disease and seven were considered truly irresectable on the basis of the extent, size and/or location of the lesions. Stage of disease was classified according to the MD Anderson classification system. Five patients had stage II disease (local recurrence or satellitosis), seven had stage IIIA (in-transit metastases), two had

Table 1. Patient characteristics and results of the sequential ILP schedule

\begin{tabular}{|c|c|c|c|c|c|c|c|c|}
\hline No. & Sex & Age & $\begin{array}{l}\text { MD An- } \\
\text { derson* }\end{array}$ & $\begin{array}{l}\text { No. of } \\
\text { lesions }\end{array}$ & $\begin{array}{l}\text { Re- } \\
\text { sponse }^{\dagger}\end{array}$ & $\begin{array}{l}\text { Duration of } \\
\text { follow-up (yr.) }\end{array}$ & $\begin{array}{l}\text { Limb re- } \\
\text { currence }\end{array}$ & $\begin{array}{l}\text { Survival } \\
\text { status }\end{array}$ \\
\hline 1 & q & 60 & II B & 5 & $\mathrm{CR}$ & 9.5 & No & NED \\
\hline 2 & q & 70 & III B & 1 & $\mathrm{CR}$ & 1.0 & No & DOD \\
\hline 3 & 우 & 52 & II A & 1 & $\mathrm{CR}$ & 6.6 & Yes & DOD \\
\hline 4 & 우 & 66 & III B & 1 & $\mathrm{CR}$ & $3(\mathrm{~m})^{\mathrm{s}}$ & No & DOD \\
\hline 5 & 우 & 48 & IV & 50 & PR & $8(\mathrm{~m})$ & No & DOD \\
\hline 6 & q & 53 & III A & 12 & $\mathrm{CR}$ & 4.7 & No & DWD \\
\hline 7 & 우 & 62 & $\| \mathrm{A}$ & 1 & $\mathrm{CR}$ & 10.2 & No & NED \\
\hline 8 & q & 65 & III AB & 7 & $\mathrm{CR}$ & $8(\mathrm{~m})$ & No & DOD \\
\hline 9 & 우 & 53 & III A & 1 & $\mathrm{CR}$ & 5.6 & No & DOD \\
\hline 10 & 우 & 78 & III A & 30 & PR & 3.7 & No & DOD \\
\hline 11 & 우 & 71 & III A & 12 & $\mathrm{CR}$ & 4.0 & No & DWD \\
\hline 12 & q & 73 & III A & 10 & PR & 1.9 & Yes & $\mathrm{D}$ \\
\hline 13 & 우 & 78 & III A & 2 & $\mathrm{PR}^{\ddagger}$ & $6(\mathrm{~m})$ & No & DOD \\
\hline 14 & q & 70 & II B & 7 & $\mathrm{CR}$ & 7.1 & Yes & DOD \\
\hline 15 & 우 & 77 & III A & 20 & NC & 3.8 & No & DOD \\
\hline 16 & $q$ & 74 & III AB & 10 & $\mathrm{CR}$ & 4.5 & Yes & DOD \\
\hline 17 & $\sigma^{x}$ & 48 & II B & 10 & $\mathrm{PR}^{\ddagger}$ & 10.6 & Yes & NED \\
\hline
\end{tabular}

* MD Anderson stage adapted for stage II: IIA = local recurrence and IIB = satellitosis within $3 \mathrm{~cm}$ from primary scar or skingraft, $32+\mathrm{CR}=$ complete response, $\mathrm{PR}=$ partial response, $\mathrm{NC}=$ no change, $\ddagger$ attained $\mathrm{CR}$ after additional excision, $\mathrm{NC}=$ no change, $\S \mathrm{m}=$ months, $\mathrm{NED}=$ alive with no evidence of disease (melanoma), DOD $=$ dead of disease, $\mathrm{DWD}=$ dead without disease, $\mathrm{D}=$ Dead of intercurrent disease with locoregional recurrences 
stage IIIAB (in-transit and regional lymph node metastases) and two patients had stage IIIB disease (regional lymph node metastases) with a large local recurrence. One patient had stage IV (distant metastases) disease and was treated with palliative intent for extensive locoregional metastases. The median number of lesions was seven (range 1-50). The five patients with one large nodule had their recurrence on the lower leg or at their knee. The size of these single lesions varied from three to nine $\mathrm{cm}$ in diameter. Three patients had been treated for in-transit metastases before by local excision. One of them had undergone an ILP three years prior to the sequential schedule. Physical condition was required to be sufficient to undergo the two operative procedures. Patients had were informed about the procedure and oral consent was obtained.

All patients were treated with a sequential ILP schedule consisting of a twohour true hyperthermic $\left(42-43^{\circ} \mathrm{C}\right)$ femoral ILP without cytostatic drug followed one week later by a one-hour normothermic $\left(37-38^{\circ} \mathrm{C}\right)$ ILP at the iliac level with high-dose melphalan $(10 \mathrm{mg} / \mathrm{l}$ perfused tissue). The application of true hyperthermia by ILP was achieved by introducing an extra heat exchanger into the arterial line of the circuit, perfusate temperatures of approximately $44^{\circ} \mathrm{C}$ and a hot water blanket with water circulating at a temperature of $44^{\circ} \mathrm{C}$ circulating, wrapped around the limb. Temperature probes were inserted into tumour nodules, muscle and subcutaneous tissues surrounding the tumour and at proximal and distal sites of the limb. The two-hour ILP period started when a temperature of $42^{\circ} \mathrm{C}$ was reached in tumour nodules or a temperature of $42.5^{\circ} \mathrm{C}$ in the normal tissues. The mean warming-up period was 40 minutes. Tissue temperatures were kept in between $42^{\circ} \mathrm{C}$ and $43^{\circ} \mathrm{C}$ throughout the entire two-hour ILP period. It was assumed that maximum tumour cell kill would be attained if the time between the two ILPs would be as short as possible. Taking into account the time needed for wound healing after the first ILP, the interval between the two ILPs was set at one week. Two patients, however, had a period of 14 days between the ILPs because of blistering on the heel and ankle combined with a transient, diffuse loss of sensibility of the perfused limb after the first ILP. Another patient had disturbed liver function tests after the hyperthermic ILP, probably due to the anaesthesia. She recovered without sequelae and had the complementary normothermic ILP with melphalan three weeks after the first.

Toxicity after ILP with melphalan was graded according to Wieberdink. ${ }^{21}$ Tumour response was measured by WHO criteria. ${ }^{22}$ Patients stayed in the hospital throughout the whole ILP schedule. Mean hospital stay was 38 days ranging from 21 to 96 days in a patient waiting for a place in a nursing home. Analysis took place at least 7.7 years after ILP. For survival and limb recurrence-free interval calculations, Kaplan-Meier analyses were applied. A logrank test was used to test differences in survival between groups. A difference was considered significant with a P-value $<0.05$

\section{Results}

The results are listed in Table 1. After the first true hyperthermic ILP, tumour regression was observed in four patients. After both ILPs, an objective response was observed in sixteen patients (94\%). Eleven patients attained CR (65\%), five 
had a partial response (PR) and one patient had no change of the tumour lesions. In two of the partial responders a CR could be obtained after additional excisions. CR was established after a median period of five months (interquartile range 3.55.5 months). Three patients with CR (27\%) relapsed in the perfused area after five, six and eighteen months, respectively. All other complete responders had no evidence of recurrent local disease during their follow-up period (median 3 years, interquartile range 4 months-7.5 years). Five-year limb recurrence-free survival for the eleven patients with a $\mathrm{CR}$ was $67 \%$. The two partial responders who were rendered tumour-free after additional excisions relapsed after two and five months respectively. In one patient, amputation of the limb had to be performed two months after ILP because of progression of the lesions after an initial partial response.

Results on acute locoregional toxicity are shown in Table 2. After the first ILP with true hyperthermia, no tissue reaction was observed in seven patients, while four patients had slight erythema of the perfused limb. Six patients developed blistering on their heels. Two patients had transient diffuse loss of sensibility of the perfused limb; one combined with a short period of motor dysfunction and moderate elevation of serum creatinine phosphokinase levels, indicating some degree of muscle damage. In one patient, complete loss of peroneal nerve function occurred immediately after the first hyperthermic ILP, probably due to pressure of the femoral tourniquet.

Following the second melphalan ILP, fifteen patients (88\%) had a grade II toxicity reaction, i.e. slight erythema and/or oedema. In two patients a grade III toxicity reaction was seen with blisters on the heel combined with considerable oedema and/or erythema. Long-term morbidity occurred only in the patient who had irreversible loss of peroneal nerve function.

At the time of analysis, three patients are still alive without evidence of disease. Eleven patients died of metastatic melanoma, one of intercurrent disease with limb recurrences and two died of intercurrent disease without melanoma. Median disease-specific survival was 5.6 years $(95 \%$ confidence interval (CI)

Table 2. Acute regional toxicity

\begin{tabular}{lll}
\hline & Hyperthermic ILP (n) & $\begin{array}{l}\text { Normothermic ILP } \\
\text { with melphalan (n) }\end{array}$ \\
\hline No tissue reaction/grade I & $7^{*}$ & \\
Slight erythema or oedema/grade II & 4 & 15 \\
Blistering/grade III & $6^{\dagger}$ & 2 \\
\hline
\end{tabular}

Since the grading system according to Wieberdink is based upon acute toxicity caused by melphalan, the grades strictly apply to toxicity after the second ILP. Descriptions are provided for tissue reaction after the first ILP.

* One patient had complete irreversible loss of peroneal nerve function

† Blistering localised on heels in all six patients. Two patients had transient sensibility loss of the limb, one combined with neurapraxia 
2.7-8.4 years) with a median overall survival of 4 years (95\% CI 3.0-5.0 years). Disease specific 5-year survival for those who attained a CR was $62 \%$ and $22 \%$ for the remaining six patients $(\mathrm{P}=0.43)$.

\section{Discussion}

The present study was performed to examine the feasibility and results of an ILP schedule using hyperthermia and melphalan at their maximum tolerable doses. To avoid the severe toxicity encountered when both treatment modalities are applied simultaneously, 5,6 we developed a sequential ILP schedule for patients with extensive recurrent melanoma.

Hyperthermia kills tumour cells through damage to cell membranes and denaturation of proteins. ${ }^{16,23}$ The extent of tumour cell kill by hyperthermia is dependent on the heat dose and the duration of hyperthermia, although these two are not simply linearly related. It is known from in vitro experiments that a change in this relationship occurs between $42^{\circ} \mathrm{C}$ and $43^{\circ} \mathrm{C}$ with an increased effectiveness of heat above $42.5^{\circ} \mathrm{C}$. To have the same therapeutic effect, a change of $1^{\circ} \mathrm{C}$ below this transition point requires a factor six increase in duration of heat application whereas this is a factor two if temperature is higher than $42.5^{\circ} \mathrm{C} .{ }^{24}$

The effect of hyperthermia has generally been found to be enhanced by a hypoxic and acidic environment, often found in regions of solid tumours. ${ }^{15-17}$ If cells are adapted to grow at low $\mathrm{pH}$, in chronic acidotic states, this thermal sensitivity diminishes.$^{16}$ However, if acidosis is acutely caused this sensitivity to heat is apparent. ${ }^{15,16}$ In another study, we demonstrated that acute acidosis in tumour tissue occurs during the hyperthermic ILP with a mean initial tumour $\mathrm{pH}$ of 7.15 decreasing with 0.41 units, significantly more than the decrease in $\mathrm{pH}$ of normal perfused tissues. This selective decrease in tumour $\mathrm{pH}$ is mainly caused by the anoxic period when the extracorporeal circulation system is connected to the limb vasculature. Hyperthermia at the clinically maximum tolerable level further decreases both tumour and normal tissue $\mathrm{pH} .{ }^{15}$ At a temperature of $42^{\circ} \mathrm{C}$ applied for 120 minutes, like in our study, a decrease in $\mathrm{pH}$ of 0.40 units results in a 100fold increase of tumour cell kill..$^{25}$

The efficacy of hyperthermia in ILP without cytostatics was previously reported by Cavaliere et al. who treated seven patients with extremity melanoma with ILP under high-dose hyperthermic conditions without cytostatics resulting in a marked regression of the tumours. ${ }^{5}$ Before the current series was performed we had treated three patients with ILP with high-dose hyperthermia without cytostatics for extremity sarcoma and have observed regression of the tumors. ${ }^{18}$ To improve complete response rates, we hypothesised that the true hyperthermia would kill cells in the acidotic and hypoxic parts of the large tumour nodules, thus reducing tumour load, and that the second ILP with melphalan would treat the well perfused parts of the tumour nodules and possible microscopic disease..$^{15,26}$

Our complete response rate of $65 \%$ is markedly higher than reported CR rates of single normothermic or mild hyperthermic ILP with melphalan $(54 \%)^{1}$ suggesting the superiority of the combination. Moreover, in bulky disease, ILP with melphalan has only limited value with low CR rates of $17 \% .{ }^{27}$ Other investiga- 
tors have also demonstrated the lower chance of CR in more extensive disease. ${ }^{7}$ It is only with the introduction of TNF $\alpha$ that $\mathrm{CR}$ rates improved, ranging from $60 \%$ to $78 \%$ in these patients. ${ }^{27-29}$ Since all our patients had extensive disease, the limb recurrence rate of $27 \%$ after a mean follow up of ten years is low compared to a mean limb recurrence rate of $44 \%$ (range $24 \%-54 \%$ ) reported in the literature after a shorter follow up. ${ }^{1,30,31}$ Although the number of patients is small, the 5 -year limb recurrence-free interval of $63 \%$ in our group with advanced recurrent melanoma compares favourable to the reported 3-year limb recurrence-free interval of $38 \%$ after normothermic ILP with melphalan. ${ }^{32}$

It appears from our study that hyperthermia alone does not result in increased limb toxicity with generally milder reactions being observed than after the use of melphalan under normothermic conditions. ${ }^{33}$ Tissue reactions specifically seen after ILP with high-dose hyperthermia alone were pressure-related blistering at the heel and transient sensory disturbances of the limb. This blistering was no longer observed once we paid special attention to avoid pressure on the patients' heels during ILP with hyperthermia. The transient diffuse sensory disturbances seen in two patients and the damaged peroneal nerve in one patient could be attributed to the specific sensitivity of nerve tissue to heat and exerted pressure by the tourniquet. ${ }^{13}$

Considering the fact that the tourniquet is applied longer during the hyperthermic ILP than usual (i.e. two hours), one should be particularly cautious with the amount of pressure applied. Since leakage is of no concern using only hyperthermia without use of a cytostatic drug, pressure can be limited to prevent nerve toxicity. Cumulative toxicity after the sequential procedure was similar to what is seen after single normothermic or mild hyperthermic ILPs with melphalan, showing mostly grade II reactions with mild erythema and oedema resolving without sequelae..$^{33}$ This emphasises the importance of the timing of hyperthermia and melphalan in avoiding or promoting synergistic toxic reactions.

Nowadays, for patients with bulky tumour load, ILP with tumour necrosis factor alpha (TNF $\alpha)$ and melphalan can be used with results comparable to the results of our sequential schedule. ${ }^{27-29}$ A disadvantage of the sequential schedule is undoubtedly that it implies two surgical procedures. This means a double operative risk, increased costs and an additional ILP, in the case of locoregional failure, may be more difficult to perform. However, from a previous study where we applied a double ILP schedule with melphalan under normothermic conditions, no increased operative risk appeared. ${ }^{3}$ Despite the presumed higher operative risk, we found little short- and long-term morbidity in the present series. As for the costs of ILP, the cost of the first hyperthermic procedure is probably outweighed by the considerable costs of TNF $\alpha$. Furthermore, a third ILP has been proven to be feasible. ${ }^{34}$ At this moment, results of ILP with TNF $\alpha$ point in the direction of a benefit in response rate and reduced time to obtained response compared to ILP with melphalan alone, especially in those patients with a high tumour load..$^{35,36}$ Final results have to be awaited of the US trial, determining the role of TNF $\alpha$ in ILP for melanoma. Based on the above, if TNF $\alpha$ is not available, as it is not registered for use in melanoma ILP in some countries, or if it is contraindicated or if there is failure after a previous ILP, the sequential schedule could be a safe and effective alternative in selected patients with bulky disease. 
In conclusion, our sequential ILP schedule using high-dose hyperthermia and melphalan results in a high complete response rate and a low limb-recurrence rate in patients with extensive, recurrent melanoma of the limbs at the cost of only mild toxicity. In patients with bulky disease, this regimen could be a valuable alternative to ILP with TNF $\alpha$ and melphalan. However larger studies are needed to define its exact role in recurrent limb melanoma.

\section{References}

1. Vrouenraets BC, Nieweg OE, Kroon BBR. Thirty-five years of isolated limb perfusion for melanoma: indications and results. Br J Surg 1996; 83:1319-1328.

2. Klaase JM, Kroon BBR, van Geel AN, Eggermont AMM, Franklin HR, van Dongen JA. Is there an indication for a double perfusion schedule with melphalan for patients with recurrent melanoma of the limbs? Melanoma Res 1994; 4 Suppl 1:13-6.:13-16.

3. Klaase JM, Kroon BBR, van Geel AN, Eggermont AMM, Franklin HR, van Dongen JA. A retrospective comparative study evaluating the results of a single-perfusion versus double-perfusion schedule with melphalan in patients with recurrent melanoma of the lower limb. Cancer 1993; 71:2990-2994.

4. Klaase JM, Kroon BBR, Eggermont AMM, van Geel AN, Schraffordt Koops H, Oldhoff J, Lienard D, Lejeune FJ, Berkel R, Franklin HR, . A retrospective comparative study evaluating the results of mild hyperthermic versus controlled normothermic perfusion for recurrent melanoma of the extremities. Eur J Cancer 1995; 31A:58-63.

5. Cavaliere R, Ciocatto EC, Giovanella BC, Heidelberger C, Johnson RO, Margottini M, Mondovi B, Moricca G, Rossi-Fanelli A. Selective heat sensitivity of cancer cells. Biochemical and clinical studies. Cancer 1967; 20:1351-1381.

6. Vaglini M, Ammatuna M, Nava M, Prada A, Rovini D, Santinami M, Cascinelli N. Regional perfusion at high temperature in treatment of stage IIIA-IIIAB melanoma patients. Tumori 1983; 69:585-588.

7. Di Filippo F, Calabro A, Giannarelli D, Carlini S, Cavaliere F, Moscarelli F, Cavaliere R. Prognostic variables in recurrent limb melanoma treated with hyperthermic antiblastic perfusion. Cancer 1989; 63:2551-2561.

8. Storm FK, Morton DL. Value of therapeutic hyperthermic limb perfusion in advanced recurrent melanoma of the lower extremity. Am J Surg 1985; 150:32-35.

9. Bryant PJ, Balderson GA, Mead P, Egerton WS. Hyperthermic isolated limb perfusion for malignant melanoma: response and survival. World J Surg 1995; 19:363-368.

10. Santinami M, Belli F, Cascinelli N, Rovini D, Vaglini M. Seven years experience with hyperthermic perfusions in extracorporeal circulation for melanoma of the extremities. J Surg Oncol 1989; 42:201-208.

11. Vaglini M, Andreola S, Attili A, Belli F, Marolda R, Nava M, Prada A, Santinami M, Cascinelli N. Hyperthermic antiblastic perfusion in the treatment of cancer of the extremities. Tumori 1985; 71:355-359.

12. Kroon BBR, Klaase JM, van Geel AN, Eggermont AMM. Application of hyperthermia in regional isolated perfusion for melanoma of the limbs. Regional Cancer Treatment 1992;223-226.

13. Kroon BBR, Klaase JM, van Geel AN, Eggermont AMM. Application of hyperthermia in regional isolated perfusion for melanoma of the limbs. Regional Cancer Treat- 
ment 1992;223-226.

14. van der Zee J, Kroon BBR, Nieweg OE, van de Merwe SA, Kampinga HH. Rationale for different approaches to combined melphalan and hyperthermia in regional isolated perfusion. Eur J Cancer 1997; 33:1546-1550.

15. van de Merwe SA, van den Berg AP, Kroon BB, van den Berge AW, Klaase JM, van der Zee J. Modification of human tumour and normal tissue $\mathrm{pH}$ during hyperthermic and normothermic antiblastic regional isolation perfusion for malignant melanoma: a pilot study. Int J Hyperthermia 1993; 9:205-217.

16. Tannock IF, Rotin D. Acid pH in tumors and its potential for therapeutic exploitation. Cancer Res 1989; 49:4373-4384.

17. Lyons JC, Kim GE, Song CW. Modification of intracellular pH and thermosensitivity. Radiat Res 1992; 129:79-87.

18. van der Zee J, Broekmeyer-Reurink MP, van den Berg AP, van Geel BN, Jansen RF, Kroon BBR, van Wijk J, Hagenbeek A. Temperature distribution and $\mathrm{pH}$ changes during hyperthermic regional isolation perfusion. Eur J Cancer Clin Oncol 1989; 25:1157-1163.

19. Jansen RF, van Geel BN, van der Zee J, Hagenbeek A, Levendag PC. Intractible cutaneous non-Hodgkin's lymphoma of the lower limb. Complete remission after sequential regional isolated hyperthermic perfusion and perfusion with 1-phenylalanine-mustard (melphalan, L-Pam). Cancer 1989; 64:392-395.

20. Kroon BBR, Klaase J, van de Merwe SA, van Dongen J, van der Zee J. Results of a double perfusion schedule using high-dose hyperthermia and melphalan sequentially for recurrent melanoma of the limbs: a pilot study. Regional Cancer Treatment 1992;305-308.

21. Wieberdink J, Benckhuijsen C, Braat RP, van Slooten EA, Olthuis GA. Dosimetry in isolation perfusion of the limbs by assessment of perfused tissue volume and grading of toxic tissue reactions. Eur J Cancer Clin Oncol 1982; 18:905-910.

22. WHO handbook for reporting results of cancer treatment. Geneva: WHO; 1979.

23. Streffer C. Molecular and cellular mechanisms of hyperthermia. In Seegenschmiedt M, Fessenden P, Vernon CC (eds). Thermoradiotherapy and thermochemotherapy. Berlin Heidelberg: Springer-Verlag; 1995:47-74.

24. Field SB, Morris CC. The relationship between heating time and temperature: its relevance to clinical hyperthermia. Radiother Oncol 1983; 1:179-186.

25. Gerweck LE. Modification of cell lethality at elevated temperatures. The $\mathrm{pH}$ effect. Radiat Res 1977; 70:224-235.

26. Kroon BBR, Klaase JM, van Geel AN, Eggermont AMM. Application of hyperthermia in regional isolated perfusion for melanoma of the limbs. Regional Cancer Treatment 1992;223-226.

27. Fraker DL. What is the best regional therapy? Melanoma Res. 7 (suppl 1), S42. 1997.

28. Liénard D, Eggermont AMM, Schraffordt Koops H, Kroon B.B.R., Towse G, Hiemstra S, Schmitz P, Clarke J, Steinmann G, Rosenkaimer F, Lejeune FJ. Isolated limb perfusion with tumour necrosis factor-alpha and melphalan with or without interferongamma for the treatment of in-transit melanoma metastases: a multicentre randomized phase II study. Melanoma Res 1999; 9:491-502.

29. Fraker DL, Alexander HR, Andrich M, Rosenberg SA. Treatment of patients with melanoma of the extremity using hyperthermic isolated limb perfusion with melphalan, tumor necrosis factor, and interferon gamma: results of a tumor necrosis factor 
dose-escalation study. J Clin Oncol 1996; 14:479-489.

30. Feldman AL, Alexander HR, Jr., Bartlett DL, Fraker DL, Libutti SK. Management of extremity recurrences after complete responses to isolated limb perfusion in patients with melanoma. Ann Surg Oncol 1999; 6:562-567.

31. Lingam MK, Byrne DS, Aitchison T, MacKie RM, McKay AJ. A single centre's 10 year experience with isolated limb perfusion in the treatment of recurrent malignant melanoma of the limb. Eur J Cancer 1996; 32A:1668-1673.

32. Klaase JM, Kroon BBR, van Geel AN, van Wijk J, Franklin HR, Eggermont AMM, Hart AAM. Limb recurrence-free interval and survival in patients with recurrent melanoma of the extremities treated with normothermic isolated perfusion. J Am Coll Surg 1994; 178:564-572.

33. Vrouenraets BC, Kroon BBR, Klaase JM, Nieweg OE, van Slooten GW, van Dongen JA. Severe acute regional toxicity after normothermic or 'mild' hyperthermic isolated limb perfusion with melphalan for melanoma. Melanoma Res 1995; 5:425-431.

34. Krementz ET, Sutherland CM, Muchmore JH. Isolated hyperthermia chemotherapy perfusion for limb melanoma. Surg Clin North Am 1996; 76:1313-1330.

35. Liénard D, Eggermont AMM, Schraffordt Koops H, Kroon BBR, Rosenkaimer F, Autier P, Lejeune FJ. Isolated perfusion of the limb with high-dose tumour necrosis factor-alpha (TNF-alpha), interferon-gamma (IFN-gamma) and melphalan for melanoma stage III. Results of a multi-centre pilot study. Melanoma Res 1994; 4 Suppl 1:21-26.

36. Fraker D, Alexander H, Ross M, Bartlett D, Tyler D, Libutti LS, Boddie A, Briele H, Karakousis G. A phase III trial of isolated limb perfusion for extremity melanoma comparing melphalan alone versus melphalan plus tumor necrosis factor (TNF) plus interferon gamma. Ann Surg Oncol 2002;S8. 



\title{
Chapter 9
}

\section{Quality of life in long-term survivors of isolated limb perfusion for melanoma of the limbs}

\author{
Noorda EM*, van Kreij RHJ, Vrouenraets BC*, Nieweg OE*, \\ Muller $M$, Kroon BBR*, Aaronson NK \\ Division of Psychosocial Research and Epidemiology, \\ The Netherlands Cancer Institute/Antoni van Leeuwenhoek hospital, Amsterdam, the Netherlands \\ * Department of Surgical Oncology
}

Submitted

\section{Introduction}

Since 1957, isolated limb perfusion (ILP) has been applied for melanoma of the extremities. ${ }^{1}$ The principle of ILP is that the whole affected limb is treated with high-dose chemotherapy to eradicate visible tumor recurrences as well as micrometastatic disease that is often thought to be present at the time of ILP. High doses of melphalan, the cytostatic mostly used, can be administered in the perfusate in a concentration that is 10 to 20 times higher than what would be tolerated systemically. ${ }^{2}$ No severe systemic toxicity is nowadays encountered. ${ }^{3}$ ILP with melphalan produces complete response (CR) rates of $54 \%$ with a mean limb recurrence rate of $44 \%$ after CR. ${ }^{4}$ Despite the continuing risk of locoregional and distant metastasis, approximately $27-46 \%$ of these patients survive five-years after ILP, mainly depending on the presence of regional lymph node metastases at the time of ILP. ${ }^{5}$ These long-term survivors can be subject of long-term disease- and/or ILP-related complaints, which may influence their quality of life after ILP. For instance, acute toxic reactions of the limb are severe in approximately $15 \%$ of the patients, with edema and blistering, ${ }^{6}$ which can result in longterm functional disturbances. ${ }^{7}$ The magnitude of the impact of physical limitations on quality of life has however been questioned. ${ }^{8}$

In long-term survivors of varying forms of cancer, an increased level of fear, especially fear of recurrences, incidence of depression, disturbed sense of self and body perception has been reported. ${ }^{9-11}$ Especially fear of recurrences and the disturbed sense of self or body perception, caused by still visible (non-vital) tumor remnants on the limb, edema or a difference in skin color between the perfused and healthy limb, could have an impact on long-term survivors after ILP. Finally, problems getting life insurance or home mortgage have been observed in long-term survivors in general. ${ }^{8,9}$

One study so far has focused specifically on quality of life of long-term survivors of melanoma ${ }^{10}$ and there is one study on quality of life in patients treated with ILP for melanoma. ${ }^{11}$ In this study however, short term quality of life was 
Table 1. Patient- and tumor characteristics at the time of ILP and toxicity and recorded morbidity after ILP

\begin{tabular}{lrl}
\hline Male gender & $5(10 \%)$ \\
Mean age (range) & $57(28-83)$ \\
Median number of lesions & $2(1-3.5)$ \\
Localization on leg versus arm & $47(92 \%) / 4(8 \%)$ \\
MD Anderson stage of disease & \\
Stage IIA & $6(12 \%)$ \\
Stage IIB & $16(31 \%)$ \\
Stage IIIA & $21(41 \%)$ \\
Stage IIIAB & $4(8 \%)$ \\
Stage IIIB & $4(8 \%)$ \\
Acute regional toxicity & $41(80 \%)$ \\
Grade I/II (mild erythema/edema) & $10(20 \%)$ \\
Grade III (erythema/edema and blistering) & \\
Morbidity at $\geq$ one year after ILP & $10(20 \%)$ \\
Edema & 0 \\
Neuropathy & $2(4 \%)$ \\
Pain & $3(6 \%)$ \\
Erysipelas & $5(10 \%)$ \\
Complaints of limb malfunction & $4(8 \%)$ \\
Muscle atrophy &
\end{tabular}

* Mean age (range) at the time of analysis 71 (38-90)

assessed in patients who received ILP for primary melanoma. Therefore, this study was performed in order to assess quality of life and possible patient-, tumor- and ILP-related factors for quality of life in long-term survivors after ILP for recurrent limb melanoma.

\section{Patients and methods}

From 1978 to 2001, 326 ILPs were performed in 292 patients with advanced melanoma of the limbs in our institution. From our computer-assisted database, containing all patient-, tumor-, treatment and follow-up data of these patients, 62 patients could be selected who were alive and disease-free for longer than six months after ILP. Family doctors were contacted to check the address and survival status. Three patients could not be traced and two could not respond due to severe cognitive dysfunction. Seventy-five eligible patients received an invitational letter to participate in the study. Three patients (5\%) did not return the questionnaire and could not be reached telephonically afterwards and three (5\%) declined to participate. Therefore, 51 patients $(89 \%)$ returned the questionnaires and were subject of this study. Data regarding patient and tumor characteristics at the time of ILP are provided in Table 1.

Forty-two patients (74\%) underwent a single normothermic ILP with melpha- 
lan, 11 patients $(19 \%)$ with melphalan and TNF $\alpha$, two patients had a sequential ILP-schedule and two patients a double normothermic schedule with melphalan. Lesions were excised before or at ILP in 22 patients (44\%). Data regarding postILP toxicity and morbidity are displayed in Table 1 . Toxicity was scored according to Wieberdink et al. ${ }^{12}$ at the ward until hospital discharge and morbidity was recorded at the outpatient clinic until the end of follow-up by the surgeon as well. Eight patients developed further limb recurrences in the perfused limb, which were treated with surgical excision in all cases. Three patients developed distant metastases during follow-up, one had mediastinal metastases and another patient had distant skin metastases with a femoral bone metastasis treated with radiation therapy. The third had a single metastasis in the jejunum, for which resection was performed. At the time of analysis, the median follow-up after ILP was 14 years (range 3-25 years).

All patients received a Dutch-language version of the MOS 36-item ShortForm Health Survey (SF-36), to assess health status and quality of life domains. ${ }^{13}$ The SF-36 is a self-administered questionnaire composed of 36 questions organized in eight subscales, assessing:

1. Physical functioning

2. Role limitations due to physical functioning

3. Bodily pain

4. Social functioning

5. General mental health

6. Role limitations due to emotional functioning

7. Vitality

8. General health perceptions

Calculation of scores in each subscale followed standard procedures. ${ }^{16}$ For all scales, linearly transformed scores range from 0 to 100 , with higher scores representing higher levels of functioning and health. The SF-36 yields a physical and a mental component scores on the basis of the scores of each subscale. The SF36 has been validated in the healthy Dutch population and in a heterogeneous group of cancer patients. ${ }^{17}$ Normative data are available for the healthy Dutch population and an age and gender matched sample of this population served as comparison group in this study with three controls selected for each patient.

The patients completed a disease-specific questionnaire developed by the authors and a questionnaire on work- and insurance related issues. ${ }^{12}$ The diseasespecific questionnaire consisted of 16 questions on (number of questions between brackets):

1. Fear of recurrences (3)

2. Physical limitations due to ILP-related complaints of the limb (5)

3. Impact of cosmetic ILP-related issues on daily activities (6)

4. Satisfaction with the choice for ILP (2)

One of the questions regarding fear of recurrences was dependent of the other two main questions. The two main questions regarding fear (i.e. fear of limb recurrences and fear of recurrences at distant sites) showed a high internal consistency $(\alpha=0.77)$. Therefore a pooled score could be calculated for these variables. The pooled score was used in the regression analysis, while the results of all individual disease-specific items were first described per item. 
An additional series of 17 questions addressed employment and problems in obtaining life insurance, health insurance or a home-mortgage, due to having had a cancer diagnosis. ${ }^{12}$

\section{Analysis}

First, a general assessment of quality of life was performed on the basis of the standard calculation of scores of the SF-36. These results were compared to the results of the SF-36 in the general Dutch population, of which a matched control group was composed. An effect size was calculated for each subscale. This is an indication for the magnitude of the difference in mean scores between the patient population and the Dutch norm population. The effect size is calculated by: (mean study population - mean comparison population) / standard deviation of comparison population. Conventional definitions of effect sizes: 0.2 is small, 0.5 is medium and 0.8 is large. 18 Students' T-test or Mann-Whitney-tests were used to test for significance of differences. Results from the disease-related questionnaire, employment- and insurance related questions were described and tested per item.

Second, sociodemographic and clinical variables were tested for their relation to the physical and mental health component scores (SF-36). Factors were selected on the basis of a clinical line of reasoning that they might influence mental and physical well being. The following variables were tested: age, gender, location of lesions on the limb, number of lesions, size of the lesions, regional lymph node dissection at or before ILP, systemic therapy, number of previous recurrences before ILP, ILP-type, response of the lesions to ILP, acute regional toxicity reaction, number of recurrences after ILP, morbidity at or after one year post-ILP and distant metastases after ILP. The correlation of the results of the following main questions of the disease-specific questionnaire with the component scores was also tested: fear of limb recurrences or distant metastases (1), the presence of edema (1), stinging sensations (1), stiffness (1), difference in color between treated and untreated limbs (1), persisting skin discolorations/non-vital lesions on the limb (1) and the necessity to wear supportive stockings (1).

A multivariate linear regression-analysis was subsequently performed to identify which of all these factors had the strongest relationship with either component score. Variables that had a P-value below 0.1 in the univariate analysis were included in the regression-analysis. With the exception of this selection criterion, all tests of significance employed a P-value of $<0.05$.

\section{Results}

$S F-36$

A summary of the results per subscale is given in Table 2. Overall, the patient population scored better than the age- and gender-matched population comparison group. This difference was significant in favor of the patient population in the domains of bodily pain, general health perceptions, the mental component score and the physical component score $(\mathrm{P}<0.05)$ and marginally significant regarding the physical functioning and role emotional scale $(\mathrm{P}<0.1)$. The effect size of the difference between the means of the two populations is also displayed. The percentage of the study population that scored below the $25 \%$-percentile score of the 
Table 2. Means, standard deviations and effect size for SF-36 scores of the patient population compared with Dutch population

\begin{tabular}{|c|c|c|c|c|c|c|c|c|}
\hline \multirow[b]{2}{*}{ Scale } & \multicolumn{8}{|c|}{ Patient population Dutch population } \\
\hline & $\mathrm{N}$ & Mean (SD) & $\%$ Low $^{*}$ & * $N$ & Mean (SD) & Low $^{*}$ & Effect $^{\dagger}$ & $\mathrm{P}^{t+}$ \\
\hline Physical function & 49 & $69.4(24.1)$ & 10 & 149 & $61.9(30.0)$ & 33 & 0.3 & 0.08 \\
\hline Role physical & 49 & $62.8(43.9)$ & 35 & 142 & $55.9(44.7)$ & 25 & 0.2 & 0.36 \\
\hline Bodily pain & 51 & $75.6(28.3)$ & 6 & 153 & $65.6(27.6)$ & 32 & 0.4 & 0.03 \\
\hline Social function & 51 & $82.6(22.1)$ & 16 & 153 & $76.6(28.3)$ & 50 & 0.2 & 0.12 \\
\hline Mental health & 50 & $76.9(19.6)$ & 16 & 149 & $71.9(19.4)$ & 56 & 0.3 & 0.12 \\
\hline Role emotional & 46 & $83.3 \quad(30.3)$ & 7 & 141 & $73.3(38.4)$ & 0 & 0.3 & 0.07 \\
\hline Vitality & 50 & $65.3(20.0)$ & 20 & 149 & $61.1(22.4)$ & 45 & 0.2 & 0.24 \\
\hline GH perceptions & 50 & 67.4 (21.4) & 10 & 148 & $59.9(20.7)$ & 42 & 0.4 & 0.03 \\
\hline CS Physical & 43 & 46.4 (9.8) & 12 & 136 & 41.1 (12.6) & 31 & 0.4 & 0.005 \\
\hline CS Mental & 43 & $54.4(8.0)$ & 12 & 136 & $51.1(10.8)$ & 45 & 0.3 & 0.04 \\
\hline
\end{tabular}

$\mathrm{GH}=$ General health, $\mathrm{CS}=$ component score

* \% Low $=\%$ patients below the $25 \%$ percentile in Dutch population, Low = value at 25\%-percentile

$\dagger$ (Mean patient population - Mean Dutch population)/SD Dutch population

t† between means, T-test, $\mathrm{P}<0.05$ is regarded significant

Dutch population is shown in column 4. In all subscales, except for the role limitations due to physical functioning, this percentage of patients was below the $25 \%$ of the Dutch population.

\section{Disease-specific questionnaire}

Results of the questionnaire regarding disease-related issues are displayed per item in Table 3. As for physical complaints, $49-55 \%$ of the study population experienced physical limitations such as stinging sensations (paresthesias), edema, or stiffness of the treated extremity at any frequency, varying from sometimes to often. Seventy-two to $82 \%$ of these patients who experienced any kind of physical limitation were impaired in their daily activities by these limitations. Regarding the cosmetic items, $31 \%$ and $37.5 \%$ of the study sample respectively reported the presence of a color difference between the extremities or visible (non-vital) skin lesions. Sixty-one to $69 \%$ of the long-term survivors with a cosmetic complaint (including edema), was reluctant to wear shorts or a bathing suit. Fear of limb recurrences was present in $77 \%$ of the study population and $63 \%$ experienced fear of recurrences at distant sites. Fifty-five per cent of the longterm survivors checked the perfused limb regularly to frequently for new recurrences. When asked, 45 of 46 respondents ( $88 \%$ of the total of 51 patients) said they would (probably or certain) choose to undergo ILP again if they were in the same situation. These 45 patients would also recommend ILP to a close friend or 


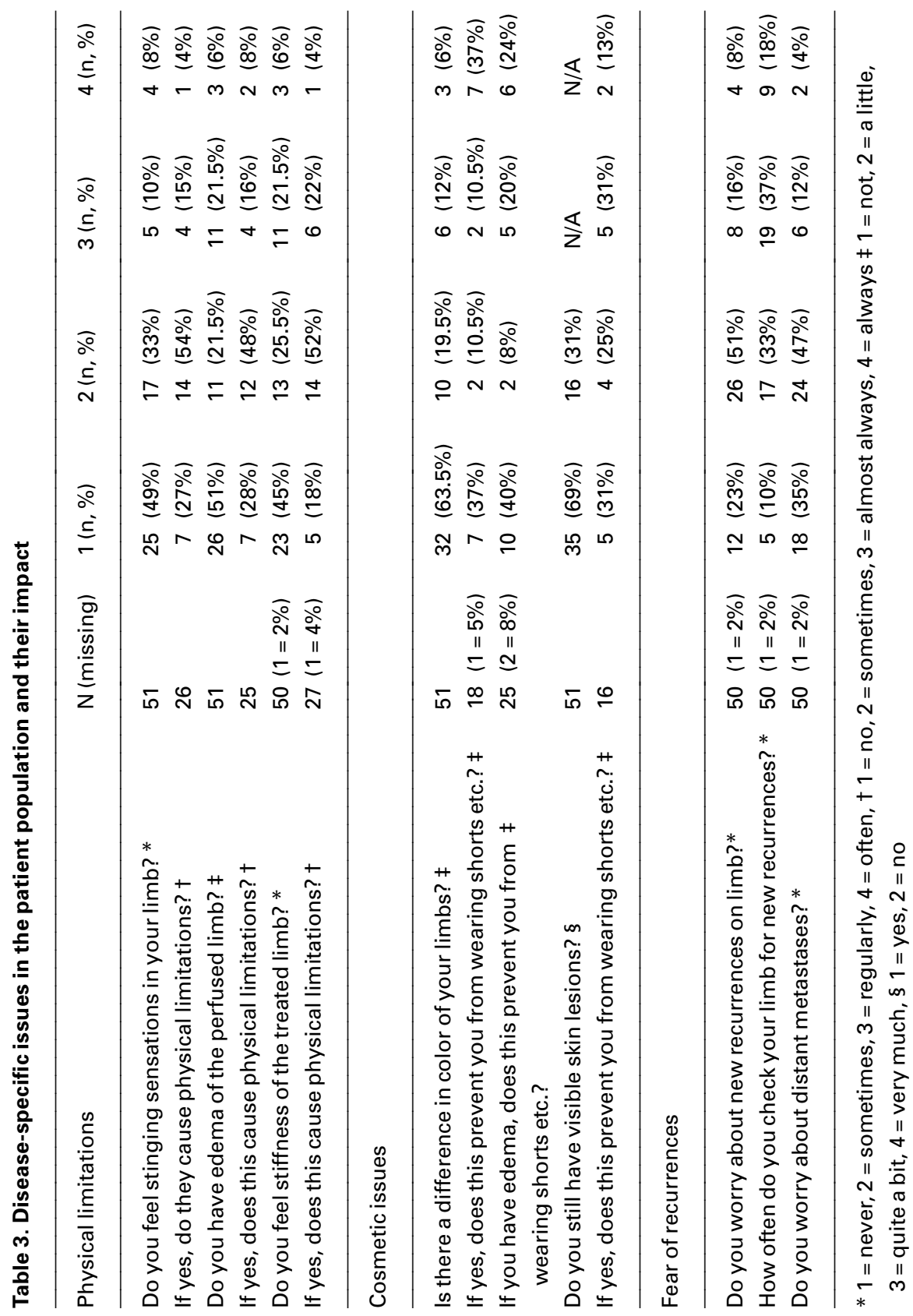


relative if it were applicable to them. The distribution of the number of complaints is displayed in Table 4.

\section{Mortgage, employment- and insurance related issues}

Four patients did not fill out the questionnaire regarding these issues. Three $(6 \%)$ of 48 patients had difficulty obtaining home mortgage, two of whom finally succeeded in obtaining it. The problems that were initially encountered were refusal of a home mortgage $(n=2)$ or at the costs of a very high premium $(n=1)$. Four (9\%) of 46 patients had difficulty getting a life insurance. Two patients were denied a life insurance, one was offered extra high premium and another had to undergo a specifically thorough health examination in order to get the insurance. Only one of them finally got the insurance. Four (8\%) of 48 patients encountered problems in getting a health insurance consisting of a denial in three patients, one of whom was denied the insurance because of a second malignancy, and another having to pay an extra high premium. Five (of 43, 11.5\%) patients were currently employed, eighteen (42\%) retired, fifteen housewives (35\%) and five $(11.5 \%)$ were considered work disabled. Two patients (of 28 who were or had been employed, 7\%) had lost their jobs because of melanoma and one patient had started to work part-time because of melanoma.

\section{Factors associated significantly with health related quality of life}

Univariately, related factors $(\mathrm{P} \leq 0.1)$ to the physical component score were: lesions on the lower leg, as opposed to other localizations ( $\mathrm{r}=0.29, \mathrm{P}=0.06)$, muscle atrophy $(\mathrm{r}=-0.48, \mathrm{P}=0.003)$, distant metastases after ILP $(\mathrm{r}=-0.45, \mathrm{P}=0.004)$, stinging sensations ( $r=-0.44, P=0.003)$, stiffness $(r=-0.59, P<0.001)$, edema of the perfused extremity $(\mathrm{r}=-0.45, \mathrm{P}=0.002)$, and a difference in color between the extremities $(\mathrm{r}=-0.40, \mathrm{P}=0.009)$. After multivariate linear regression analysis following a forward stepwise method, stiffness of the perfused limb $(\mathrm{P}<0.001)$ was negatively related and lesions located on the lower leg, as opposed to other localizations $(\mathrm{P}<0.05)$ was positively related to physical functioning $\left(\mathrm{R}^{2}=38 \%\right)$.

In univariate analysis, the following factors were related to the mental component score with a $\mathrm{P} \leq 0.1$ : age at the time of analysis $(\mathrm{r}=-0.25, \mathrm{P}=0.1)$, limb recurrences after ILP $(\mathrm{r}=-0.26, \mathrm{P}=0.1)$, difference in color between extremities $(\mathrm{r}=-$ $0.45, \mathrm{P}=0.003)$, persistent discoloration/non-vital skin lesions on the perfused extremity $(\mathrm{r}=-0.30, \mathrm{P}=0.05)$, stiffness of the perfused extremity $(\mathrm{r}=-0.49$,

Table 4. Distribution of the number of disease specific complaints per patient

$\begin{array}{rrl}5 & 5 & (10 \%) \\ 4 & 9 & (17.5 \%) \\ 3 & 9 & (17.5 \%) \\ 2 & 7 & (14 \%) \\ 1 & 11 & (21.5 \%) \\ 0 & 10 & (19.5 \%)\end{array}$


$\mathrm{P}=0.001)$, stinging sensations $(\mathrm{r}=-0.34, \mathrm{P}=0.03)$, and the standardized scale for fear of limb recurrences and distant metastases $(\mathrm{r}=-0.47, \mathrm{P}=0.002)$.

When all factors were included in a linear regression analysis, stiffness of the extremity $(\mathrm{P}<0.001)$, fear of recurrences $(\mathrm{P}<0.05)$, stiffness of the extremity $(\mathrm{P}<0.001)$ and the age at analysis $(\mathrm{P}<0.05)$ were the strongest negative prognostic factors for mental well being $\left(\mathrm{R}^{2}=24 \%\right.$, Table 5).

\section{Discussion}

In this study, an assessment of health related quality of life was performed among 51 long-term survivors after ILP for recurrent extremity melanoma. Although the study group was relatively small, it demonstrated that this group of patients scored better on all domains of quality of life compared to an age- and sexmatched Dutch comparison group. This difference in quality of life was statistically significant regarding bodily pain, general health perception and the overall mental and physical health scores. Nevertheless, the perfused patients reported a considerable amount of disease- and treatment related specific morbidity, fear of recurrent disease and cosmetic problems.

Although the favorable outcome for ex-ILP patients is a counter-intuitive finding, it has also been reported for other cancer types. ${ }^{9,14-16}$ There are several possible explanations why the survivors perform better. First, this study population is a selection $(21 \%)$ of all 292 patients that underwent an ILP for recurrent extremity melanoma in our institution. These patients are the most favorable of a group of patients that generally has a short life expectancy due to their disease, and is probably mostly happy to have survived for a median of 14 years after ILP. Second, the patients' standards and values of life may have changed during the course of the disease, as part of the process of accommodating to the illness, a phenomenon known as response-shift. ${ }^{17}$ For example, long-term survivors may get used to a persistent physical complaint although the severity of the complaint itself has not changed over time. ${ }^{18}$ Consequently, they tend to value their com-

Table 5. Factors that are significantly related to the mental or physical component score (multivariable logistic regression analysis)

\begin{tabular}{|c|c|c|c|c|c|}
\hline \multicolumn{3}{|l|}{ Physical $\left(\mathrm{R}^{2}=38 \%\right)$} & \multicolumn{3}{|l|}{ Mental $\left(\mathrm{R}^{2}=24 \%\right)$} \\
\hline Factor & B & P-value & Factor & B & P-value \\
\hline $\begin{array}{l}\text { Stiffness of the } \\
\text { perfused extremity }\end{array}$ & -6.4 & 0.000 & $\begin{array}{l}\text { Stiffness of the } \\
\text { perfused extremity }\end{array}$ & -5.8 & 0.000 \\
\hline \multirow[t]{3}{*}{ Lesions on lower leg } & 5.8 & 0.02 & $\begin{array}{l}\text { Necessity for } \\
\text { supportive stockings }\end{array}$ & -0.007 & 0.004 \\
\hline & & & $\begin{array}{l}\text { Age at the time } \\
\text { of analysis }\end{array}$ & -2.9 & 0.007 \\
\hline & & & Fear of recurrences & -2.1 & 0.045 \\
\hline
\end{tabular}


plaints less severe than someone who has not survived cancer. Third, the study group was relatively old, as well as the comparison group, meaning that both populations have relatively many other health problems that come with aging. As these were probably perceived as less disabling by the long-term survivors than by the comparison group, this might have enlarged the difference by both groups. ${ }^{8,19}$

Approximately half of the patients have complaints of edema, stiffness of the extremity or stinging sensations to some extent. This limits $72-82 \%$ of them in their daily activities, with $19-25 \%$ being severely hindered. An evaluation of early physical functional after ILP has been performed by Wiarda et al. in the framework of a randomized controlled trial, in which patients were treated for primary extremity melanoma with wide local excision with or without ILP ${ }^{20,21}$ They found a significant difference in the ability to walk and especially run, in favor of the non-perfused group, and a restriction in ankle function. Olieman et al. assessed physical function in patients from their center, participating in the same aforementioned trial at that time..$^{21,22}$ They found paresthesias and pain in the ILP group as the most important symptoms still present at one year after treatment. It was stated that this did not hinder the patients' functioning, as measured by physical examination of these patients. Unfortunately, no assessment was done of the patients' subjective perception of limitations. Others have also found physical impairment on the long-term after ILP, with stiffness of the treated limb and restriction in motion of the ankle or wrist in $25-40 \%$ of the patients. ${ }^{23,24}$

Regarding cosmetics, a third of the patients had some complaints, a color difference of the extremities, visible remnants of (non vital) skin lesions and/or edema. This prevented more than half of them from wearing shorts, bathing suits, or anything that would leave their treated extremity naked.

More than two-thirds of the patients had any degree of fear for further recurrences. Ninety per cent of the patients still checked their limbs and body for recurrences at any frequency. This could be an expression of fear, or an act of compliance, since patients are told to contact their physician if new lesions would appear. It is remarkable, however, because the risk of new cutaneous lesions in these patients, at a median of 14 years after treatment, is approximately $5 \%$ at the most. Although almost $60 \%$ of the patients have more than one disease- or treatment related complaint at a median of 14 years after ILP, $88 \%$ of all patients would (probably) choose to undergo ILP again or would advise their relatives or friends to do so. It has been stated by others that patients who have survived cancer tend to value the fact that they are still alive highly and attribute this to the treatment that rendered them disease-free. ${ }^{14,25}$ The only clinical trial that has compared patients who underwent amputation with limb sparing treatment (resection and radiotherapy) for extremity soft tissue sarcoma, illustrates this by showing no difference in quality of life between these groups. ${ }^{26}$ This also leads to the assumption that long-term survivors value the fact that they survived highly and they are consequently usually satisfied with the treatment that rendered them disease-free.

As for work- and insurance related issues, only a few patients experienced problems in these fields. Compared to the results with the same questionnaire in a study on long-term survivors of Hodgkin lymphoma in the Netherlands, our results were more favorable with $6 \%$ problems in obtaining a mortgage compared 
to $14 \%$ in their study and $9 \%$ problems getting life insurance compared to $27 \%{ }^{8}$ This might be explained by the fact that our patients were older and probably already had a mortgage and life insurance. In comparison with American figures, our results also compare favorably, which is probably due to the better social security and healthcare system in the Netherlands. ${ }^{9,27}$

Stiffness of the treated extremity was negatively associated with physical performance in these long-term survivors, while lesions located on the lower leg at the time of ILP influenced physical functioning positively. Earlier studies have also shown that objectively measured stiffness of joints in the treated extremity is often the only sign of long-term morbidity after ILP. ${ }^{22-24}$ Lesions on the lower leg can usually be treated by a femoral ILP which is associated with less morbidity, due to the absence of the iliac lymph node dissection and a lower dose of melphalan, than a procedure performed at the iliac level. This is probably the explanation for the fact that localization of lesions on the lower leg is a relatively favorable prognostic sign for later physical function. The most important factors that influenced these long-term survivors' mental well being appeared to the perceived stiffness of the extremity, the necessity to wear supportive stockings, age at analysis and fear of recurrences. The fact that patients are daily confronted with their past disease by the necessity to wear stockings impacts mental wellbeing by causing a disturbed sense of self or body perception that has also been reported in other studies to be a specific phenomenon of long-term survivors of cancer. ${ }^{14,15,25}$ Chronic stiffness of an extremity could have a psychosocial impact by being limited in one's range of action; others have also stated an association between depressive symptoms and physical functioning..$^{28}$ A higher incidence of depression has been reported at higher age, caused by all age specific life-events as well as the fact that older persons tend to be alone more often. ${ }^{27,29}$ This study confirms what has been found by others, that fear of recurrences is an important persistent issue in long term survivors of cancer. ${ }^{29}$

Unfortunately, for the present study no control group could be composed of long-term survivors of recurrent limb melanoma managed by other treatments than ILP. This is due to the fact that there are only few long-term survivors of recurrent limb melanoma, that have been cured by other treatments, such as surgical excision, $\mathrm{CO}_{2}$ laser ablation, radiotherapy and/or systemic chemo- or immunotherapy, due to the limited prognosis of this disease. ${ }^{5}$ Consequently, the best comparison available was one with an age- and gender-matched group from the general Dutch population. The cross-sectional design of this study might have introduced bias by assessing quality of life at only one point in time, at a variable time distance of ILP for each patient. Secondly, the fact that this analysis was cross-sectionally performed at a long interval after ILP has introduced the aforementioned effects that in retrospection, patients tend to value their complaints as less severe.

From this first study on quality of life after ILP for recurrent melanoma it can be concluded that long-term survivors have a better quality of life than age- and sex-matched Dutch controls. Nevertheless, disease- and treatment specific problems do still impact their lives at a median of 14 years after ILP, with only $20 \%$ of them being free of any complaints. Patients and physicians are fairly ignorant of the impact of late sequelae of ILP. The findings of this study can be useful in 
informing patients and physicians better of what to expect after ILP in terms of quality of life. Further studies should be performed in order to find out whether earlier psychological support or more specific physiotherapy can prevent the reported late physical and mental sequelae.

\section{References}

1. Creech DG, Krementz ET, Ryan RF, Winblad JN. Chemotherapy of cancer: regional perfusion utilising an extracorporeal circuit. Ann Surg 1958; 148:616-632.

2. Sonneveld EJ, Vrouenraets BC, van Geel BN, Eggermont AMM, Klaase JM, Nieweg OE, van Dongen JA, Kroon BBR. Systemic toxicity after isolated limb perfusion with melphalan for melanoma. Eur J Surg Oncol 1996; 22:521-527.

3. Kroon BBR. Regional isolation perfusion in melanoma of the limbs; accomplishments, unsolved problems, future. Eur J Surg Oncol 1988; 14:101-110.

4. Vrouenraets BC, Nieweg OE, Kroon BBR. Thirty-five years of isolated limb perfusion for melanoma: indications and results. Br J Surg 1996; 83:1319-1328.

5. Balch CM, Buzaid AC, Soong S-J, Atkins MB, Cascinelli N, Coit DG, Fleming ID, Gershenwald JE, Houghton A, Jr., Kirkwood JM, McMasters KM, Mihm MF, Morton DL, Reintgen DS, Ross MI, Sober A, Thompson JA, Thompson JF. Final version of the American Joint Committee on Cancer staging system for cutaneous melanoma. $J$ Clin Oncol 2001; 19:3635-3648.

6. Vrouenraets BC, Eggermont AMM, Klaase J, van Geel A, van Dongen JA, Kroon BBR. Long-term neuropathy after regional isolated perfusion with melphalan for melanoma of the limbs. Eur J Surg Oncol 1994; 20:681-685.

7. Vrouenraets BC, Klaase JM, Kroon BBR, van Geel BN, Eggermont AMM, Franklin HR. Long-term morbidity after regional isolated perfusion with melphalan for melanoma of the limbs. The influence of acute regional toxic reactions. Arch Surg $1995 ; 130: 43-47$.

8. van Tulder MW, Aaronson NK, Bruning PF. The quality of life of long-term survivors of Hodgkin's disease. Ann Oncol 1994; 5:153-158.

9. Joly F, Heron JF, Kalusinski L, Bottet P, Brune D, Allouache N, Mace-Lesec'h J, Couette JE, Peny J, Henry-Amar M. Quality of life in long-term survivors of testicular cancer: a population-based case-control study. J Clin Oncol 2002; 20:73-80.

10. Dirksen SR. Perceived well-being in malignant melanoma survivors. Oncol Nurs Forum 1989; 16:353-358.

11. Hahn D, Meiland F, Wiarda V, Rumke Ph., van Dam F, Kroon BBR. Quality of life in early stage perfused and non-perfused melanoma patients. 1990.

12. Wieberdink J, Benckhuijsen C, Braat RP, van Slooten EA, Olthuis GA. Dosimetry in isolation perfusion of the limbs by assessment of perfused tissue volume and grading of toxic tissue reactions. Eur J Cancer Clin Oncol 1982; 18:905-910.

13. Ware JE, Jr., Sherbourne CD. The MOS 36-item short-form health survey (SF-36). I. Conceptual framework and item selection. Med Care 1992; 30:473-483.

14. Ganz PA, Desmond KA, Leedham B, Rowland JH, Meyerowitz BE, Belin TR. Quality of life in long-term, disease-free survivors of breast cancer: a follow-up study. $J$ Natl Cancer Inst 2002; 94:39-49.

15. Ramsey SD, Berry K, Moinpour C, Giedzinska A, Andersen MR. Quality of life in 
long term survivors of colorectal cancer. Am J Gastroenterol 2002; 97:1228-1234.

16. Fredette SL. Breast cancer survivors: concerns and coping. Cancer Nurs 1995; 18:3546.

17. Sprangers MA. Quality-of-life assessment in oncology. Achievements and challenges. Acta Oncol 2002; 41:229-237.

18. Longo DL. Interferon toxicity worse in retrospect; impact on Q-TWiST? QualityAdjusted Time Without Symptoms or Toxicity. J Clin Oncol 1998; 16:3716.

19. McHorney CA, Kosinski M, Ware JE, Jr. Comparisons of the costs and quality of norms for the SF-36 health survey collected by mail versus telephone interview: results from a national survey. Med Care 1994; 32:551-567.

20. Wiarda V, Wimmers R, in 't Veld G, Meiland F, Hahn D, van Dam F, Kroon B. Functioneel en functieonderzoek van de onderste extremiteit na een regionale geïsoleerde perfusie behandeling. Nederlands Tijdschrift voor Fysiotherapie 1992; 4:103-108.

21. Schraffordt Koops H, Vaglini M, Suciu S, Kroon BBR, Thompson JF, Gohl J, Eggermont AM, Di Filippo F, Krementz ET, Ruiter D, Lejeune FJ. Prophylactic isolated limb perfusion for localized, high-risk limb melanoma: results of a multicenter randomized phase III trial. J Clin Oncol 1998; 16:2906-2912.

22. Olieman AF, Schraffordt Koops H., Geertzen JH, Kingma H, Hoekstra HJ, Oldhoff J. Functional morbidity of hyperthermic isolated regional perfusion of the extremities. Ann Surg Oncol 1994; 1:382-388.

23. van Geel AN, van Wijk J, Wieberdink J. Functional morbidity after regional isolated perfusion of the limb for melanoma. Cancer 1989; 63:1092-1096.

24. Vrouenraets BC, in 't Veld GJ, Nieweg OE, van Slooten GW, van Dongen JA, Kroon BBR. Long-term functional morbidity after mild hyperthermic isolated limb perfusion with melphalan. Eur J Surg Oncol 1999; 25:503-508.

25. Gotay CC, Muraoka MY. Quality of life in long-term survivors of adult-onset cancers. J Natl Cancer Inst 1998; 90:656-667.

26. Sugarbaker PH, Barofsky I, Rosenberg SA, Gianola FJ. Quality of life assessment of patients in extremity sarcoma clinical trials. Surgery 1982; 91:17-23.

27. Cella DF. Cancer survival: psychosocial and public issues. Cancer Invest 1987; 5:5967.

28. Fiske A., Kasl-Godley J.E., Gatz M. Mood disorders in late life. In Bellack A.S., Hersen M. (eds). Comprehensive clinical psychology. Oxford: Elsevier Science; 2003:193-229.

29. Ganz PA. Late effects of cancer and its treatment. Semin Oncol Nurs 2001; 17:241248. 


\title{
Chapter 10
}

\section{Isolated limb perfusion with TNF- $\alpha$ and melphalan for unresectable soft tissue sarcoma of the extremities}

\author{
Noorda EM, Vrouenraets BC, Nieweg OE, van Coevorden F, \\ van Slooten $G W$, Kroon BBR \\ Department of Surgery, The Netherlands Cancer Institute / Antoni van Leeuwenhoek hospital, \\ Amsterdam, the Netherlands
}

Cancer 2003; 7:1483-1490

\section{Introduction}

Since 1957, isolated limb perfusion (ILP) with melphalan is a well-accepted treatment modality for locoregionally unresectable melanoma of the extremities. ${ }^{1}$ The application of ILP as a treatment of soft tissue sarcoma (STS) of the extremities has gained success after Liénard et al. first added tumor necrosis factor-alpha (TNF $\alpha$ ) to melphalan-ILP in $1992 .{ }^{2}$ Before that time, no other anti-sarcoma drugs had lead to the promising results with acceptable toxicity attained with TNF $\alpha$ in the isolated circuit. ${ }^{3}$

In the first four patients with unresectable recurrent STS treated with TNF $\alpha$ and melphalan, a $100 \%$ tumor response rate was reported after ILP. ${ }^{2}$ Later results of TNFo-ILP for unresectable STS of the extremities from other institutions showed overall response rates varying from 79 to $91 \% .^{4-7}$ TNF $\alpha$-ILP could enable limb-sparing surgery in responding patients, thereby aiming at a diseasefree extremity with preserved function, without compromising long-term survival. ${ }^{8,9}$

Possible drawbacks exist as well. ILP is a considerable surgical procedure with a risk of regional and systemic complications. Severe regional toxicity can cause long-term impaired extremity-function and the risk of a shock-like syndrome is considerable if more than $10 \%$ leakage of TNF $\alpha$ to the systemic circulation during ILP occurs. ${ }^{10,11}$ Moreover, the risk of local recurrence after limbsparing surgery is considerable ${ }^{8,12}$ and response and limb salvage rates after TNF $\alpha$-ILP are promising, but vary and tend to get lower over time..$^{4-7}$

In view of the above, we studied the results of limb salvage surgery with TNF $\alpha$-ILP regarding toxicity, limb salvage rate, local relapse rate, functional outcome and survival in patients with locally unresectable sarcoma of the extremities who were treated in our institution. 


\section{Patients and methods}

\section{Patient characteristics}

From 1992 to 2001, 49 consecutive patients with unresectable STS of an extremity underwent ILP with TNF $\alpha$ and melphalan in our institution. Of these patients, 29 $(58 \%)$ were male and the mean age was 51 years (range 14-85 years). Tumors were considered unresectable when local control was only possible by mutilating surgery resulting in major functional morbidity or by amputation of the affected extremity. Resectability with adequate margins was judged on the basis of clinical examination and computed tomography scans or magnetic resonance imaging. Criteria for unresectability (with the number of patients between brackets) were:

\section{Multifocality (2)}

2. Fixation to vital neural/vascular structures or bone (10)

3 . Recurrences in a previously irradiated area without possibilities for radical surgery (2)

4. Localization at or near a joint (5)

5. Large size ( $>8 \mathrm{~cm}$ in diameter) of which radical surgery would lead to functional amputation (17)

6. Combination of factors (13)

Tumor characteristics regarding histological subtypes, tumor grade and stage of disease at the time of ILP are displayed in Tables 1, 2 and 3. Grade was pathologically scored following criteria according to Coindre et al., i.e. degree of differentiation, necrosis and mitotic figures. ${ }^{13}$ Stage of disease was determined following AJCC standards. ${ }^{14}$ Median tumor size was $14 \mathrm{~cm}$ (range 8-20 cm). For a multifocal localization this concerned the largest lesion. Nine patients had undergone prior systemic chemotherapy.

Table 1. Histological subtypes $(n=49)$

\begin{tabular}{lll}
\hline Histological subtype & N & $\%$ \\
Liposarcoma & 9 & 19 \\
Leiomyosarcoma & 8 & 17 \\
Synovial sarcoma & 6 & 12 \\
Malignant peripheral nerve sheath tumor & 5 & 10 \\
Rhabdomyosarcoma & 5 & 10 \\
Epitheloid cell tumor & 4 & 8 \\
MFH & 4 & 8 \\
Agressive fibromatosis & 2 & 4 \\
Angiosarcoma & 2 & 4 \\
Other sarcoma types* & 4 & 8 \\
\hline
\end{tabular}

*Two pleiomorph sarcomas, one myxoid chondrosarcoma and one sarcoma NOS 
Table 2. Histological grade $(n=49)$

\begin{tabular}{lrr}
\hline Grade & N & $\%$ \\
\hline I & 10 & 20 \\
II & 16 & 33 \\
III & 21 & 43 \\
N/A* & 2 & 4 \\
\hline
\end{tabular}

* Not applicable: two patients with aggressive fibromatosis

\section{ILP drugs and technique}

Our ILP methodology has been described earlier in detail. ${ }^{15}$ During ILP, the major artery and vein are clamped at the desired level, collateral vessels are ligated and a tourniquet is applied around the limb, proximal to the region of ILP. After insertion of the catheters, the isolated limb is perfused by an extra-corporeal circulation, oxygenated and propelled by a heart-lung machine. A melphalan dose of $13 \mathrm{mg} / \mathrm{l}$-perfused tissue in the upper limb and $10 \mathrm{mg} / \mathrm{l}$ for the lower limb is added to the perfusate. For TNF $\alpha$ this is $3 \mathrm{mg}$ and $4 \mathrm{mg}$ respectively, irrespective of limb volume. In five patients interferon-gamma (IFN $\alpha$ ) was added, as part of a multicenter study. ${ }^{5}$ This was injected subcutaneously on the two days before surgery $(0.2 \mathrm{mg}$ IFN $\alpha)$ and the same dose was given during ILP. TNF $\alpha \pm$ IFN $\alpha$

Table 3. Stage of disease with American Joint Committee on Cancer (AJCC) TNM classification $14(n=49)$

\begin{tabular}{llrr}
\hline Stage & TNM $^{\dagger}$ & N & $\%$ \\
\hline IB & (G1-G2, T2a, N0, M0) & 3 & 6 \\
IIA & (G1-G2, T2b, N0, M0) & 15 & 31 \\
IIB & (G3-G4, T1a-b, N0, M0) & 2 & 4 \\
III & (G3-G4, T2b, N0, M0) & 12 & 24 \\
IVA & (Any grade, any size, N1M0) & 2 & 4 \\
IVB & (Any grade, any size, N0M1) & 13 & 27 \\
N/A & & 2 & 4 \\
\hline
\end{tabular}

* Not applicable: two patients with aggressive fibromatosis

${ }^{\dagger}$ AJCC TNM grading system:

G1-G2 Low grade: well/moderately differentiated

G3-G4 High grade: poorly/undifferentiated

T1 Small $\leq 5 \mathrm{~cm}$

T2 Large $>5 \mathrm{~cm}$

a Superficial tumor is above the superficial fascia without invading the fascia

b Deep tumor is either beneath the superficial fascia and/or invading the fascia

No/N1 No regional lymph node metastases/regional lymph node metastases

M0/M1 No distant metastases/distant metastases 
was injected as a bolus at the beginning of the ILP and was circulated for 90 minutes. Melphalan was injected 30 minutes after the administration of TNF $\alpha \pm$ IFN $\alpha$ and was circulated for the remaining 60 minutes. During ILP, adequate tissue temperatures are achieved and maintained by heating the heparinized perfusate and application of a warm water blanket around the limb. Limb temperatures are kept between $38^{\circ} \mathrm{C}$ and $40^{\circ} \mathrm{C}$ (mild hyperthermia). At termination of the procedure, the perfusate is drained out and the limb is rinsed with an electrolyte solution. The tourniquet is then released and catheters are removed. Two ILPs were at the axillary, ten at the brachial, 16 at the iliac and 21 at the femoral isolation level. Leakage from the isolated circuit into the systemic circulation was continuously monitored with radioactive labeled human serum albumin.

\section{Complications and toxicity}

Postoperative complications recorded were seroma, wound infection, postoperative bleeding, arterial and venous thrombosis. Acute regional toxicity was graded from I to $\mathrm{V}$ according to Wieberdink et al. ${ }^{16}$ Systemic toxicity was measured according to Common Toxicity Criteria. ${ }^{17}$ Signs that were evaluated were: nausea/vomiting, fever, hypotension, rhythm disturbances, serum bilirubin, alanineamino transferase, asparagine-amino transferase (ASAT), white blood cell and platelet counts.

\section{Tumor response}

Clinical tumor responses were assessed according to standardized WHO criteria. ${ }^{18}$ Complete responses (CR) were defined as the complete disappearance of tumor in the extremity for more than four weeks, partial responses (PR) as regression of tumor size by more than $50 \%$ during more than four weeks, no change (NC) as regression of tumor size less than $50 \%$ for more than four weeks, and progressive disease (PD) as progression of more than $25 \%$. After resection of the tumor remnant, pathological examination provided a second assessment of response. The percentage of necrosis was estimated on the basis of macroscopic evaluation of necrotic tissue and histological examination of tissue surrounding the necrotic tissue area. A tumor in complete response was $100 \%$ necrotic. If the tumor had 50-99\% necrosis, the response was considered partial. If the tumor was $<50 \%$ necrotic, response was classified as no change. Final tumor response was based upon a combination of clinical and pathological responses. If a clinical PR proved to be $100 \%$ necrotic at pathological examination, the response was upgraded to a CR. Pathological assessment was decisive with one exception. If tumor size had decreased clinically more than $50 \%$ but at pathological examination less than $50 \%$ necrosis was found, the response was not downgraded, but still regarded a PR since the regression of the tumor was more than $50 \%$ and had allowed local resection.

\section{Final treatment of the tumor remnant}

Local resection of the tumor remnant was performed at maximal response and if the tumor was considered resectable at that time. Generally, this was aimed to be at approximately 10 weeks after ILP. Postoperative radiation therapy was considered indicated in case of marginal or positive resection margins. 
Table 4. Tumor response $(n=49)$

\begin{tabular}{lccc}
\hline & Clinical response & Histological response * & Final response \\
\hline CR & $1(2 \%)$ & $4(8 \%)$ & $4(8 \%)$ \\
PR & $23(47 \%)$ & $14(29 \%)$ & $27(55 \%)$ \\
$N C$ & $17(35 \%)$ & $24(49 \%)$ & $12(25 \%)$ \\
PD & $7(14 \%)$ & & $5(10 \%)$ \\
NE & $1(2 \%)$ & $7(14 \%)$ & $1(2 \%)$ \\
\hline
\end{tabular}

$\mathrm{NE}=$ not evaluable

* Histological material was available from eight amputations, three punctures/biopsies and 31 local resections

\section{Long-term morbidity and follow-up}

Long-term morbidity was scored by identifying the following signs/symptoms: edema, venous thrombosis, arterial occlusion, nerve injury, muscle atrophy/fibrosis, recurrent infections, pain and extremity malfunction. Morbidity was considered irreversible if complaints persisted longer than two years after ILP. Median follow-up was 26 months (range 2 days-103 months) after ILP. Three patients were lost to follow-up at five, 11, and 16 months after ILP; all left for their home countries after successful resection of the tumor remnant.

\section{Results}

Tumor response and resection of the tumor remnant

Clinical tumor response, pathological response and final response are displayed in Table 4. In one patient ( $2 \%$ ) who died two days after ILP, tumor response could not be assessed. A clinical CR was attained in one patient (2\%), 23 patients (47\%) had a PR, 17 patients (35\%) NC of the tumor and seven patients PD (14\%) Pathological response was a CR in four patients (8\%), a PR in 14 (29\%) and NC in 24 $(49 \%)$ of these patients. The combined final response rate was a $\mathrm{CR}$ in four patients (8\%), a PR in 27 patients $(55 \%), \mathrm{NC}$ in $12(25 \%)$ and PD in five patients (10\%). Although after 34 ILPs (69\%) sufficient clinical response was seen to locally resect the tumor remnant, resection was actually done in only 31 patients $(63 \%)$ because of progressive distant metastasic disease in the other three patients. Thirteen of these patients had a clinical NC response, but a substantial amount of tumor necrosis on dynamic MRI. Histological material was further available from eight amputations and three punctures/biopsies. Tumor resection was performed at a median of 3.9 months after ILP (range 10 days- 8 months). The resection that was done at 10 days after ILP was in a 17-year-old boy with extremely fast necrosis of the tumor. In some patients resection was performed longer than 10 weeks after ILP, as was the aim, because maximal tumor regression was still ongoing at that time. Resection margins were considered macroscopically involved in 11 patients and microscopically in four. In 16 patients the margins were considered to be tumor negative, although marginal (with less than 
Table 5. Final tumor response related to tumor grade $(n=46) *$

\begin{tabular}{lcrll}
\hline & CR & PR & NC & PD \\
\hline Low (I) & 0 & 5 & 4 & 1 \\
Intermediate (II) & 3 & 7 & 4 & 1 \\
High (III) & 1 & 13 & 4 & 3 \\
\hline
\end{tabular}

* 46 cases were included because two patients had ILP because of aggressive fibromatosis which is not defined by any tumor grade and in one patient response was not evaluable dueto early death. $\mathrm{X} 2$ test, $\mathrm{p}=0.58$

$5 \mathrm{~mm}$ margin of healthy tissue) in eight. Additional radiation therapy was given in the 23 patients with involved or marginally free resection margins.

Neither initial tumor size nor grade influenced final response in univariate analysis. When tumor size was divided in those smaller or equal to $8 \mathrm{~cm}$ and larger than $8 \mathrm{~cm}$, responses were similar, with no versus four CRs, six versus 21 PRs, three versus nine NCs and two versus three PDs, respectively (Fischer's Exact Test, $\mathrm{p}=0.64)$. The lack of relation between final tumor response and histological grade is shown in Table 5.

\section{Amputations}

In 13 patients $(27 \%)$ amputation of the limb was performed. Eight patients underwent amputation of the extremity following insufficient reponse to ILP, which was a PR in three and PD in five patients.. The other five patients underwent amputation for local recurrence $(n=2) 20$ and 32 months after ILP respectively, for progression after initial PR $(n=2)$ four and 12 months after ILP respectively and for treatment-related complications $(n=1) 20$ months after ILP. Although in 36 of 49 patients (74\%) the limb was not amputated, eight of them had persistent unresectable local disease for which amputation was not performed because of progressive distant metastases. One of them underwent a second ILP for local tumor progression that failed to render the tumor resectable. He died 31 months after the first ILP due to systemic metastases. Finally, ILP resulted in local tumor control with preservation of the affected limb in 28 of 49 patients $(57 \%)$.

\section{Locoregional relapse}

Four of the 32 patients (13\%) who had been rendered clinically tumor-free by ILP with $(n=31)$ or without $(n=1)$ subsequent resection \pm radiation therapy relapsed locally in the treated extremity at six, seven, 20 and 32 months after ILP, respectively. In two of them the recurrence could be treated by local surgery, keeping their extremities salvaged. Five-year local relapse-free survival was $83 \%$ for the 32 patients who were initially rendered tumor-free by ILP \pm subsequent resection and radiation therapy. 


\section{Survival}

Five-year disease-specific survival was $48 \%$ for the 49 patients. Median overall survival was 49 months (95\% CI 2-96 months). The 13 patients with stage IVB disease at ILP had a median overall survival of 8 months (95\% CI 4-11 months). The other 36 patients with locoregional disease only at ILP had a median overall survival of 91 months (95\% CI 24-158 months, $\mathrm{P}<0.0001)$. Two of these latter patients died from other causes than sarcoma: one from treatment-related complications (see earlier) and one patient from intercurrent disease, being free from sarcoma.

\section{Toxicity and complications}

Acute regional toxicity was mild (grade I/II reactions) in 35 patients (71\%) and more severe (grade III reactions) in twelve patients $(25 \%)$. A grade IV reaction was observed in one patient $(2 \%)$ and resulted in fibrosis and functional impairment that was reversible within four months after ILP. Nevertheless, after resection of the tumor remnant and subsequent radiation therapy, this patient developed radiation-induced necrosis with a severe wound infection necessitating an above knee amputation 20 months after ILP. Overall, seven of the 31 patients $(23 \%)$ who underwent local resection of the tumor remnant developed wound healing disturbances: one patient without additional radiotherapy had delayed wound healing and six patients developed wound infections after additional radiation therapy, with wound problems lasting for one and six years in two of these patients.

There was little systemic toxicity after TNF $\alpha-$ ILP, no severe cardiovascular reactions with hypotension or disturbances of the cardiac rhythm were observed. Two patients $(4 \%)$ had short-lived postoperative fever and four were nauseous needing anti-emetics (8\%). Transient elevation of liver function tests was observed in 17 patients $(35 \%)$. One patient $(2 \%)$ had a mildly lowered white blood cell count.

Three patients (6\%) had major ILP-related complications: two patients had arterial thrombosis directly following ILP, one after a brachial and one after a femoral ILP. Thrombectomy was performed after which both recovered completely. One patient died due to treatment-related factors. He underwent an iliac ILP for recurrent leiomyosarcoma of his right thigh and had previously undergone radiation therapy of the inguinal area after resection of lymph node metastases. At ILP, the epigastric vessels were ligated as usual. Within 24 hours postoperatively he developed a severe soft tissue infection in his right lower abdominal wall and became septic. Subsequently, he developed gas gangrene up unto his neck and died two days after ILP despite hyperbaric oxygen treatment and surgery.

Functional morbidity is displayed in Table 6. Two patients had neurapraxia that recovered within one month after ILP, another two had isolated peroneal nerve dysfunction and combined peroneal and tibial nerve dysfunction respectively, both recovering after seven to eight months after ILP. Nerve damage was probably caused by initial tumor swelling surrounding the sciatic nerve and/or pressure of the femoral tourniquet. Four patients had irreversible nerve dysfunction following ILP. In one, the tumor remnant appeared to originate from the per- 


\begin{tabular}{|c|c|c|c|c|}
\hline & $\begin{array}{l}1 \text { month } \\
(\mathrm{n}, \%) \\
\mathrm{n}=48^{*}\end{array}$ & $\begin{array}{l}3 \text { months } \\
\text { ( } n, \%) \\
n=47^{*}\end{array}$ & $\begin{array}{l}1 \text { year } \\
(n, \%) \\
n=26^{*}\end{array}$ & $\begin{array}{l}2 \text { years } \\
(n, \%) \\
n=17^{*}\end{array}$ \\
\hline Edema & N/A & $6(13 \%)$ & $6(23 \%)$ & $6(35 \%)$ \\
\hline Recurrent infections & $1(2 \%)$ & $1(2 \%)$ & $4(15 \%)$ & $2(12 \%)$ \\
\hline Muscle atrophy/fibrosis & N/A & $1(2 \%)$ & $4(15 \%)$ & $3(18 \%)$ \\
\hline Pain & $\mathrm{N} / \mathrm{A}$ & $8(17 \%)$ & $3(12 \%)$ & $2(12 \%)$ \\
\hline Neuropathy & $8(16 \%)$ & $6(13 \%)$ & $4(16 \%)$ & $3(19 \%)$ \\
\hline
\end{tabular}

$\mathrm{N} / \mathrm{A}=$ not applicable, ${ }^{*}$ numbers of patients left at risk, alive without amputation

oneal nerve and it was subsequently resected. In two patients, peroneal nerve dysfunction was apparent directly following ILP, due to tumor invasion of the sciatic nerve and subsequent tumor swelling. The fourth patient developed peroneal nerve palsy after the tumor remnant had been resected from the sciatic nerve. Of the 26 patients alive one year after ILP, eight patients (31\%) experienced extremity malfunction due to muscle fibrosis and atrophy $(n=3)$, recurrent infections and edema $(n=1)$ and the aforementioned irreversible nerve dysfunctions $(n=4)$. Three of these patients (18\%) were among the 17 patients still alive at two years after ILP and had persistent complaints of extremity malfunction.

\section{Discussion}

Amputation of the extremity undoubtedly results in the highest local control rate in patients with locally unresectable STS of an extremity..$^{19}$ However, no survival benefit has been shown after amputation compared to limb sparing treatment modalities in these patients, and nowadays the latter is increasingly pursued.

In the present series, we studied the effectiveness of TNF $\alpha$-ILP as part of a limb sparing treatment modality. The overall response rate of $63 \%$ is lower than the $79-91 \%$ response rates reported in the literature..$^{4-7}$ Factors determining tumor response after TNF $\alpha$-ILP in unresectable STS are unknown. It is assumed that high-grade tumors respond better to ILP than low-grade tumors, ${ }^{5}$ although we could not demonstrate that in our series. The four CRs attained in intermediate and high-grade tumors could give a hint in this direction. Also tumor size, with large and highly vascularized tumors responding better, ${ }^{20}$ did not determine response in our series. A possible explanation for our lower response rates could be that response rates tend to decrease over time when ILP is more widely applied, probably due to patient selection, a development similar to that observed in the application of TNF $\alpha$-ILP in melanoma. , $^{2,21,22}$

In $73 \%$ of our patients, the limb was not amputated during the course of their disease. This percentage is comparable to previously reported limb salvage rates of $81-86 \% .^{4-7}$ We consider this so-called limb-salvage rate of $73 \%$ as misleading, since eight of these patients still had unresectable local tumors that were not 
amputated due to progressive distant disease. We prefer to define limb salvage as local control of tumor with preservation of the affected limb, which was the case in our study in $57 \%$ of the patients.

Factors determining this limb salvage rate are tumor response to ILP, the indications for post-ILP amputation and the duration of follow-up. Our aim has always been to achieve a locally radical complete resection after ILP and if this was not considered possible after ILP without severely compromising limb function, amputation was performed. With longer follow-up, more patients will have a risk of recurrence leading to amputation. Our median follow-up of 26 months compares favourably to the follow-up duration of 14, 18 and 26 months, respectively, of other series, ${ }^{4,6,23}$ with two of our patients being amputated at 32 and 60 months after ILP. Our relatively low limb salvage rate could partly be explained by these three factors.

Our local recurrence rate of $13 \%$ is in the lower range of that reported in the literature, which varies from $11-48 \% .^{4-7}$ The percentage of tumor-involved margins after resection (48\%) was lower in our series than reported by Olieman et al. $(58 \%)$, which was unfortunately the only group that reported these exact numbers.7 Recurrent disease as indication for TNF $\alpha$-ILP and postoperative radiation therapy could also influence the local relapse rate.7,12,19 In our series, $18 \%$ of the patients underwent TNF $\alpha$-ILP for a recurrence which is similar to patients treated by the group from Groningen $(12 \%){ }^{7}$ but much lower than in other reports (45-60\%). ${ }^{4-7,23}$ The indication for the application of additional radiation therapy in these studies seems comparable, namely for positive or close margins of resection. ${ }^{24}$

The encountered acute regional tissue toxicity after TNF $\alpha$-ILP is comparable to literature data, with some erythema and edema in $71 \%$ of patients. ${ }^{25}$ Three major ILP-related complications occurred consisting of arterial thrombosis in two patients and one ILP-related death due to fulminant Clostridial infection. Long-term morbidity was seen in several patients. In our series, one amputation was performed for infected radiation-induced necrosis, a complication that has been reported before. ${ }^{7}$ Irreversible procedure-related neuropathy was seen in four patients $(8 \%)$, which is comparable to other studies (3-9\%) $)^{4,5,23}$ The incidence of long-term neuropathy in melanoma patients treated with ILP with melphalan alone has been $20 \%$ after axillary and $2 \%$ after iliac ILPs in our institution, with other institutions reporting a wide range of long-term neuropathy in 1-48\% of the patients. ${ }^{26}$ Finally, $31 \%$ of our patients who were still alive one year after ILP reported extremity malfunction to some extent, and $18 \%$ after 2 years.

Twenty-five per cent of the patients in our series had distant metastases at the time of TNF $\alpha$-ILP. Previous studies on TNF $\alpha$-ILP in unresectable sarcoma have included 3-16\% patients with distant metastatic disease at the time of ILP but did not mention survival rates.-7,23 Only Lejeune et al., who included 11 patients (50\%) with distant metastases, reported a five-year survival of $32 \%$ (versus $48 \%$ in the present series). ${ }^{4}$

Apart from the variable response and the risk of long-term morbidity, TNF $\alpha$ ILP is an extensive and expensive procedure that has to be valued critically. First, its benefit should be compared to that of, for example, preoperative radiotherapy, the results of which are scarce for unresectable soft tissue sarcoma of the extrem- 
ities. ${ }^{27}$ Secondly, although distant disease is likely to be present at the time of primary presentation in high-risk tumors, it is unknown whether an adverse effect on survival results from delayed tumor resection after ILP as compared to radical amputation performed as soon as the diagnosis is made. ${ }^{8,19}$ Third, it is questionable whether an extensive limb-sparing surgery modality as TNF $\alpha$-ILP, resection and radiation therapy is preferable to immediate radical amputation, when functional and psychological outcome is regarded. The only randomized trial comparing patients whose extremities were amputated with those who were treated sparingly, did not show any significant difference in quality of life. ${ }^{28}$ Amputees can have considerable mobility if good prostheses are prescribed with well-guided rehabilitation. ${ }^{29}$ From a study that compared quality of life and extremity function between patients who were either limb salvaged or had amputation for extremity osteosarcoma, it appeared that the limb salvaged patients scored higher in extremity function but both groups had a similar ability to walk, amount of pain and acceptance of the postoperative state. ${ }^{30}$

If limb-sparing surgery were considered, criteria would be helpful to select those patients who are likely to respond well. It was assumed that high-grade, highly-vascularized and/or large sarcomas are most likely to respond to TNF $\alpha$ ILP, expressed in tumor size reduction and necrosis. ${ }^{5}$ However, we have not been able to confirm these assumptions. It could be that different histological tumor types react differently to TNF $\alpha$-ILP. Histological subgroups of sarcoma are usually too small to draw conclusions, as in this analysis. The predictive value of FDG-PET for tumor response is promising and should be further confirmed. ${ }^{31}$ Since no clear data are available to identify those who are most likely to benefit from ILP, and survival, functional and psychological status are similar after radical amputation and limb-sparing surgery, both options should be considered and discussed with the patient.

In conclusion, ILP in combination with limb salvage surgery can provide local tumor control in the majority of patients with unresectable extremity STS. This intensive extremity sparing treatment modality is not free from some troublesome complications. A better selection of those who are most likely to benefit from TNF $\alpha$-ILP is needed.

\section{References}

1. Vrouenraets BC, Nieweg OE, Kroon BBR. Thirty-five years of isolated limb perfusion for melanoma: indications and results. Br J Surg 1996; 83:1319-1328.

2. Liénard D, Ewalenko P, Delmotte JJ, Renard N, Lejeune FJ. High-dose recombinant tumor necrosis factor alpha in combination with interferon gamma and melphalan in isolation perfusion of the limbs for melanoma and sarcoma. J Clin Oncol 1992; 10:5260 .

3. Klaase JM, Kroon BBR, Benckhuijsen C, van Geel AN, Albus-Lutter CE, Wieberdink $\mathrm{J}$. Results of regional isolation perfusion with cytostatics in patients with soft tissue tumors of the extremities. Cancer 1989; 64:616-621.

4. Lejeune FJ, Pujol N, Lienard D, Mosimann F, Raffoul W, Genton A, Guillou L, Landry M, Chassot PG, Chiolero R, Bischof-Delaloye A, Leyvraz S, Mirimanoff RO, 
Bejkos D, Leyvraz PF. Limb salvage by neoadjuvant isolated perfusion with TNFalpha and melphalan for non-resectable soft tissue sarcoma of the extremities. Eur J Surg Oncol 2000; 26:669-678.

5. Eggermont AMM, Schraffordt Koops H, Klausner JM, Kroon BBR, Schlag PM, Liénard D, van Geel AN, Hoekstra HJ, Meller I, Nieweg OE, Kettelhack C, Ben Ari G, Pector JC, Lejeune FJ. Isolated limb perfusion with tumor necrosis factor and melphalan for limb salvage in 186 patients with locally advanced soft tissue extremity sarcomas. The cumulative multicenter European experience. Ann Surg 1996; 224:756-764.

6. Gutman M, Inbar M, Lev-Shlush D, Abu-Abid S, Mozes M, Chaitchik S, Meller I, Klausner JM. High dose tumor necrosis factor-alpha and melphalan administered via isolated limb perfusion for advanced limb soft tissue sarcoma results in a $>90 \%$ response rate and limb preservation. Cancer 1997; 79:1129-1137.

7. Olieman AF, Pras E, van Ginkel RJ, Molenaar WM, Schraffordt Koops H, Hoekstra HJ. Feasibility and efficacy of external beam radiotherapy after hyperthermic isolated limb perfusion with TNF-alpha and melphalan for limb-saving treatment in locally advanced extremity soft-tissue sarcoma. Int J Radiat Oncol Biol Phys 1998; 40:807814.

8. Rosenberg SA, Tepper J, Glatstein E, Costa J, Baker A, Brennan M, DeMoss EV, Seipp C, Sindelar WF, Sugarbaker P, Wesley R. The treatment of soft-tissue sarcomas of the extremities: prospective randomized evaluations of (1) limb-sparing surgery plus radiation therapy compared with amputation and (2) the role of adjuvant chemotherapy. Ann Surg 1982; 196:305-315.

9. Williard WC, Hajdu SI, Casper ES, Brennan MF. Comparison of amputation with limb-sparing operations for adult soft tissue sarcoma of the extremity. Ann Surg 1992; 215:269-275.

10. Vrouenraets BC, Klaase JM, Kroon BBR, van Geel BN, Eggermont AMM, Franklin HR. Long-term morbidity after regional isolated perfusion with melphalan for melanoma of the limbs. The influence of acute regional toxic reactions. Arch Surg $1995 ; 130: 43-47$.

11. Vaglini M, Santinami M, Manzi R, Inglese MG, Santoro N, Persiani L, Belli F. Treatment of in-transit metastases from cutaneous melanoma by isolation perfusion with tumour necrosis factor-alpha (TNF-alpha), melphalan and interferon-gamma (IFNgamma). Dose-finding experience at the National Cancer Institute of Milan. Melanoma Res 1994; 4 Suppl 1:35-38.

12. Collin CF, Friedrich C, Godbold J, Hajdu S, Brennan MF. Prognostic factors for local recurrence and survival in patients with localized extremity soft-tissue sarcoma. Semin Surg Oncol 1988; 4:30-37.

13. Coindre JM, Trojani M, Contesso G, David M, Rouesse J, Bui NB, Bodaert A, De Mascarel I, De Mascarel A, Goussot JF. Reproducibility of a histopathologic grading system for adult soft tissue sarcoma. Cancer 1986; 58:306-309.

14. Soft tissue sarcoma. In Fleming ID, Cooper JS, Henson D.E. (eds). AJCC Cancer Staging Manual. Philadelphia: Lippincott-Raven Publishers; 1997:149-156.

15. Kroon BBR. Regional isolation perfusion in melanoma of the limbs; accomplishments, unsolved problems, future. Eur J Surg Oncol 1988; 14:101-110.

16. Wieberdink J, Benckhuijsen C, Braat RP, van Slooten EA, Olthuis GA. Dosimetry in isolation perfusion of the limbs by assessment of perfused tissue volume and grading of toxic tissue reactions. Eur J Cancer Clin Oncol 1982; 18:905-910. 
17. Cancer Therapy Evaluation Program. Common Toxicity Criteria, Version 2.0. DCTD, NCI, NIH, DHHS. 1998.

18. WHO handbook for reporting results of cancer treatment. Geneva: WHO; 1979.

19. Pisters PW, Leung DH, Woodruff J, Shi W, Brennan MF. Analysis of prognostic factors in 1,041 patients with localized soft tissue sarcomas of the extremities. $J$ Clin Oncol 1996; 14:1679-1689.

20. Lejeune FJ. High dose recombinant tumour necrosis factor (rTNF alpha) administered by isolation perfusion for advanced tumours of the limbs: a model for biochemotherapy of cancer. Eur J Cancer 1995; 31A:1009-1016.

21. Eggermont AMM, ten Hagen TL. Isolated limb perfusion for extremity soft-tissue sarcomas, in-transit metastases, and other unresectable tumors: credits, debits, and future perspectives. Curr Oncol Rep 2001; 3:359-367.

22. Liénard D, Eggermont AMM, Schraffordt Koops H, Kroon B.B.R., Towse G, Hiemstra S, Schmitz P, Clarke J, Steinmann G, Rosenkaimer F, Lejeune FJ. Isolated limb perfusion with tumour necrosis factor-alpha and melphalan with or without interferongamma for the treatment of in-transit melanoma metastases: a multicentre randomized phase II study. Melanoma Res 1999; 9:491-502.

23. Eggermont AMM, Schraffordt Koops H, Liénard D, Kroon BBR, van Geel AN, Hoekstra HJ, Lejeune FJ. Isolated limb perfusion with high-dose tumor necrosis factoralpha in combination with interferon-gamma and melphalan for nonresectable extremity soft tissue sarcomas: a multicenter trial. J Clin Oncol 1996; 14:2653-2665.

24. Suit H, Willett C. Radiation therapy of sarcomas of the soft tissues. Cancer Treat Res 1991;64.

25. Vrouenraets BC, Klaase JM, Nieweg OE, Kroon BBR. Toxicity and morbidity of isolated limb perfusion. Semin Surg Oncol 1998; 14:224-231.

26. Vrouenraets BC, Eggermont AMM, Klaase J, van Geel A, van Dongen JA, Kroon BBR. Long-term neuropathy after regional isolated perfusion with melphalan for melanoma of the limbs. Eur J Surg Oncol 1994; 20:681-685.

27. Suit HD, Mankin HJ, Wood WC, Gebhardt MC, Harmon DC, Rosenberg A, Tepper JE, Rosenthal D. Treatment of the patient with stage M0 soft tissue sarcoma. J Clin Oncol 1988; 6:854-862.

28. Sugarbaker PH, Barofsky I, Rosenberg SA, Gianola FJ. Quality of life assessment of patients in extremity sarcoma clinical trials. Surgery 1982; 91:17-23.

29. Lane JM, Christ GH, Khan SN, Backus SI. Rehabilitation for limb salvage patients: kinesiological parameters and psychological assessment. Cancer 2001; 92:1013-1019.

30. Rougraff BT, Simon MA, Kneisl JS, Greenberg DB, Mankin HJ. Limb salvage compared with amputation for osteosarcoma of the distal end of the femur. A long-term oncological, functional, and quality-of-life study. J Bone Joint Surg Am 1994; 76:649656.

31. van Ginkel RJ, Hoekstra HJ, Pruim J, Nieweg OE, Molenaar WM, Paans AM, Willemsen AT, Vaalburg W, Schraffordt Koops H. FDG-PET to evaluate response to hyperthermic isolated limb perfusion for locally advanced soft-tissue sarcoma. $J$ Nucl Med 1996; 37:984-990. 


\title{
Chapter 11
}

\section{Isolated limb perfusion with melphalan for femoral metastases of breast cancer: case report}

\author{
Noorda EM,Vrouenraets BC, Nieweg OE,Pinedo HM*, Kroon BBR \\ The Netherlands Cancer Institute/ Antoni van Leeuwenhoek hospital, \\ Department of Surgery, Amsterdam, the Netherlands \\ *VU Medical Center, Department of Medical Oncology, Amsterdam, the Netherlands
}

Journal of Surgical Oncology 2002; 81:209-212

\section{Introduction}

Bone metastases are the most common form of distant spread in breast cancer patients. They are radiologically identified before death in $69 \%$ of metastasized cases. ${ }^{1}$ Important complications of bone destruction occur in 10-29\% of them and consist of hypercalcaemia, pathologic fracture or spinal cord compression. ${ }^{1}{ }^{2}$ Treatment of these metastases is mainly palliative with systemic chemotherapy, hormonal therapy and/or local radiotherapy to alleviate pain. An impending fracture is usually treated by surgical fixation in order to retain normal function. ${ }^{3}$

Isolated limb perfusion (ILP) with cytostatic agents is an established treatment for locally irresectable tumours of the extremities, first applied for melanoma in 1958 by Creech et al. ${ }^{4}$ During ILP, isolation of the blood circuit of a limb is achieved by clamping the major artery and vein, ligating collateral vessels and applying a tourniquet around the limb. After cannulation of the vessels, the isolated limb is perfused by an extracorporeal circulation, oxygenated and propelled by a heart-lung machine. High doses of cytostatic drugs can be administered in the perfusate. The concentration of melphalan, the cytostatic mostly used, can be 10 to 20 times higher in this isolated circuit than in systemic treatment. ${ }^{5}$

In this report, a rare indication for ILP with melphalan is presented. This approach resulted in a desirable long-lasting palliative effect in a patient with painful impending femoral fractures due to multiple metastases of breast cancer.

\section{Case report}

A 43-year old woman was referred to our hospital for palliative treatment of symptomatic metastases in the left femur and prevention of a pathologic fracture. Six years before, breast conserving therapy with axillary dissection was performed for T3N1bM0 breast cancer. Three years later she had a local recurrence for which she underwent ablative surgery. Two years after salvage surgery, she was treated with radiotherapy and hyperthermia for multiple skin metastases around the scar of the mastectomy. Thereafter, bone scintigraphy showed multi- 
ple lesions in the left humerus, two ribs and the left femur at the level of the greater trochanter, midshaft and the medial condyle. Because of the presence of estrogen receptors, bilateral oophorectomy was performed and tamoxifen and paminodronate were started. For the severe complaints of her left leg, she received $800 \mathrm{cGy}$ of irradiation to the femur, with only little pain reduction and no signs of amelioration on X-ray.

When she presented at our hospital, one month later, she could not bear any weight on her left leg and walked with crutches, because of the pain and risk of fracturing. Repeat X-rays of the pelvis and both femoral bones revealed besides small asymptomatic metastases in the distal right femur, the three large bone metastases in the left femur. Because of the location of these metastatic masses, intramedullary nailing was not considered feasible (Fig.1a and Fig.2). Therefore, an iliacal ILP under normothermic conditions (tissue temperatures between $37-$ $\left.38^{\circ} \mathrm{C}\right)$ was performed with a total dose of $86 \mathrm{mg}$ of melphalan $(10 \mathrm{mg} /$ liter perfused tissue). Postoperative recovery was uneventful with a grade II regional toxicity reaction, according to the Wieberdink classification, with only mild oedema and erythema. ${ }^{6}$ She was discharged from our hospital two weeks after ILP.

xxxxxFigure 1a, $1 \mathrm{~b}$ and 2.xxxxx

The pain considerably subsided and six months after ILP she could bear weight on the left leg again. One year after ILP she was asymptomatic in the left leg and from then on walked without crutches and without pain, until her death two years later. Radiological evidence for this clinical improvement was found three months after ILP, when increased calcification was described in the lesser trochanter of the left femur on X-ray films (Fig.1b), with stable disease at the left midshaft and distal sites. Furthermore magnetic resonance imaging (MRI) performed nine months after ILP confirmed the clinical improvement. A decrease in size of all lesions was shown (Fig.3) which was confirmed on subsequent bone scintigraphy.

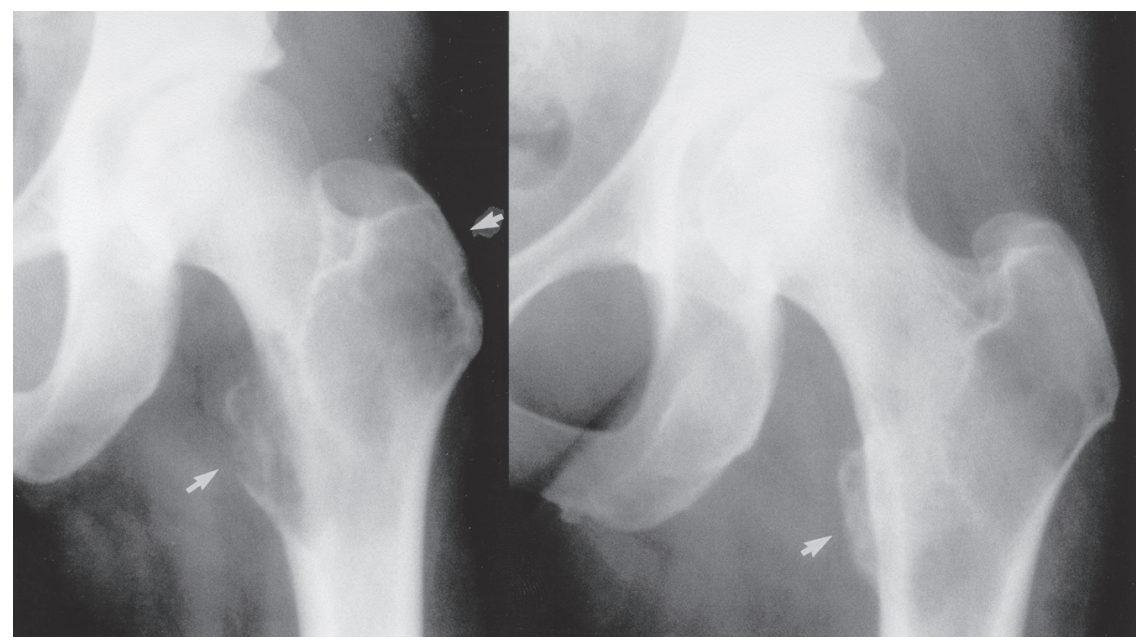

Fig. 1a/1b. X-ray before and after ILP showing metastases in the greater and lesser trochanter before ILP (left) and X-ray three months after ILP, showing increased calcification in the lesser trochanter and stable disease in the greater trochanter (right) 


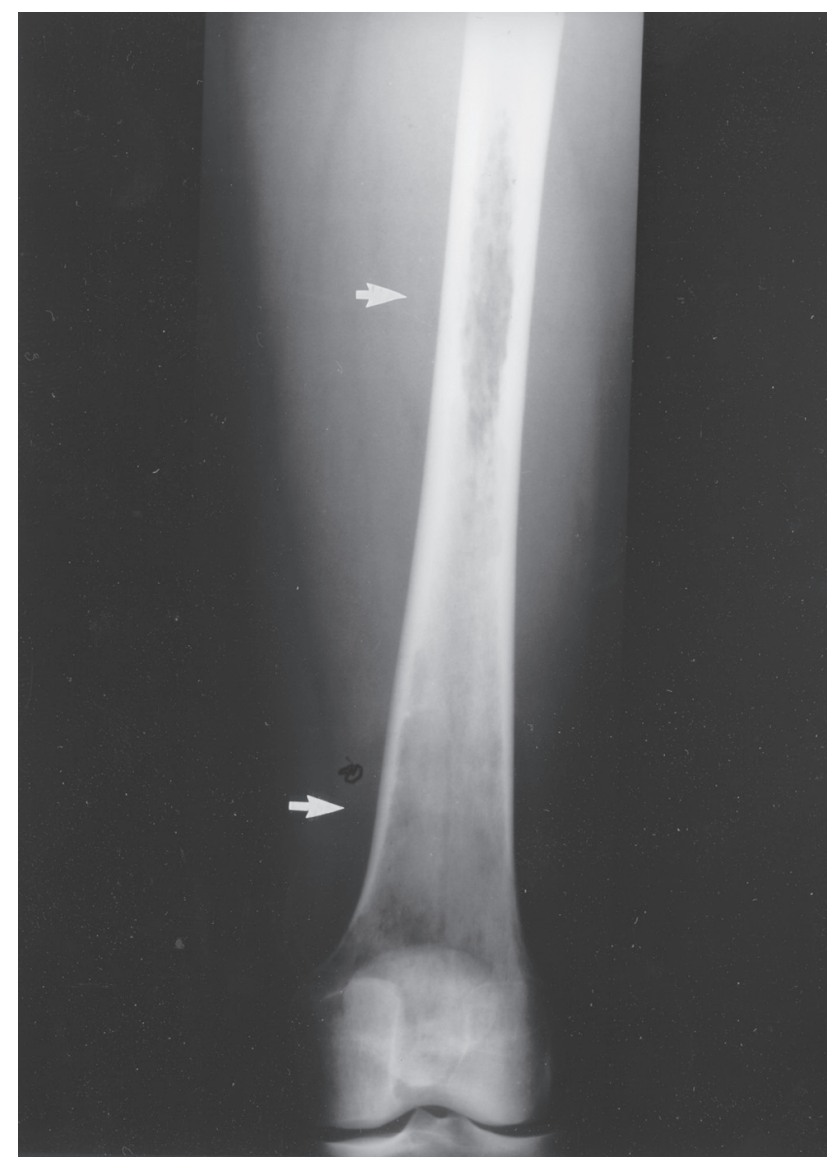

Fig. 2. X-ray before ILP, showing the midshaft and distal metastases in the left femur

One month after ILP she started treatment with cyclophosphamide, methotrexate and 5-fluorouracil (CMF) for her other metastases. However, metastases at the skin of the right thorax, the left humerus and in the ribs were progressive. Because of this progression, the CMF regimen was stopped one and a half year after ILP. Despite treatment with radiotherapy, photodynamic therapy and different chemotherapeutical agents, she died three years after ILP from widely metastasized breast cancer. She had been able to walk without crutches and with no complaints of her left leg during these last years of her life.

\section{Discussion}

To our knowledge, this is the first report describing ILP with melphalan for bone metastases of any tumor. ILP resulted in long-lasting palliation with an objective response of at least one year in a patient with painful femoral metastasis of breast cancer with impending fracture. ILP was given as a last resource one month after inadequate pain alleviation by radiotherapy. Surgical fixation with aN 


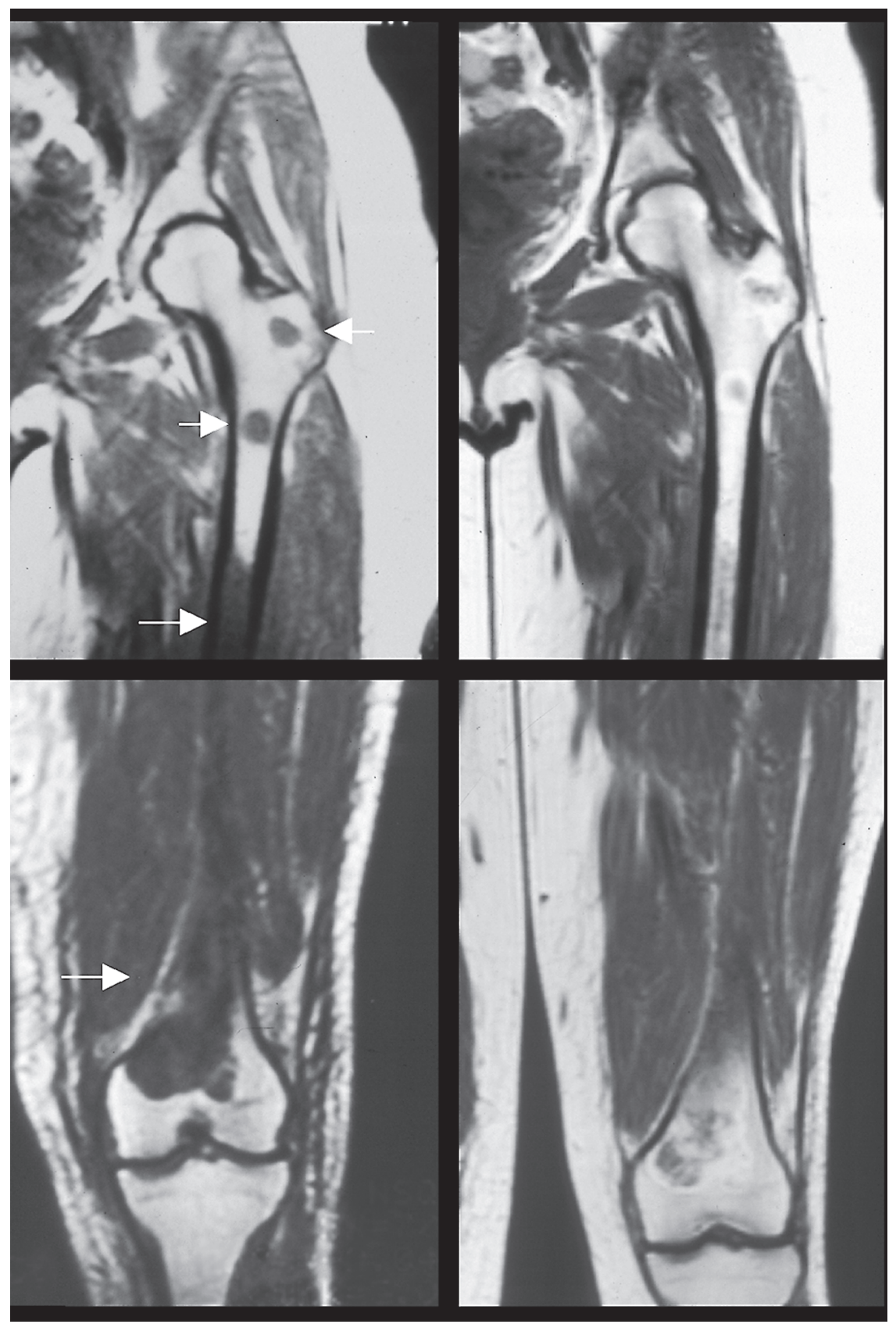

Fig. 3a/3b. Magnetic resonance imaging (T1 weighted) before and after ILP showing metastatic lesions in the left femur before ILP (left top and bottom) and nine months after ILP, showing a decrease in tumor mass in the left femur (right top and bottom) 
Intramedullary nail was opted against since stable locking of a nail both proximally and distally was considered impossible, due to multiple metastases in both the proximal and distal left femur.

Apart from osteosarcoma, no reports have been published on the use of ILP for bone lesions. In osteosarcoma, the biological response modifier recombinant tumor necrosis factor alpha (TNF $\alpha$ ) is the effective agent nowadays being used, preferably in combination with melphalan or another cytostatic agent, with a reported response rate of $77 \% .^{7,8}$ Melphalan alone in this tumor has no significant effect. ${ }^{8}$ It is questionable whether the treatment of osteosarcoma is comparable with that for osteolytic bone metastases, considering the different nature of these tumors. ${ }^{9}$ Since TNF $\alpha$ is said to enhance osteoclastic activity ${ }^{10}$ one could speculate that while $\mathrm{TNF} \alpha$ is very effective in osteosarcoma with increased osteoid production by osteoblasts, it would not have been useful in a lytic lesion because it would further increase bone resorption. Melphalan alone was chosen, because of our wide experience with that drug in ILP and its proven moderate efficacy in the systemic treatment of breast cancer with remission rates up to $28 \%$ as a single agent. ${ }^{11-13}$ Furthermore, a substantially higher dose of melphalan can be administered through ILP than would be tolerated systemically (10-20 times higher). Possibly, the response of breast cancer metastases to melphalan would be improved considerably through this dose-escalation.

In the present report, the patient was treated with $\mathrm{CMF}$ in the year following ILP. Therefore, one could doubt if systemic chemotherapy rather than ILP had caused the effect. However, other bone and soft tissue lesions progressed under chemotherapeutical treatment while the lesions in the left femur were shrinking. Moreover, systemic chemotherapy has not been reported to result in objective reossification, as in our patient. The slow response to ILP with gradual pain relief is similar to the often slow response seen after ILP with melphalan in patients with symptomatic recurrent melanoma.

In conclusion, in selected patients with symptomatic large bone metastases from breast cancer, and no other treatment options, ILP with melphalan may be used for successful palliation.

\section{References}

1. Coleman RE, Rubens RD. The clinical course of bone metastases from breast cancer. Br J Cancer 1987; 55:61-66.

2. Wedin R, Bauer HC, Rutqvist LE. Surgical treatment for skeletal breast cancer metastases: a population-based study of 641 patients. Cancer 2001; 92:257-262.

3. Greenall M.J. Cancer of the breast. In Morris P.J., Malt R.A., . (eds). Oxford textbook of surgery. New York: Oxford University Press; 1994:837.

4. Creech DG, Krementz ET, Ryan RF, Winblad JN. Chemotherapy of cancer: regional perfusion utilising an extracorporeal circuit. Ann Surg 1958; 148:616-632.

5. Vrouenraets BC, Nieweg OE, Kroon BBR. Thirty-five years of isolated limb perfusion for melanoma: indications and results. Br J Surg 1996; 83:1319-1328.

6. Wieberdink J, Benckhuijsen C, Braat RP, van Slooten EA, Olthuis GA. Dosimetry in isolation perfusion of the limbs by assessment of perfused tissue volume and grading 
of toxic tissue reactions. Eur J Cancer Clin Oncol 1982; 18:905-910.

7. Cavaliere R, Di Filippo F, Santori FS, Piarulli L, Carlini S, Calabro A, Pagliarin M, Cavaliere F, Cerulli P, Monticelli G. Role of hyperthermic perfusion in the treatment of limb osteogenic sarcoma. Oncology 1987; 44:1-5.

8. Bickels J, Manusama ER, Gutman M, Eggermont AM, Kollender Y, Abu-Abid S, van Geel AN, Lev-Shlush D, Klausner JM, Meller I. Isolated limb perfusion with tumour necrosis factor-alpha and melphalan for unresectable bone sarcomas of the lower extremity. Eur J Surg Oncol 1999; 25:509-514.

9. Fontana A, Delmas PD. Markers of bone turnover in bone metastases. Cancer 2000; 88:2952-2960.

10. Bertolini DR, Nedwin GE, Bringman TS, Smith DD, Mundy GR. Stimulation of bone resorption and inhibition of bone formation in vitro by human tumour necrosis factors. Nature 1986; 319:516-518.

11. Bergh J, Jonsson PE, Glimelius B, Nygren P. A systematic overview of chemotherapy effects in breast cancer. Acta Oncol 2001; 40:253-281.

12. Jones S, Winer E, Vogel C, Laufman L, Hutchins L, O'Rourke M, Lembersky B, Budman D, Bigley J, Hohneker J. Randomized comparison of vinorelbine and melphalan in anthracycline-refractory advanced breast cancer. J Clin Oncol 1995; 13:2567-2574.

13. Canellos GP, Pocock SJ, Taylor SG, III, Sears ME, Klaasen DJ, Band PR. Combination chemotherapy for metastatic breast carcinoma. Prospective comparison of multiple drug therapy with L-phenylalanine mustard. Cancer 1976; 38:1882-1886. 


\title{
Chapter 12
}

\section{Summary and conclusions/Samenvatting en conclusies}

\begin{abstract}
Summary
In chapter one a brief introduction and outline of this thesis is provided. The context for this thesis is further elaborated in chapter two, a systematic review of the best evidence available for the application of isolated limb perfusion (ILP) in extremity melanoma and soft tissue sarcoma. Several clinical questions regarding the indications of ILP are answered. Due to the limited regional decrease in locoregional recurrence rate and absence of an increase in overall survival, ILP with melphalan cannot be recommended as an adjunct to excision of primary or recurrent melanoma. However, ILP has a remarkable effect on micrometastatic disease, illustrated by a relative risk reduction of further locoregional metastases of $33 \%$ to $50 \%$ for both primary and recurrent melanoma, respectively and in the latter group also a significant increase in disease-free interval in the extremity of 10 to 17 months. Therapeutic ILP is indicated in unresectable melanoma, although randomized controlled trials (RCTs) comparing ILP with other treatment options are lacking. A higher response rate after ILP with tumor necrosis factor- $\alpha$ (TNF $\alpha)$ and melphalan is attained than after ILP with melphalan alone but with equal recurrence rates and survival. In unresectable soft tissue sarcoma (STS) of the extremities, limb salvage can be obtained in $76-86 \%$ of patients with neoadjuvant ILP with $\mathrm{TNF} \alpha$ and melphalan \pm resection. The only alternative with similar response rates is intra-arterial chemotherapy which has generally resulted in a higher complication rate. Further RCTs should establish its role in these patients.
\end{abstract}

Although the general consensus is that ILP in extremity melanoma should only be applied for truly unresectable melanoma lesions, without other local treatment options, data supporting this are scarce. Therefore, in chapter three the results of ILP in unresectable extremity melanoma in our institutions are reported. In this chapter, definitions of unresectability are suggested to facilitate comparison of results from different institutions. From our computer-assisted database, containing all characteristics and results of ILP for extremity melanoma, 130 patients could be selected who had undergone an ILP for truly unresectable lesions. This selection was made on the basis of number $(>10)$ or size $(>3 \mathrm{~cm})$ of the lesions or their localization on the extremity. A complete tumor response was obtained in more than half of the patients $(55 \%, 95 \%$ CI $46-63 \%)$ with a tendency for a better response rate after ILP with TNF $\alpha$ and melphalan compared to ILP with melphalan alone $(45 \%, 95 \%$ CI $29-61 \%$ and 59\%, 95\% CI 49-69\% respectively, $\mathrm{P}=0.14$ ). The limb salvage rate was $96 \%$. Overall five-year survival was $29 \%$ (95\% CI 20-38\%). The absence of lymph node metastasis increased the chance of a complete response and longer tumor-free survival. Patients with a complete response and relatively small tumor nodules $(<3 \mathrm{~cm})$ had a significantly better overall survival in multivariate analysis. 
Therefore, it is concluded that ILP is a valuable treatment option in patients with locoregional unresectable extremity melanoma, for whom there are no effective alternatives.

An additional benefit of ILP over other locoregional treatment modalities such as local excision, $\mathrm{CO}_{2}$ laser ablation or radiation therapy, is that it treats the micrometastases in the limb, which are not (yet) macroscopically visible. This is then expressed in a delay or absence of further recurrences after ILP. Also, the number of recurring lesions could then be smaller. To test these hypotheses, a study was performed, the results of which are reported in chapter four. All 43 patients who had their first ILP for a third or further limb recurrence were selected from our computer database. Eighteen patients had resectable and 25 had locally unresectable lesions at the time of ILP. The patients had a total of 269 intervals between treatment of their primary melanoma and last recurrence or last followup. Median follow-up was 35 months (interquartile range 14-64 months). The median limb recurrence-free interval decreased over time from primary melanoma to the third or further recurrence for which ILP was performed $(\mathrm{P}<0.001)$. The median limb recurrence-free interval was 4.7 (95\% CI: 2.8-7.9, $\mathrm{P}<0.001)$ times longer after ILP compared to the last interval before ILP. Patients with resectable lesions had a median limb recurrence-free interval that was 5.9 (95\% CI: 2.7-13, $\mathrm{P}<0.001)$ times longer. In all patients, the number of lesions increased with $22 \%$ per recurrence number $(95 \% \mathrm{CI} 10-35 \%, \mathrm{P}=0.02)$. At the same recurrence number, patients before ILP had a 2.6 fold $(95 \%$ CI 1.6-4.5) higher mean number of lesions compared to patients after ILP $(\mathrm{P}<0.001)$.

ILP lengthens the limb recurrence-free interval and decreases the number of lesions per recurrence significantly in patients with repeatedly recurrent limb melanoma. Therefore, ILP could be a valuable adjunct to excisional surgery of intransit metastases in these patients whose limb recurrence-free intervals tend to shorten over time.

Although the technique of ILP is relatively simple, it is a four to five hour operative procedure under general anaesthesia with a risk of locoregional and systemic toxicity. Therefore, some physicians appeared to be reluctant to refer older patients for ILP. To test the efficacy and safety of ILP in elderly patients, a study was performed in which the results in older patients who underwent ILP for advanced melanoma lesions were compared to younger patients. In chapter five the results are described of 218 therapeutic ILPs with melphalan \pm TNF $\alpha$ were performed in 202 patients with locoregionally recurrent, measurable melanoma. Fifty-three patients $(28 \%)$ were 75 years or older. Complete response rates were $56 \%$ for those aged over 75 years and $58 \%$ for the younger group $(\mathrm{P}=0.8)$. Locoregional relapse occurred in $56 \%$ of the older group after a median period of nine months (interquartile range 5-18 months) versus $51 \%$ after a median of six months in the younger group $(25-75 \%$ range $4-14$ months, $\mathrm{P}=0.6)$. Limb toxicity, systemic toxicity, local complications and long-term morbidity were similar in both age groups. In patients older than age $75,19 \%$ had a grade III/IV toxicity reaction $(28 \%$ in the younger group, $\mathrm{P}=0.2)$. Peri-operative mortality was low, with one procedure related death in the elderly, six months after ILP. Older 
patients stayed in the hospital for a median of 23 days (younger patients 19 days, $\mathrm{P}<0.01)$.

Concluding, ILP resulted in similar response rates in the elderly with recurrent melanoma without increased toxicity, complications and long-term morbidity compared to younger patients. Older age on itself is not a contraindication for ILP.

The treatment of recurring melanoma is a continuing challenge, since new intransit metastases frequently occur. Despite ILP, about $70 \%$ of the patients have new recurrences that pose a therapeutic problem. In chapter six the feasibility and effectiveness of a repeat ILP with TNF $\alpha$ is described, on the basis of the results in our institution. Between 1991 and 1999, 21 patients underwent repeat ILP using TNF $\alpha$ for recurrent melanoma or persisting disease after a previous ILP. First ILPs had been performed with melphalan alone in 13 patients and with $\mathrm{TNF} \alpha$ and melphalan in eight, for a median of nine lesions (interquartile range 2-23 lesions). Repeat ILP was performed with TNF $\alpha$ and melphalan in all 21 patients for a median of nine lesions (IQ range 5-25 lesions). Mean follow-up after repeat ILP was 48 months (range 2-115 months). Thirteen patients (62\%, 95\% CI 39-85\%) attained a complete response after repeat ILP compared to 11 $(65 \%, 95 \%$ CI $39-90 \%, \mathrm{P}=0.3)$ of 17 with measurable lesions at the first ILP. Nine patients $(69 \%$, 95\% CI 40-98\%) relapsed again after CR. Median limb recurrence-free survival was 13 months (95\% CI 5-22 months). Fourteen patients $(66 \%, 95 \%$ CI 45\%-89\%) had mild acute regional toxicity after repeat ILP compared to $18(85 \%, 95 \%$ CI $68 \%-102 \%)$ after the first ILP $(\mathrm{P}=0.3)$. One patient underwent amputation for critical limb ischaemia 10 months following repeat ILP, leading to a limb salvage rate of $95 \%$. Overall median survival was 62 months (95\% CI 36-89 months) after CR compared to 13 months (95\% CI 0.426 months) for those without $\mathrm{CR}(\mathrm{P}=0.006)$.

Repeat ILP with TNF $\alpha$ and melphalan appears to be well feasible in patients with recurrent disease after previous ILP with mild regional toxicity. The complete response rate is relatively high and comparable to that of the first procedure with a considerable limb-recurrence free survival and high limb salvage rate.

Patients with recurrent melanoma have a five-year survival varying from $27-56 \%$. Some of these patients do not survive longer than one year after treatment. ILP entails, usually mild, locoregional toxicity that subsides in two to three months and a maximum response of the lesions is seen at a median of four months after the procedure. Considering this, a selection of patients, that will live long enough to experience the benefits of ILP, would be desirable. In an attempt to identify prognostic factors for short-term survival, a study was performed and the results are described in chapter seven. Data from all 439 patients (95 men (22\%)) who underwent a first ILP for melanoma of the extremities were analyzed. Ninety percent of the patients had MD Anderson stage IIB or III disease at the time of ILP. ILP was performed with melphalan with or without TNF $\alpha$ under mild hyperthermic $\left(38-40^{\circ} \mathrm{C}\right)$ or normothermic $\left(37-38^{\circ} \mathrm{C}\right)$ conditions in $80 \%$ of the cases. A multivariable logistic regression analysis was performed for death within one year after ILP. Sixty-nine patients (16\%) died within this period, 64 of metastatic 
melanoma. Patients with stage IIIB regional lymph node metastases, for whom the indication for ILP was an unresectable primary $(n=3)$, a local recurrence $(n=24)$ or adjuvant to excision of primary lesions $(n=17)$, or stage IIIAB with satellites and/or in-transit metastases had a relative risk of 4.6 (95\% CI 2.0-6.6) and 3.6 (95\% CI 2.1-10) of dying within one year from ILP, respectively $(\mathrm{p}<0.001)$. In patients with stage IV disease (distant metastases) the relative risk was 22 (95\% CI 3.8-127, p=0.001).

Therefore, patients with limb melanoma have an increased risk of dying within one year after ILP when regional lymph node or distant metastases are present. The indication for ILP should be carefully considered in these patients.

In search of better tumor response rates, high-dose hyperthermia in ILP has been applied. In chapter eight the results are described of a sequential ILP schedule, in which an ILP with high-dose hyperthermia $\left(42-43^{\circ} \mathrm{C}\right)$ without cytostatics, is followed a week later by ILP with melphalan under normothermic conditions. It was known that hyperthermia had a cell-killing effect on tumor cells, but its simultaneous application with cytostatics had proven to be too toxic. This sequential schedule was developed to have the cytotoxic effect of both high-dose hyperthermia and melphalan, without the increase in locoregional toxicity caused by their synergy. Seventeen patients with extensively recurrent or bulky extremity melanoma were treated with this schedule between 1989 and 1994. Eleven (65\%) patients had a complete response. Three (27\%) patients had limb recurrences after five, six and 18 months respectively. The five-year limb recurrence-free survival for patients with $\mathrm{CR}$ was $63 \%$. Limb toxicity was mild with only pressurerelated blistering and transient sensory disturbances after the hyperthermic ILP. After the second ILP, $88 \%$ of the patients had the desired grade II reaction (mild erythema and edema).

Concluding, this sequential ILP schedule results in a high complete response rate and a low limb-recurrence rate in patients with extensive, recurrent melanoma of the limbs at the cost of only mild toxicity. This regimen could be an alternative to ILP with TNF $\alpha$ and melphalan, which seems indicated in extensive or bulky lesions.

In chapter nine, the quality of life of long-term survivors after ILP for extremity melanoma is reported. ILP can result in long-term morbidity in up to $40 \%$ of the patients and the (recurrent) disease itself could impact these patients' lives. Quality of life has not been assessed before in this specific patient group. Fiftyseven patients were selected from our computer-assisted database (with 292 patients from only one of our centers) because they were currently still alive, disease-free for over six months with preservation of the limb, without distant metastases and with complete contact information. They were sent an invitational letter and three questionnaires: the MOS 36-item Short Form Health Survey (SF-36), a disease-specific questionnaire and a questionnaire on work- and insurance related problems. The questionnaires were returned by $51(89 \%)$ patients (mean age 71 (38-90) years), a median of 14 (3-25) years after ILP. The outcome of the SF-36 was compared with an age- and gender-matched Dutch comparison group. A linear regression analysis was performed to identify factors related to 
the mental and physical health component scores from the SF-36. The patient population scored better on all items of the SF-36 than the comparison group, significant $(\mathrm{P}<0.05)$ in the domains of bodily pain, general health perceptions, mental score and physical score. However, stinging sensations, stiffness or edema of the affected limb were reported by $49-55 \%$ of the patients. Color difference between the extremities and visible skin lesions were reported by $31 \%$ and $38 \%$ of the study group respectively. Fear of recurrences was reported by $63-77 \%$ of the patients. Twenty percent of the patients had no complaints, while $10 \%$ had more than five complaints. Problems in obtaining a mortgage or life insurance were reported by $6-9 \%$ of patients. Stiffness of the extremity $(\mathrm{P}<0.001)$ was negatively related to the physical score while lesions on the lower leg $(\mathrm{P}<0.05)$ were positively related. Stiffness of the extremity $(\mathrm{P}<0.001)$, the necessity to wear supportive stockings $(\mathrm{P}<0.05)$, older age at analysis $(\mathrm{P}<0.05)$ and fear of recurrences $(\mathrm{P}<0.05)$ were negatively related to the mental score.

Concluding, long-term survivors after ILP for melanoma have a better health related quality of life than a matched comparison group, although many disease and treatment related problems are reported. This counter-intuitive outcome can be due to the composition of the study group, a favorable selection of long-term survivors and to "response shift", meaning that patients have changed their perspectives over time and accommodated to their complaints.

In 1992, ILP with TNF $\alpha$ was introduced in the treatment of unresectable extremity soft tissue sarcoma, after ILP with other agents had not been successful in these patients. The results of ILP with TNF $\alpha$ and melphalan in soft tissue sarcoma of the extremities in our institution are described in chapter ten. From 1992 to 2001,49 patients (mean age 51years, range 14 - 85 years) underwent ILP for unresectable soft tissue sarcomas of the extremities. All patients received melphalan and TNF $\alpha$ (four patients also received Interferon- $\alpha$ ). Median follow-up was 26 months (range 2 days-103 months). In one patient (2\%), who died two days after ILP, response and acute limb toxicity could not be assessed. Tumor resection was performed in 31 patients $(63 \%)$. Histological material was further available from eight amputations and three punctures/biopsies. Final response, based upon both clinical and pathological assessment in which pathology was decisive, was complete in four patients $(8 \%)$ and partial in 27 patients $(55 \%)$, resulting in a final overall response rate of $63 \%$. Local control with preservation of the limb was attained in $28(57 \%)$ of the patients. Four $(13 \%)$ of the 32 patients who had been rendered tumor-free by ILP $+/$ - resection and radiotherapy, developed a local recurrence. Five-year disease-specific survival was $48 \%$ for the 49 patients. Acute limb toxicity was a mild grade I/II reaction in $35(71 \%)$ patients, a grade III reaction in 12 patients $(25 \%)$ and a grade IV reaction in one patient $(2 \%)$. Three major ILP-related complications were encountered consisting of arterial thrombosis in two patients and a fulminant Clostridial infection leading to death in one patient. There were no severe cardiovascular reactions.

In these patients with unresectable soft tissue sarcomas of the limbs treated by ILP with TNF $\alpha$ and melphalan, followed by resection of the tumor remnant when possible, a $63 \%$ overall tumor response rate and $57 \%$ local control with limb preservation rate are achieved. 
In chapter eleven, a case is described of a woman with femoral metastases of breast cancer, which caused impending fracturing and pain. Radiation therapy did not result in sufficient relieve of pain and intra-medullary fixation was not considered optional because of the localization of the metastases. Melphalan in low doses has little response on disseminated breast cancer, but in this case there was no other treatment option. She was experimentally treated with ILP with melphalan in a high dose and was successfully palliated: she could walk without crutches and without pain in her leg for the last two years of her life.

\section{Future prospects}

\section{Melanoma}

Generally, ILP can only be recommended if localized disease is unresectable. This term however has scarcely been specified and is subject of personal judgment. In this thesis a number of criteria were provided such as the number and size of the lesions, their localization on the extremity and the vulnerability of the affected area, for example due to previous radiotherapy. The definition of unresectability should be specified in reports on ILP, in order to make comparison, judgment of results and proper application in clinical practice possible. Because it has been demonstrated that ILP has an effect on micrometastases, there could be indications for its use in resectable lesions but only in patients who frequently have recurrences. For future studies it can also be interesting to see whether patients who have a first recurrence benefit from an adjuvant ILP as well in terms of limb recurrence free survival or even absence of recurrences. Randomized studies are needed to find this out. The recently developed micro-array technique, might give information about tumor characteristics on the basis of an analysis of its genome, such as the ability to generate locoregional metastases only or also metastases at distant sites. ${ }^{1}$ This could lead to a change in the treatment of patients with recurrent extremity melanoma, where the first group might be offered ILP in an earlier stage of disease.

\section{Soft tissue sarcoma}

The application of ILP in soft tissue sarcoma has been successful with a reported limb salvage rate between 79 to $92 \%$. As described in this thesis, results can be disappointing with a local control rate with limb salvage of only $57 \%$. Its application should therefore be limited to those with a clear indication for amputation of the limb. In future, the possible influence of grade and histology of the tumors on response should be studied, in order to select only those patients who have a high chance to benefit from the procedure. Sofar, TNF $\alpha$ is an expensive and possible lethal drug if leakage occurs to the systemic circulation. The results of ongoing studies on dose reduction of TNF $\alpha$ are awaited and might make ILP with TNF $\alpha$ a more readily available (and cheaper) treatment modality as an alternative to for example preoperative radiotherapy.

\section{Other tumors}

The application of a high-dose of drugs to the extremity offers a possibility to treat other tumors on the extremity as well. For example the application for 
metastases of breast cancer that, despite its successful palliative effect as reported in this thesis, has not been repeated. Various other unresectable tumors, such as squamous cell carcinoma and Merkel's cell carcinoma on extremities have been treated successfully by ILP. ${ }^{2}$ Another application is ILP for osteosarcoma, which has been proven to be effective in rats and the results of which are awaited in patients. ${ }^{3}$

\section{References}

1. 't Veer LJ, Dai H, van de Vijver MJ, He YD, Hart AA, Mao M, Peterse HL, van der KK, Marton MJ, Witteveen AT, Schreiber GJ, Kerkhoven RM, Roberts C, Linsley PS, Bernards R, Friend SH. Gene expression profiling predicts clinical outcome of breast cancer. Nature 2002; 415:530-6.

2. Olieman AF, Lienard D, Eggermont AM, Kroon BB, Lejeune FJ, Hoekstra HJ, Koops HS. Hyperthermic isolated limb perfusion with tumor necrosis factor alpha, interferon gamma, and melphalan for locally advanced nonmelanoma skin tumors of the extremities: a multicenter study. Arch Surg 1999; 134:303-7.

3. Manusama ER, Nooijen PT, ten Hagen TL, Van Der Veen AH, De Vries MW, de Wilt JH, Van Ijken MG, Marquet RL, Eggermont AMM. Tumor necrosis factor-alpha in isolated perfusion systems in the treatment of cancer: the Rotterdam preclinical-clinical program. Semin Surg Oncol 1998; 14:232-7. 



\title{
Appendix
}

Nederlands Tijdschrift voor Geneeskunde 2003;147: 529-533

Klinische lessen

\section{Regionale isolatieperfusie: ook bij bejaarde patiënten goed toepasbaar}

\author{
E.M. Noorda, B.C. Vrouenraets, O.E. Nieweg en B.B.R. Kroon
}

\section{Dames en Heren,}

Patiënten met lokaal irresectabele tumoren van extremiteiten krijgen vaak intensieve behandelingscombinaties van radiotherapie, chemotherapie en chirurgie, waarmee zonder amputatie lokale controle bereikt kan worden. Bij (hoog)bejaarde patiënten rijst dan de vraag in hoeverre dergelijke belastende behandelingen zinvol zijn, gezien de kortere levensverwachting en de kans op functieverlies van de aangedane extremiteit. Deze situatie doet zich met name Voor bij een kleine groep patiënten met lokaal irresectabel melanoom of wekedelensarcoom Van een extremiteit.

Met regionale isolatieperfusie kan gepoogd worden de extremiteit te sparen en toch locoregionale controle te bereiken. Deze behandeling wordt nu bijna 40 jaar in Nederland toegepast bij patiënten met lokaal irresectabel melanoom Van de extremiteiten. ${ }^{1}$ Het principe is dat een hoge dosis chemotherapie kan worden toegediend aan de aangedane extremiteit zonder ernstige Systemische toxiciteit. Bij het melanoom is melfalan het cytostaticum van keuze ${ }^{2}$ en sinds 1992 , na de invoering Van de combinatie van melfalan met recombinant tumor necrosis factor-alfa (TNF-alfa), wordt regionale isolatieperfusie ook met succes toegepast bij het lokaal irresectabele wekedelensarcoom van de extremiteiten. ${ }^{3}$

In de dagelijkse praktijk lijkt er terughoudendheid te bestaan om een intensieve behandeling als regionale isolatieperfusie toe te passen bij de oudere patiënt, gezien de in het algemeen met de leeftijd toegenomen perioperatieve sterfte ${ }^{4}$ het grotere aantal postoperatieve complicaties en de langere opnameduur. ${ }^{5-7} \mathrm{Bij}$ regionale isolatieperfusie moet men bovendien rekening houden met de kans op blijvend functieverlies van de extremiteit, meestal als gevolg van een ernstige acute regionale toxiciteitsreactie, ${ }^{8-9}$ en met potentieel ernstige systemische bijwerkingen van de combinatie van melfalan en TNFalfa. ${ }^{3}$ Met behulp van moderne perfusietechnieken kan lekkage van melfalan en TNF-alfa echter tot een verwaarloos-

Het Neder1ands Kanker Instituut/Antoni van Leeuwenhoek Ziekenhuis, afd. Chirurgische Oncologie, Plesmanlaan 121, 1966 CX Amsterdam. Mw. E.M. Noorda, arts-onderzoeker; dr. O.E. Nieweg en prof.dr. B.B.R. Kroon, oncologisch chirurgen. Sint Lucas Andreas Ziekenhuis, afd. Heelkunde, Amsterdam.Dr.B.C.Vrouenraets, chirurg.Correspondentieadres: mw.E.M.Noorda(e.noorda@nki.nl). 
baar niveau worden teruggebracht, waardoor ernstige systemische toxiciteit van TNF-alfa, zoals hemodynamische problemen, kan worden voorkomen. ${ }^{10}$

Dat regionale isolatieperfusie ook op hoge leeftijd succesvol kan worden toegepast bij vergevorderde locoregionale ziekteprocessen, illustreren wij $\mathrm{u}$ aan de band van enkele casussen.

Patiënt A, een 82-jarige vrouw, werd naar onze polikliniek verwezen wegens locoregionale metastasen van een melanoom. Zeven jaar tevoren was een amelanotisch melanoom van de rechter voetzool geëxcideerd (Breslow-dikte: 4,2 mm). Zij had hierna geen recidieven gehad. Zij was bekend wegens hartritmestoornissen en gebruikte carbasalaatcalcium (American Society of Anesthesiologists (ASA)classificatie II).

Zij presenteerde zich met enkele verheven bruinrode afwijkingen op de mediale voetzool en het onderbeen rechts. Elders waren biopten genomen die aantoonden dat het ging om in-transitmetastasen' van melanoom (metastasen die onderweg van primaire tumor naar regionale lymfklierstations uitgroeien in lymfvaten). Bij het lichamelijk onderzoek werd een tiental i tot $5 \mathrm{~mm}$ grote, verheven afwijkingen gezien, verspreid over de mediale zijde van haar voet en onderbeen. Er waren geen palpabele klieren in de lies. De elders gemaakte CT-scan van de thorax en het abdomen toonde geen aanwijzingen voor hematogene metastasen.

Gezien de uitgebreidheid van de afwijkingen werd besloten tot een femorale regionale isolatieperfusie met melfalan onder normotherme condities $\left(37-38^{\circ} \mathrm{C}\right)$. De procedure verliep ongecompliceerd en zonder lekkage van melfalan van het been naar de systemische circulatie. Postoperatief had patiënte gering erytheem en oedeem van de geperfundeerde extremiteit. Het postoperatieve beloop was ongecompliceerd en nadat volledige mobilisatie bereikt was, werd patiënt na 19 dagen naar huis ontslagen.

Twee maanden later was er bij controle op de polikliniek een complete remissie. De postoperatieve toxiciteitsreactie was verdwenen en patiënte liep zoals vóór de perfusie. Twee en een half jaar later werd er op de kuit wederom een in-transitmetastase gevonden, die radicaal kon worden geëxcideerd. Vijf jaar na regionale iso-latieperfusie, op 87-jarige leeftijd, werd patiënte op eigen verzoek uit controle ontslagen azonder tekenen van locoregionale recidivering of metastasen op afstand.

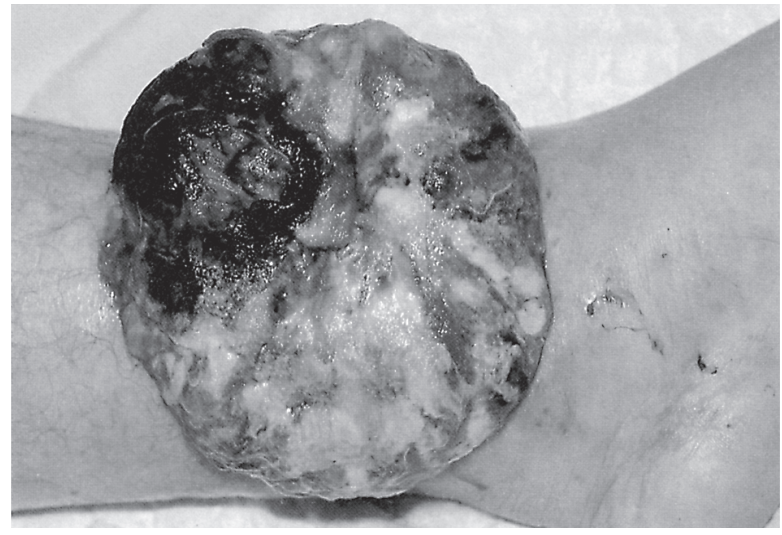

Figuur 1. Patiënt B. Lokaal recidiefmelanoom op het linker onderbeen. 


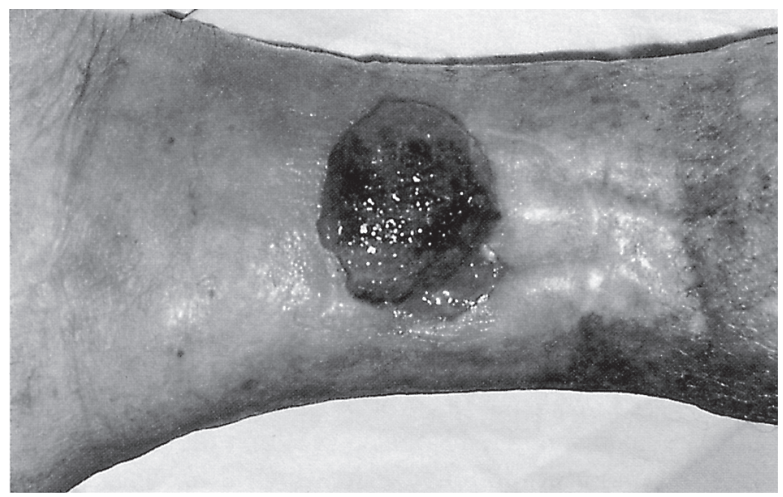

Figuur 2. Patiënt B.

Partiële remissie,

10 weken na

regionale isolatie-

perfusie.

Patiënt B, een 78-jarige vitale vrouw, werd verwezen in verband met een recidiefmelanoom op het linker onderbeen. De primaire tumor was 4 jaar eerder ruim lokaal geëxcideerd, waarna de wond gesloten was met een huidtransplantaat. Histologisch was er indertijd een ulcererend melanoom met een Breslow-dikte van 1,4 mm. Patiënte was in goede conditie (ASA 1) en was 24 jaar tevoren succesvol behandeld voor een cervixcarcinoom.

$\mathrm{Nu}$ presenteerde zij zich met een snelgroeiende tumor ter plaatse van de huidplastiek net proximaal van de mediale malleolus (figuur 1). De 10 x $10 \mathrm{~cm}$ grote tumor riekte en bloedde spontaan. Er waren geen suspecte klieren in de lies palpabel. Cytologisch onderzoek bevestigde de diagnose 'recidiefmelanoom'. Op de röntgenfoto van de thorax werden geen aanwijzingen voor metastasen gezien. Er werd besloten tot regionale isolatieperfusie van het been, aangezien de tumor niet te reseceren was zonder ernstig functieverlies van de enkel en de voet.

Er werd een femorale regionale isolatieperfusie verricht met melfalan en TNFalfa onder licht hypertherme condities $\left(38-40^{\circ} \mathrm{C}\right)$. De procedure verliep ongecompliceerd zonder systemische lekkage van melfalan en TNF-alfa. Postoperatief was patiënte de eerste dagen misselijk, en ontwikkelde zij een geringe weefselreactie met enig erytheem en oedeem. Twee weken na regionale isolatieperfusie werd débridement verricht van de grotendeels necrotische tumor. Patiënte werd 4 weken na de regionale isolatieperfusie volledig mobiel naar huis ontslagen.

$\mathrm{Na} 10$ weken was er een partiële remissie, met progressie van een kleine rest vitaal tumorweefsel (figuur 2), die 3 maanden na de regionale isolatieperfusie radicaal werd gereseceerd. Het huiddefect werd gesloten met behulp van een 'split skin graft' en de wondgenezing was voorspoedig.

Bij controle 5 jaar later waren er bij de inmiddels 83-jarige vrouw geen aanwijzingen voor locoregionale of hematogene metastasering. De functie van haar enkel was normaal.

Patiënt C, een 83-jarige vrouw, presenteerde zich in een ziekenhuis elders met een zwelling aan de dorsale zijde van de linker onderarm, net proximaal van de pols. Deze zwelling bestond reeds 6 maanden en zij had hierbij geen functieverlies van de hand of pols ontwikkeld. Afgezien van een goed gecontroleerde hypertensie was zij vitaal (ASA II). Er was een niet-radicale resectie verricht en pathologisch 
onderzoek wees uit dat het om een niet nader gespecificeerde maligne wekedelentumor ging. Reeds tijdens de wondgenezing ontstond lokaal nieuwe tumorgroei en patiënte werd naar ons verwezen.

Bij lichamelijk onderzoek vonden wij 2 vast aanvoelende afwijkingen ter plaatse van het litteken op de mediodorsale zijde van de linker onderarm, met een grootte van 1 tot $2 \mathrm{~cm}$. Patiënte had een ongestoorde functie van pols en hand. Bij histologische revisie werd de tumor opnieuw geduid als een hooggradig sarcoom, waarschijnlijk een leiomyosarcoom. Een MRI-scan toonde een wekedelentumor die reikte tot op de cortex van de ulna en de pees van de M. extensor carpi ulnaris (figuur 3). Vanwege het multifocale, snelgroeiende karakter van de tumor, met een grote kans op opnieuw irradicale of sterk mutilerende resectie, werd er besloten tot een regionale isolatieperfusie met TNF-alfa en melfalan. ${ }^{11}$ Bij opname, 6 weken later, waren er inmiddels 2 nieuwe tumoren ontstaan ter plaatse van het litteken (figuur 4).

De regionale isolatieperfusie werd verricht via de V. en de A. brachialis met melfalan en TNF-alfa gedurende 1,5 uur onder licht hypertherme condities $\left(38-40^{\circ} \mathrm{C}\right)$. Er was minder dan $0,1 \%$ lekkage van de arm naar de lichaamscirculatie. Direct na de operatie vertoonde patiënte motorische en sensibele stoornissen van de onderarm, waarschijnlijk veroorzaakt door de hoge druk van de isolerende tourniquet tijdens de perfusie, met enig oedeem en erytheem. De sensibiliteit van haar arm herstelde zich binnen 2 weken; na 20 dagen werd patiënte in goede conditie naar huis ontslagen.

Zes weken na de perfusie was ook de motoriek van haar arm weer volledig hersteld. De tumoren waren bij lichamelijk onderzoek niet veel kleiner geworden, maar voelden weker aan; de klinische respons werd geclassificeerd als onveranderd..$^{12}$ Een MRI-scan bevestigde echter het vermoeden dat er een aanzienlijke centrale necrose in de tumor was opgetreden (figuur 5). Tien weken na regionale isolatieperfusie volgde resectie, waarbij het defect werd gesloten met een huidtransplantaat. Histologisch onderzoek toonde een partiële respons met ongeveer $50 \%$ necrose van de tumor. Het bleek uiteindelijk om een hooggradig

Figuur 3. Patiënt C. MRI-scan waarop een deel van het multifocaal maligne fibreus histiocytoom (MFH) van de linker onderarm te zien is.
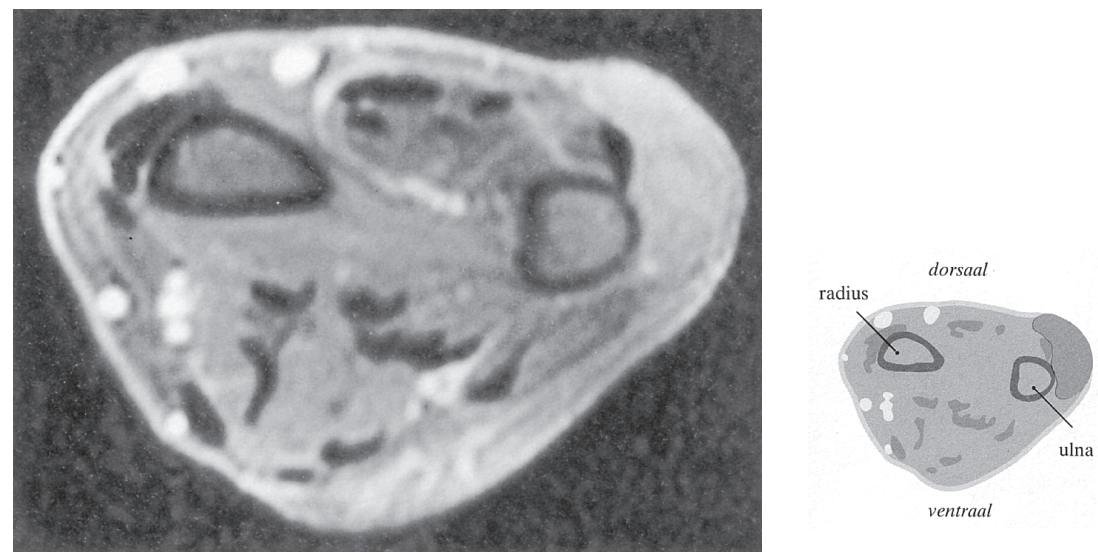

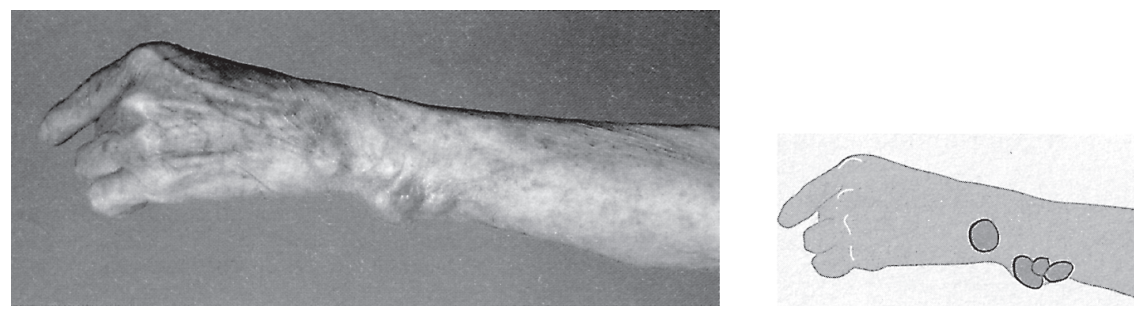

Figuur 4. Patiënt $C$. Vier lokalisaties van recidietsarcoom van de linker onderarm.

maligne fibreus histiocytoom te gaan, dat krap radicaal was gereseceerd. Postoperatief onderging patiënte aanvullende radiotherapie.

Bij controle 3 jaar na de regionale isolatieperfusie, op 86-jarige leeftijd, had patiënte een goede functie van de pols en de hand zonder tekenen van locoregionale of hematogene metastasering.

De eerste regionale isolatieperfusie werd in 1957 uitgevoerd bij een 76-jarige man met uitgebreide in-transitmetastasen van een melanoom op het been. Deze patiënt heeft tot zijn 92e levensjaar ziektevrij geleefd..$^{13} \mathrm{Om}$ een optimale tumorrespons te bereiken, is er in de loop van de jaren geëxperimenteerd met verschillende delen van deze therapie, onder andere de indicatie voor perfusie (adjuvant of therapeutisch), het gebruikte cytostaticum en de temperatuur waaronder geperfundeerd wordt. Tegenwoordig wordt regionale isolatieperfusie met een hoge dosis melfalan uitgevoerd bij het uitgebreid locoregionaal gerecidiveerde melanoom in de vorm van lokaal recidief, in-transit- of satellietmetastasen (patiënt A). In het algemeen wordt hierbij een klinisch relevante tumorrespons bij $80 \%$ van de patiënten verkregen, van wie ongeveer $50 \%$ een complete remissie heeft en ongeveer $30 \%$ na 3 jaar geen recidief in de extremiteit heeft. ${ }^{2}$ Regionale isolatieperfusie met melfalan en TNF-alfa wordt toegepast bij grote afwijkingen van recidiefmelanoom met een sarcoomachtige groeiwijze (patiënt B).${ }^{14} \mathrm{Bij}$ recidiefmelanoom na eerdere regionale isolatieperfusie met melfalan bestaat er ook een indicatie. ${ }^{15}{ }^{16}$ Tenslotte vindt toepassing plaats bij een irresectabel wekedelensarcoom van de extremiteiten (patiënt C), met als doel een zodanige remissie te bereiken dat de tumor resectabel wordt en een amputatie kan worden voorkomen. Dit lukt bij 82-87\% van deze patiënten, met complete remissies bij 29-36\% van hen. ${ }^{11} 17$

De acute toxiciteitsreactie van de geperfundeerde extremiteit is tegenwoordig gering, met bij ongeveer $80 \%$ van de patiënten tijdelijk gering oedeem en erytheem en bij ongeveer $20 \%$ blaarvorming. Ernstige regionale toxiciteit met een logesyndroom of uitgebreider weefselverval waarvoor een amputatie noodzakelijk is, treedt bij 1-2\% van de patiënten op. De langetermijnmorbiditeit, zoals functiestoornissen met spieratrofie, fibrose of zenuwuitval, wordt grotendeels bepaald door de ernst van de acute toxiciteitsreactie en is relatief gering. ${ }^{9} \mathrm{Bij} 25-40 \%$ van de patiënten werd enige objectieve bewegingsbeperking gevonden, maar zonder dat zij hiervan in het dagelijks leven hinder ondervonden. ${ }^{918}$

Dat de bovengenoemde responspercentages ook bij oudere patiënten met een lokaal irresectabel melanoom bereikt worden, bleek uit een recente analyse, waar- 

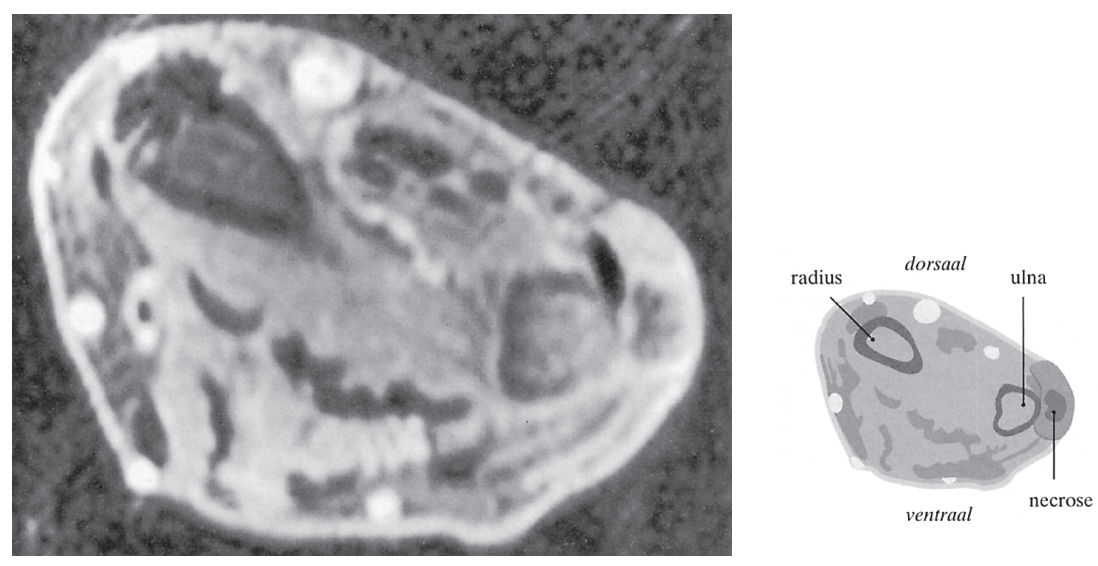

Figuur 5. Patiënt C. MRI-scan, 8 weken na regionale isolatieperfusie, met centrale necrose van een tumor aan de linker onderarm.

bij wij bij 53 patiënten ouder dan 75 jaar een completeresponspercentage van $56 \%$ vonden na regionale isolatieperfusie met melfalan met of zonder TNF-alfa en van $58 \%$ bij ' 49 patiënten jonger dan 75 jaar. Hierbij waren de acute regionale toxiciteit, postoperatieve complicaties en langetermijnmorbiditeit bij de oudere en de jongere patiënten vergelij kbaar. ${ }^{19}$ De perioperatieve sterfte na regionale isolatieperfusie, gedefinieerd als de sterfte binnen de eerste 30 dagen na de ingreep, varieert in het algemeen tussen 0 en $1 \%,{ }^{8}$ en in de beschreven groep overleed geen van de oudere patiënten. De risico-inschatting bij de gangbare preoperatieve screening op grond van comorbiditeit lijkt voldoende om te bepalen of een patiënt de procedure kan ondergaan, ongeacht de leeftijd. Voor het gebruik van TNF-alfa geldt daarbij een aantal specifieke contra-indicaties, zoals emstige cardiovasculaire aandoeningen, lever- of nierfunctiestoornissen, hematologische afwijkingen en contra-indicaties voor het gebruik van sympathicomimetica (vasoconstrictoren) of anticoagulantia.

Op 75-jarige leeftijd is de levensverwachting bij mannen gemiddeld 8,5 jaar en voor vrouwen is dit 11 jaar. ${ }^{40}$ Omdat een optimale kwaliteit van leven moet worden nagestreefd, kunnen intensieve behandelingen ook in deze fase van het leven van groot belang zijn, met een acceptabel risico op door de behandeling veroorzaakte morbiditeit. ${ }^{20}$ Met name bij patiënten bij wie alleen palliatie mogelijk is, is controle van locoregionale tumorgroei daarbij een eerste vereiste.

Dames en Heren, onze ervaring leert dat ook aan oudere patiënten met uitgebreide locoregionale tumoren van een extremiteit een grote kans op behoud van functionaliteit daarvan kan worden geboden met regionale isolatieperfusie, zonder dat daarbij toename optreedt in sterfte, toxiciteit of langetermijnmorbiditeit.

Belangenconflict: geen gemeld. Financiële ondersteuning: geen gemeld. 


\begin{abstract}
Regional isolated limb perfusion: also applicable in elderly patients. - In 3 patients over 75 years of age with a malignancy, limb salvage was achieved through the application of isolated limb perfusion with melphalan with or without tumour necrosis factor alpha: an 82-year-old woman with extensive locoregional melanoma metastases on her lower leg, a 78-year-old woman with a large, ulcerating recurrence of melanoma on her lower leg and an 83-year-old woman with recurrent sarcoma of the lower arm. There were no complications and the women recovered well. Isolated limb perfusion can be effectively and safely used in older patients with irresectable tumours of the extremities, offering them limb salvage for the remainder of their lives.
\end{abstract}

\title{
LITERATUUR
}

1 Schraffordt Koops H, Eibergen R, Oldhoff J, Ploeg E van der, Vermey A. Enkele aspecten van de behandeling van het primaire melanohiastoom aan de ledematen met regionale perfusie. Ned Tij dschr Geneeskd '975;' 19:1746-53.

2 Vrouenraets BC, Nieweg 0E, Kroon BBR. Thirty-five years of isolated limb perfusion for melanoma: indications and results. Br J Surg 1996;83:1319-28.

3 Liénard D, Ewalenko P, Delmotte JJ, Renard N, Lejeune FL. Highdose recombinant tumor necrosis factor alpha in combination with interferon gamma and melphalan in isolation perfusion of the limhs for melanoma and sarcoma. J Clin Oncol 1992;I0:5260 .

4 Thomas DR, Ritehie CS. Preoperative assessment of older adults. J Am Geriatr Soc 1995;43:811-21.

5 Polanezyk CA, Marcantonio E, Goldman L, Rohde LE, Orav J, Mangione CM, et al. Impact of age on perioperative complications and length of stay in palients undergoing noncardiac surgery. Ano totern Mcd 2001;134:637-43.

8 Bonenkamp JJ, Songun t, Hermans J, Sasako M, Welvaart K, Plukker JT, et al. Randomised comparison of morbidity after DI and D2 dissection for gastrie cancer in 996 Dutch patients. Laneet 1995;345:745-8.

7 Hobler KE. Colon surgery for cancer in the very elderly. Cost and 3-year survival. Ann Surg 1986;203:129-31.

8 Sonneveld EJ, Vrouenraets BC, Geel BN van, Eggermont AMM, Klaase JM, Nieweg $\mathrm{OE}$, et al. Systemie toxicity after isolated limb perfusion with melphalan for melanoma. Etir J Surg Oncol 1996; 22:521-7.

9 Vrouenraets BC, Klaase JM, Kroon BBR, Geel BN van, Eggermont AMM, Franklin HR. Long-term morhidity after regional isolated perfusion with melphalan for melanoma of the limbs. The infioence of acute regional toxie reactions. Arch Surg 1995; 130:43-7.

10 Vrouenraets BC, Kroon BBR, Ogilvie AC, Geel AN van, Nieweg 0E, Swaak AJ, et al. Absenee of severe systemie toxicity after leakage-controlled isolated limb perfusion with tumor necrosis factoralpba and melphalan. Ann Surg Oncol 1999;6:405-12.

11 Eggermont AMM, Schraffordt Koops H, Klausner JM, Kroon BBR, Schiag PM, Liénard D, et al. Isolated limb perfusion with tumor necrosis factor and meiphalan for 
limb salvage in i86 patieuts wjth locally advaneed soft tissue extremity sarcomas. The cumulative multicenter European experience. Ano Surg 1996;224:756-64.

12 WHO handbook for reporting resuits of cancer treatment. Genève: WHO; '979.

13 Creech DG, Krementz ET, Ryan RF, Winbiad JN. Chemotherapy of cancer: regional perfusion utilising an extracorporal circuit. Ann Surg 1958;148:616-32.

14 Fraker DL, Alexander HR, Andrieb MP, Rosenberg SA. Palliation of regional symptoms of advanced extremity melanoma by isolated limb perfusion with meiphalan and high-dose tumor necrosis factor. Cancer J Sci Am 1995;I:122.

15 Liénard D, Eggermont AMM, Koops HS, Kroon BBR, Towse G, Hiemstra S, et al. Isolated limb perfusion with tumour necrosis factor-alpha and melphalan with or without interferon-gamma for the treatment of in-transit melanoma metastasel: a multicentre randomized phase II study. Melanoma Res 1999;9:491-502.

16 Bartlett DL, Ma G, Alexander HR, Libutti SK, Fraker DL. Isolated limb reperfusion with tumor necrosis factor and melphalan in patieuts with extremity melanoma after failure of isolated limli perfusion with chemotherapeutics. Cancer 1997;80:2084-90.

17 Eggermont AMM, Schraffordt Koops H, Liénard D, Kroon BBR, Geel AN van, Hoekstra HJ, et al. Isolated limli perfusion with highdose tumor necrosis factor-alpha in combination with interferongamma and meiphalan for nonresectable extremity soft tissoe sarcomas: a multicenter trial. J Clin Oncol 1996;14:2653-65.

18 Geel AN van, Wijk J van, Wieberdink J. Functional morhidity after regional isolated perfusion of the limb for melanoma. Cancer 1989;63:1092-6.

19 Noorda EM, Vrouenraets BC, Nieweg 0E, Geel AN van, Eggermont AMM, Kroon BBR. Safety and efficacy of isolated limb perfusion in elderly melanoma patients. Ann Surg Oncol 2002;9:968-74.

28 Zenilman ME. Surgery in the elderly. Curr Probl Surg 1998;35:99-179.

\section{Aanvaard op 17 september 2002}




\section{Dankwoord}

In de twee jaar die ik in het Antoni van Leeuwenhoek ziekenhuis/Het Nederlands Kanker Instituut heb gewerkt, heb ik verschillende aspecten van de chirurgische oncologie leren kennen.

Allereerst de verschillende kanten van de toepassing van regionale isolatie perfusie: de procedure op zich, waarbij ik meermalen heb mogen assisteren tot het begeleiden van de patiënten die geperfundeerd werden. Veel tijd heb ik besteed aan het verzamelen en toepassen van alle bewijs in de internationale literatuur rondom deze techniek en het zelf genereren van nieuwe gegevens op basis van ruim 25 jaar ervaring in dit instituut, waarvan $u$ het bewijs in dit proefschrift verzameld ziet. Daarnaast heb ik vrijwel elk afzonderlijk artikel in dit proefschrift, op congressen in Nederland, Frankrijk of de Verenigde Staten mogen presenteren en verdedigen en daarbij de internationale gemeenschap van chirurgen die regionale isolatie perfusie toepassen, ontmoet. Tijdens al deze werkzaamheden heb ik (wetenschappelijk) leren schrijven, presentaties leren maken en voordrachten leren houden. In deze tijd heb ik ook de algemene praktijk van de chirurgische oncologie leren kennen, de multidisciplinaire aard van de oncologische behandeling leren begrijpen en de basis van het oncologisch denken geleerd. Ik realiseer me dat dit nog maar een zeer klein deel is van wat er op dit gebied nog te leren valt.

Zonder de onvermoeibare inspanningen van mijn promotor en co-promotoren en ook niet zonder de bijdragen, wetenschappelijk of niet, van vele anderen, was deze ervaring en dit proefschrift niet tot stand gekomen. Vandaar dit dankwoord.

Allereerst dank ik mijn waardige (ik ken niemand die dit bijvoeglijk naamwoord zo verdient) promotor, prof.dr B.B.R. Kroon. Beste Bin, tijdens een promotie zijn er betere en slechtere periodes voor een onderzoeker. Maar altijd als ik met $\mathrm{u}$ van gedachten had gewisseld, was het voor mij duidelijk waarom ik mijn zegeningen met dit promotieonderzoek moest tellen. Uw charisma, betrokkenheid, rust, wijsheid, opmerkzaamheid en humor heb ik telkens weer als een grote bron van inspiratie ervaren. Ik bewonder uw gave om alle facetten van het werk als chirurgisch oncoloog recht te doen: de personen die $u$ opleidt, het wetenschappelijk werk, de patiënt, de techniek, uw gezin, het ziekenhuis, de maatschappij, waar wij ook menige discussie over hebben gevoerd. Ik ben zeer dankbaar dat ik uw pupil heb mogen zijn.

Ik dank mijn eerste co-promotor en begeleider, dr B.C. Vrouenraets. Beste Bart (Brad), ik dank alles wat ik heb geleerd in de afgelopen twee jaar voor een groot deel aan jou. De onderwerpen van alle artikelen waren of door jou of samen met jou bedacht. De vele versies van elk stuk kreeg ik onvermoeibaar terug met aanwijzingen en correcties, totdat ze goed waren. Als ik je belde in het St LucasAndreas ziekenhuis of soms thuis, was er altijd tijd om iets door te spreken. Bart, 
ik heb geleerd van de snelheid van je denken, de hoeveelheid parate kennis (percentages, citaten, onderzoeksresultaten) en je snelle beoordelingsvermogen. Ik hoop dat ik een goede eerste promovenda voor je ben geweest, voor mij was je een top-begeleider.

Ook dank ik mijn tweede co-promotor, dr O.E. Nieweg. Omgo, je begeleiding was altijd secuur en gecommitteerd. Elk woord ligt bij jou op als goud op een schaaltje, hetgeen ik zeer heb gewaardeerd. Als een stuk door jou was goedgekeurd, wist ik dat het goed was omdat geen detail aan je oplettend oog ontglipt. Je rust en je onophoudelijke inzet heb ik zeer op prijs gesteld, alsmede je gevoel voor humor in je presentaties (Antoni, Antonie, Anthony en Antonius).

Prof. dr A.M.M. Eggermont, beste Lex en dr A.N. van Geel, beste Bert. Ook al was het op afstand, ook veel dank voor jullie suggesties vanuit Rotterdam. Ik heb gebruik mogen maken van een unieke samenwerking tussen Amsterdam en Rotterdam en hoop dat die ook in de toekomst, voor anderen, weer vruchten afwerpt. Dank jullie voor de bijdrage aan dit werk.

Dr F. van Coevorden, beste Frits, ook dank aan jou. Met name je bijdrage aan ons werk aan de wekedelensarcomen waardeer ik zeer. Met veel plezier was ik steeds bij de sarcoombesprekingen en was vereerd als je me als "perfusie-expert" aan het woord liet. Je bent de enige heer die nog stijl kan dansen (Los Angeles) en met veel plezier.

Voor hun bijdrage aan delen van dit proefschrift wil ik nog bedanken: dr J.M. Klaase, beste Joost, je was de eerste in rij van jonge promovendi/a op dit specifieke uithoekje van de chirurgische oncologie. Ik dank je dat ik op jouw werk verder heb kunnen bouwen. Dr J. van der Zee, beste Coby, voor je medewerking aan een van onze artikelen. Dr A.A.M. Hart, beste Guus, veel dank voor al je werk en onderwijs in de statistiek. Ik denk daar nu wel iets van begrepen te hebben. Ook dank aan G.W. van Slooten, beste Gooike, vaak onopvallend, maar een stabiele en onmisbare factor in de perfusiepraktijk van Bin en Omgo.

Ik dank de overige stafleden van de chirurgische oncologie en de andere snijdende specialismen (het HOD) voor de aandacht die zij steeds weer gaven aan het kritisch beoordelen van een nieuw resultaat uit de perfusiebron, bij sectie XI vergaderingen, als proefpraatje voor een congres maar ook wel eens persoonlijk. In het bijzonder dank ik H. Klomp, beste Houke, en dr.H.S.A. Oldenburg, beste Hester, de vrouwen die mij voorgaan in dit vak. Ik neem graag een voorbeeld aan hoe jullie je vak nu uitoefenen.

Het secretariële personeel, en in het bijzonder Noëlle Tameris, wil ik bedanken voor jullie steun bij al het (papieren) werk dat een promotie met zich meebengt. Het versturen van een belangrijke envelop of het regelen van een spoed-CD-rom is vaak van onzichtbaar maar groot belang. Dank jullie wel. 
Prof. dr J.C.J.M. de Haes, prof. dr F.J. Lejeune, prof. dr W.J. Mooi, prof. dr H. Schraffordt Koops, dr G.R. Schaap en dr J.H.W. de Wilt dank voor het zitting nemen in mijn promotie commissie en de vragen die gesteld zullen worden. Special thanks to prof.dr F.J. Lejeune, for coming to Amsterdam and the progress you have made in the research of isolated limb perfusion. In het bijzonder ook dank aan prof. Dr W.J.Mooi, beste Wolter, voor de samenwerking die zijn vruchten nog zal afwerpen op het veelbelovende gebied van de micro-array.

Ruben van Kreij, student Psychologie en Bart Takkenberg, student Geneeskunde wil ik bedanken voor het vertrouwen in mij als jullie (eerste) onderzoeksbegeleider. Ik hoop dat jullie veel hebben geleerd en wens jullie veel succes in jullie carrière.

Ook dank ik dr M.G.M. Statius Muller, beste Markwin, als collega in opleiding (ik nog niet) in het Slotervaartziekenhuis, heb je mij op dit onderzoek gewezen. Twee jaar later heb je mij weer een stap dichter bij mijn opleidingsplek Chirurgie gebracht. Straks zijn we weer collega's, allebei in opleiding in het Slotervaartziekenhuis. Misschien kunnen we dan samen een volgende AGNIO een artikeltje laten schrijven.

Mijn mede onderzoekers Anne Lont, dr.Serge van Ruth, dr.Pieter Tanis, Susanne Estourgie, tevens paranimf, Roelien Olivier, Jacco Nieuwenhuizen en Bin Kroon jr. wil ik hierbij zeer bedanken voor het vele lachen en ook de vele sombere buien die ons onderzoekersleven rijk waren. Het was een enorm genoegen met jullie deze tijd door te maken.

Mijn tweede paranimf, Eline Regeer, wil ik ook erg bedanken. Lieve Eline, je was een perfecte ceremoniemeester op ons huwelijk, nu mijn paranimf. Je bent een geweldige vriendin en ik ben blij dat je mijn paranimf wilde zijn, ondanks je drukke leven naast je opleiding tot psychiater.

Aan mijn ouders heb ik dit werk opgedragen. Jullie zijn de bron van mijn (wetenschappelijke) ambities. Jullie creativiteit en streven om het maximale uit het leven te halen, heeft mij geïnspireerd.

Als laatste dank ik Ben, mijn lieve echtgenoot. Zoals we beloofd hebben als partners door het leven te gaan, was jij ook echt een partner in het voltooien van mijn promotieonderzoek. Op dagen dat ik het niet meer zag zitten, wist je me altijd weer aan te sporen, Door jou is het onmogelijk om niet te bereiken wat ik zou willen. 


\section{Curriculum vitae}

Eva Magdaleen Noorda werd geboren op 19 oktober 1974 in Amsterdam. Het grootste deel van haar jeugd woonde zij in Amsterdam. In 1986 ging zij naar het Barlaeus gymnasium te Amsterdam, waar zij in 1992 eindexamen deed. Zij heeft hierna een jaar in de Verenigde Staten gestudeerd (Liberal Arts) in Portland, Oregon. In 1993 begon zij met de studie Geneeskunde aan de Universiteit van Amsterdam. Ze deed haar verpleeghulpstage in het eerste jaar in Washington DC in het Children's National Medical Center. Tijdens de doctoraalfase van haar studie was zij student-assistent Medische Psychologie, waarbij ze les gaf in arts-patiënt communicatie. In die periode zat ze in verschillende commissies van o.a. medische studenten vereniging Asklepios en de Co-raad. Tijdens de co-schappen werd haar keuze voor de Chirurgie duidelijk. Na haar arts-examen (mei 2000) werkte ze een jaar als AGNIO Heelkunde in het Slotervaart ziekenhuis. Hierna heeft ze twee jaar in het Antoni van Leeuwenhoek ziekenhuis/Het Nederlands Kanker Instituut aan haar promotie-onderzoek gewerkt. Ook heeft ze toen lesgegeven in de Anatomie aan Geneeskunde studenten van de Universiteit van Amsterdam. Vanaf 1 juli 2003 werkte zij als AGNIO Heelkunde in het VU Medisch Centrum in Amsterdam. Zij is op 1 januari 2004 gestart met de opleiding tot chirurg in de regio Amsterdam-VU Medisch Centrum bij opleiders prof. dr J.A. Rauwerda en dr. B.J.Dwars. 